\title{
Sensitivities of Five Alpha Continuous Air Monitors for Detection of Airborne ${ }^{239} \mathrm{Pu}$
}

Charles V. Mclsaac

Cecilia R. Amaro

Published July 1992
Idaho National Engineering Laboratory
EG\&G Idaho, Inc.
Idaho Falls, Idaho 83415

Prepared for the

U.S. Department of Energy

Office of Environmental Restoration and Waste Management

Under DOE Idaho Field Office

Contract DE-AC07-76ID01570

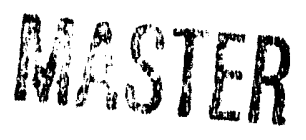


Sensitivities of Five Alpha Continuous Air Monitors for Detection of Airborne

${ }^{239} \mathrm{Pu}$ EGG-WTD-10314

Approved by:

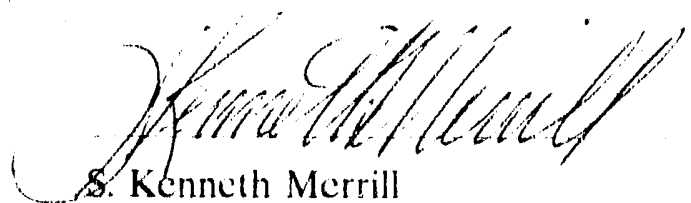

Buried Waste Integrated Demonstration Coordinator

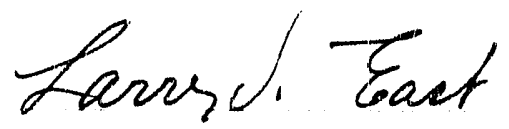

Larry V. East, Unit Manager

Radiation Measurements
$7 / 21 / 42$

Date

$7 / 20 / 92$

Date

Prepared by:

Cher Imirame

Charles V. Mclsaac, Senior Scientist Radiation Measurements

Reviewed by:

P. ll. Randolph

Peter D. Randolph, Principal Scientist

Nuclear Sciences and Radiochemistry

$$
7 / 21 / 92
$$

Date

$$
7 / 21 / 92
$$




\begin{abstract}
Results of measurements of the sensitivities of five alpha continuous air monitors (CAMs) for detection of airborne ${ }^{239} \mathrm{Pu}$ are presented. Four commercially available alpha CAMs (Kur\%. model 8311. Merlin Gerin Edgar, RADeCO model 452, and Victoreen model 758) and a prototype alpha CAM currenlly in use at Argonne National Laboratory. West (ANL-W) were tested sampling natural ambient air and laboratory-generated atmospheres laden with either biank dust or dust containing $\mathrm{nCi}$ g concentrations of ${ }^{239} \mathrm{Pu}$. Cumulative alpha spectra were stored at 30 or 60 minute intervals during each sampling and were subsequently analyzed using three different eommonly used alpha spectrum analysis algorithms. The effect of airborne dust concentration and sample lilter porosity on detector resolution and sensitivity for airborne ${ }^{2.39} \mathrm{Pu}$ are described.

When airborne dust concentrations were below $0.008 \mu \mathrm{g} / \mathrm{L}$ and one-hour long counting intervals were used, the ANL-W and Kurz CAMs had by far the best sensitivities for airborne ${ }^{2.39} \mathrm{Pu}$. The average lower limit of delection (LLD) coneentrations for these two CAMs were 0.(0)045 and $0.0(0) 3 \mathrm{pCi} / \mathrm{L}$, respectively. The best average LLDs for the Merlin Gerin, RADeCO, and Victoreen CAMs under these same conditions were all approximately a factor of twenty higher than the LLD for the ANL-W CAM. While the LLDs of the ANL-W and Kurz CAMs were unalfected by the choice of analysis algorithm, the LLDs for the RADeCO and Victoreen CAMs showed some dependence on which algorithm was used for analysis.

The two-stage virtual impactor installed in the ANL-W CAM and the inertial plate impactor installed in the Kury CAM are responsible for their remarkably low detection limits. However, in 1 : case of the Kurz CAM, which collects particulates directly on the face of a solid-state silicon detector, only about $18 \%$ of the airborne ${ }^{234} \mathrm{Pu}$ activity that entered the Kurz CAM remained fixed to the surlace of the silicon detector following the completion of sampling. The inferior particle ictention efliciency of the Kurz CAM makes it a poor candidate for quantitative measurements of airborne ${ }^{23 \%} \mathrm{Pu}$. Based on its excellent sensitivity for airborne ${ }^{239} \mathrm{Pu}$ and extensive use at. ANL-W, the ANL-W CAM is recommended for monitoring air quality during future waste retrieval operations conducted at the Idaho National Enginecring Laboratory Radioactive Waste Management Complex.
\end{abstract}




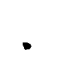




\section{EXECUTIVE SUMMARY}

During past years defense-related waste contaminated with transuranic (TRU) isolopes was stored in shallow pits and trenches at the Radioactive Waste Management Complex (RWMC) at the Idaho National Engineering Laboratory (INEL). Due to concerns regarding the long-term stability of the waste, an option currently being considered is the retrieval and repackaging of the waste. It is anticipated that waste containers have degraded over the years and that a significant fraction of the backlill material is now contaminated with TRU isotopes. Therefore, during the waste retricval effort, the air and soil will have to be monitored continuously for alpha emitting isotopes as an aide to controlling the spread of TR'] contamination.

In order to restrict exposure of workers to TRU and organic contaminants, waste buricd at the RWMC will be exhumed and processed using robotic techniques. However, there will be oceasions when workers will be required to enter the building enclosing the excavation site to maintain and decontaminate equipment and perform other tasks. At these times, the airborne concentrations of TRU radionuclides inside the enclosure building must be known so that adequate protective clothing can be selected. Also, during the retrieval operation the sucess of the contamination control methods will need to be continuously evaluated so that changes in operations can be made in a timely manner. An alpha continuous air monitor (CAM) will provide continuous real-time monitoring of the concentrations of airborne TRU isotopes.

All alpha CAMs detect the presence of airborne alpha eontamination by pulse height analysis of the alpha activity removed from air that is sampled. A typical measurement of the eoncentrations of airbornc alpha-emitting radionuclides is performed by pulling a continuous sample of air through a filler positioned close to a solid-state silicon alpha detector. The alpha-emilting radionuclides are attached 10 the acrosel particles that are trapped by the filter.

This measurement approach presents three major interactive problems. The lirst problem stems from the lact that dust is normally collected continuously and it gradually covers the activity previously deposited on the filter. Because the range of an alpha particle in solid material is only about $30 \mu \mathrm{m}$. alphat particles lose energy in passing through overlaying dust and when degraded in encrgy contribute a continum of counts to the spectrum, resulting in higher backgrounds and broader, less well defined alpha peaks. The seeond difliculty stems from the fact that the filter is fixed so that the current concentration of an alpha emitting radionuclide must be calculated based on a small change in detector count rate. The third, and perhaps the most fundamental problem, is the presence of naturally occurring alpha-emitting isotopes in the environment. When degraded in energy as a result of interactions with the filter medium and overlaying dust, these alpha particles contribute a continum of eounts to the spectrum in the energy region of the ${ }^{2.39} \mathrm{Pu}$ alpha peak.

In the present work, the sensitivities of five alpha CAMs for detection of airborne ${ }^{239} \mathrm{Pu}$ were experimentally determined. Four commercially available alpha CAMs (the Kurz model 8311, Merlin Gerin Edgar, RADeCO model 452, and Victoreen model 758) and a prototype CAM currently used at Argonne National Laboratory-West (ANL-W) were tested sampling natural ambient air and laboratory-generated atmospheres laden with either blank dust or dust spiked with $\mathrm{nCi} / \mathrm{g}$ concentrations of ${ }^{239} \mathrm{Pu}$. Two of the five CAMs that were evaluated (the Kurz model 8311 and the ANL-W prototype CAM) were equipped with impactors that removed some fraction of the indigenous alpha emitting activity from the sample airstream prior to the point of impaction on the 
sample collection medium. The RADeCo model 452 and Merlin Gerin Edgar CAMs were equipped with multi-vaned collimators positioned between the sample collection filter and the solid-state silicon alpha detector. Because alpha particles that leave the collection filter at oblique angles strike the collimator, they do not reach the detector and, consequently, the resolutions of CAMs equipped with collimators are much better than the resolutions that can be achieved using conventional designs that employ sample collection filters. A third mechanistic approach to reducing the effect of background alpha particles achieves the same goal as the collimator by simply eliminating the sample filter. This approach is used in the Kurz model 8311 alpha CAM. Acrosols entrained in the sample airstream are collected directly on the face of the silicon alpha detector. Because the alpha particles do not traverse an air gap, they are only degraded in energy as a result of passing through whatever layer of dust was present prior to their emission. The fifth CAM that was evaluated, the Victoreen model 758. is representative of conventional designs, lacking impactors and collimators, that pump air through a porous filter placed in close proximity to a solid-state silicon alpha detector.

The evaluations of the five alpha CAMs included (a) measuring the resolutions of the dominant radon and thoron background alpha peaks as a function of air dust loading, (b) determining the count rate in the ${ }^{239} \mathrm{Pu}$ energy region as a function of air dust loading in the absence of ${ }^{239} \mathrm{Pu}$, (c) quantifying the net count rate in the ${ }^{239} \mathrm{Pu}$ energy region during samplings of ambient air and air laden with blank and ${ }^{239} \mathrm{Pu}$-spiked dust using several commonly used spectrum analysis algorithms, (d) calculating the lower limit of detection (LLD) concentration of ${ }^{239} \mathrm{Pu}$ at the $95 \%$ confidence level, and (e) performing quantitative measurements of airborne ${ }^{239} \mathrm{Pu}$. The equations for calculating lower :imit of detection concentrations for airborne ${ }^{239} \mathrm{Pu}$ are given.

Of the spectrum analysis methods that have been developed, the most commonly used are those that determine net counts in the ${ }^{239} \mathrm{Pu}$ peak by subtracting from the total counts in the ${ }^{239} \mathrm{Pu}$ peak some fraction of the counts in adjacent regions of the spectrum. In each case, the expression for net ${ }^{2.39} \mathrm{Pu}$ counts is a linear function of counts in the ${ }^{2.39} \mathrm{Pu}$ and background regions of the spectrum. Three such spectrum analysis algorithms, which are currently installed in the majority of commercially available alpha CAMs, were evaluated.

The ANL-W, Kurz model 8311, Merlin Gerin Edgar, RADeCO model 452, and Victoreen model 758 alpha CAMs each had LLDs for ${ }^{239} \mathrm{Pu}$ that met or exeeded the sensitivity requirement of 8 DAC-hours specified in DOE Order 5480.11. When airborne dust concentrations were less than $0.008 \mu \mathrm{g} / \mathrm{L}$ and one-hour long counting intervals were used, the ANL-W and Kurz CAMs exhibited by far the best sensitivities for airborne ${ }^{239} \mathrm{Pu}$. The average LLDs for these two CAMs were $0.00(145$ and $0.003 \mathrm{pCi} / \mathrm{L}$, respectively. The best average LLDs for the Merlin Gerin, RADeCO, and Victoreen CAMs were all about $0.01 \mathrm{pCi} / \mathrm{L}$, about a factor of twenty higher than the average LLD for the ANL-W CAM. While the LLDs of the ANL-W and Kurz CAMs were unaffected by the choice of analysis algorithm, the LLDs for the RADeCO and Victoreen CAMs showed some dependence on which algorithm was used for analysis. In the case of the latter two CAMs, the three-window algorithm yiclded the lowest LLDs.

When airborne dust concentrations were above $0.2 \mu \mathrm{g} / \mathrm{L}$, the Kurz CAM was much more sensitive than the RADCCO, Victoreen, or Merlin Gerin CAMs. The best average LLD for the Kurz CAM was $0.001 \mathrm{pCi} / \mathrm{L}$ for the two-window analysis algorithm, which was about a factor of 10 better than the best average LLDs for the RADeCO, Victoreen, and Merlin Gerin CAMs. For the 
samplings of aerosolized blank dust, the three-window analysis algorithm provided the best sensitivity for the RADeCO, Victoreen, and Merlin Gerin CAMs.

The two-stage virtual impactor installed in the ANL-W CAM and the inertial plate impactor installed in the Kurz CAM removed the majority of the radon and thoron daughters entrained in their sample airstreams. The removal of these indigenous alpha emitters significantly reduced background count rates in the ${ }^{239} \mathrm{Pu}$ region of interest (ROI). This is reflected in the remarkably low ${ }^{239}$ Pu LLDs measured for the ANL-W and Kurz CAMs. However, in the case of the Kurz CAM, which collects particulates directly on the face of a solid-state silicon detector, this benefit must be weighed against the possible detriment of discarding some fraction of the particulates in the air being sampled. Results of this study indicate that, on average, only about $18 \%$ of the airborne ${ }^{239} \mathrm{Pu}$ activity that entered the Kurz CAM remained fixed to the surfece of the silicon detector following tive completion of sampling. The inferior particle retention efficiency of the Kurz CAM and the possibility that the retention efficiency might be dependent on sampling duration and airborne dust concentration make it a poor candidate for quantitative measurements during buried waste retrieval operations at the RWMC.

The resolutions of the ANL-W and Victoreen CAMs were comparable and much worse than the resolutions of the Merlin Gerin and Kurz CAMs. The reason the ANL-W CAM had the best sensitivity for airborne ${ }^{239} \mathrm{Pu}$ can be attributed to its relatively good counting efficiency, the stability of the widths of the background alpha peaks, the high rate at which it sampled $(240 \mathrm{~L} / \mathrm{min})$, and the fact that the two-stage inertial impactor discarded better than $95 \%$ of the radon daughters present in the sample airstrearn. 


\section{CONTENTS}

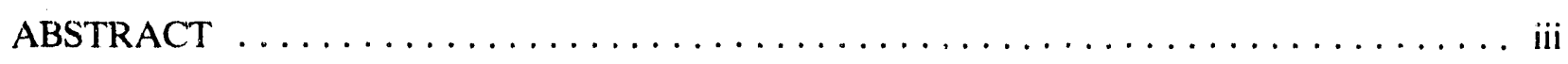

EXECUTIVE SUMMARY $\ldots \ldots \ldots \ldots \ldots \ldots \ldots \ldots \ldots \ldots \ldots \ldots \ldots \ldots$

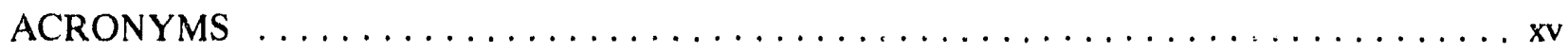

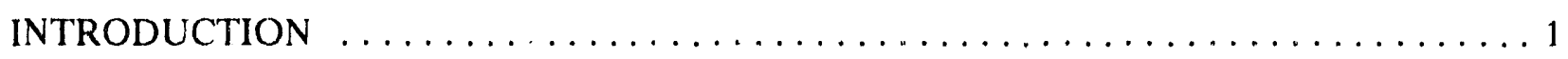

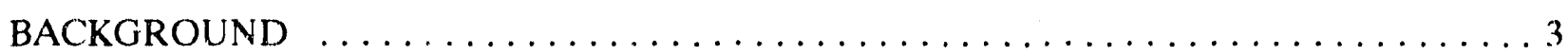

INSTRUMENTATION $\ldots \ldots \ldots \ldots \ldots \ldots \ldots \ldots \ldots \ldots \ldots \ldots \ldots \ldots \ldots \ldots$

Description of Alpha CAMs $\ldots \ldots \ldots \ldots \ldots \ldots \ldots \ldots \ldots \ldots \ldots \ldots \ldots$

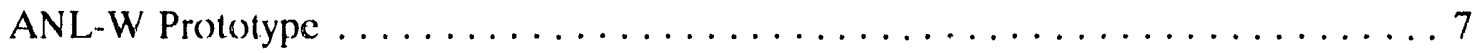

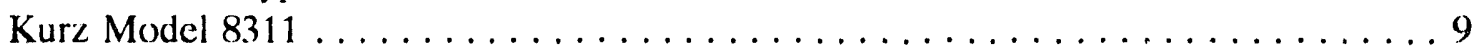

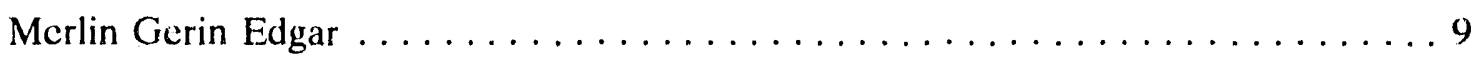

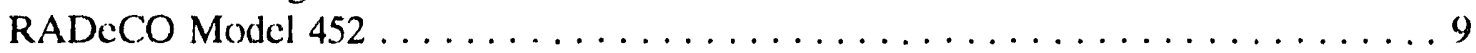

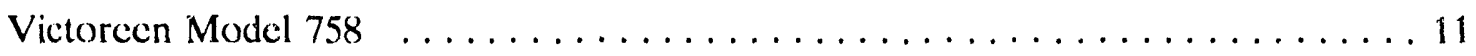

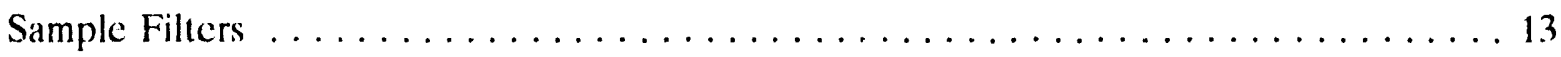

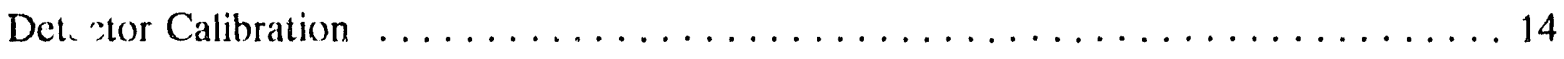

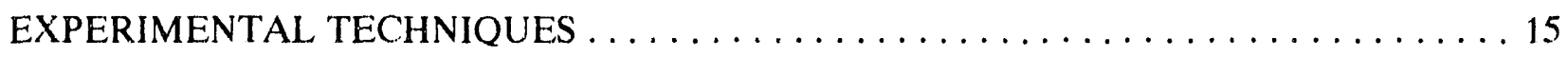

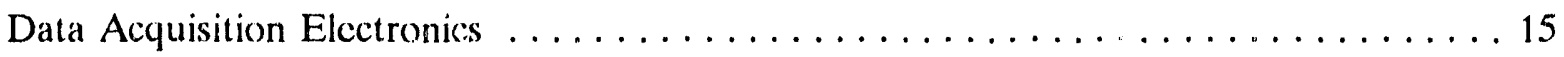

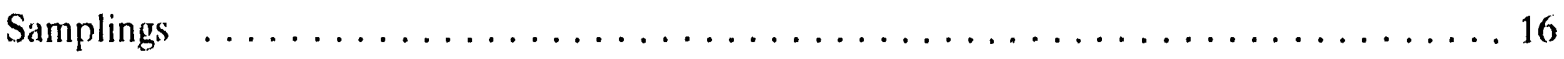

Natural Ambient Air . . . . . . . . . . . . . . . . . . . 17

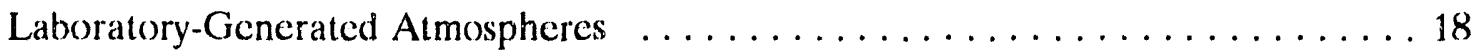

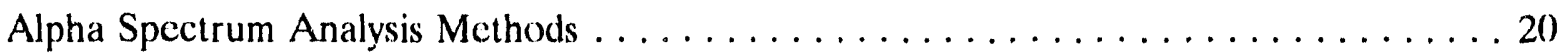

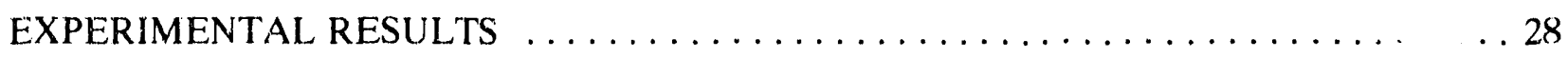

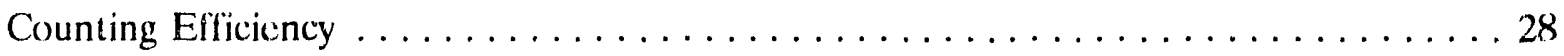

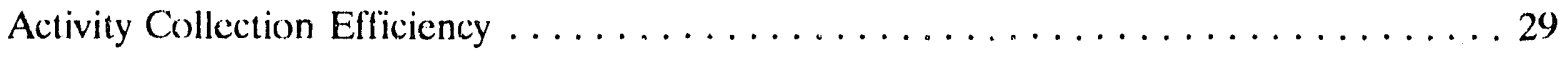

Radon Daughter Removal Efficiency of Inertial Impactors $\ldots \ldots \ldots \ldots \ldots \ldots \ldots \ldots$

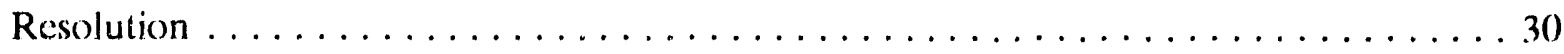


Coefficients Used in Analysis Algorithms $\ldots \ldots \ldots \ldots \ldots \ldots \ldots \ldots \ldots \ldots$

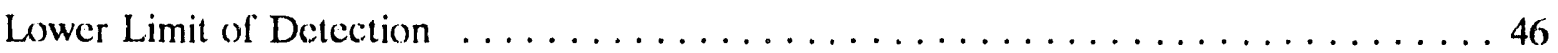

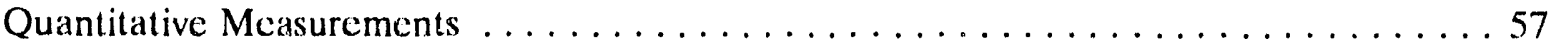

CONCLUSIONS AND RECOMMENDATIONS $\ldots \ldots \ldots \ldots \ldots \ldots \ldots \ldots \ldots \ldots \ldots$

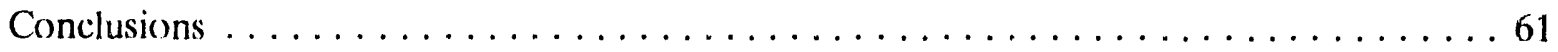

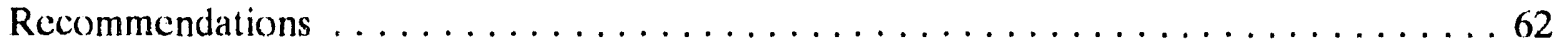

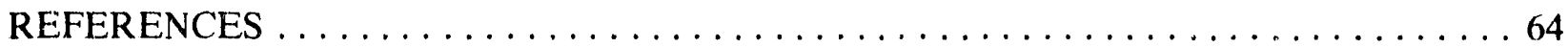

Appendix A-Description of Alpha Spectrum Analysis Methods $\ldots \ldots \ldots \ldots \ldots \ldots \ldots$ A 1

Appendix B-Resolution: Additional Data and Plots $\ldots \ldots \ldots \ldots \ldots \ldots \ldots \ldots$

Appendix $\mathrm{C}-$ Spectrum Analysis Results $\ldots \ldots \ldots \ldots \ldots \ldots \ldots \ldots \ldots \ldots \ldots \ldots$

\section{FIGURES}

1a. Spectrum collected using the Merlin Gerin alpha CAM showing the relative positions

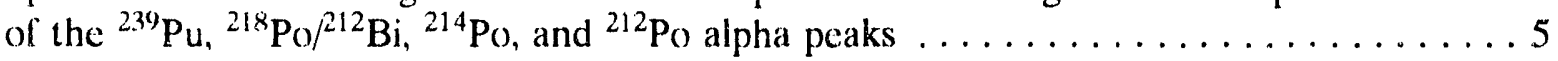

1b. Spectrum collected using the Victoreen alpha CAM showing the relative positions of the

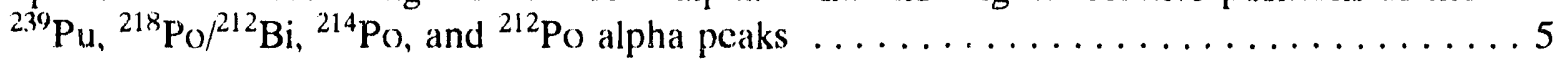

2. Schematic of a virtual impactor and cutaway view of the ANL-W alpha CAM showing arrangement of the (wo-stage virtual impactor and solid-state detector $\ldots \ldots .8$

3. Cutaway view of the Kurz model 8311 alpha CAM $\ldots \ldots \ldots \ldots \ldots \ldots \ldots \ldots \ldots$

4. Schematic of Merlin Gerin alpha CAM showing arrangement of the solid-state detector,

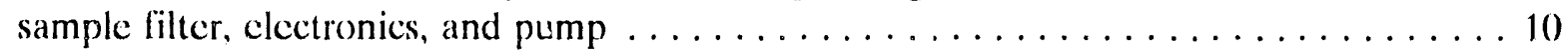

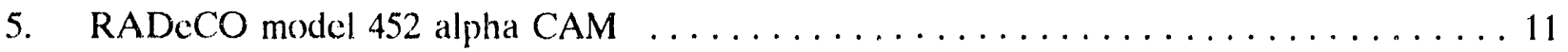

6. Photograph of Victoreen model 758 alpha CAM showing electronics module, sampling

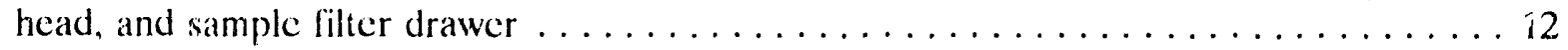

7. Cutaway view of Victoreen model 758 sampling head showing arrangement of sample

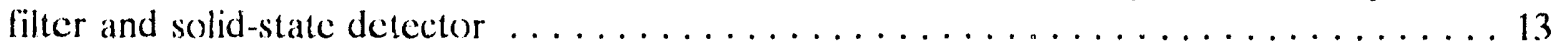

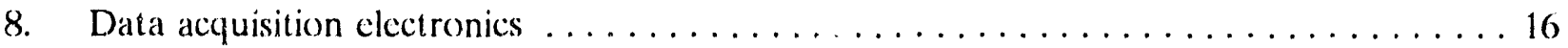


9. (a) ROIs used to analyze spectra using the two- and threc-window analysis algorithms,

(b) ROIs used to analyze spectra using the four-window analysis algorithm $\ldots \ldots \ldots 21$

10. $\sigma_{\mathrm{hgd}}$ as a function of the standard deviation of $k$ for $k$ equal to 0.05 or 0.5 and $\mathrm{N}_{\mathrm{B}}$ equal

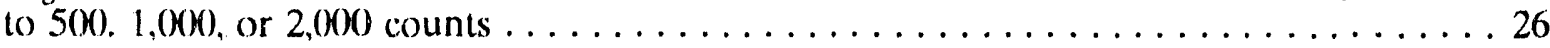

11. FWHM of ${ }^{218} \mathrm{Po} /{ }^{212} \mathrm{Bi}$ alpha peak versus sampling time for samplings of ambient air performed using the Merlin Gerin alpha CAM equipped with three different sample

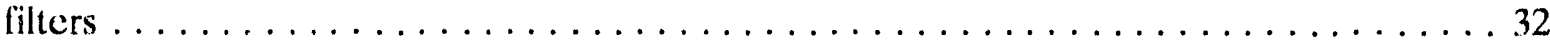

12. FWTM of ${ }^{218} \mathrm{Po} /{ }^{212} \mathrm{Bi}$ alpha peak versus sampling time for samplings of ambient air performed using the Merlin Gerin alpha CAM equipped with three different sample

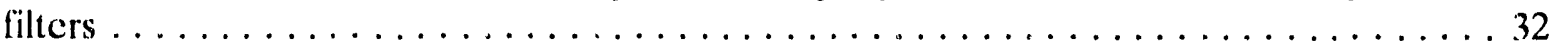

13. FWHM of ${ }^{214} \mathrm{Po}$ alpha peak versus sampling time for samplings of ambient air performed using the Merlin Gerin alpha CAM equipped with three different sample filters $\ldots \ldots .33$

14. FWTM of ${ }^{214}$ Po alpha peak versus sampling time for samplings of ambient air performed using the Merlin Gerin alpha CAM equipped with three different sample filters $\ldots . \ldots 33$

15. FWHM of ${ }^{214} \mathrm{Po}$ alpha peak versus average airborne dust loading for samplings performed using the Merlin Gerin Edgar alpha CAM equipped with three different sample

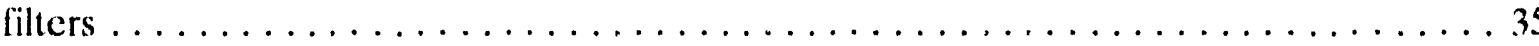

16. FWTM of ${ }^{214} \mathrm{Po}$ alpha peak versus average airborne dust loading for samplings performed using the Merlin Gerin Edgar alpha CAM equipped with three different

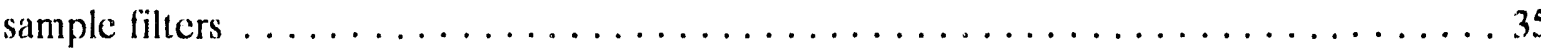

17. FWHM of the ${ }^{214} \mathrm{Po}$ alpha peak versus sampling time for samplings of ambient air performed using the ANL-W, Kurz model 8311, Merlin Gerin Edgar, and Victoreen

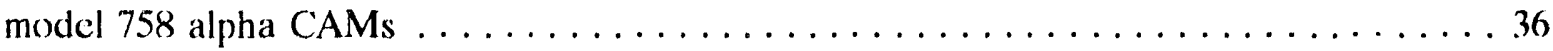

18. FWTM of the ${ }^{214}$ Po alpha peak versus sampling time for samplings of ambient air performed using the ANL-W, Kurz model 8311, Merlin Gerin Edgar, and Victrreen

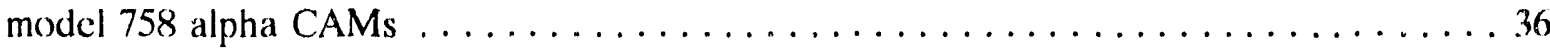

19. FWHM of the ${ }^{214} \mathrm{Po}$ alpha peak versus sampling time for samplings of acrosolized blank dust performed using the ANL-W, Kurz model 8311, Merlin Gerin Edgar, and Victoreen

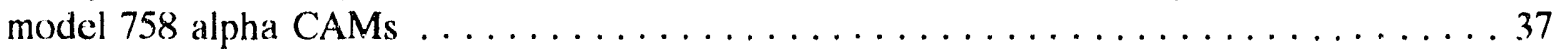

20. FW'TM of the ${ }^{214} \mathrm{Po}$ alpha peak versus sampling time for samplings of aerosolized blank dust performed using the ANL-W, Kurz model 8311, Merlin Gerin Edgar, and Victoreen

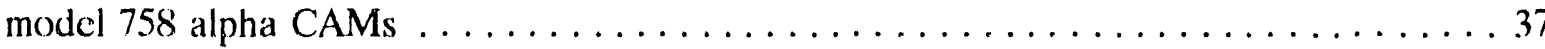

21. Average value of coefficient $\mathrm{k}_{1}$ for the Merlin Gerin CAM versus average airborne

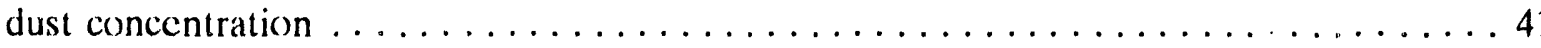


22. Average value of coefficient $\mathrm{k}_{2}$ for the Merlin Gerin CAM versus average airborne

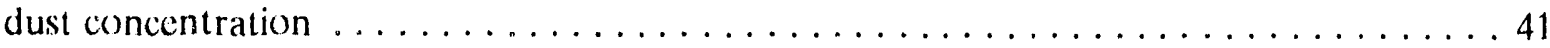

23. Average value of coefficient $\mathrm{k}_{3}$ for the Merlin Gerin CAM versus average airborne

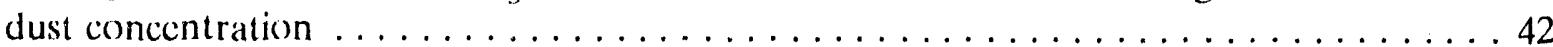

24. Standard deviations of coefficients $\mathrm{k}_{1}, \mathrm{k}_{2}$, and $\mathrm{k}_{3}$ versus average airborne dust concentration for samplings performed using the Merlin Gerin CAM equipped with a

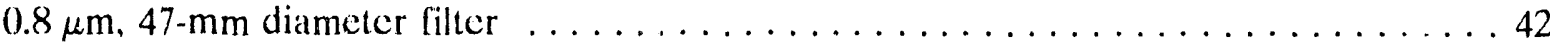

25. Standard deviations of coefficients $\mathrm{k}_{1}, \mathrm{k}_{2}$, and $\mathrm{k}_{3}$ versus average airborne dust concentration for samplings perlormed using the Merlin Gerin CAM equipped with a $2.0 \mu \mathrm{m}, 47-\mathrm{mm}$ diameter filter

26. $\mathrm{K}_{1}$ values versus the FWHM of the ${ }^{214}$ Po alpha peak for three samplings performed using

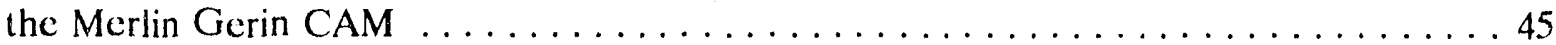

27. $\mathrm{K}_{1}$ values versus the FWTM of the ${ }^{214} \mathrm{Po}$ alpha peak for three samplings performed using

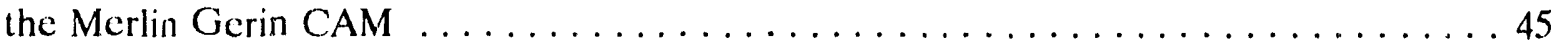

28. $\mathrm{K}_{2}$ values versus the FWHM of the ${ }^{214} \mathrm{Po}$ alpha peak for three samplings pertormed using the Merlin Gerin CAM .........................

29. $\mathrm{K}_{2}$ values versus the FWTM of the ${ }^{214} \mathrm{Po}$ alpha peak for three samplings peri. ormed using

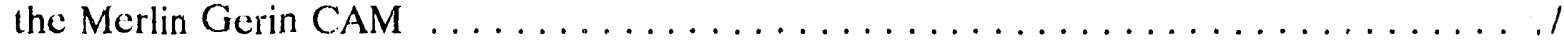

30. $\mathrm{K}_{3}$ values versus the FWHM of the ${ }^{214}$ Po alpha peak for three samplings performed using the Merlin Gerin CAM ........................... 48

31. $\mathrm{K}_{3}$ values versus the FWTM of the ${ }^{214} \mathrm{P}_{0}$ alpha peak for three samplings performed using

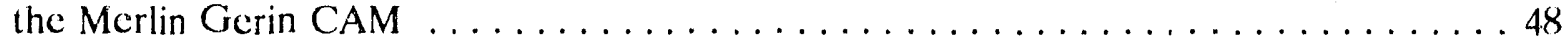

32. Average ${ }^{239} \mathrm{Pu}$ LLD concentration versus average airborne dust concentration for samplings performed using the Merlin Gerin Edgar alpha CAM equipped with a $0.8 \mu \mathrm{m}$,

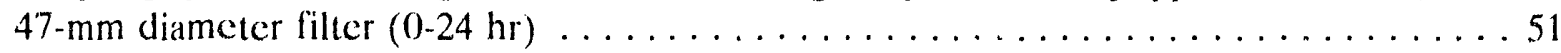

33. Average ${ }^{239} \mathrm{Pu}$ LLD concentration versus average airborne dust concentration for samplings performed using the Merlin Gerin Edgar alpha CAM equipped with a $2.0 \mu \mathrm{m}$,

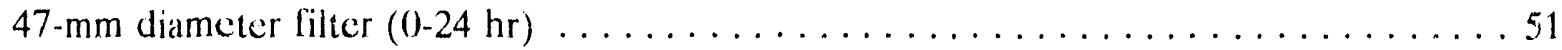

34. ${ }^{239} \mathrm{Pu}$ LLD concentration versus sampling time for the two-window algorithm for samplings of ambient air performed using the ANL-W, Kurz model 8311, Merlin Gerin Edgar, RADeCO model 452, and Victoreen model 758 alpha CAMs . . . . . . . . 53

35. ${ }^{239} \mathrm{Pu}$ LLD concentration versus sampling time for the three-window algorithm for samplings of ambient air performed using the ANL-W, Kur\& model 8311, Merlin Gerin Edgar. RADeCO model 452, and Victoreen model 758 alpha CAMs . . . . . . . . . 53 
36. ${ }^{239} \mathrm{Pu}$ LLD concentration versus sampling time for the four-window algorithm for samplings of ambient air performed using the ANL.W, Kurz model 8311, Merlin Gerin Edgar, RADeCO model 452, and Victoreen model 758 alpha CAMs . . . . . . . . . 54

37. Two-window algorithm $\left(\mathrm{N}_{13}\right)_{n}$ during samplings of ambient air performed using the ANL.W, Kurz, Merlin Gerin, RADeCO, and Victores CAMs . . . . . . . . . . . 55

38. Two-window algorithm ( $\left.a_{\text {hgd }}\right)_{n}$ during samplings of ambient air performed using the ANL-W. Kurz, Merlin Gerin, RADeCO, and Victoreen CAMs . . . . . . . . . . 55

39. ${ }^{239} \mathrm{Pu}$ concentration versus sampling time for a sampling of acrosolized spiked dust performed July 25-26, 1991 using the Merlin Gerin Edgar alpha CAM . . . . . . . 60

40. ${ }^{239} \mathrm{Pu}$ concentration versus sampling time for a sampling of acrosolized spiked dust perlormed July 30-August $x, 1991$ using the Meriin Gerin Edgar alpha CAM . . . . . 60

\section{'TA.BLES}

1. Detectors and lilters installed in alpha CAMs $\ldots \ldots \ldots \ldots \ldots \ldots \ldots \ldots \ldots \ldots$

2. Surnmary of samplings of ambient air performed using the Merlin Gerin Edgar

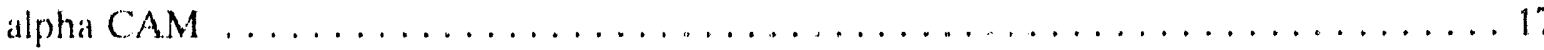

3. Summary of samplings of aerosolized blank dust performed using the Merlin Gerin Edgar alpha CAM ..............................

4. Summary of samplings of acrosolized spiked performed using the Merlin Gerin Edgar

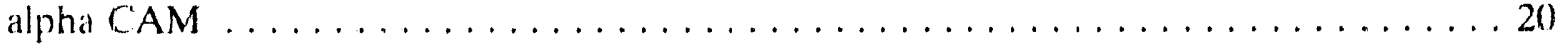

5. Summary of detector absolute counting efficiencies for ${ }^{239} \mathrm{Pu}$ for the ${ }^{239} \mathrm{Pu}$ ROIs used with the two-. three-, and four-window analysis algorithms founts per

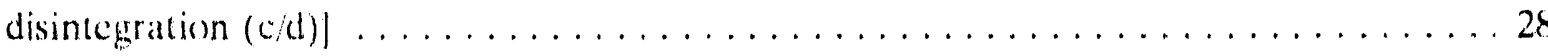

6. Average FWHM and FWTM of ${ }^{218} \mathrm{Po} /{ }^{212} \mathrm{Bi}$ and ${ }^{214} \mathrm{Po}$ alpha peaks for selected samplings performed using the Merlin Gerin alpha CAM (14-24hr) . . . . . . . . 30

7. Average values of coefficients $k_{1}$. $k_{2}$, and $k_{3}$ for the Merlin Gerin alpha CAM for samplings of ambient air and acrosolized blank t.ust $\ldots \ldots \ldots \ldots \ldots \ldots \ldots \ldots \ldots$. $\ldots \ldots$

8. Average values of coefficients $i_{1}, k_{2}$, and $k_{3}$ for the ANL-W, Kurz. Merlin Gerin. RADeCO. and Victoreen CAMs for selectea samplings of ambient air and aerosolized

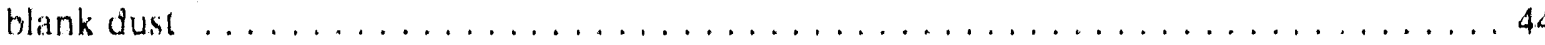

9. Average ${ }^{239} \mathrm{Pu}$ LLD concentration during samplings of ambient air and acrosoliced blank dust performed using the Merlin Gerin CAM 


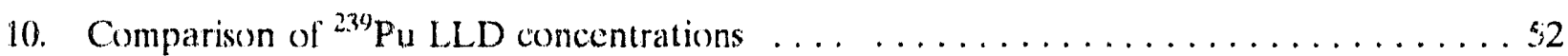

11. Operating parameters during samplings of ambient air $\ldots \ldots \ldots \ldots \ldots \ldots \ldots \ldots$

12. Average concentrations of airborne dust and ${ }^{239} \mathrm{Pu}$ based on weighings and

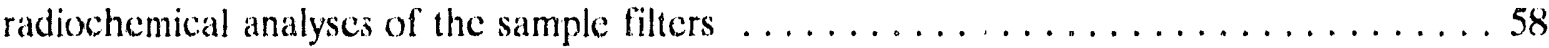

13. Comparison of average airborne ${ }^{239} \mathrm{Pu}$ concentrations $(\mathrm{pCi} / \mathrm{L}) \ldots \ldots \ldots \ldots \ldots$ 


\section{ACRONYMS}

ADC

AMD

ANL-W

CAM

DAC

DOE

FWHM

FWTM

INEL

ITRI

LLD

MCA

MPC

RFP

ROI

RWMC

TRA

TRU analog to digital converter

acrodynamic mean diameter

Argonne National Laboratory-West

continuous air monitor

derived air concentration

Department of Energy

full width at half maximum

full width at tenth maximum

Idaho National Enginecring Laboratory

Inhalation Toxicology Research Institute

lower limit of detection

multi-channel analyzer

maximum permissible concentration

Rocky Flats Plant

region of (spectrum of) interest

Radioactive Waste Management Complex

Test Reactor Area

transuranic 


\section{Sensitivities of Five Alpha Continuous Air Monitors for Detection of Airborne ${ }^{239} \mathrm{Pu}$}

\section{INTRODUCTION}

During the years 1950 to 1970 approximately $57,000 \mathrm{~m}^{3}$ of defense-related waste contaminated with transuranic (TRU) isotopes was buried in pits and trenches at the Radioactive Waste Management Complex (RWMC) at the Idaho National Engineering Laboratory (INEL). The waste was contained in metal drums, plywood boxes, cardboard boxes, and other miscellaneous containers. As a demonstration project, waste in one of the pits will be retrieved and repackaged. It is anticipated that waste containers have degraded over the years and that a significant fraction of the backfill material has become contaminated with TRU isotopes. Therefore, during the waste retricval effort there will be a high probability for TRU contamination spread via direct (soil spills) and indirect (airborne) pathways. Contamination control and health physics programs will require that all pathways be monitored to determine the spread of and magnitude of any TRU contamination within the inner building, the secondary building, and the environment.

Department of Energy (DOE) Order DOE 5480.11 ${ }^{1}$ establishes maximum permissible concentrations (MPCs), or derived air concentrations (DACs), for airborne TRU isotopes. These limits are established to protect a worker from undue risk from airborne radioactive contaminants. Remote operations will be utilized during the retrieval demonstration project to restrict exposure of workers to TRU and organic contaminants. However, there will be oceasions when workers will be required to enter the inner building to maintain and decontaminate equipment and perform other tasks. At these times, the airborne concentrations of TRU radionuclides inside the primary containment building must be known so that adequate protective clothing can be selected. Also, during the retrieval operation the success of the contamination control methods will need to be monitored so that changes in operations can be made in a timely manner. An alpha continuous air monitor (CAM) will provide real-time leedbaink on the conditions inside the inner building.

This report describes work performed to determine the sensitivities of live alpha CAMs for detection of airborne ${ }^{239} \mathrm{Pu}$. The work commenced during FY 1989 with the experimental evaluation of the Victoreen model 758 alpha CAM. ${ }^{2}$ During FY 1990, three additional alpha CAMs [the Kurz model 8311, the RADeCO model 452, and a prototype alpha CAM that has been in use at the Argonne National Laboratory-West (ANL-W) for the past 17 years/ were obtained and these three CAMS and the Victoreen CAM were subjected to a more extensive series of tests ${ }^{3,4}$ to evaluate their performanec in dusty environments similar to those that might be encountered during waste retrieval operations. During FY 1991, a fifth alpha CAM, the French-designed Edgar alpha/beta CAM that is distributed in the U.S. by Merlin Gerin, Inc., Smyrna, Georgia, was subjected to the same types of lests.

Two of the alpha CAMs tested during FY 1990, the Kurz model 8311 and the ANL-W, are equipped with impactors that remove alpha-emitting daughters of radon $\left({ }^{222} \mathrm{Rn}\right)$ and thoron $\left({ }^{220} \mathrm{Rn}\right)$ from the sample airstream. A third, the RADeCO model 452, is equipped with a thin collimator positioned over the face of the alpha detector that reduces the widths of alpha peaks in collected spectra. The fourth, the Victoreen model 758 , is representative of conventional designs lacking 
impactors and collimators that pump air through a porous filter placed in close proximity to a solid-state silicon alpha detector.

The Merlin Gerin Edgar alpha/beta CAM was selected for evaluation during FY 1991 because the system has several unique features that might make the CAM particularly useful for the purpose of monitoring air quality during buried waste retricval. The design of the Edgar alpha/beta CAM is novel in a number of respects, but from the point of view of sensitivity, the most important design feature is the relatively thick collimator that is installed between the lilter and alpha detector. Because alpha particles that leave the collection filter at oblique angles strike the collimator, they do not reach the detector and, consequently, the resolution of the Edgar alpha CAM is much better than can be achieved using conventional designs that employ sample collection filters.

This report describes (a) the basic operating principles of alpha CAMs and the fundamental problems associated with performing measurements with alpha CAMs, (b) the main components of the five alpha CAMs tested and how the alpha CAMs are operated, (c) the methods used to calibrate the solid-state detectors installed in the CAMs for the determination of the concentration of airborne ${ }^{2.39} \mathrm{Pu}$, (d) the methods used to sample laboratory-generated and natural ambient atmospheres, and (c) the methods used to transmit, store, and analyze spectral data. Summaries of calculated ${ }^{239} \mathrm{Pu}$ lower limit of detection (LLD) concentrations for each of the five CAMs are presented. The data quality objectives of the experiments performed using the alpha CAMs were previously defined in Test Plan for Contamination Con'rol Related Experiments ${ }^{5}$ and Test Plan for FY-91 Alpha CAM Evaluation." 


\section{BACKGROUND}

All alpha CAMs detect the presence of airborne alpha contamination by pulse height analysis of the alpha activity removed from air that is sampled. A typical measurement of the concentrations of airborne alpha-emitting radionuclides is performed by pulling a continuous sample of ambient air through a filter having a pore size small enough to trap aerosolized particles. The filter is positioned close to an alpha detector, which is normally a solid state silicon detector, to maximize counting efficiency and minimize the loss of alpha particle energy during transit from the filter to the detector. The alpha-emitting radionuclides are attached to the aerosol particles that are trapped by the filter. The amount of aerosol material collected on the filter depends on its concentration in the ambient air, the sampling llow rate, and the particle collection efficiency of the CAM.

This measurement approach presents three major interactive problems. The first is that the lilter collects the normal dust present in the ambient environment. The dust is normally collected continuously and it gradually covers the material previously deposited on the filter. Alpha particles emitted by acrosols imbedded in the dust lose energy in passing through the dust layer. Alpha particles that are degraded in energy contribute a continuum of counts to the spectrum, resulting in higher backgrounds and broader, less well defined alpha peaks. In environments where a lot of dust is generated, airborne dust can significantly reduce the sensitivity of the CAM for airborne TRU contaminants.

The second difficulty stems from the fact that the filter is fixed so that the current concentration of an alpha emitting radionuclide must be calculated based on a change in detector count rate. The instrument must determine a differential value of the count rate to determine concentration. The inherent problem is that the count rates that occur for typical concentrations of alpha emitting TRU contaminants are very low. For example, if air having a ${ }^{239} \mathrm{Pu}$ concentration of $1 \mathrm{DAC}(0.002 \mathrm{pCi} / \mathrm{L})$ is sampled at $56.6 \mathrm{~L} / \mathrm{min}\left(2 \mathrm{ft}^{3} / \mathrm{min}\right)$, after 1 hour only about $7 \mathrm{pCi}$ of ${ }^{239} \mathrm{Pu}$ would be collected on the filter. For an alpha detector having a counting efficiency of $30 \%$, the count rate in the ${ }^{239} \mathrm{Pu}$ peak, ignoring the background, would be only about $5 \mathrm{cpm}$ after 1 hour. Low counting rates dictate that relatively long counting times must be used in order to achieve statistically meaningful results.

The third, and perhaps the most fundamental problem, is the presence of naturally occurring alpha-emitting isotopes in the environment. These background isotopes, which are present throughout the earth's crust, are products of three natural radioactive decay chains- the ${ }^{238} \mathrm{U},{ }^{232} \mathrm{Th}$, and ${ }^{235} \mathrm{U}$ series. All three of these radioactive decay chains yield isotopes of radon, which is a noble gas that may escape from the ground to the surrounding air. Because radon is a gas, it passes through the sample collection filler and is not detected; however, radon decays to isotopes of polonium, lead, and bismuth that become attached to acrosols that are trapped by the sample collection filter. Portions of the ${ }^{2.38} \mathrm{U}$ and ${ }^{2.32} \mathrm{Th}$ decay chains resulting in ${ }^{222} \mathrm{Rn}$ and ${ }^{220} \mathrm{Rn}$ and daughter products are shown below. Alpha particles emitted by ${ }^{218} \mathrm{Po},{ }^{214} \mathrm{Po},{ }^{212} \mathrm{Bi}$, and ${ }^{212} \mathrm{Po}$ have energies of 6.00, $7.69,6.06$, and $8.78 \mathrm{McV}$, respectively. When degraded in energy as a result of interactions with the filter medium and overlaying dust, these alpha particles contribute a continuum of counts to the spectrum in the energy region of the ${ }^{239} \mathrm{Pu}$ alpha peak, which has an energy of $5.15 \mathrm{MeV}$. Examples of alpha spectra collected using the Merlin Gerin and Victoreen CAMs that show the positions of the polonium and bismuth alpha peaks relative to the location of the ${ }^{239} \mathrm{Pu}$ 
${ }^{238} \mathrm{U}$ Decay Chain

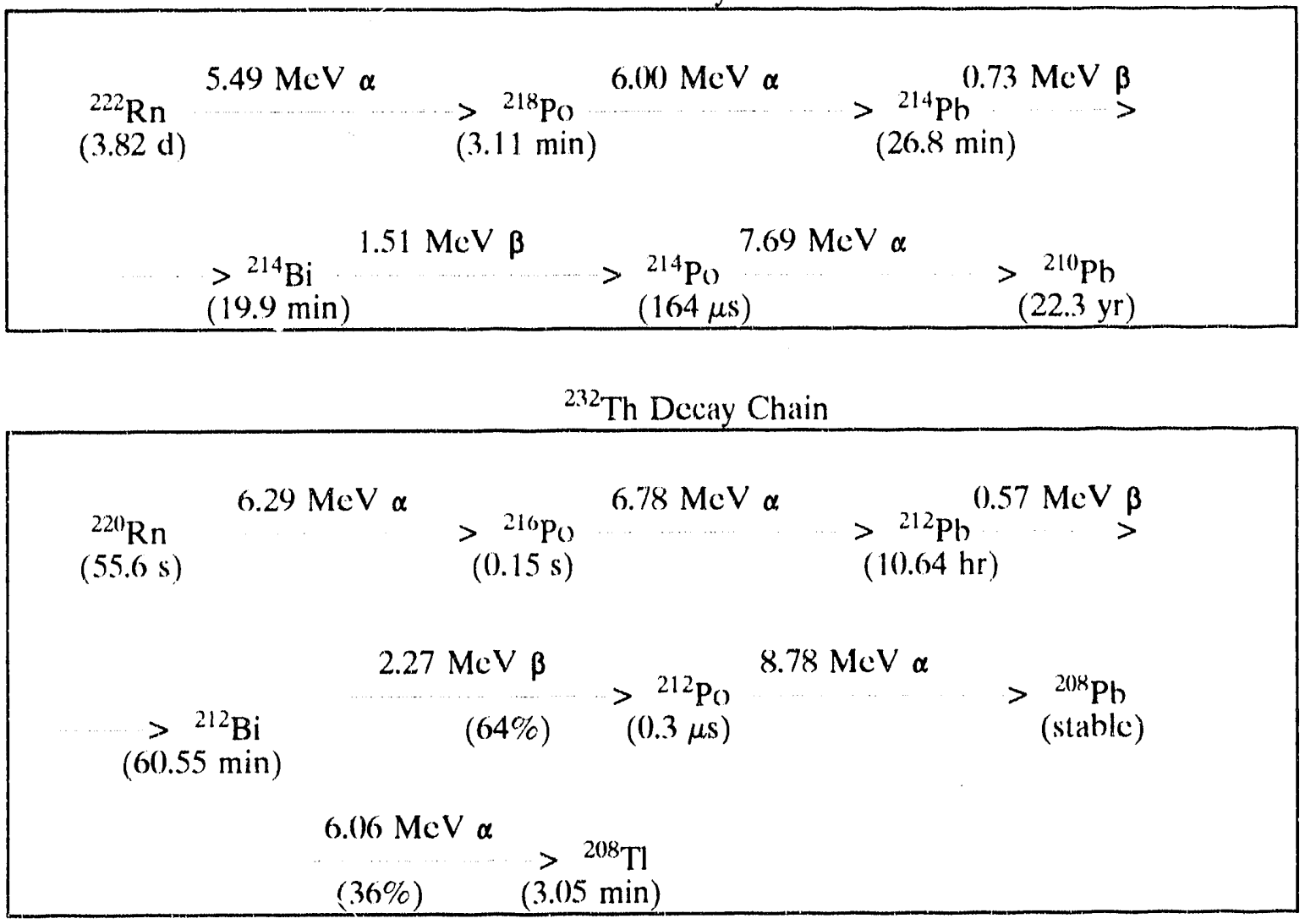

alpha peak are presented in Figures $1 \mathrm{a}$ and $1 \mathrm{~b}$, respectively. As evident in Figure $1 \mathrm{~b}$, the low-energy tails of these background peaks can contribute a significant number of eounts to the region of the ${ }^{239} \mathrm{Pu}$ alpha peak.

The half-lives of the radon and thoron daughters are such that, under steady state conditions, ${ }^{218} \mathrm{Po}$ activity on the sample filter will reach equilibrium in a matter of minutes, but ${ }^{214} \mathrm{Po}$ activity will continue to increase during the first hour or so of sampling. As shown above, the precursor of ${ }^{212} \mathrm{Bi}$ and ${ }^{212} \mathrm{Po}$ is $10.6-\mathrm{hr}{ }^{212} \mathrm{~Pb}$. Due to the relatively long half-life of ${ }^{212} \mathrm{~Pb},{ }^{212} \mathrm{Bi}$ and ${ }^{212} \mathrm{Po}$ activities on the sample filter will continue to increase throughout the first cay of sampling. Due to the fact that ${ }^{212} \mathrm{Po}$ has a half-life of only $0.3 \mu \mathrm{s}$, it will always be in secular equilibrium with ${ }^{212} \mathrm{Bi}$ and because ${ }^{212} \mathrm{Bi}$ decays by alpha emission only $36 \%$ of the time, the number of eounts contributed by ${ }^{212} \mathrm{Bi}$ to the 6.(1) $\mathrm{MeV}$ aipha peak will always be equal to about one-half the number of counts in the ${ }^{212} \mathrm{Po}$ alpha peak.

Both mechanistic and analytical approaches have been developed to mitigate the effect of natural background alpha radiation. One mechanistic approach to reducing natural alpha background relies on the use of inertial impactors. Results reported in the literature ${ }^{7}$ indicate that radon and thoron daughters, which are the main contributors to background alpha activity, are primarily associated with small-diameter particulates. Impactors reduce alpha background by removing some fraction of the small-diameter particulates from the sample airstream prior to the point of particulate collection. Plutonium bearing particles, having greater density than the smaller particles associated 


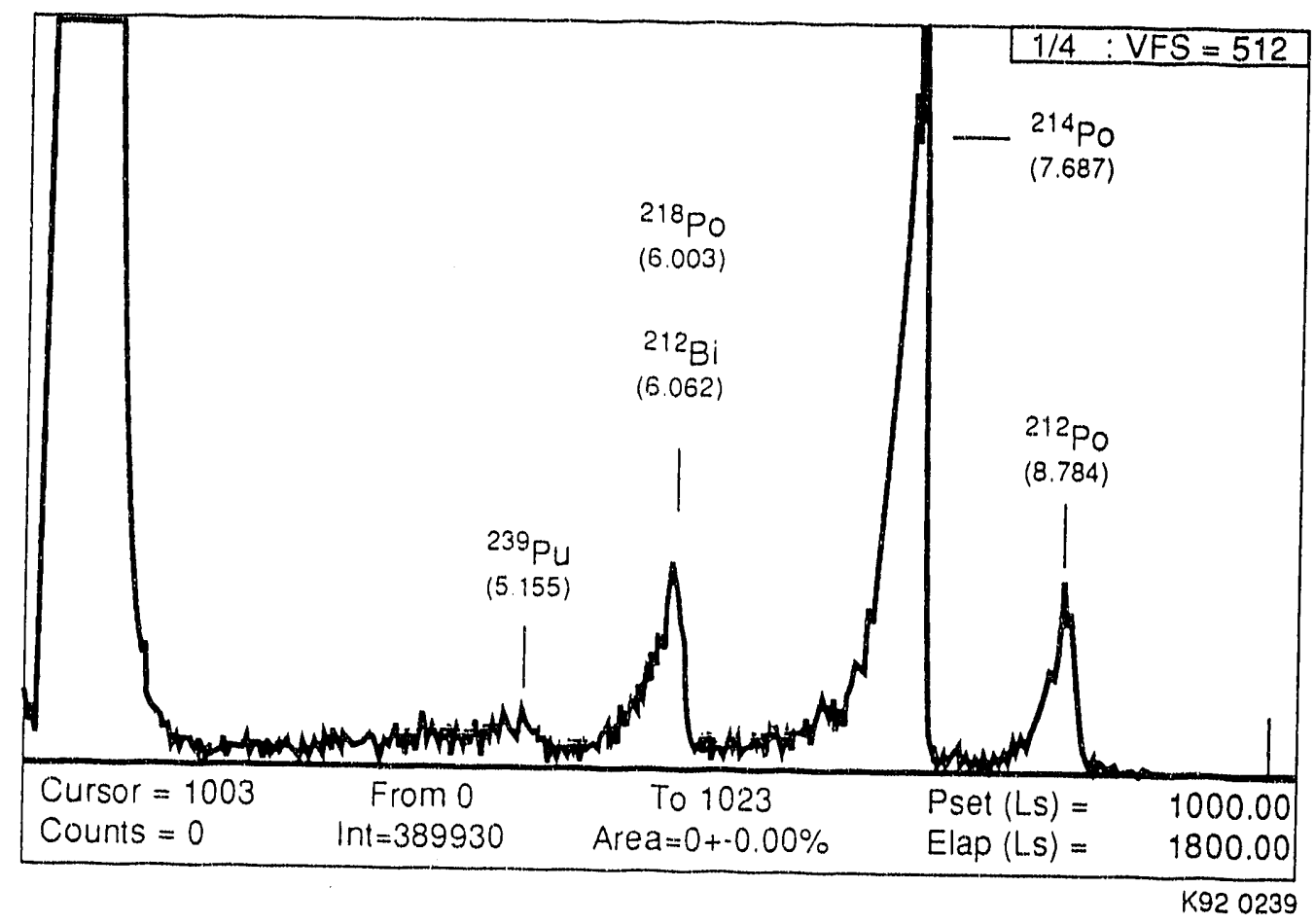

Figure 1a. Spectrum collected using the Merlin Gerin alpha CAM showing the relative positions of the ${ }^{239} \mathrm{Pu},{ }^{218} \mathrm{Po} /{ }^{212} \mathrm{Bi},{ }^{214} \mathrm{Po}$, and ${ }^{212} \mathrm{Po}$ alpha peaks.

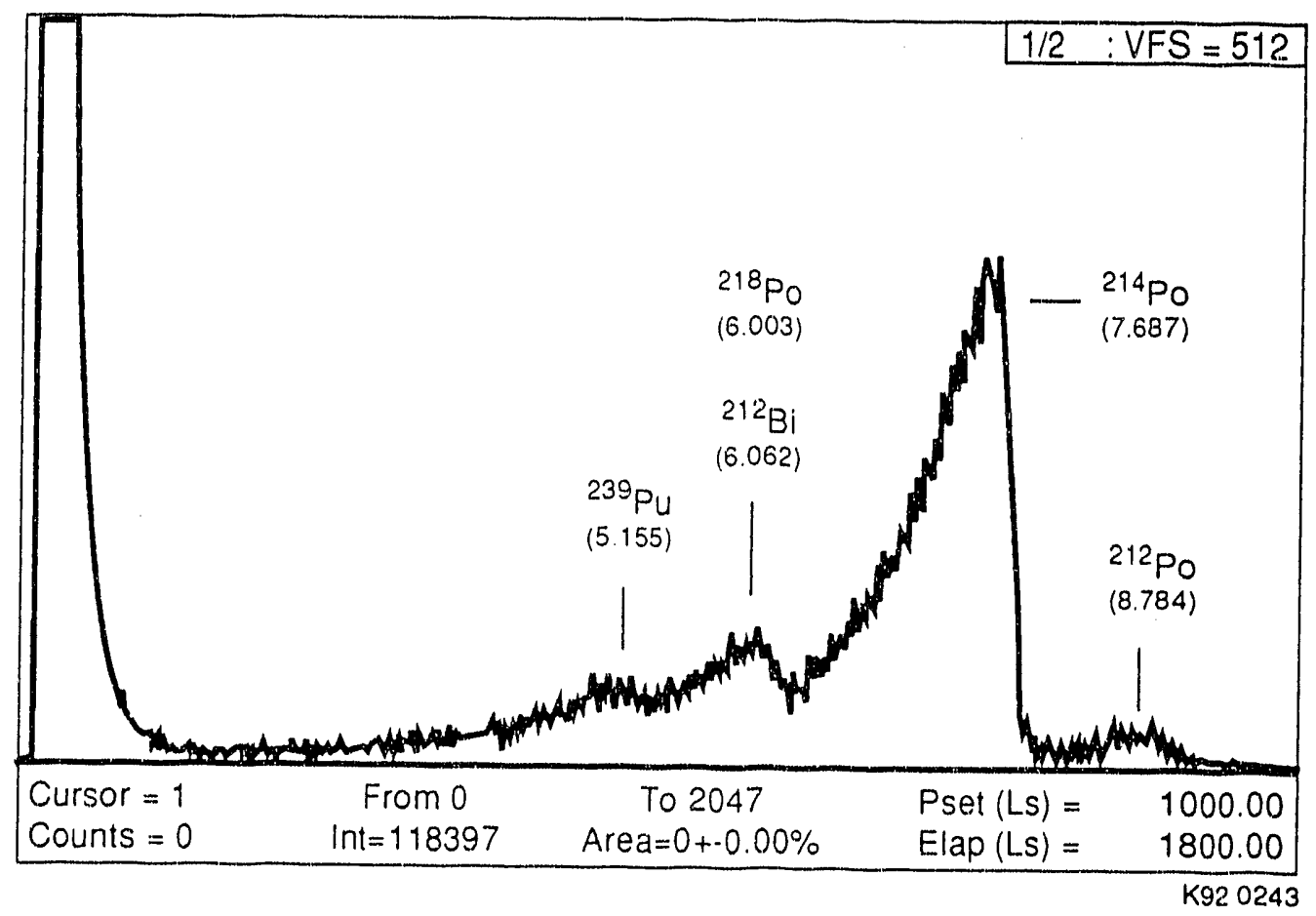

Figure 1b. Spectrum collected using the Victoreen alpha CAM showing the relative positions of the ${ }^{239} \mathrm{Pu},{ }^{218} \mathrm{Po} /{ }^{212} \mathrm{Bi},{ }^{214} \mathrm{Po}$, and ${ }^{212} \mathrm{Po}$ alpha peaks. 
with radon daughter activity, pass through the impactor and are collected on a filter or other collection medium. Two of the four CAMs that were evaluated, the Kurz model 8311 and the ANL-W prototype CAM, were equipped with impactors.

Other mechanistic approaches focus not on eliminating the background isotopes from the sample airstream but on reducing their effect on the quality of collected spectra. As was previously mentioned, the RADeCo model 452 and Merlin Gerin Edgar CAMs are equipped with multi-vaned collimators positioned between the sample collection filter and the solid-state silicon alpha detector. Alpha particles emitted from the sample filter at oblique angles strike the collimator and consequently do not reach the silicon detector. Thus, alpha particles significantly degraded in energy due to longer path lengths through dust collected on the filter and through the air between the filter and silicon detector are eliminated from the spectrum. The result is narrower peaks that contribute fewer counts to the region of the ${ }^{239} \mathrm{Pu}$ alpha peak. A third mechanistic approach to reducing the effect of background alpha particles achieves the same goal as the collimator by simply climinating the sample filter. This approach is used in the Kurz model 8.311 alpha CAM. Acrosols entrained in the sample airstream are collected directly on the face of the silicon alpha detector. Because the alpha particles do not traverse an air gap, they are only degraded in energy as a result of passing through whatever layer of dust was present prior to their emission. Consequently, the widths of alpha peaks in collected spectra are much narrower than the widths that can normally be achieved using a sample collection filter.

Of the spectrum analysis methods that have been developed, the most commonly used are those that determine net counts in the ${ }^{239} \mathrm{Pu}$ peak by subtracting from the total counts in the ${ }^{239} \mathrm{Pu}$ peak some fraction of the counts in adjacent regions of the spectrum. In each case, the expression for net ${ }^{239} \mathrm{Pu}$ counts is a linear function of counts in the ${ }^{239} \mathrm{Pu}$ and background regions of the spectrum. Three such spectrum analysis algorithms, which are currently installed in the majority of commercially available alpha CAMs, were evaluated. 


\section{INSTRUMENTATION}

\section{Description of Alpha CAMs}

As was previously mentioned, of the five alpha CAMs tested, four were commercial units while the fifth was a prototype currently used at ANL-W. The commercial CAMs tested were the Kurz model 8311, Merlin Gerin Edgar, RADeCO model 452, and the Victoreen model 758. A preliminary evaluation of the Victoreen model 758 CAM was performed during FY 1989 (sec Reference 2) and the ANL-W, Kurz, RADeCO, and Victoreen CAMs were subjected to more rigorous tests during FY 1990) (sec References 3 and 4). The Merlin Gerin Edgar CAM was subjected to similar tests during FY 1991.

The ANL-W prototype CAM has been in use at ANL-W since 1975..$^{7,8,9}$ The four commercial CAMs were chosen for testing because they were representative of state-of-the-art designs. The ANL-W CAM was also selected for testing because it has been reported to have the capability of detecting $1 \mathrm{DAC}$ of ${ }^{239} \mathrm{Pu}$ in less than one-half hour in the presence of $1 \mathrm{pCi} / \mathrm{L}$ of ${ }^{218} \mathrm{Po}$ (see Reference 7).

This section provides a brief description of the main components of the five alpha CAMs. Information regarding the solid-state silicon detector installed in each CAM, the sample collection filter(s) used during testing, the distance between the filter and detector, and the sampling flow rate recommended by each manufacturer is summarized in Table 1.

\section{ANL-W Prototype}

The ANL-W alpha CAM (see References 7-9) is equipped with a two-stage virtual impactor to eliminate radon progeny and concentrate airborne plutonium-bearing particulates. A schematic of a virtual impactor and cutaway view of the ANL-W CAM showing the general arrangement of the two-stage virtual impactor and solid-state silicon detector is presented in Figure 2. Air, which is sampled at the relatively high rate of $283.2 \mathrm{~L} / \mathrm{min}\left(10 \mathrm{ft}^{3} / \mathrm{min}\right)$, is drawn through a circular array of inlet jets and is directed towards a complementary array of receiving tubes. A major portion of the air leaving the jets $(205.3 \mathrm{~L} / \mathrm{min})$ is drawn off laterally before the airstream enters the receiving tubes. Small particles entering the inlet jets follow the lateral flow of air and do not enter the receiving tubes. Large particles not able to follow the lateral airllow enter the receiving tubes. This arrangement is repeated in a second stage in the impactor, with the lateral flow in this stage being $58.4 \mathrm{~L} / \mathrm{min}$. In principle, the miror $(19.5 \mathrm{~L} / \mathrm{min})$ airllow exiting the second set of receiving tubes contains most of the plutonium-bearing particulates that entered the impactor. This minor airflow is directed to a sample collection filter spaced about $3 \mathrm{~mm}$ from a $800 \mathrm{~mm}^{2}$ surface barrier silicon detector. The cut point, or size at which $50 \%$ of the particles pass through the impactor, corresponds to an aerodynamic mean diameter (AMD) of about $1.5 \mu \mathrm{m}$, which is equivalent to a geometric diameter of $0.4 \mu \mathrm{m}$ for a plutonium oxide particle (sec Reference 7). Thus, particles larger than $0.4 \mu \mathrm{m}$ are collected on the sample filter with greater than $50 \%$ efficiency. Detailed descriptions of other components of the ANL-W alpha CAM may be found in Reference 9. 
Tabie 1. Detectors and filters installed in alpha CAMs.

\begin{tabular}{|c|c|c|c|c|c|c|}
\hline \multirow[b]{2}{*}{ CAM } & \multirow[b]{2}{*}{$\begin{array}{l}\text { Type of } \\
\text { silicon detector }\end{array}$} & \multicolumn{2}{|c|}{ Detcctor } & \multirow{2}{*}{$\begin{array}{l}\text { Filler- } \\
\text { detector } \\
\text { separation } \\
(\mathrm{mm})\end{array}$} & \multirow[b]{2}{*}{$\begin{array}{c}\text { Type of } \\
\text { collection filter }\end{array}$} & \multirow[b]{2}{*}{$\begin{array}{c}\text { Recommended } \\
\text { now rate } \\
(\mathrm{L} / \mathrm{min})\end{array}$} \\
\hline & & $\begin{array}{l}\text { Diameter } \\
(\mathrm{mm})\end{array}$ & $\begin{array}{c}\text { Surface } \\
\text { area } \\
\left(\mathrm{mm}^{2}\right)\end{array}$ & & & \\
\hline ANL.W & Surface Barrier & 31.9 & 800 & 3.2 & Millipore AA $0.8 \mu \mathrm{m}$ & 283.2 \\
\hline Kurz & Diffused Junct. & 25.0 & 490 & NA & None & 56.6 \\
\hline Merlin Gerin & Ion implanted & 47.0 & 1735 & 11.0 & $\begin{array}{l}\text { Millipore AW } 2.0 \mu \mathrm{m} \\
\text { Millipore AA } 0.8 \mu \mathrm{m}\end{array}$ & 40.0 \\
\hline RADeCO & Ion implanted & 43.7 & 1500 & 6.4 & $\begin{array}{l}\text { Millipore SM } 5.0 \mu \mathrm{m} \\
\text { Millipore AA } 0.8 \mu \mathrm{m}\end{array}$ & 56.6 \\
\hline Victoreen & Ion implanted & 46.5 & 1700 & 1.8 & Millipore AA $0.8 \mu \mathrm{m}$ & 56.6 \\
\hline
\end{tabular}
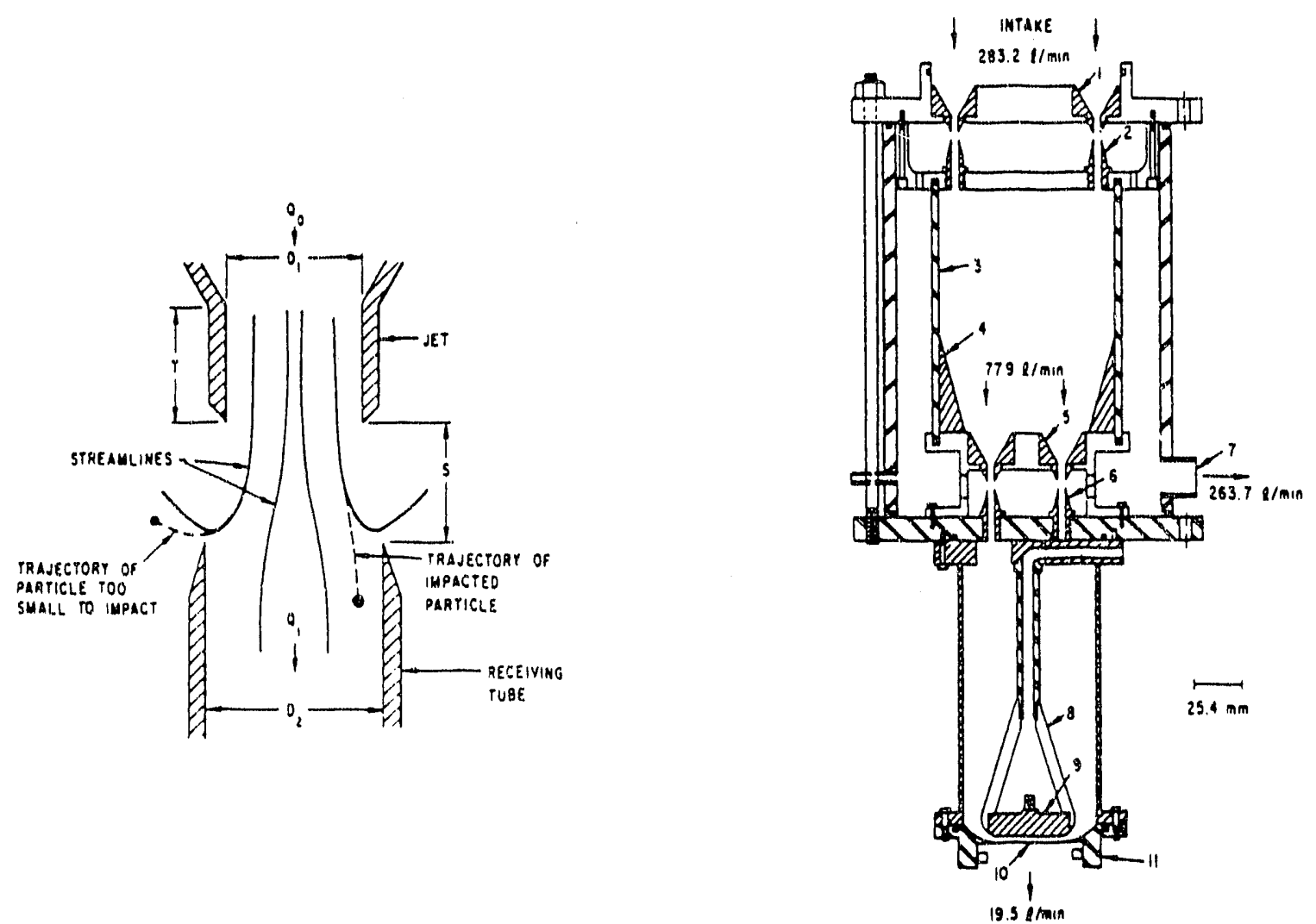

Figure 2. Schematic of a virtual impactor and cutaway view of the ANL-W alpha CAM showing arrangement of the two-stage virtual impactor and solid-state detector. 


\section{Kurz Model 8311}

The Kurz model 8311 alpha CAM is manufactured by Kurz Instruments Inc., Monteray, California. This CAM employs an inertial dichotomous impactor that directs entrained particulates directly onto the face of a $490 \mathrm{~mm}^{2}$ diffused junction silicon detector. A cutaway vicw of the Kurz model 8311 alpha CAM is shown in Figure 3. Air enters the CAM through a 360)-degree circumferential inlet slot with a width ordinarily set to eliminate particles larger than $20 \mu \mathrm{m}$ from the inlet air stream. ${ }^{10}$ The air then passes through the inertial impactor, which is a plate containing two sets of concentrically arranged holes. The effluent face of the impactor plate is positioned directly over the silicon detector. In principle, larger particles strike and adhere to the face of the silicon detector, while the smaller-diameter particulates remain entrained in the airstream and are exhausted from the CAM. The cut point of the model 8311 impactor has been reported by Kurz Instruments to be about 0.7 $\mu \mathrm{m}$ AMD (see Reference 10). Because this CAM does not use a collection filter, alpha particles do not have to traverse an air gap before striking the detector, and hence, alpha spectra collected using the Kurz 8.,11 exhibit a resolution much better than that normally achieved using conventional designs that employ filters. A detector amplifier/line-driver circuit allows remote operation of the CAM sample collection head at ciistances up to $1200 \mathrm{~m}$. A mass flow sensor and associated electronics that monitor sampling flow rate and cumulative air sample volume are incorporated into the Kurz model $8311 \mathrm{FE}$ and $8311 \mathrm{FT}$ CAMs.

\section{Merlin Gerin Edgar}

The French-designed Edgar alpha/beta CAM is distributed in the U.S. by Merlin Gerin, Inc., Smyrna, Georgia. The CAM is equipped with a $1735 \mathrm{~mm}^{2}$ ion-implanted silicon detector and a NSC800 microprocessor analyzer. The detector and analyzer are housed in two separate modules which are electrically connected via a cable. A schematic of the Edgar CAM showing the arrangement of the sensor and electronics modules and air sampling pump is presented in Figure 4.

From the point 'f view of sensitivity, the most important design feature of the Edgar CAM is the collimator that is installed between the filter and alpha detector. The spacing between the filter and detector is $11 \mathrm{~mm}$, which is about a factor of four greater than the spacing used in most alpha CAMs. (This spacing corresponds to the mean range of a $2 \mathrm{MeV}$ alpha particle in air at STP, meaning that alpha particles emitted from the sample filter with energies less than about $2 \mathrm{MeV}$ will not reach the detector.) The collimator, which is positioned directly over the face of the silicon detector, consists of six very thin metal vanes, each about $10 \mathrm{~mm}$ high, that extend like spokes of a wheel from the eenter of the collimator. Alpha particles emitted from the sample filter at oblique angles strike the collimator and consequently do not reach the silicon detector. Thus, alpha partivies degraded in energy due to longer path lengths through dust collected on the filter and through the air between the lilter and silicon detector are eliminated from the spectrum. The result is narrower peaks that contribute 'ewer counts to the region of the ${ }^{2.39} \mathrm{Pu}$ alpha peak. Merlin Gerin, Inc., claims that the resolution of the Edgar CAM is so good that less than $0.3 \%$ of the alpha particles emitted by radon daughters are degraded into the energy region of the ${ }^{239} \mathrm{Pu}$ alpha peak.

\section{RADeCO Model 452}

The RADeCO model 452 alpha CAM is manufactured by SAIC/RADcCO, San Dicgo, California. The model 452 is equipped with a $1500 \mathrm{~mm}^{2}$ ion-implanted silicon detector and a 


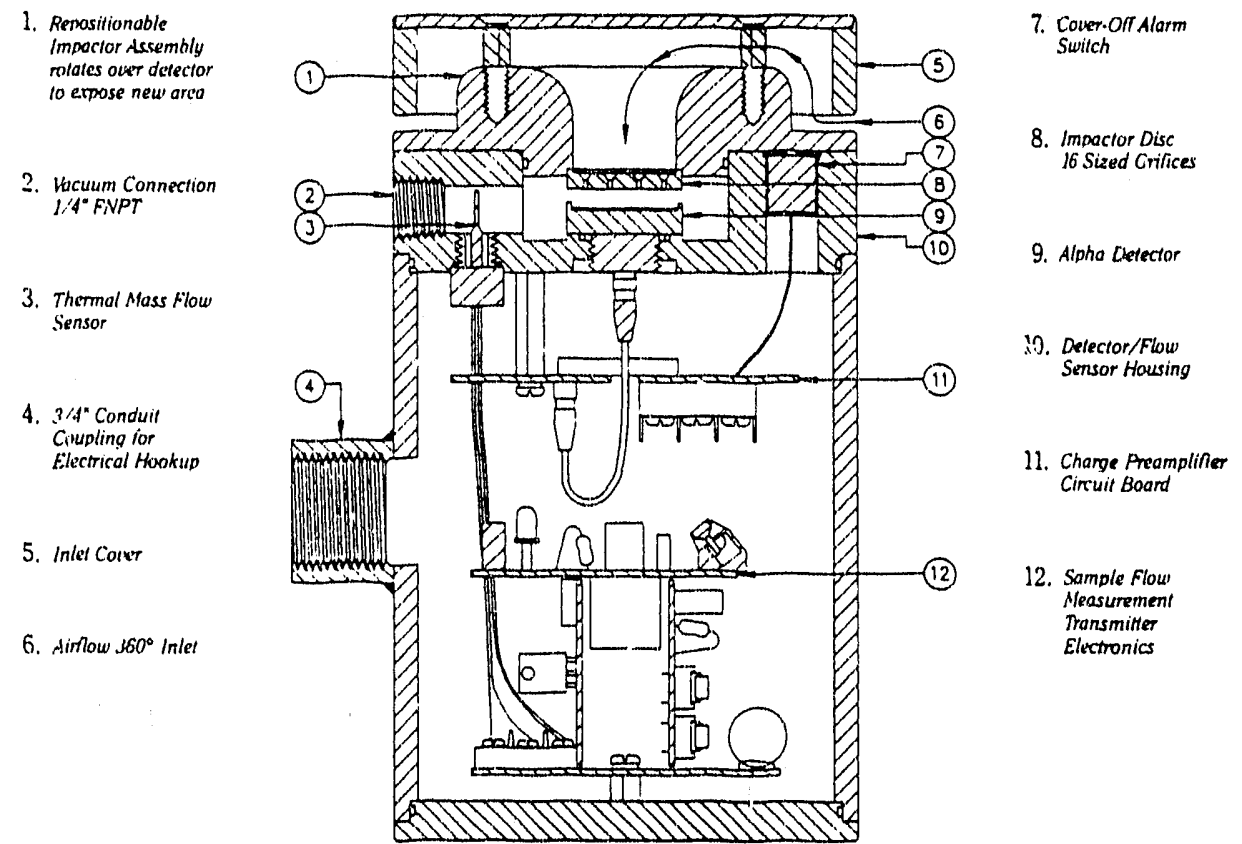

Figure 3. Cutaway view of the Kurz model 8311 alpha CAM.

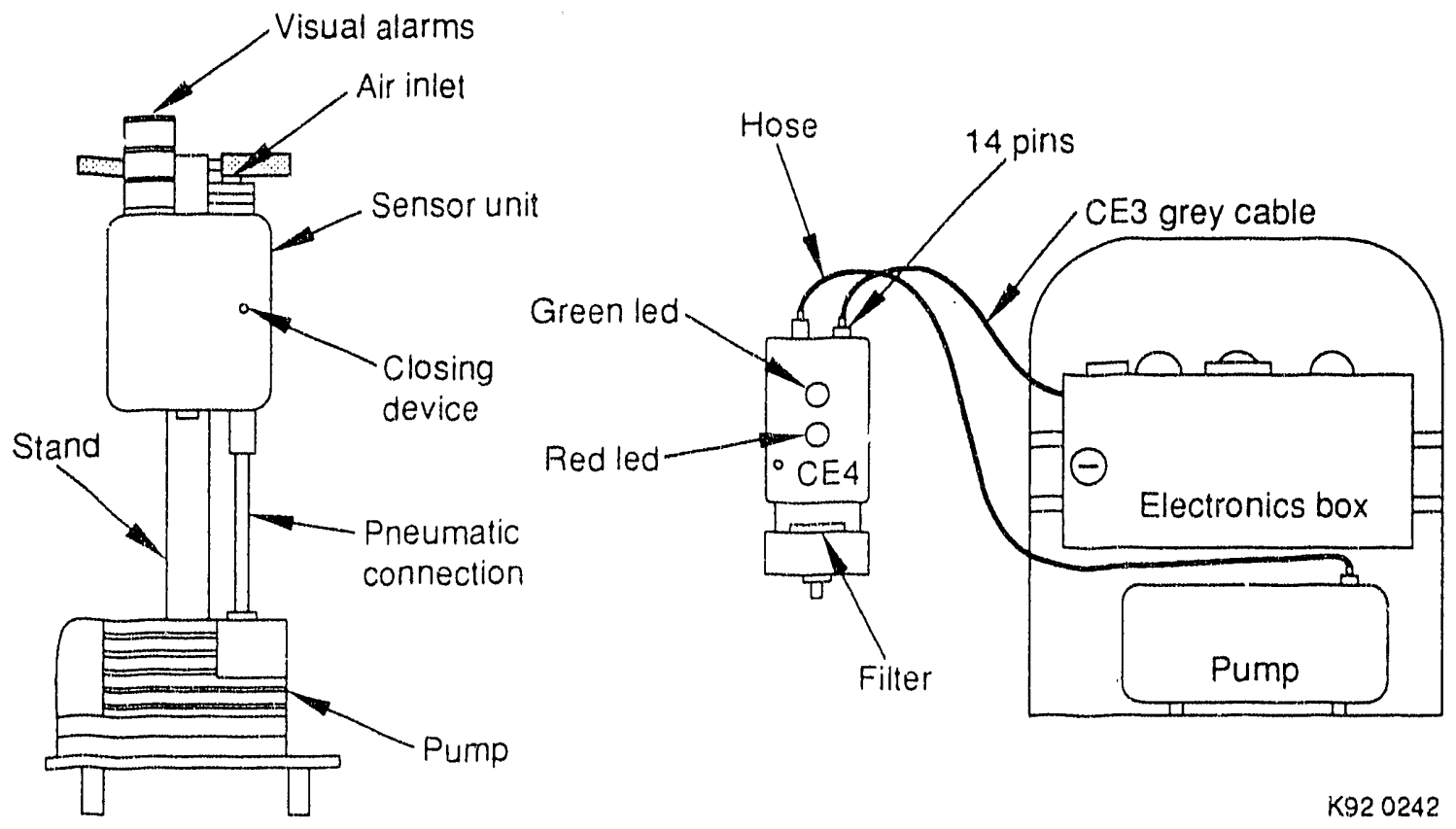

Figure 4. Schematic of Merlin Gerin Edgar alpha CAM showing arrangement of the solid-state detector, sample filter, electronics, and pump. 
512-channel multi-channel analyzer (MCA) for data accumulation and storage. The detector and analyzer are housed in two separate modules which are electrically connected via a cable that can be as long as $60 \mathrm{~m}$. A photograph of the RADeCO model 452 alpha CAM showing the electronics module and sampling head is shown in Figure 5. Similar in design to the Merlin Gerin Edgar CAM, a multi-vane collimator is installed directly over the face of the RADeCO model 452 silicon detector. As indicated in Table 1, the filter-detector separation in the RADeCO model 452 CAM is only about one-half the distance used in the Merlin Gerin Edgar CAM. The smaller separation is a compromise design that achieves a modest improvement in peak resolution with only a slight reduction in counting efficiency.

Of the five CAMs that were tested, only the RADeCO model 452 utilizes spectrum analysis software that continuously calculates the background counts in the ${ }^{239} \mathrm{Pu}$ alpha peak region taking into account the contributions from each of the three major background alpha peaks not only to the ${ }^{239} \mathrm{Pu}$ alpha peak region but also to lower-energy background peaks. So rather than assuming the contributions from the background peaks to the ${ }^{239} \mathrm{Pu}$ alpha peak region are fixed factions of the background peak areas, the RADeCO analysis algorithm recalculates the proportionality constant for each background peak on a continuous basis.

\section{Victoreen Model 758}

The Victoreen model 758 alpha CAM is manufactured by Victoreen, Inc., Cleveland, Ohio, and is typical of conventional alpha CAM designs that do not employ impactors or collimators. The unit is equipped with a $1700 \mathrm{~mm}^{2}$ ion-implanted silicon detector and a 256-channel MCA for data accumulation and storage. The detector and analyzer are housed in two separate niodules which are

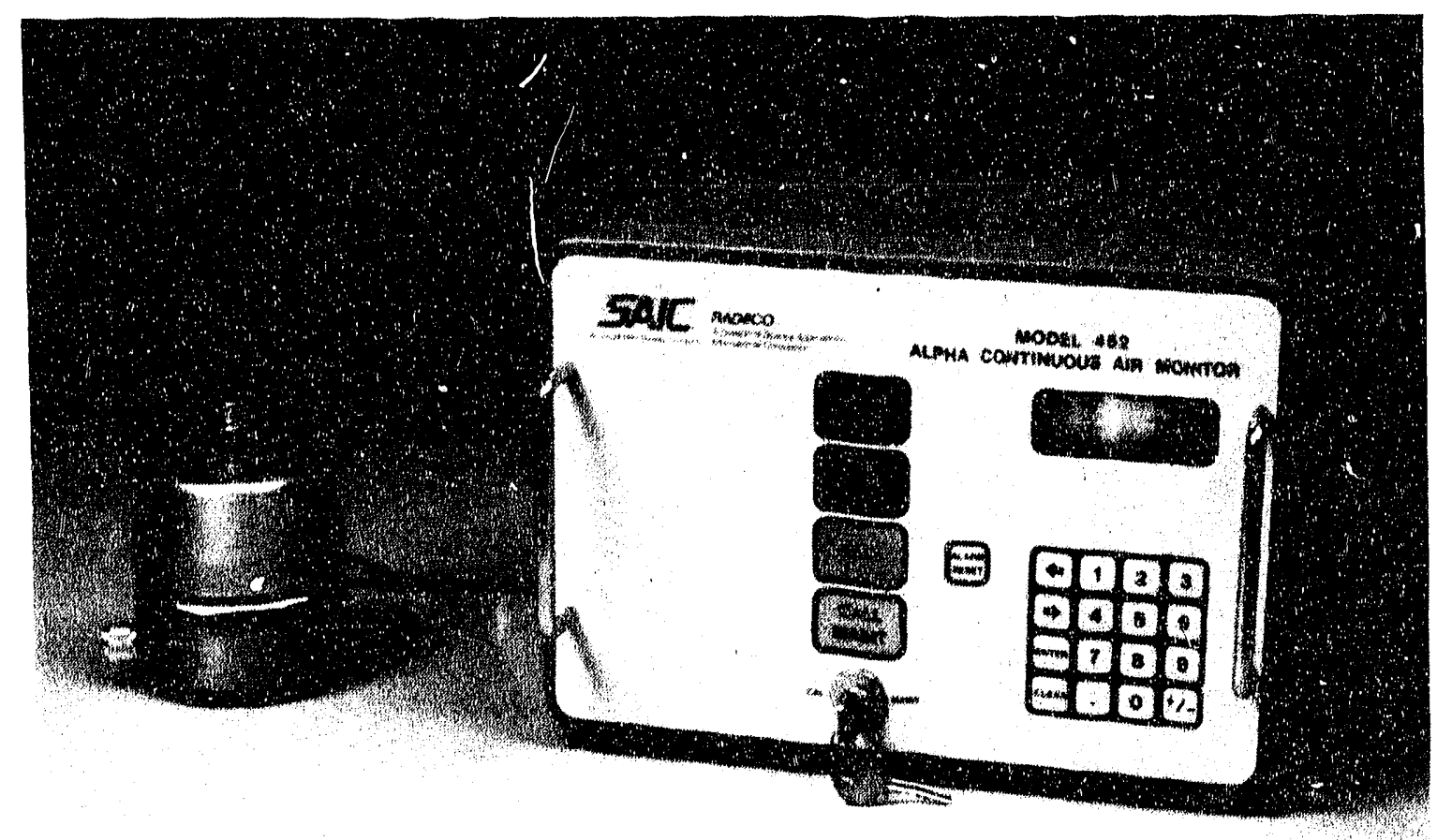

Figure 5. RADeCO model 452 alpha CAM. 
electrically connected via a cable that can be as long as $60 \mathrm{~m}$. A photograph of the Victorecen model 758 alpha CAM showing the electronics module, sampling head, and filter drawer is shown in Figure 6 and a cutaway view of the sampling head showing the arrangement of the sample filter and silicon detector is presented in Figure 7.

As shown in Figure 7. the filter/delector module houses the silicon detector, sample collection filter, detector pre-amplifier, and a mass flow sensor. In the view shown in Figure 7, air enters the filteridetector module through the short tube on the right side of the module, moves counterelockwise inside the modlik. passes down through the collection lilter, and then exits the module through the exhaust pipe at the botlom. The filler holder, which is designed for filters $47 \mathrm{~mm}$ in diameter, is a drawer that may be pulled out of the module to allow changing the filter. A stainless steel ring that is attached (1) the drawer by four magnets holds the filter against a supporting course-mesh sereen. The drawer is sealed by a synthetic rubber gaskel and ring. The positioning of the drawer is such that the spacing between the detector and the filter is $1.8 \mathrm{~mm}$.

The electronics module consists of an NSS-890) micro-processor batsed 256-channel MCA for alpha spectral analysis, a liquid erystai display, a numeric/function keypad, audible and visible alarms, and at stable low voltage power supply for the solid state silicon detector.

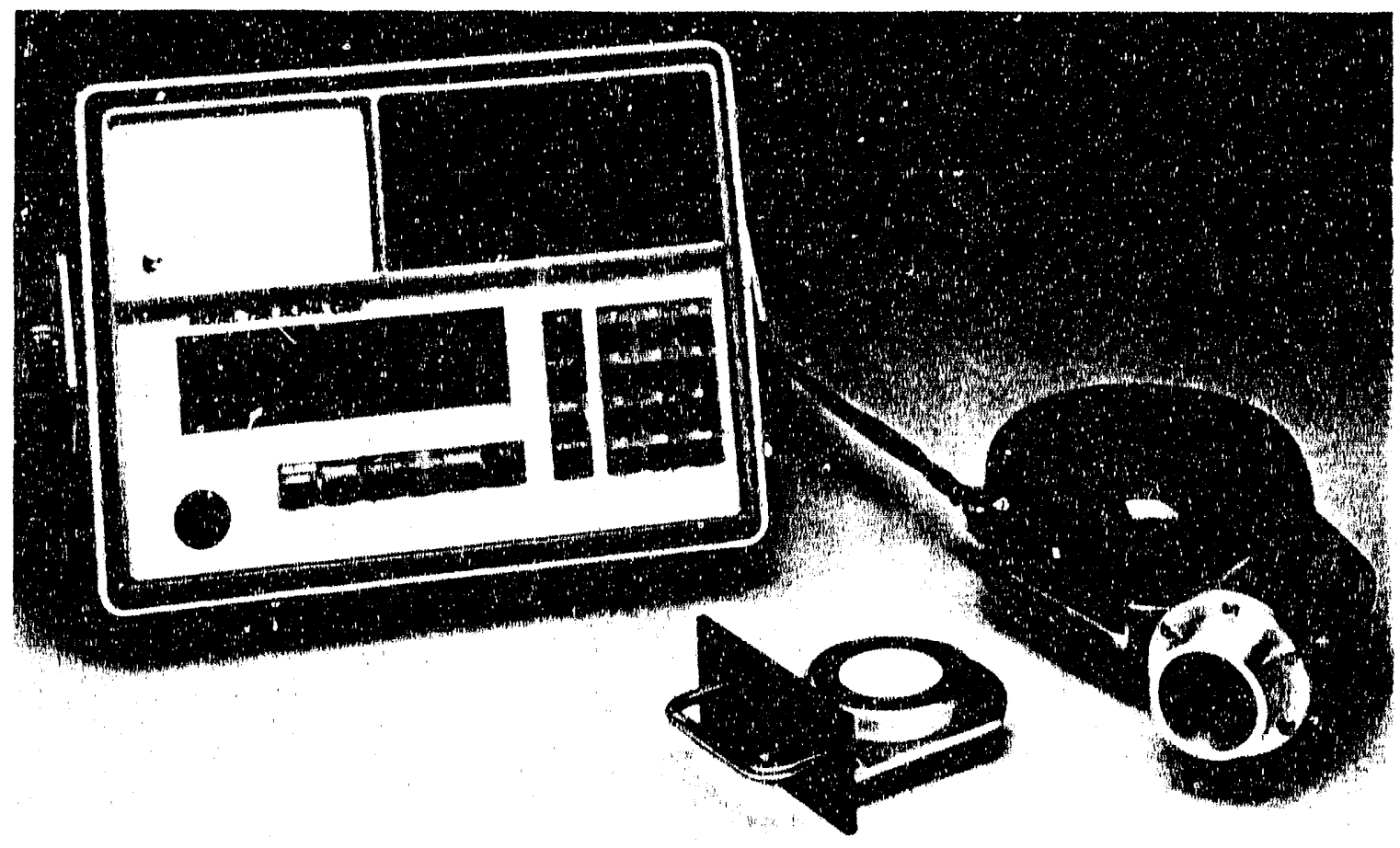

Figure 6. Photograph of Victorecen model 758 alpha CAM showing electronics module. sampling head, and sample filter drawer. 


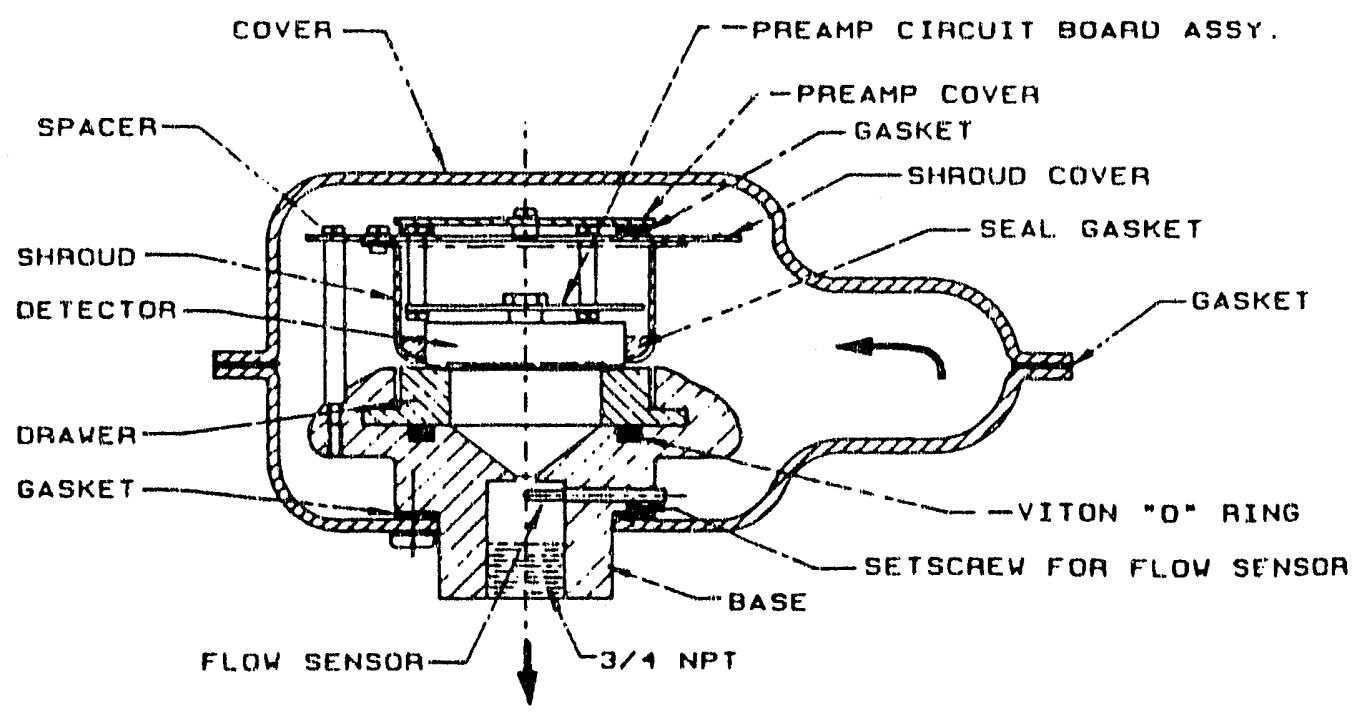

Figure 7. Cutaway view of Victoreen model 758 sampling head showing arrangement of sample fïler and solid-state delector.

\section{Sample Filters}

As indicated in Table 1, three different sample collection filters were used. Merlin Gerin supplies Millipore AW $2.0 \mu \mathrm{m}$ lilters with the Edgar CAM and RADeCO supplies Millipore SM $5.0 \mu \mathrm{m}$ filters with the model 452 CAM. The Merlin Gerin CAM was lested using Millipore AW $2.0 \mu \mathrm{m}$ and both $47-$ and $25-\mathrm{mm}$ diameler Millipore AA $0.8 \mu \mathrm{m}$ filters. The RADeCO CAM was lested using both the lilters supplied by RADeCO and Millipore 47- $\mathrm{mm}$ diameter AA $0.8 \mu \mathrm{m}$ filters. The ANL-W and Vicureen CAMS were tested using only $47-\mathrm{mm}$ diameter Millipore AA $0.8 \mu \mathrm{m}$ lifters. Specilications of the three Millipore filters are described below.

\section{Millipore AA 0.8}

The filler is a fortuous path membrane filter eomposed of eellulose acetate and cellulose nitrate and has a collection efficiency better than $99.999 \%$ for particles greater than $0.8 \mu \mathrm{m}$ in diameter. The lilters used were either 47 or $25 \mathrm{~mm}$ in diameter and were between 120) and 1.50 $\mu \mathrm{m}$ thick.

\section{Millipore AW 2.0}

The filter consists of homogeneous microporous polymers of cellulose esters. Pore size varies from 2.1 to $4.5 \mu \mathrm{m}$ from lot to $\mathrm{kt}$. The filters used were $47 \mathrm{~mm}$ in diameter.

\section{Millipore SM 5}

The filler is a tortuous path membrane filter eomposed of cellulose acetate and cellulose nitrate and has a collection efficiency better than $99.999 \%$ for particles greater than $5 \mu \mathrm{m}$ in diameter. The filters used were $47 \mathrm{~mm}$ in diameter and between 120 and $150 \mu \mathrm{m}$ thick. 


\section{Detector Calibration}

The energy calibration of each solid-state silicon detector was determined and intermittently checked by measuring a filter standard that contained ${ }^{230} \mathrm{Th},{ }^{239} \mathrm{Pu}$, and ${ }^{244} \mathrm{Cm}$. The three isotopes emit alpha particles having average energies of $4.67,5.15$, and $5.80 \mathrm{McV}$, respectively. The absolute counting efficiency of each alpha detector was determined by measuring either the same filter standard used to perform energy calibrations or filter standards that contained known quantities of ${ }^{23 .} \mathrm{Pu}$. The latter standirds were prepared using membrane fillers having a pore size of $0.1 \mu \mathrm{m}$. The ${ }^{239} \mathrm{Pu}$ activity was transferred to the filters using a neodymium fluoride carrier in dilute perchloric acid. The method has been shown to provide an even distribution of activity over a filler surface with minimal loss of alpha particle energy. ${ }^{11}$ The surface density of the material deposited on the filter standards was about $50 \mu \mathrm{g} / \mathrm{cm}^{2}$. 


\section{EXPERIMENTAL TECHNIQUES}

This section describes the methods used to collect and store alpha spectra, the experimental procedures used to sample natural ambient and laboratory-generated atmospheres, and the methods used to analyze collected alpha spectra. Because the ANL-W CAM was needed for a separate study being conducted at the Inhalation Toxicology Research Institute (ITRI) in Albuquerque, NM, during this study it was tested sampling only ambient air. The remaining four CAMs were tested sampling ambient air, air synthetically laden with aerosolized blank dust, and air synthetically laden with acrosolized dust that had been spiked with $\mathrm{nCi} / \mathrm{g}$ concentrations of ${ }^{2.39} \mathrm{Pu}$.

\section{Data Acquisition Electronics}

In order to provide a common basis for comparing the performances of the CAMs and provide a convenient means of storing spectral data, signal processing electronics and data storage devices were kept as similar as possible. The same basic signal processing electronics were used to collect and store spectral data from the ANL-W, Kurz, Merlin Gerin, and Victoreen CAMs. In the case of the four previously mentioned CAMs, data aequisition was controlled and cumulative spectra were stored using a Canberra System 100 personal computer equipped with two MCAs. The primary components of the spectral data acquisition system used with the ANL-W, Kurz, Merlin Gerin, and Victoreen CAMs are identified in Figure 8. Because information regarding the power and signal circuitry of the RADeCO model 452 CAM was not available when measurements commenced, the electronics supplied with the model 452 CAM were used to process spectral data collected using the unit. During each sampling using the RADeCO CAM, spectral data were transferred from the 512-channel MCA to the hard disk of a personal computer using software supplied by RADeCO. Specilic details regarding the pulse processing electronies used with the ANL-W. Kurz, Merlin Gerin, and Victoreen CAMs are provided below.

In the case of the ANL-W CAM, the output of the Ortec 121 preamplifier installed in the CAM was connected to an Ortec 572 shaping amplifier and then to a Canberra model 8075 analog to digital converter (ADC) and finally 10 an MCA installed in the System 10). An 80-volt power supply, which was installed in the ANL-W CAM when received, supplied detector bias voltage. Data collection was performed using a 2,(1)47-channel MCA.

The preamplifier and shaping amplifier of the Kurz model 8311 CAM are installed inside the CAM body and the entire system operates on $+24 \mathrm{Vdc}$. A de power supply was used to supply the $+24 \mathrm{Vde}$ required to operate the Kur $\angle$ CAM. The output of the Kurz shaping amplifier was routed to a Canberra model 8077 ADC and then to a 4,096-channel MCA in the System 100.

To make the Merlin Gerin Edgar CAM compatible with the Canberra System 100, a signal cable equipped with a standard BNC connector on one end was soldered to the amplifier output on the circuit board inside the detector housing. The amplifier output was routed to a Canberra 8077 ADC and the output of the ADC was fed into a 1,(24-channel MCA in the System 100.

Because the Victoreen model $758 \mathrm{MCA}$ was not used during this study, the $\pm 8 \mathrm{~V}$ required to drive the preamplificr was supplied by a de power supply and the detector bias voltage was supplied using a combination of $67.5 \mathrm{Vde}$ from a battery and $60 \mathrm{Vdc}$ from a second de power supply. The 


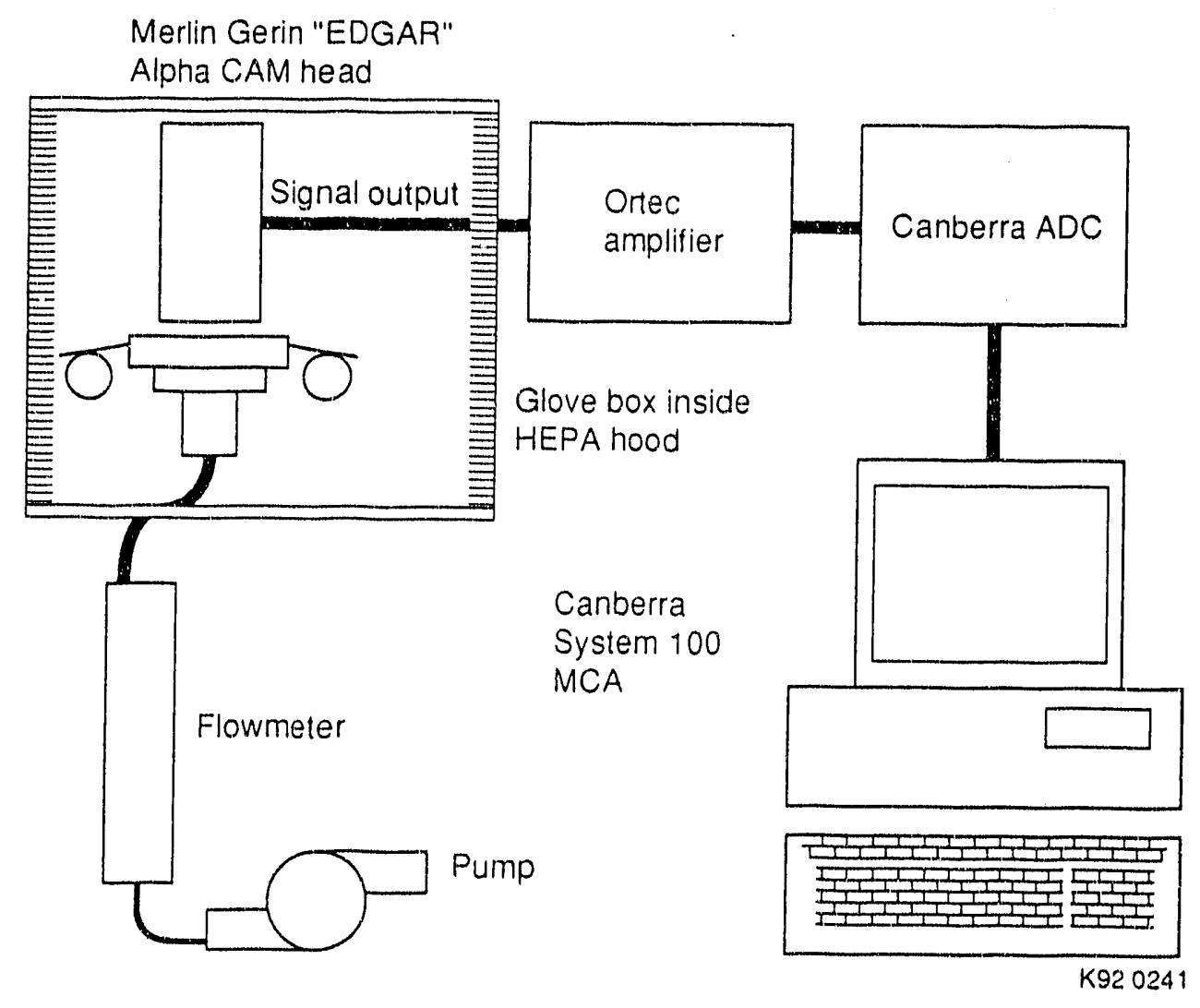

Figure 8. Data aquisition electronics.

output of the Victoreen preamplifier was routed to an Ortec 572 shaping amplifier and then to a Canberra model $8077 \mathrm{ADC}$ and finally to a 2,047-channel MCA in the System 100.

\section{Samplings}

During the initial samplings of natural ambient air performed during FY 1990, when the ANL-W and Kurz or ANL-W and Vicloreen CAMs were operated simultaneously, cumulative spectra were stored every 60) minutes throughout each sampling. During all subsequent samplings performed using the ANL-W, Kurz, Merlin Gerin, RADeCO, and Victoreen CAMs, spectra were stored every 30) minutes throughout each sampling. Following each sampling, the spectra stored on hard disk were transferred to floppy disks. The spectra files stored on lloppy disks were later combined on 10 megabyte Bernoulli cartridges.

Detailed descriptions of samplings performed using the ANL-W, Kurz, RADeCO, and Victoreen CAMs may be found in Reference 3. The following sections describe the samplings performed during FY 1991 using the Merlin Gerin Edgar alpha CAM.

During each sampling performed using the Merlin Gerin Edgar CAM, the sampling pump provided with the Edgar CAM was used to maintain airflow through the CAM. Air llow rate was monitored using a Dwyer flowmeter and Asheroft vacuum gauge. In all cases, the sample filter was 
weighed before and following the completion of sampling using an electronic balance with a sensitivity of $0.01 \mathrm{mg}$.

\section{Natural Ambient Air}

Seven samplings of natural ambient air were performed using the Merlin Gerin Edgar alpha CAM. During these samplings the CAM was equipped with either a $0.8 \mu \mathrm{m}, 47-\mathrm{mm}$; a $0.8 \mu \mathrm{m}$, $25-\mathrm{mm}$; or a $2.0 \mu \mathrm{m}, 47-\mathrm{mm}$ diameter filter. Measurements of ambient air were made both in an unconfined space inside a laboratory and also inside a glove box located in another laboratory. During five samplings of room air conducted outside the glove box, the Merlin Gerin detector/filter assembly was placed in the open, suspended about $1.5 \mathrm{~m}$ above the floor. During the two samplings of room air performed inside the glove box (June 24-26 and July 3-8, 1991), the detector/filter assembly was positioned such that it was no closer than $30 \mathrm{~cm}$ from any glove-box surface. An access door on the glove box was left open during samplings of ambient air.

The durations of samplings of ambient air ranged from 49 to 118 hours at sampling flow rates that averaged between 19 and $25 \mathrm{~L} / \mathrm{min}$. Information regarding filter pore size and diameter, sampling duration, average flow rate at STP, total sample volume, and mass of particulate collected on the sample filter at the end of sampling is summarized in Table 2 for each sampling of ambient air. Also listed in Table 2 are the average airborne dust concentrations calculated by dividing the mass of collected particulate by the total sample volume. The results indicate that during samplings of ambient air, average dust concentrations ranged from about 0.004 to $0.03 \mu \mathrm{g} / \mathrm{L}$.

Table 2. Summary of samplings of ambient air performed using the Merlin Gerin Edgar alpha CAM.

\begin{tabular}{|c|c|c|c|c|c|c|}
\hline $\begin{array}{l}\text { Sampling } \\
\text { dates } \\
(\mathrm{m} / \mathrm{d} / \mathrm{y})\end{array}$ & $\begin{array}{l}\text { Start } \\
\text { time } \\
\text { (h:m) }\end{array}$ & $\begin{array}{l}\text { Sampling } \\
\text { duration } \\
\text { (h) }\end{array}$ & $\begin{array}{l}\text { Average } \\
\text { flow } \\
\text { rate at } \\
\text { STP } \\
(\mathrm{I} / \mathrm{m})\end{array}$ & $\begin{array}{l}\text { Total } \\
\text { sample } \\
\text { volume } \\
\text { (L) }\end{array}$ & $\begin{array}{l}\text { Sample } \\
\text { filter mass } \\
\text { loading } \\
(\mathrm{mg})\end{array}$ & $\begin{array}{l}\text { Average } \\
\text { airborned } \\
\text { dust } \\
\text { concentration } \\
(\mu \mathrm{g} / \mathrm{L})\end{array}$ \\
\hline \multicolumn{7}{|c|}{$0.8 \mu \mathrm{m} 47-\mathrm{mm}$ diameter filter } \\
\hline $07 / 03-08 / 91$ & $10: 52$ & 117.87 & 18.69 & $1.32 \mathrm{E}+0.5$ & 0.57 & $4.31 \pm 0.48 \mathrm{E}-0.3$ \\
\hline $06 / 24-26 / 91$ & $10: 57$ & 49.10 & 19.81 & $5.84 \mathrm{E}+04$ & 0.72 & $1.23 \pm 0.14 \mathrm{E}-02$ \\
\hline $06 / 18-21 / 91$ & $14: 04$ & 67.92 & 19.83 & $8.08 \mathrm{E}+04$ & 1.93 & $2.39 \pm 0.27 \mathrm{E}-02$ \\
\hline \multicolumn{7}{|c|}{$0.8 \mu \mathrm{m} 25-\mathrm{mm}$ diameter filter } \\
\hline $06 / 14-18 / 91$ & $12: 53$ & 94.12 & 21.99 & $1.24 \mathrm{E}+0.5$ & 2.16 & $1.74 \pm 0.19 \mathrm{E}-(12$ \\
\hline \multicolumn{7}{|c|}{$20 \mu \mathrm{m} \mathrm{47-mm} \mathrm{diameter} \mathrm{filter}$} \\
\hline $06 / 07-10 / 91$ & $09: 48$ & 70.92 & 24.40 & $1.04 \mathrm{E}+0.5$ & 0.8 .5 & $8.19 \pm 0.92$ E -0.3 \\
\hline $06 / 04-06 / 91$ & $12: 01$ & 49.55 & 24.59 & $7.31 \mathrm{E}+04$ & 0.70 & $9.58 \pm 1.07 \mathrm{E}-03$ \\
\hline $06 / 11-14 / 91$ & $09: 28$ & 73.82 & 23.57 & $1.04 \mathrm{E}+0.5$ & 3.39 & $3.25 \pm 0.36 \mathrm{E}-02$ \\
\hline
\end{tabular}




\section{Laboratory-Generated Atmospheres}

A glove hox and an acrosolizer were used to generate atmospheres of dust-laden air. The plastic-walled glove box, which was about $1.2 \mathrm{~m}$ long, $0.9 \mathrm{~m}$ high, and $1.1 \mathrm{~m}$ decp, was equipped with two glove ports and an aceess door. The acrosolizer consisted of a V-shaped Plexiglas tray measuring about $30 \mathrm{~cm}$ high by $46 \mathrm{~cm}$ long. At the top, the inside width of the cavity in the tray was about $20 \mathrm{~cm}$. A perforated $0.95-\mathrm{cm}$ diameter plastic tube was installed near the bottom inside surface of the tray and the tube was plumbed to a plant air supply. A flow meter was installed between the perforated tube in the acrosolizer tray and the plant air source so as to allow setting the flow rate of air being supplied to the acrosolizer. About $250 \mathrm{~g}$ of finely sieved soil was placed in the acrosolizer tray prior to each sampling. Acrosolization of the soil was initiated by starting airflow through the perforated tube in the bottom of the acrosoilzer tray. During samplings, the flow rate through the acrosolizer was usually maintained between 5 and $10 \mathrm{~L} / \mathrm{min}$.

Aerosolized Blank Dust. Ninc samplings of air synthetically laden with blank dust were performed using the Merlin Gerin CAM. The soil used during the experiments was collected from the dry lake bed southwest of the RWMC and was sieved to 200 mesh $(<75 \mu \mathrm{m})$. During five of these samplings, the CAM was equipped with a $0.8 \mu \mathrm{m}, 47-\mathrm{mm}$ diameter filter and during the remaining four samplings it was equipped with a $2.0 \mu \mathrm{m}, 47-\mathrm{mm}$ diameter filter. The detector/filter assembly was positioned such that it was no closer than $30 \mathrm{~cm}$ from the acrosolizer tray or any glove-box surface. An aceess door on the glove box was left partially open during samplings of acrosolized blank dust.

The durations of samplings of air synthetically laden with blank dust ranged from about 21 to 71 hours with average sampling llow rates ranging between about 17 and $24 \mathrm{~L} / \mathrm{min}$. Sampling duration, the duration the aerosolizer was uncovered, average flow rate at STP, total sample volume, and mass of particulate collected on the sample filter at the end of sampling are summarized in Table 3 for each sampling. Also listed in Table 3 are the average airborne dust concentrations calculated by dividing the mass of eollected particulate by the volume of air sampled while the acrosolizer was operating and uncovered. The results indicate that during these nire samplings of dust-laden air, average dust concentrations ranged from about 0.008 to $0.9 \mu \mathrm{g} / \mathrm{L}$.

As indicated in Table 3, with the exception of the sampling performed June 26-27, 1991, the acrosolizer was operated continuously throughout each sampling. A heavy Plexiglas cover was positioned over the acrosolizer tray when flow to the aerosolizer was initiated and the eover was normally kept in place 151020 minutes in order to allow the dust cloud inside the acrosolizer to dissipate. When the inside of the acrosolizer eleared, the cover was gently removed and soon thereafter sampling and spectral data acquisition was initiated. In the case of the sampling performed June 26-27, sampling and acquisition of spectral data commeneed about 3 ours prior to the time the acrosolizer was uncovered. So during this particular samplin., for about 3 hours the CAM sampled normal ambient air and then for about 18 hours it sampled air having an average dust concentration of $0.9 \mu \mathrm{g} / \mathrm{L}$.

Aerosolized Spiked Dust. The same soil used for the samplings previously described was later aed with ${ }^{2.39} \mathrm{Pu}$. Deionized water was stirred into $1 \mathrm{~kg}$ of the soil until it became a slurry. The ${ }^{239} \mathrm{Pu}$ spike, which was prepared as a plutonium nitrate solution, was then stirred into the soil slurry. The mixte was then heated on a hot plate and stirred continuously until the liquid had evaporated 
Table 3. Summary of samplings of aerosolized blank dust performed using the Merlin Gerin Edgar alpha CAM.

\begin{tabular}{|c|c|c|c|c|c|c|c|}
\hline $\begin{array}{l}\text { Sampling dates } \\
(\mathrm{m} / \mathrm{d} / \mathrm{y})\end{array}$ & $\begin{array}{l}\text { Start } \\
\text { lime } \\
\text { (h:m) }\end{array}$ & $\begin{array}{l}\text { Sampling } \\
\text { duration } \\
\text { (h) }\end{array}$ & $\begin{array}{l}\text { Duration } \\
\text { aerosolizer } \\
\text { uncovered } \\
\text { (h) }\end{array}$ & $\begin{array}{l}\text { Average } \\
\text { flow } \\
\text { rate at } \\
\text { STPa } \\
(\mathrm{L} / \mathrm{m})\end{array}$ & $\begin{array}{c}\text { Sample } \\
\text { volume }^{b} \\
\text { (L) }\end{array}$ & $\begin{array}{l}\text { Sample } \\
\text { filter mass } \\
\text { loading } \\
\text { (mg) }\end{array}$ & $\begin{array}{c}\text { Average } \\
\text { airborne } \\
\text { dust } \\
\text { concentration }(\mu \mathrm{g} / \mathrm{L})\end{array}$ \\
\hline $07 / 02-03 / 91$ & $12: 01$ & 22.45 & 22.45 & 19.29 & $2.60 \mathrm{E}+04$ & 0.22 & $8.47 \pm 0.95 \mathrm{E}-03$ \\
\hline $06 / 28-07 / 01 / 91$ & $09: 48$ & 70.67 & 70.67 & 18.60 & $7.89 \mathrm{E}+04$ & 5.93 & $7.52 \pm 0.84$ E-02 \\
\hline $07 / 08-09 / 91$ & $10: 23$ & 22.45 & 22.45 & 18.32 & $2.47 E+04$ & 5.20 & $2.11 \pm 0.24 \mathrm{E}-01$ \\
\hline $07 / 01-02 / 91$ & $09: 34$ & 24.02 & 24.02 & 18.44 & $2.66 \mathrm{E}+04$ & 12.10 & $4.55 \pm 0.51 \mathrm{E}-01$ \\
\hline $06 / 26-27 / 91$ & $13: 17$ & 20.92 & 17.70 & 17.15 & $1.82 \mathrm{E}+04$ & 16.54 & $9.08 \pm 1.02 \mathrm{E}-01$ \\
\hline $07 / 17-18 / 91$ & $17: 09$ & 22.47 & 22.47 & 23.49 & $3.17 E+04$ & 1.59 & $5.02 \pm 0.56 \mathrm{E}-02$ \\
\hline $07 / 10-11 / 91$ & $10: 00$ & 24.00 & 24.00 & 23.09 & $3.33 \mathrm{E}+04$ & 3.39 & $1.02 \pm 0.11 \mathrm{E}-01$ \\
\hline $07 / 15-16 / 91$ & $09: 35$ & 28.57 & 28.57 & 23.97 & $4.11 \mathrm{E}+04$ & 9.39 & $2.29 \pm 0.26 \mathrm{E}-01$ \\
\hline $07 / 09-10 / 91$ & $09: 40$ & 23.48 & 23.48 & 20.90 & $2.95 \mathrm{E}+04$ & 24.77 & $8.41 \pm 0.94 \mathrm{E}-01$ \\
\hline
\end{tabular}

a. Average flow rate during the time the acrosolizer was uncovered.

b. Sample volume during the time the acrosolizer was uncovered.

and the material hardened. The dried soil was then ground using a coffee grinder and the resulting powder was sieved through a 100 mesh $(<150 \mu \mathrm{m})$ screen. Three samples of the sieved soil, each approximately $10 \mathrm{mg}$ in size, were removed from different regions of the bulk sample and were analyzed using radiochemical separation techniques and alpha spectrometry to determine the concentration and homogeneity of ${ }^{239} \mathrm{Pu}$ in the soil. The measured concentrations of ${ }^{239} \mathrm{Pu}$ in the three soil samples were $1.91 \pm 0.09,1.71 \pm 0.07$, and $1.76 \pm 0.07 \mathrm{nCi} / \mathrm{g}$, showing that ${ }^{239} \mathrm{Pu}$ was homogeneously distributed throughout the soil.

Five samplings of air synthetically laden with dust spiked with ${ }^{239} \mathrm{Pu}$ were performed with the CAM equipped with a $0.8 \mu \mathrm{m}, 47-\mathrm{mm}$ diameter filter. During measurements performed with spiked dust, the glove box was installed inside a ventilated hood. The detector/filter assembly was positioned inside the glove box the same way it was positioned during measurements of aerosolized blank dust. An acess door on the glove box was left partially open during the samplings of aerosolized sf."red dust.

The durations of samplings of air synthetically laden with spiked dust ranged from about 12 to 39 hours with average sampling flow rates ranging between about 17 and $20 \mathrm{~L} / \mathrm{min}$. Sampling duration, the duration the acrosolizer was uncovered, average flow rate at STP, total sample volume, and mass of particulate collected on the sample filter at the end of sampling are summarized in Table 4 for each sampling. Also listed in Table 4 are the average airborne dust concentrations calculated by dividing the mass of collected particulate by the volume of air sampled while the aerosolizer was operating and uncovered. The results indicate that during these five samplings, average airborne dust concentrations ranged from about 0.2 to $2.0 \mu \mathrm{g} / \mathrm{L}$. 
Table 4. Summary of samplings of acrosolized spiked dust performed using the Merlin Gerin Edgar alpha CAM.

\begin{tabular}{|c|c|c|c|c|c|c|c|}
\hline $\begin{array}{l}\text { Sampling } \\
\text { dattes } \\
(\mathrm{n} / \mathrm{d} / \mathrm{y})\end{array}$ & $\begin{array}{l}\text { Slart } \\
\text { time } \\
\text { (h:m) }\end{array}$ & $\begin{array}{c}\text { Sampling } \\
\text { duration } \\
\text { (h) }\end{array}$ & $\begin{array}{l}\text { Duration } \\
\text { aerosolizer } \\
\text { uncovered } \\
\text { (h) }\end{array}$ & $\begin{array}{l}\text { Average } \\
\text { flow } \\
\text { rale al } \\
\text { slipil } \\
(1 . / \mathrm{m})\end{array}$ & $\begin{array}{c}\text { Sample } \\
\text { volume } \\
\text { (1.) }\end{array}$ & $\begin{array}{l}\text { Sample } \\
\text { liller } \\
\text { masss } \\
\text { leatding } \\
\text { (mg) }\end{array}$ & $\begin{array}{c}\text { Average } \\
\text { airborne } \\
\text { dust } \\
\text { concentration } \\
(\mu \mathrm{g} / \mathrm{l} .)\end{array}$ \\
\hline $07 / 24 / 91$ & $07: 00$ & 12.22 & 7.6 .3 & 20.00 & $9.161 \vdots+0.3$ & $2 .(10)$ & $2.28 \pm(1.25 \mid i .01)$ \\
\hline $07 / 30()-(18 / 0 / 01 / 91$ & $18: 42$ & 38.78 & 8.77 & 18.94 & $9.971 i+(1.3$ & 0.78 & $0.80 \pm 0.70 ! \cdot 1$ \\
\hline$(07 / 24-2.5 / 91$ & $20: 18$ & 18.37 & 7.62 & 18.94 & $8.601:+0.3$ & 0.48 & $7.48 \pm(1.84+1:-01$ \\
\hline$(07 / 25-2(1 / 4) 1$ & $1.5: 58$ & 23.98 & 0.10 & 18.94 & $0.9 .31 i+(1.3$ & $\times .26$ & $1.19 \pm(0.1 .315+0(0)$ \\
\hline $07 / 29-30 / 91$ & $13: 36$ & 28.07 & 8.67 & 17.40 & $9.0 .51 i+0.3$ & 18.47 & $2.04 \pm 0.231 i+(k)$ \\
\hline
\end{tabular}

a. Average llow rate during the time the acrosolizer was unecevered.

h. Sample volume during the time the acerosolizer wals uncevered.

As indicated in Table 4, the acrosolizer was operated for only between about 6 and 9 he,urs during any given sampling. The CAM was allowed to sample ambient air for between about 5 and 30) hours before the acrosolizer was turned on in order to allow the radon progeny being deposited on the lilters to come into equilibrium. As usual, the acrosolizer tray was covered when llow through the acrosolizer was started and it remained covered for 15 to 20 minutes $t o$ allow the initial dost cloud to dissipate. The removal of the acrosolizer cover was always eoordinated with the spectrum accumulation cycle so that the cover was removed at the beginning of a new 30-minute counting interval. With the exception of the sampling performed July 30-August 1, 1991, once acrosolization was started it was continued until sampling was terminated. During the July 30-August 1, 1991 sampling, beginning about 14 hours into the sampling, the acrosolizer was operated for about 9 hours, but rather than terminating sampling when the acrosolizer was shut off, sampling was continued for another 16 hours. One other perturbation should be mentioned. When the acrosolizer was uncovered during the July 29-30, 1991 sampling, the acrosolizer tray was intentionally tapped several times in order to generate a dust cloud. The tapping was repeated about 4 hours later at the beginning of a spectrum accumulation cycle. The purpose was to determine whether or not the CAM was capable of delecting momentary increases in airborne ${ }^{239} \mathrm{Pu}$ activity.

\section{Alpna Spectrum Analysis Methods}

Three different spectrum analysis algorithms were used to analyze each alpha spectrum that was collected during samplings performed using the five alpha CAMs. These mathematical algerithms determine nel counts in the ${ }^{239} \mathrm{Pu}$ peak by subtracting from the total counts in the ${ }^{239} \mathrm{Pu}$ peak some fraction of the eounts in adjacent background regions of the spectrum. These regions, or energy windows, are commonly referred to as regions of interest (ROIs). The three algorithms employ one ROI that encompasses the energy region of the ${ }^{239} \mathrm{Pu}$ peak and either one, (wo or three background ROls. Hence, they are commonly referred $t(1)$ as the 1 wo-, three-and lour-window spectrum analysis algorithms. The focations of the ROls used in the two- and three-window analysis algerithms are shown in Figure 9a, where regions 1 and 2 correspond, respectively, 10 the ${ }^{239} \mathrm{Pu}$ and background ROIs used in the two-window algorithm and regions 3, 4, and 5 correspond to the lower background,

${ }^{234} \mathrm{Pu}$, and upper background ROIs used in the three-window algorithm. The keations of the ROIs 


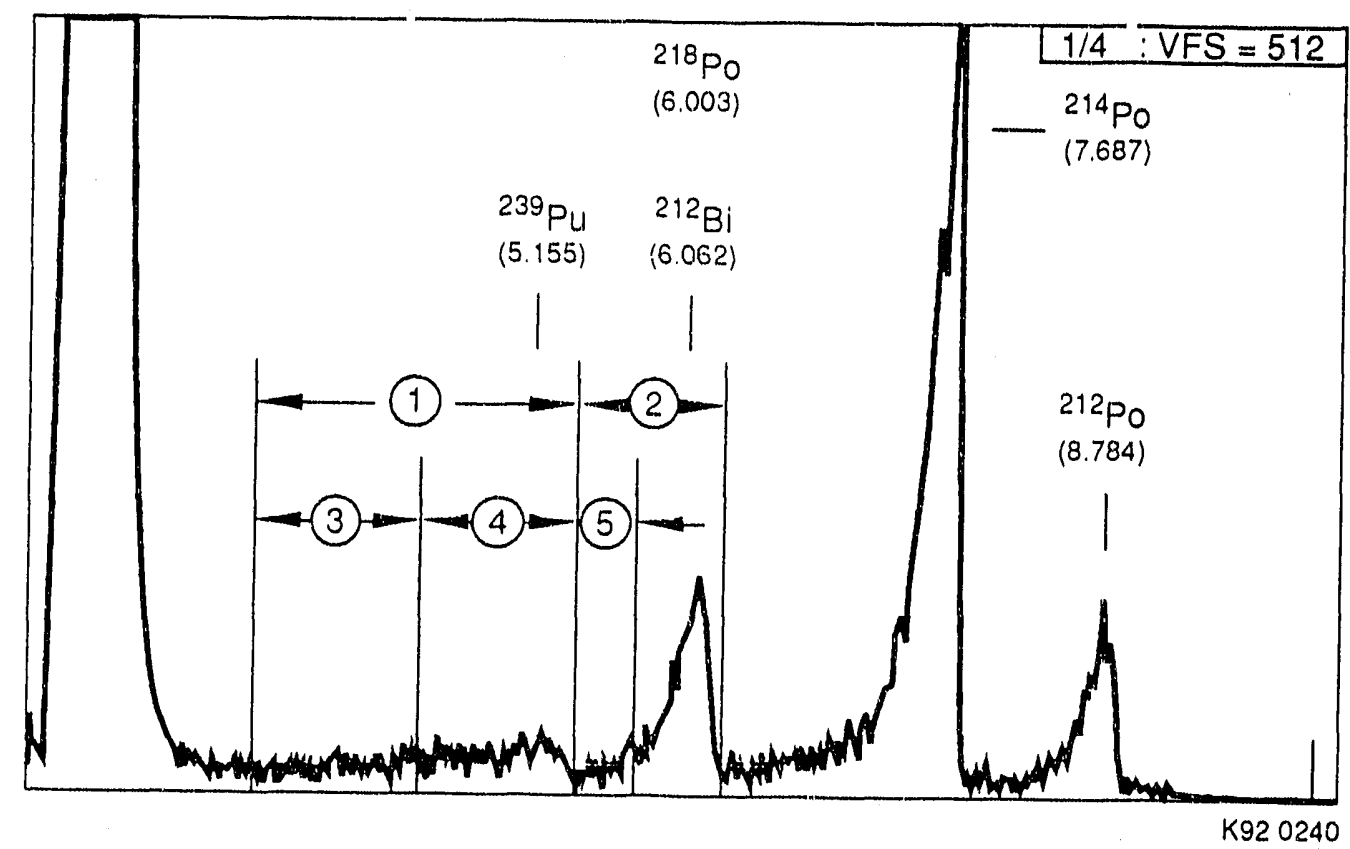

Figure 9a. ROIs used to analyze spectra using the two- and three-window analysis algorithms.

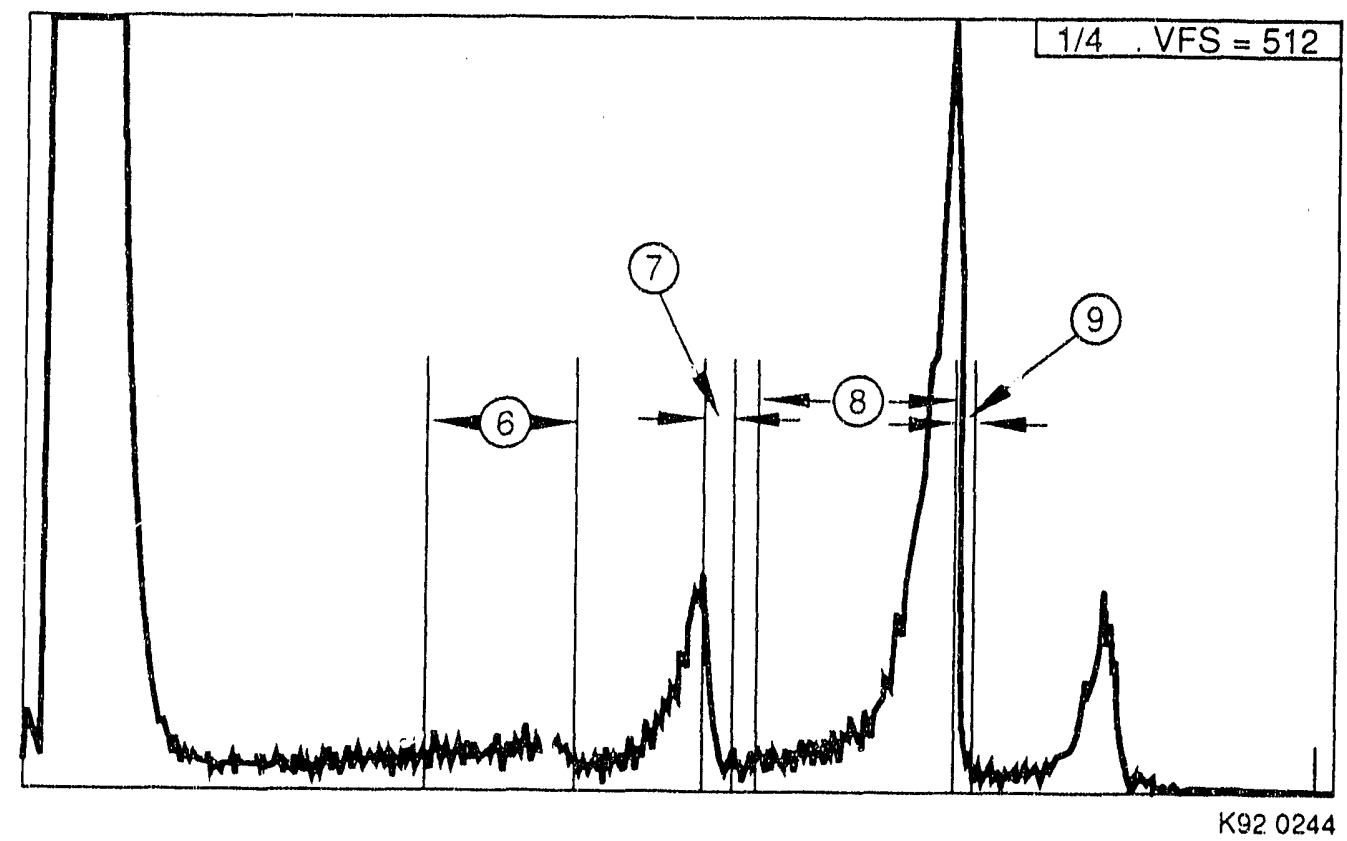

Figure 9b. ROIs used to analyze spectra using the four-window analysis algorithm. 
used in the four-window algorithm are indicated as regions 6 through 9 in Figure 9 b, were region 6 is the ${ }^{239} \mathrm{Pu} \mathrm{ROI}$ and regions 7,8 , and 9 are background ROls.

As shown in Figure 9a, the background ROI used in the two-window algorithm is located just alove the ${ }^{239} \mathrm{Pu} \mathrm{ROI}$ and encompasses the 6.(0) $\mathrm{MeV}{ }^{218} \mathrm{Po} /{ }^{212} \mathrm{Bi}$ alpha peak. The (wo background ROIs used in the three-window algorithm are below and above the ${ }^{23^{19}} \mathrm{Pu} \mathrm{ROI}$ and are both adjacent to it. In this casc, the background ROI above the ${ }^{239} \mathrm{Pu}$ ROI encompasses the low-energy tail of the 6.(1) $\mathrm{MeV}{ }^{218} \mathrm{Po} /{ }^{212} \mathrm{Bi}$ alpha peak. The three background $\mathrm{RO}$. algorithm encompass the high-energy side of the $6.00 \mathrm{McV}{ }^{218} \mathrm{Po} /{ }^{212} \mathrm{Bi}$ peak and the low- and high-energy sides of the $7.69 \mathrm{MeV}{ }^{214} \mathrm{Po}$ alpha peak. In the ease of the four-window algorithm, the basic assumption is that in the absence of ${ }^{239} \mathrm{Pu}$ the ratio of counts in the low-energy side of a background peak to the counts in the high-energy side of the same peak should be proportional to the same ratio determined for other background peaks. When ${ }^{239} \mathrm{Pu}$ is present in the sample airstream, it contributes counts to the low-energy tail of the $6.00 \mathrm{McV}{ }^{218} \mathrm{Po} /{ }^{21} 3 \mathrm{i}$ peak and these counts must be subtracted from the ROI in order for the equality to remain true.

For all three algorithms, the number of net counts in the ${ }^{2.39} \mathrm{Pu}$ peak is expressed as a simple linear equation involving a single coefficient whose value must be experimentally determined. The value of the coefficient determines what fraction of the counts in the background ROI(s) must be subtracted from the counts in the ${ }^{239} \mathrm{Pu}$ ROI in order to yield zero net counts in the absence of ${ }^{2.39} \mathrm{Pu}$. The three equations for net counts in the ${ }^{239} \mathrm{Pu} \mathrm{ROI}$ are:

Two-window algorithm:

$C_{P_{u}}=C_{1}-k_{1} C_{2}$

Threc-window algorithm:

$C_{P_{u}}=C_{4}-k_{2}\left(C_{3}+C_{5}\right)$

Four-window algorithm:

$C_{P u}=C_{6}-k_{3} \frac{\left\{C_{7} C_{8}\right\}}{C_{9}}$

where $C_{1}, C_{4}$, and $C_{6}$ are the total number of eounts in the ${ }^{2.39} \mathrm{Pu}$ ROI and $\mathrm{C}_{2}, \mathrm{C}_{3}, \mathrm{C}_{5}, \mathrm{C}_{7}, \mathrm{C}_{8}$ and $\mathrm{C}_{9}$ are the total number of eounts in the corresponding background ROIs. The energy ranges of the ${ }^{239} \mathrm{Pu}$ and background ROIs used for analysis are given in Table A-1 in Appendix A.

Spectra collected during each sampling of ambient air and air synthetically laden with blank dust were analyzed to determine the value and standard deviation of each of the coefficients in Equations (1). (2), and (3). The equations used to calculate the coeflicients $k_{1}, k_{2}$, and $k_{3}$ are derived in Appendix A. The initial step in the analysis of each alpha spectrum was the determination of the gross number of counts in each of the 9 ROIs previously defined. (For the purpose of monitoring their relative activities as a function of sampling time, the gross number of counts in each of the three major background alpha peaks were also determined for each spectrum.) Spectra were analyzed and 
the coeflicients were calculated using a spectrum analysis program that was written and compiled in $\mathrm{C}$ and installed on a VAX 3200 computer. Values of the coefficients were initially determined using spectral data for two consecutive counting intervals, meaning that the coefficients were determined at 30 or 60 minute intervals throughout each sampling depending on which data acquisition cycle time was used. As was previously mentioned, the initial samplings of ambient air performed using the ANL-W, Kurz, and Victoreen CAMs were performed using a one-hour counting interval, but all subsequent samplings were done using a 30-minute counting interval. For selected samplings where a 30-minute counting interval was used, the values of the coefficients were also determined using data for every other spectrum. This allowed determing the coefficients during these samplings based on an hour counting interval. The average value and standard deviation of each of the three coefficients were determined for each sampling of ambient air and aerosolized blank dust.

Having detcrmined average values of the coefficients in Equations (1), (2), and (3), the concentration of airborne ${ }^{239} \mathrm{Pu}$ during any given counting interval was calculated as:

$$
\left(X_{P u}\right)_{n}=\frac{\left(C_{P u}\right)_{n}-\left(C_{P u}\right)_{n-j}}{2.22 \epsilon Y\left[F\left(n-\frac{j}{2}\right) \Delta T\right][j \Delta T]}
$$

where

$$
\begin{aligned}
& \left(\mathrm{X}_{\mathrm{Pu}}\right)_{\mathrm{n}} \quad=\quad \text { the concentration of airborne }{ }^{239} \mathrm{Pu} \text { during counting interval } \mathrm{n}(\mathrm{pCi} / \mathrm{L}) \\
& \left(\mathrm{C}_{\mathrm{P}_{\mathrm{u}}}\right)_{\mathrm{n}} \text { and }\left(\mathrm{C}_{\mathrm{P}_{\mathrm{u}}}\right)_{\mathrm{n}-\mathrm{j}}=\text { the number of background-corrected counts in the }{ }^{239} \mathrm{Pu} \text { ROI at the } \\
& \text { end of counting intervals } n \text { and } n-j \\
& 2.22=\text { the number of disintegrations per minute }(\mathrm{dpm}) \text { per } \mathrm{pCi} \\
& \epsilon \quad=\quad \text { the absolute counting efficiency of the alpha detector (counts per } \\
& \text { disintegration) } \\
& \mathrm{Y}=\text { the }{ }^{239} \mathrm{Pu} \text { collection efficiency of the CAM } \\
& \mathrm{F}=\text { the sampling flow rate }(\mathrm{L} / \mathrm{min}) \\
& \Delta \mathrm{T} \quad=\text { the length of the counting interval used during sampling (min) } \\
& =\text { an integer. (When } \mathrm{j} \text { is set equal to 1, data from consecutive spectra } \\
& \text { are used and when } \mathrm{j} \text { is set equal to } 2 \text {, data from every other spectrum } \\
& \text { are used.) }
\end{aligned}
$$


The lower limit of detection (LLD) concentration for airborne ${ }^{239} \mathrm{Pu}$ during any given counting interval was calculated at the $95 \%$ confidenec leyel ising the methods described by Currie. ${ }^{12}$ LLDs were calculated as:

$$
\left(X_{d}\right)_{n}=\frac{4.653\left(\sigma_{h g d}\right)_{n}}{2.22 \epsilon Y \frac{|F j \Delta T||j \Delta T|}{2}}
$$

where

$$
\begin{aligned}
& \left(\mathrm{X}_{\mathrm{d}}\right)_{\mathrm{n}}=\text { the LLD concentration of airborne }{ }^{239} \mathrm{Pu} \text { during counting interval } \mathrm{n}(\mathrm{pCi} / \mathrm{L}) \\
& \left(\sigma_{\text {hgd }}\right)_{\mathrm{n}}=\text { the standard deviation in the difference between the }{ }^{2.39} \mathrm{Pu} \text { ROI background }
\end{aligned}
$$

Equations (4) and (5) are derived in Appendix A. Also provided in Appendix A are the assumptions used to derive them. Note that the constant 2.71 normally added to the numerator of Equation (5) is absent. The constant was always much smaller than the product $4.653\left(\sigma_{\text {hgd }}\right)_{n}$, so LLD concentrations were calculated omitting the constant.

The statistical uncertainty in the change in ${ }^{239} \mathrm{Pu}$ ROI background counts was calculated for each counting interval using the following three formulas:

Two-window algorithm:

$\left(\sigma_{\mathrm{hgd}}\right)_{\mathrm{n}}=\left\{\mathrm{k}_{1}{ }^{2}\left(\mathrm{~N}_{\mathrm{B}}\right)_{\mathrm{n}}+\left(\mathrm{N}_{\mathrm{B}}\right)_{\mathrm{n}}^{2}\left(\sigma_{\mathrm{k}_{1}}\right)^{2}\right\}^{1 / 2}$

Three-window algorithm:

$\left(\sigma_{\text {bgd }}\right)_{11}=\left\{k_{2}^{2}\left(N_{13}\right)_{n}+\left(N_{13}\right)_{n}^{2}\left(\sigma_{k_{2}}\right)^{2}\right\}^{1 / 2}$

Four-window algorithm:

$$
\left(\sigma_{\text {hgd }}\right)_{n}=\left\{k_{3}^{2}\left(N_{13}\right)_{n}+\left(N_{B}\right)_{n}^{2}\left(\sigma_{k_{3}}\right)^{2}\right\}^{1 / 2}
$$

where

$$
\begin{aligned}
\left(\mathrm{N}_{13}\right)_{n}= & \text { the change in gross counts in the background ROI(s) during } \\
& \text { counting interval } n \\
\left(\sigma_{k_{1}}\right),\left(\sigma_{k_{2}}\right) \text {, and }\left(\sigma_{k_{3}}\right)= & \text { the standard deviations of } k_{1}, k_{2} \text {, and } k_{3} \text {, respectively. }
\end{aligned}
$$

Equation (5) shows that the sensitivity of any CAM is determined by a number of interrelated factors. For example, a collimator like those installed on the RADCCO and Merlin Gerin CAMs will 
improve peak resolution and reduce background count rates and thus serve to minimize ( $\sigma_{\text {hgd }}$ ). However, a deleterious effect of a collimator is that it reduces counting efficiency $(\epsilon)$. Because the LLD is proportional to $\left(\sigma_{\text {hgd }}\right)$ but inversely proportional to counting efficiency $(\epsilon)$, a collimator may only modestly improve sensitivity. The same type of argument holds for a CAM such as the Kurz that does not use a sample collection filter. The improved resolution of such a CAM results in lower background count rates, but because entrained particles must stick to the face of the silicon detector to be detected, the activity collection efficiency $(Y)$ may be significantly lower than the collection efficiencies achieved using conventional sample collection filters. So again, a benefit may be offset by a drawback in the design of a CAM. A final point, as shown hy Equation (5), the LLD is inversely proportional to sample flow rate. In the absence of an inertial impactor, increasing the sampling flow rate would result in a proportionate increase in background count rates and would thus not result in a lower LLD. However, sampling at very high flow rates may be practical if the CAM is equipped with an incrtial impactor that keeps background count rates in check.

Equations (6), (7), and (8) show that the LID is a function of the count rate(s) in the background ROI(s) but is also a function of the standard deviation of the coefficient used for background subtraction. Equations (6), (7), and (8) can cach be rewritten as:

$o_{\mathrm{hgd}}=\mathrm{k} \cdot\left(\mathrm{N}_{\mathrm{B}}\right)\left\{\frac{1}{\left(\mathrm{~N}_{\mathrm{B}}\right)}+\left(\frac{\sigma_{\mathrm{k}}}{\mathrm{k}}\right)^{2}\right\}^{1 / 2}$

For $\mathrm{N}_{\mathrm{B}}>>1$,

$\left.\sigma_{\text {hgd }}=\frac{k \cdot\left(N_{13}\right)}{100}\left\{\frac{\sigma_{k}}{k} \cdot 100\right)\right\}$

or

$\sigma_{\text {bgd }}=\sigma_{k} \cdot\left(N_{B}\right)$

Equations (10) and (11) show that for cases where background count rates are not negligible, the LLD will be projortional to the product of the standard deviation of $k$ and the change in the number of counts in the background $\mathrm{ROI}(\mathrm{s})$ during a given counting interval. The relationship between $\sigma_{\text {hgd }}$ and $k, \sigma_{k}$, and $N_{13}$ is shown in Figure 10 where $\sigma_{\mathrm{hgd}}$ is plotted as a function of the standard deviation of $\mathrm{k}$, expressed in $\%$, for $\mathrm{k}$ equal to 0.05 or 0.5 and $\mathrm{N}_{\mathrm{B}}$ equal to $500,1,0(0)$, or $2,0(0)$ counts. By Equation (10), the slope of each line is equal to $\left.\left(k \bullet \mathrm{N}_{13}\right) / 100\right)$, which is simply the change in the number of background counts contributed to the ${ }^{239} \mathrm{Pu}$ ROI divided by $1(0)$. The results plotled in Figure 10 show that if the average value of the coefficient $k$ is small, as would be the case with a CAM having good peak resolution, and/or the background count rate is not too high, as would be the case with a CAM ecuipped with an effective inertial impactor, then the uncertainty in $k$ is relatively unimportant insofar as the LLD is concerned. If, on the other hand, $k$ is large, as would be the case with a CAM having poor peak resolution, and/or the background count rate is large, 


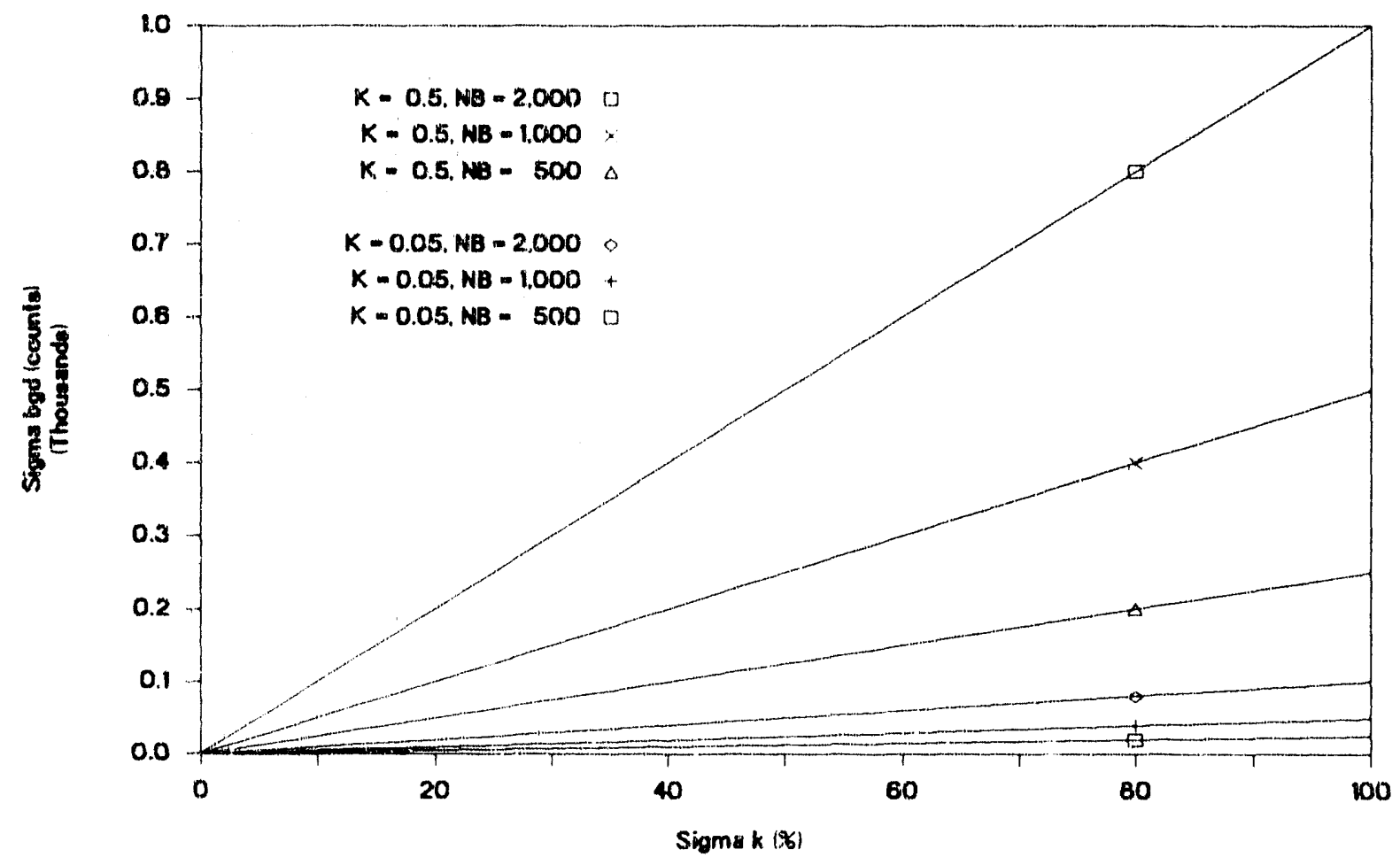

Figure 10. $o_{\mathrm{hgd}}$ as a function of the standard deviation of $\mathrm{k}$ for $\mathrm{k}$ equal 100.05 or 0.5 and $\mathrm{N}_{\mathrm{B}}$ equal (c) $5(0) .1 .000)$, or $2.0(x)$ counts.

which would be the case with a high-volume CAM not equipped with an impactor, then the LLD of the CAM increases rapidly as the uncertainty in $k$ increases. Airborne dust is one cause of poor peak resolution. When airborne dust concentrations are elevated, background alpha peaks are much broader and background count rates in the ${ }^{239} \mathrm{Pu}$ ROI are much higher than when the air being sampled is relatively free of dust. Under these conditions, the coefficient $k$ increases, and by Equation (10) the increase in $k$ with increasing dust concentration results in higher LLDs.

ANL.-W. Kure Instruments, and Merlin Gerin, Ine. currently use the two-window algorithm to analyes alpha spectra. Victoreen originally equipped the model 758 alpha CAM with the four-windew algorithm. but recently changed to the three-wind w algorithm. Eberline currently uses the four-windes algerithm in the Eberline Alpha $6 \mathrm{CAM}$. In the case of the RADeCO model 452 CAM. a much more sophisticated method is used to cstimate background counts in the ${ }^{239} \mathrm{Pu}$ ROI. The RADeCO spectrum analysis algerithn employs one ${ }^{239} \mathrm{Pu}$ ROI and three background ROIs and determines more than one cofficient for sach background ROI since it cvaluates the contribution of higher energy bakkground peaks to lower-energy background peaks. These coeflicients are not considered comstants but are trequently recvaluated during CAM operation. More detailed information regarding the RADeCO spectrum analysis technique cannot be presented here because the method is proprictary. The RADeCO analysis methed was not evaluated in this study; only the three relatively simple analysis algorithms previously described were used to analya spectra collected using the live (AMs that were tested. 
In addition to the spectrum analyses previously described, the centroids and resolutions of the ${ }^{218} \mathrm{Po} / 212 \mathrm{Bi},{ }^{214} \mathrm{Po}$, and ${ }^{212} \mathrm{Po}$ alpha peaks were measured as a function of time during a number of samplings performed using the ANL-W, Kurz, Merlin Gerin, and Victoreen alpha CAMs. Similar measurements of these peaks in spectra collected using the RADeCO CAM were not performed because these spectra were stored in a format that made these types of analyses quite difficult. The centroids and resolutions of peaks in spectra collected using the four previously mentioned CAMs were determined using a Canberra System 100 analysis routine. For each peak, the centroid, full width at half maximum (FWHM) and full width at tenth maximum (FWTM) were determined. The System 100 calculated the centroid of each peak using a center of mass method and it calculated the FWHM and FW'TM, respectively, by determining the peak width at heights corresponding to one-half and one-tenth the maximum number of counts in the peak. These values were calculated in channels and were later converted to energies using measured energy calibration functions. 


\section{EXPERIMENTAL RESULTS}

This section presents experimentally determined values for the main parameters that affect CAM perlormance. Those parameters include absolute counting efficiency, activity collection efficiency, background count rate, peak resolution, and the coefficients used for hackground subtraction. L.LDs for airborne ${ }^{239} \mathrm{Pu}$ are presented for each CAM for each of the three spectrum analysis algorithms that were evaluated. Finally, the results of quantitative measurements of airborne ${ }^{2.39}$ Pu are presented.

\section{Counting Efficiency}

Because spectra were to be analyeed using three different spectrum analysis algorithms that employed diflerent ROIs for the ${ }^{234} \mathrm{Pu}$ alpha peak. the absolute counting efficiency of eatin detector for ${ }^{239} \mathrm{Pu}$, expressed as counts per disintegration (c/d), was normally determined for three different energy windows. The results are presented in Table 5. The three ${ }^{239} \mathrm{Pu}$ ROIs over which counts were integrated for each detector are given in Table 5. As shown in Table 5 , the highest delector efficiencies were measured when the ${ }^{231} \mathrm{Pu}$ ROI encompassed a larger portion of the low energy tail of the ${ }^{2.31} \mathrm{Pu}$ peak.

Counting effiriencies for ${ }^{239}$ Pu ranged from a low of about $3 \%$ for the Merlin Gerin CAM 10 a high of about $42 \%$ for the Kurk CAM. The very low counting efficiency of the Merlin Gerin CAM may be allributed to the thick collimator installed over the lace of the alpha detector and the large spacing between the lilter and detector, while the relatively high osunting efficiency measured for the Kurz CAM is due to the lact that entrained acrosols adhere directly to the face of the detector. In the case of the Kurz CAM, alpha particles emitted from acrosols collected on the face of the detector have about a 50:50 chance of striking the detector and they lose energy in transil fo the detector only through interactions with acrosols previously collected. The collimator and $6.4 \mathrm{~mm}$ liller-detector separation are responsible for the somewhat lower counting elficiency of the RADeCO CAM

Table 5. Summary of delector absolute counting efliciencies for ${ }^{239} \mathrm{Pu}$ for the ${ }^{2319} \mathrm{Pu}$ ROIs used with the (wo)- three-, and four-window analysis algorithms focounts per disinlegration (c/d)|.

\begin{tabular}{|c|c|c|c|c|c|c|}
\hline \multirow[b]{2}{*}{$C A M$} & \multicolumn{2}{|c|}{$\begin{array}{l}\text { Two-window } \\
\text { algorithm }\end{array}$} & \multicolumn{2}{|c|}{$\begin{array}{l}\text { Threc-window } \\
\text { algorithm }\end{array}$} & \multicolumn{2}{|c|}{$\begin{array}{l}\text { Four-window } \\
\text { algorithm }\end{array}$} \\
\hline & $\begin{array}{c}\left.{ }^{231} \mathrm{Pu} \mathrm{RO}\right) \\
(\mathrm{McV})\end{array}$ & $\begin{array}{l}\text { IElf. } \\
(c / d)\end{array}$ & $\begin{array}{c}{ }^{23.1} \mathrm{Pu} \mathrm{ROI} \\
(\mathrm{McV})\end{array}$ & $\begin{array}{l}\text { Iill. } \\
(c / d)\end{array}$ & $\begin{array}{c}{ }^{2.39} \mathrm{Pu} \mathrm{ROI} \\
(\mathrm{McV})\end{array}$ & $\begin{array}{l}\text { LEfl. } \\
\text { (c/d) }\end{array}$ \\
\hline ANI.W & $3 .(n)-5.29)$ & 0.335 & $4.13-5.29$ & 0.3 .32 & $4.101-.5 .18$ & 0.291 \\
\hline Kure. & $.5 .(1)-.5 .25$ & $0.36 \mathrm{x}$ & $4 .(19)-5.25$ & 0.423 & $4 .(19-5.21$ & 0.41 .5 \\
\hline $\begin{array}{l}\text { Merlin } \\
\text { Gerin }\end{array}$ & $3.013-.5 .19$ & 0.033 & $4.15-5.19$ & 0.0133 & $4.14-5.19$ & 0.1033 \\
\hline RADCCO & $2.49)-5.27$ & 0.185 & $4.13-5.27$ & 0.183 & $4.11--.5 .21$ & 0.161 \\
\hline Victoreen & $3 .(N)-5.24$ & 0.27 .3 & $4.13-5.29$ & 0.264 & $4.11-5.17$ & 0.232 \\
\hline
\end{tabular}


compared to the counting efficiencies of the ANL-W and Victoreen CAMs. Counting efficiencies for the RADeCO CAM ranged from 16\% to $19 \%$ while similar values for the ANL-W and Victoreen CAMs ranged from $29 \%$ to $34 \%$ and from $23 \%$ to $27 \%$, respectively.

\section{Activity Collection Efficiency}

Measurements performed during FY 1990 (see Reference 3) determined the ${ }^{239}$ Pu collection efficiencies of the Kurz, RADeCO, and Victoreen alpha CAMs. Following samplings of acrosolized ${ }^{239} \mathrm{Pu}$-spiked dust. ${ }^{239} \mathrm{Pu}$ activities deposited on the sample collection filter and on a filter installed in the air stream exiting each CAM were measured using radiochemical scparation techniques and high-resolution alpha spectrometry. For each sampling, the ${ }^{239} \mathrm{Pu}$ collection efficiency of each C.AM was determined by dividing the activity on the sample collection filter by the sum of the activities collected on the sample and effluent air stream filters. The results showed that the average ${ }^{239} \mathrm{Pu}$ collection efficiencies of the RADeCO and Victoreen CAMs were $0.97 \pm 0.01$ and $0.973 \pm 0.0(0) 3$, respectively. The average ${ }^{2.39} \mathrm{Pu}$ collection efficiency of the Kur\& CAM was significantly lower, being $0.18 \pm 0.03$. The activity collection efficiency of the Kurz CAM ranged from $12.8 \%$ to $27.5 \%$. The relatively wide range of ${ }^{239} \mathrm{Pu}$ collection efficiencies determined for the Kurz CAM may be due to the fact that ${ }^{239} \mathrm{Pu}$ was removed from the face of the detector using cotton swabs wetted in lanolin. In eleaning the outer edge of the detector, ${ }^{239} \mathrm{Pu}$ activity may have inadvertently been collected from the surfaces of the metal support ring that enclosed the detector.

An acrosol study recently conducted at ITRI experimentally determined the particle collection efficiency of the Kurz 8.311 alpha CAM. Newton reported that the face of the detector in the Kurz CAM retained only about $5 \%$ of the $10 \mu \mathrm{m}$ particles entrained in the sample air stream. The aerosols used in the study were spherical latex particles. Apparently, larger particles simply recoil from the surface of the detector and are swept away in the eflluent airllow. The ITRI results help explain the low activity collection efficiencies measured for the Kurz model 8311 CAM during the course of this study.

\section{Radon Daughter Removal Efficiency of Inertial Impactors}

The grcsis number of counts in the three major background alpha peaks $\left({ }^{218} \mathrm{Po} /{ }^{212} \mathrm{Bi}\right.$ at 6.(0) $\mathrm{MeV},{ }^{214} \mathrm{Po}$ at $7.69 \mathrm{McV}$, and ${ }^{212} \mathrm{Po}$ at $8.78 \mathrm{McV}$ ) were mcasured for cach spectrum that was collected. Incremental count rates in each of the three peaks were calculated as a function of time during samplings of ambient air performed when the ANL-W and Kurz or ANL-W and Victoreen CAMs were operated simultaneously. Because the sampling flow rates of the CAMs were different, in order to esmpare the efficiencies with which the impactors installed on the ANL-W and Kurz CAMs removed radon progeny from the sample air stream, count rates in the three background alpha peaks were divided by sampling flow rate to obtain eounts per liter of air sampled. Values of the ratio of counts per liter for the ANL-W and Victoreen CAMs showed that the two-stage virtual impactor installed in the ANL-W CAM removed, on average greater than $95 \%$ of the radon daughter activity from the sample air stream during samplings of ambient air. In the case of the Kurz

a. Private communication, G. Newion, Lovelace Inhalation Toxicology Research Institute, Albuquerque, NM, May 1992. 
CAM, the results showed that, on average, the plate impactor removed about $40 \%$ of the ${ }^{218} \mathrm{Po}$ and 9()$\%$ or more of the ${ }^{212} \mathrm{Bi},{ }^{214} \mathrm{Po}$, and ${ }^{212} \mathrm{Po}$ from the sample air stream during samplings of ambient air.

\section{Resolution}

Average full widths of the ${ }^{218} \mathrm{Po} /{ }^{212} \mathrm{Bi}$ and ${ }^{214} \mathrm{Po}$ alpha peaks at one-half and one-tenth their maximum heights with the baselines removed are presented in Table of for selected samplings performed using the Merlin Gerin alpha CAM. Results presented in Table 6 are average values of the FWHM and FWTM between 14 and 24 hours following the initiation of sampling. Also given in Table 6 are the average airborne dust concentration and type of filler used during each sampling. Similar results for the ANL-W, Kurz, and Victoreen CAMs are presented in Tables B-1, B-2, and B-3, respectively, in Appendix B. Results presented in the latter tables are average values for

Table 6. Average FWHM and FWTM of ${ }^{218} \mathrm{Po}()^{212} \mathrm{Bi}$ and ${ }^{214} \mathrm{Po}$ alpha peaks for selected samplings performed using the Merlin Gerin alpha CAM (14-24 hr).

\begin{tabular}{|c|c|c|c|c|c|}
\hline \multirow[b]{2}{*}{$\begin{array}{c}\text { Sampling } \\
\text { datc(s) } \\
(\mathrm{m} / \mathrm{d} / \mathrm{y})\end{array}$} & \multirow[b]{2}{*}{$\begin{array}{c}\text { Average dust } \\
\text { concentration } \\
(\mu \mathrm{g} / \mathrm{L})\end{array}$} & \multicolumn{2}{|c|}{${ }^{218} \mathrm{Po} /{ }^{212} \mathrm{Bi}$} & \multicolumn{2}{|c|}{${ }^{214} \mathrm{P}_{0}$} \\
\hline & & $\begin{array}{l}\text { FWHM } \\
(\mathrm{kcV})\end{array}$ & $\begin{array}{l}\text { FWTH } \\
(\mathrm{kcV})\end{array}$ & $\begin{array}{l}\text { FWHM } \\
(\mathrm{kcV})\end{array}$ & $\begin{array}{l}\text { FW'TM } \\
(\mathrm{kcV})\end{array}$ \\
\hline \multicolumn{6}{|c|}{$0.8 \mu \mathrm{m}, 47-\mathrm{mm}$ filtcr } \\
\hline $07 /(0.3-0) 8 / 91$ & $4.31 \pm 0.48 \mathrm{E}-(0.3$ & $210 \pm 10$ & $546 \pm 3$ & $195 \pm 1$ & $475 \pm 13$ \\
\hline $06 / 28-(17 / 01 / 91$ & $7.52 \pm 0.84 \mathrm{E}-() 2$ & $185 \pm 12$ & $686 \pm 22$ & $232 \pm 7$ & $708 \pm 19$ \\
\hline$(07 /(01-(1) 2 / 91$ & $4.55 \pm 0.51 \mathrm{E}-01$ & $144 \pm 3$ & $476 \pm 38$ & $280 \pm 3$ & $887 \pm 15$ \\
\hline$(07 / 30-() 8 /(01 / 91$ & $6.80 \pm 0.76 \mathrm{E}-(01$ & $206 \pm 3$ & $549 \pm 4$ & $205 \pm 4$ & $513 \pm 24$ \\
\hline$(17 / 24-25 / 91$ & $7.48 \pm(1.84 \mathrm{E}-() 1$ & $173 \pm 3$ & 44()$\pm 26$ & $197 \pm 4$ & $516 \pm 1$ \\
\hline $06 / 26-27 / 91$ & $9 .(18 \pm 1.02 \mathrm{E} .(01$ & $177 \pm 26$ & $487 \pm .34$ & $228 \pm 2$ & $650 \pm 30$ \\
\hline$(17 / 25-26 / 91$ & $1.19 \pm 0.13 \mathrm{E}+(0)$ & $186 \pm 1$ & $5(16 \pm 24$ & $205 \pm 1$ & $507 \pm 9$ \\
\hline$(07 / 29-30 / 91$ & $2.114 \pm 0.23 \mathrm{E}+(0)$ & $194 \pm 1$ & $477 \pm 3$ & $199 \pm 2$ & $487 \pm 10$ \\
\hline \multicolumn{6}{|c|}{$0.8 \mu \mathrm{m}, 25-\mathrm{mm}$ filter } \\
\hline$(6 / 14-18 / 91$ & $1.74 \pm(1.19 \mathrm{E} .02$ & $189 \pm 21$ & $511 \pm 36$ & $220 \pm 3$ & $597 \pm 12$ \\
\hline \multicolumn{6}{|c|}{ 2.0 $\mu \mathrm{m}, 47$ - $\mathrm{mm}$ filter } \\
\hline $06 /(14-06 / 91$ & $9.58 \pm 1.07 \mathrm{E}-(0.3$ & $198 \pm 5$ & $538 \pm 17$ & $178 \pm 2$ & $414 \pm 5$ \\
\hline$(06 / 11-14 / 91$ & $3.25 \pm 0.36 \mathrm{E}-(12$ & $160 \pm \pm 5$ & $523 \pm 22$ & $176 \pm 3$ & $447 \pm 19$ \\
\hline$(07 / 15-16 / 91$ & $2.29 \pm 0.26 E-()]$ & $167 \pm 14$ & $529 \pm 55$ & $222 \pm .3$ & $807 \pm 7$ \\
\hline$(17 /(09-10 / 91$ & $8.41 \pm(0.94 \mathrm{E}-() 1$ & $119 \pm 7$ & $396 \pm 27$ & $303 \pm 2$ & $915 \pm 2$ \\
\hline
\end{tabular}


three different time intervals, generally 4 to 12 hours, 14 to 24 hours, and 26 to 48 hours after the beginning of sampling.

In the case of samplings performed with the Merlin Gerin CAM, the average FWHM of the ${ }^{218} \mathrm{Fo} /{ }^{212} \mathrm{Bi}$ and ${ }^{214} \mathrm{Po}$ peaks between 14 and 24 hours following the initiation of sampling ranged from 119 to $210 \mathrm{keV}$ and from $176 \mathrm{to} 303 \mathrm{keV}$, respectively. The FWTM ranged from 396 to $686 \mathrm{keV}$ and from 414 to $915 \mathrm{keV}$ for the two respective peaks. So, the average values of the FWHM and FWTM of these two background peaks both varied by about a factor of two for samplings performed using the Merlin Gerin CAM.

The FWHM and FWTM of the $6.00 \mathrm{MeV}{ }^{218} \mathrm{Po} /{ }^{212} \mathrm{Bi}$ peak during four samplings of ambient air performed using the Merlin Gerin CAM when the CAM was equipped with either a $0.8 \mu \mathrm{m}$, $47-\mathrm{mm}$; a $0.8 \mu \mathrm{m}, 25-\mathrm{mm}$; or a $2.0 \mu \mathrm{m}, 47-\mathrm{mm}$ diameter filter are plotted as a function of sampling time in Figures 11 and 12, respectively. Similar results for the $7.69 \mathrm{MeV}{ }^{214}$ Po peak for the same four samplings are plotted in Figures 13 and 14, respectively. Figures 11 through 14 show that the resolution of the $6.00 \mathrm{MeV}$ peak behaved differently than the resolution of the $7.69 \mathrm{MeV}$ peak. They also show that filter pore size and diameter affected peak resolution. For all three filters, the width of the $6 .(0) \mathrm{MeV}$ peak generally increased rapidly during the first 20 hours of sampling. Thereafter, it remained relatively stable in the case of the $0.8 \mu \mathrm{m}$ filters but continued to increase in the case of the two samplings performed using a $2.0 \mu \mathrm{m}, 47-\mathrm{mm}$ diameter filter. As shown in Figures 13 and 14 , the resolution of the $7.69 \mathrm{MeV}$ peak decreased monotonically throughout both samplings performed using $0.8 \mu \mathrm{m}$ filters but continued to increase at relatively constant rates throughout the samplings perlormed using the $2.0 \mu \mathrm{m}, 47-\mathrm{mm}$ diameter filter.

The resolutions of the $6 .(0)$ and $7.69 \mathrm{MeV}$ peaks behaved differently as a function of sampling time, in part, due to the differences in half-lives of ${ }^{218} \mathrm{Po}$ and the precursors of ${ }^{212} \mathrm{Bi}$ and ${ }^{214} \mathrm{Po}$. As was previously discussed, 3.1-minute ${ }^{218} \mathrm{Po}$ is the direct offspring of ${ }^{222} \mathrm{Rn}$, so ${ }^{218} \mathrm{Po}$ activity on the filter very quickly reaches an equilibrium value and because its half-life is so short it never becomes covered by aerosols collected at later times. However, because the half-life of ${ }^{212} \mathrm{~Pb}$ is 10.6 hours and that of its daughter ${ }^{212} \mathrm{Bi}$ is 61 minutes, ${ }^{212} \mathrm{Bi}$ activity continues $t o$ build up on the sample filter throughout the first 24 hours of sampling. During this time, the average thickness of the particulate layer on the collection filter that alpha particles emitted from ${ }^{212} \mathrm{Bi}$ must pass through continues 10 increase. The enhanced energy straggling causes the 6.(0) McV peak to continue to broaden until the ${ }^{212} \mathrm{Bi}$ activity on the filter reaches an equilibrium value. In the $\mathrm{c}$ se of ${ }^{214} \mathrm{Po}$, its longest-lived precursor is 26.8 -minute ${ }^{214} \mathrm{~Pb}$, so ${ }^{214} \mathrm{Po}$ activity on the collection filter reaches an equilibrium value within an hour or two, meaning that the average thickness of dust that its alpha particles must pass through in transit to the alpha detector reaches a constant value fairly quickly. The slight improvement in the resolution of the $7.69 \mathrm{MeV}$ peak with sampling time when the $0.8 \mu \mathrm{m}$ pore size filters were used probably indicates that pockets or other irregularities in the surface of the filter were gradually filled during sampling so that the average thickness of material the $7.69 \mathrm{MeV}$ alpha particles had to pass through slowly decreased. The continuing degradation of the resolution of the $7.69 \mathrm{MeV}$ alpha peak during samplings with the $2.0 \mu \mathrm{m}$ pore size filter indicates that acrosols continued to be trapped inside the filler medium.

Although during the first 30 to 40 hours of sampling, the resolutions of the 6.00 and $7.69 \mathrm{McV}$ alpha peaks were comparable to or slightly lower using the $2.0 \mu \mathrm{m}$ filter than the $0.8 \mu \mathrm{m}$ filter, the results show that the resolutions of these two peaks were more stable when the $0.8 \mu \mathrm{m}$ filters were 


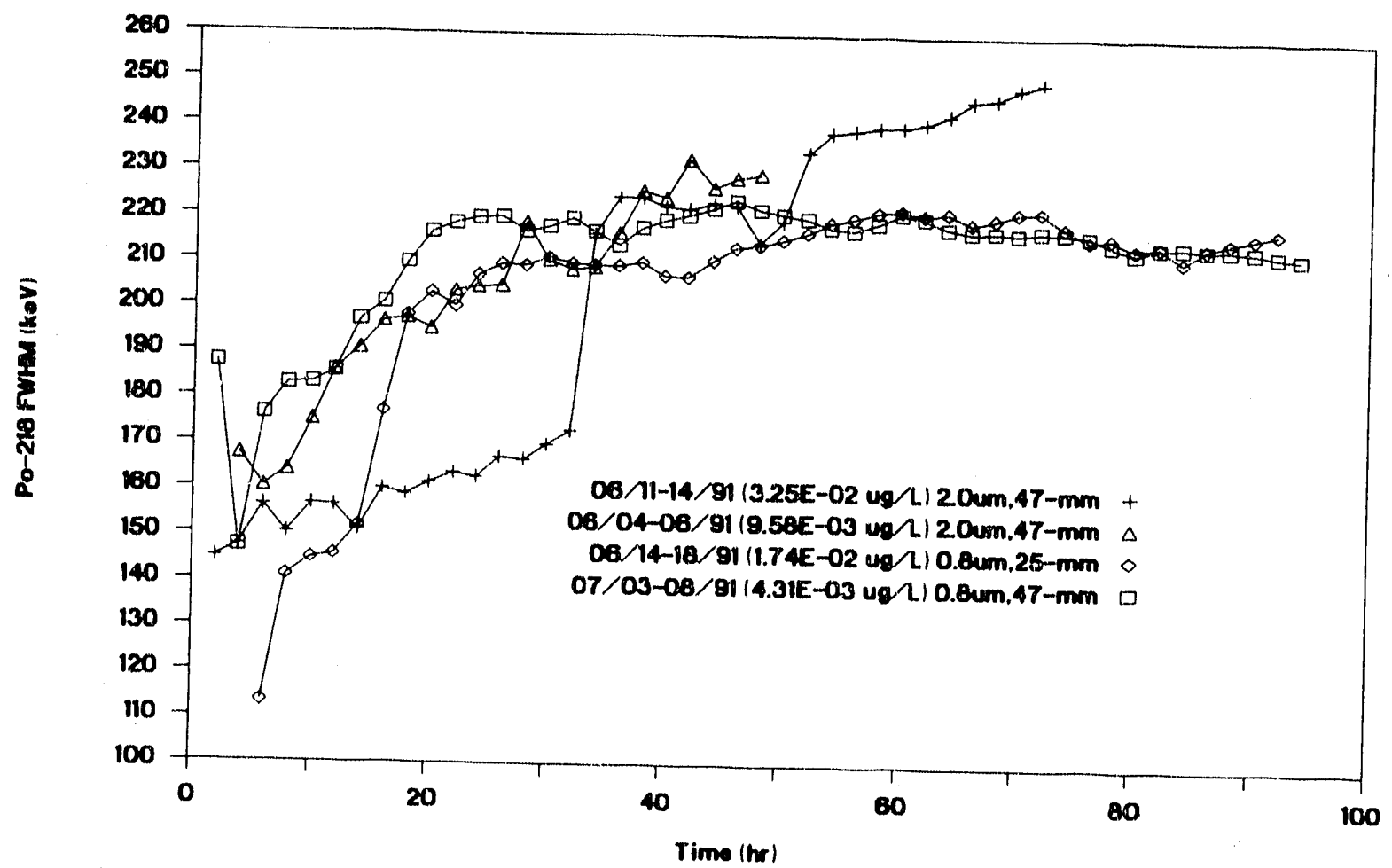

Figure 11. FWHM of ${ }^{218} \mathrm{Po} /{ }^{212} \mathrm{Bi}$ alpha peak versus sampling time for samplings of ambient air performed using the Merlin Gerin alpha CAM equipped with three different sample filters.

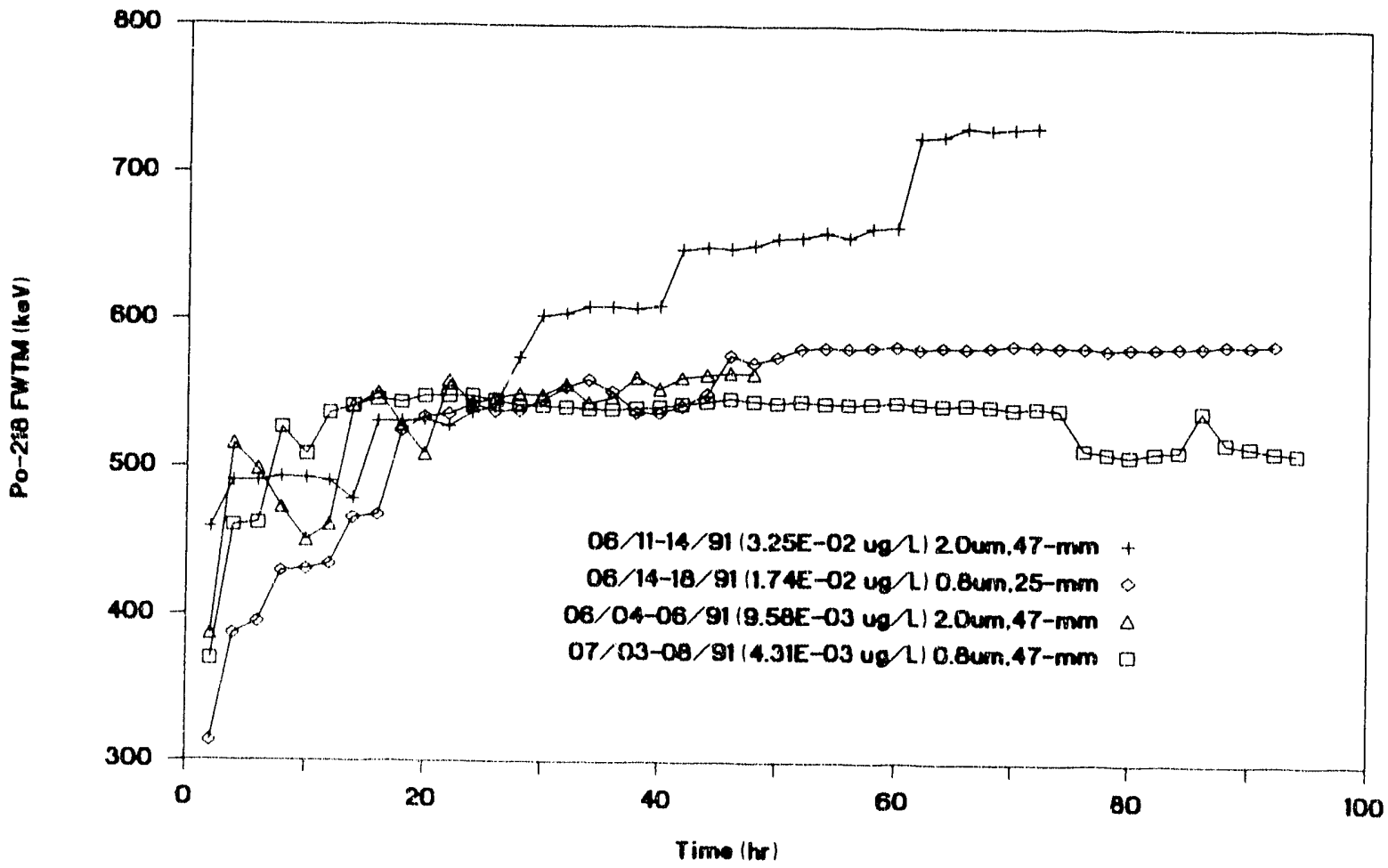

Figure 12. FWTM of ${ }^{218} \mathrm{Po} / 212 \mathrm{Bi}$ alpha peak versus sampling lime for samplings of ambient air performed using the Merlin Gerin alpha CAM equipped with three different sample filters. 


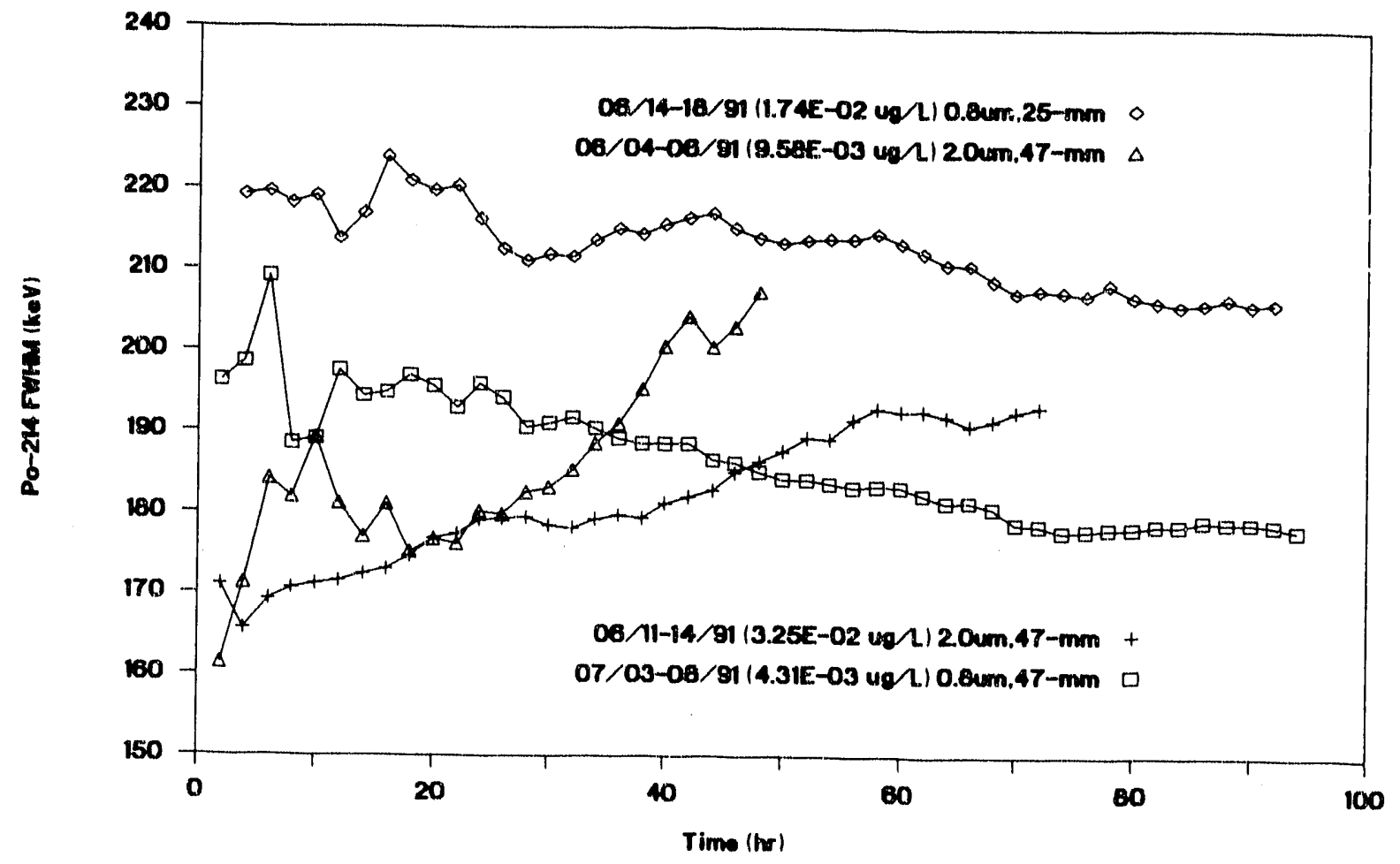

Figure 13. FWHM of ${ }^{214} \mathrm{Po}$ alpha peak versus sampling time for samplings of ambient air performed using the Merlin Gerin alpha CAM equipped with three different sample filters.

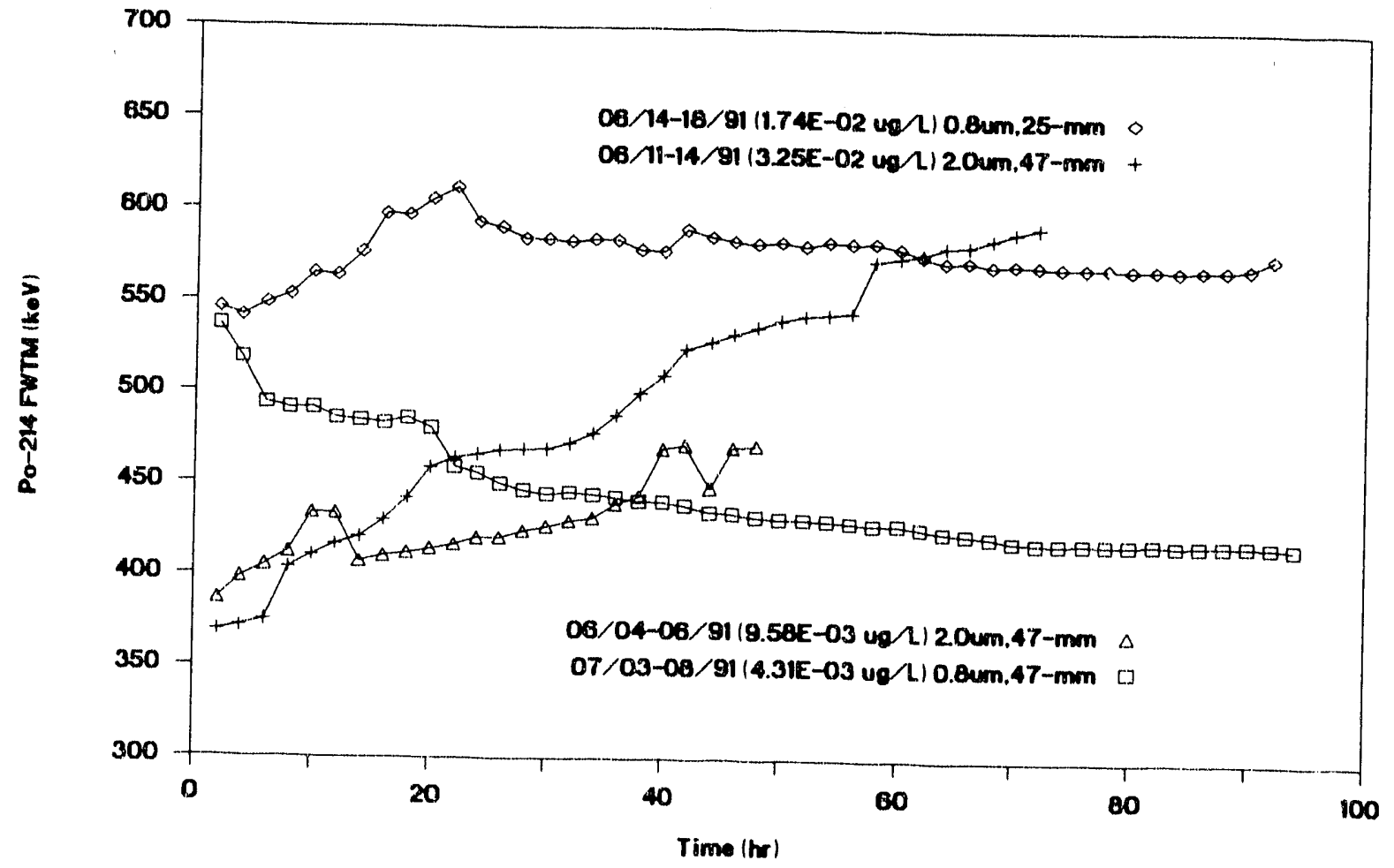

Figure 14. FWTM of ${ }^{214} \mathrm{Po}$ alpha peak versus sampling time for samplings of ambient air perlormed using the Merlin Gerin alpha CAM equipped with three different san ple filters. 
used. This implies that the coefficients used for background subtraction will be more stable and will consequently exhibit smaller standard deviations when the smaller pore size filter is used. This suggests that the $0.8 \mu \mathrm{m}$ filter will provide better sensitivity and more reliable determinations of airborne TRU concentrations.

The average FWHM and FWTM of the $7.69 \mathrm{MeV}{ }^{214}$ Po alpha peak listed in Table 6 are plotted as a function of average airborne dust concentration in Figures 15 and 16, respectively. For samplings performed using the $0.8 \mu \mathrm{m}, 47-\mathrm{mm}$ diameter filter, the FWHM and FWTM of the $7.69 \mathrm{McV}$ peak both increased rapidly with increasing dust concentration when dust concentrations were in the range 0.004 to $0.5 \mu \mathrm{g} / \mathrm{L}$; but when average dust concentrations were above $0.5 \mu \mathrm{g} / \mathrm{L}$, they both decreased to values similar to those measured when the dust concentration was $0904 \mu \mathrm{g} / \mathrm{L}$. The results for samplings performed using a $2.0 \mu \mathrm{m}, 47-\mathrm{mm}$ diameter filter show that the resolution of the 7.69 MeV peak continued to worsen with increasing dust concentration for dust concentrations ranging from 0.01 to $0.8 \mu \mathrm{g} / \mathrm{L}$. The average FWHM and FWTM of the $7.69 \mathrm{MeV}$ peak during the single sampling performed using a $0.8 \mu \mathrm{m}, 25-\mathrm{mm}$ diameter filter, when the dust concentration averaged about $0.02 \mu \mathrm{g} / \mathrm{L}$, are similar to corresponding values determined for the $0.8 \mu \mathrm{m}, 47-\mathrm{mm}$ diameter filter when dust concentrations ranged from 0.004 to $0.08 \mu \mathrm{g} / \mathrm{L}$.

In the case of samplings performed using the $0.8 \mu \mathrm{m}, 47-\mathrm{mm}$ diameter filter, the abrupt improvement in the resolution of the $7.69 \mathrm{MeV}$ peak when dust concentrations were above $0.5 \mu \mathrm{g} / \mathrm{L}$ might be due to the higher rate at which acrosols were being deposited on the sample collection filter. When the aerosol deposition rate is sufficiently high, 26.8 -minute ${ }^{214} \mathrm{~Pb}$ and 19.9 -minute ${ }^{214} \mathrm{Bi}$ atoms already collected on the filter are buried so quickly that the aerosol layer becomes, for all practical purposes, infinitely thick to alpha particles emitted by $164-\mu \mathrm{sec}{ }^{214} \mathrm{Po}$. Cnly those ${ }^{214} \mathrm{Bi}$ atoms that decay as soon as or soon after they reach the filter produce ${ }^{214} \mathrm{Po}$ daughters that emit alpha particles that have a chance of reaching the alpha detector. Alpha particles emitt:d from ${ }^{214} \mathrm{Po}$ atoms that are created at later times are absorbed by overlaying dust.

The FWHM and FWTM of the $7.69 \mathrm{MeV}{ }^{214} \mathrm{Po}$ alpha peak are plotted as a function of sampling time in Figures 17 and 18, respectively, for four samplings of ambient air performed using the ANL-W, Kurz, Merlin Gerin, and Victoreen alpha CAMs. FWHM and FWTM results for the ANL-W and Kur' CAMs are for a sampling performed when the two CAMs were operated simultaneously in the same environment. Average dust concentrations during the four samplings were similar, ranging from about 0.02 to $0.07 \mu \mathrm{g} / \mathrm{L}$. Sampling durations ranged from 94 to 112 hours. Similar results are plotted in Figures 19 and 20, respectively, for seven samplings of aerosolized blank dust performed using the Kurz, Merlin Gerin, and Victoreen CAMs. Average airborne dust concentrations during these latter samplings ranged from about 0.07 to $0.9 \mu \mathrm{g} / \mathrm{L}$. The Kurz and Victoreen CAMs were operated simultaneously in the same environment on both dates for which resolution data is presented. The FWHM and FWTM of the $6.00 \mathrm{MeV}{ }^{218} \mathrm{Po} /{ }^{212} \mathrm{Bi}$ alpha peak during these same samplings of ambient air and aerosolized blank dust are plotted as a function of sampling time in Figures B-1 through B-4 in Appendix B.

The results plotted in Figures 17 and 18 show that, as expected, the Kurz CAM exhibited the best resolution. The fact that aerosols adhere directly to the face of the Kurz alpha detector and do not have to traverse an air gap before striking the detector accounts for the better resolution of the Kurz CAM. However, as is evident in Figures 17 and 18, in the case of the Kurz CAM, the width of the ${ }^{214}$ Po peak continued to broaden throughout the sampling, whereas in the case of the 


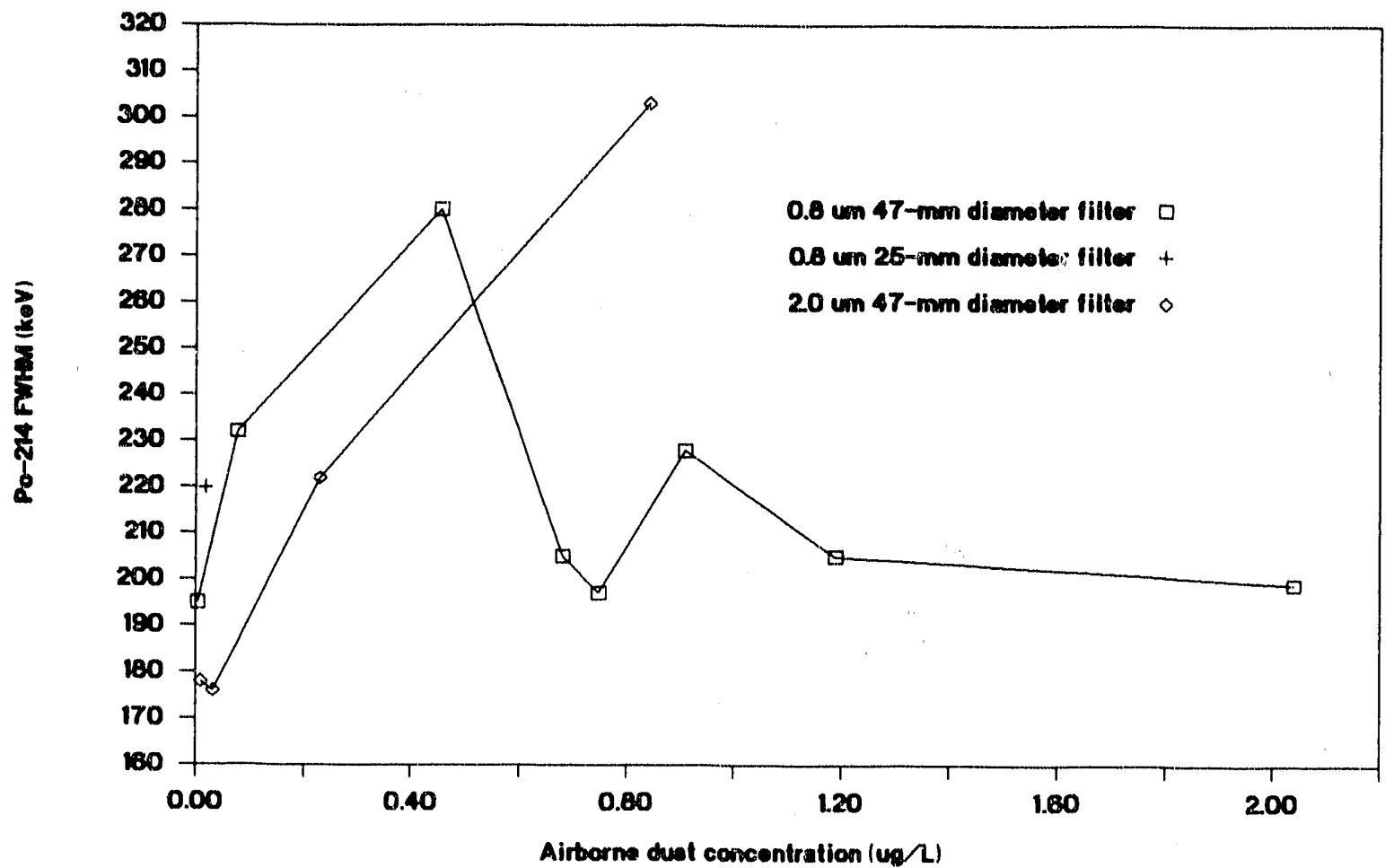

Figure 15. FWHM of ${ }^{214} \mathrm{Po}$ ) alpha peak versus average airborne dust loading for samplings performed using the Merlin Gerin Edgar alpha CAM equipped with three different sample filters.

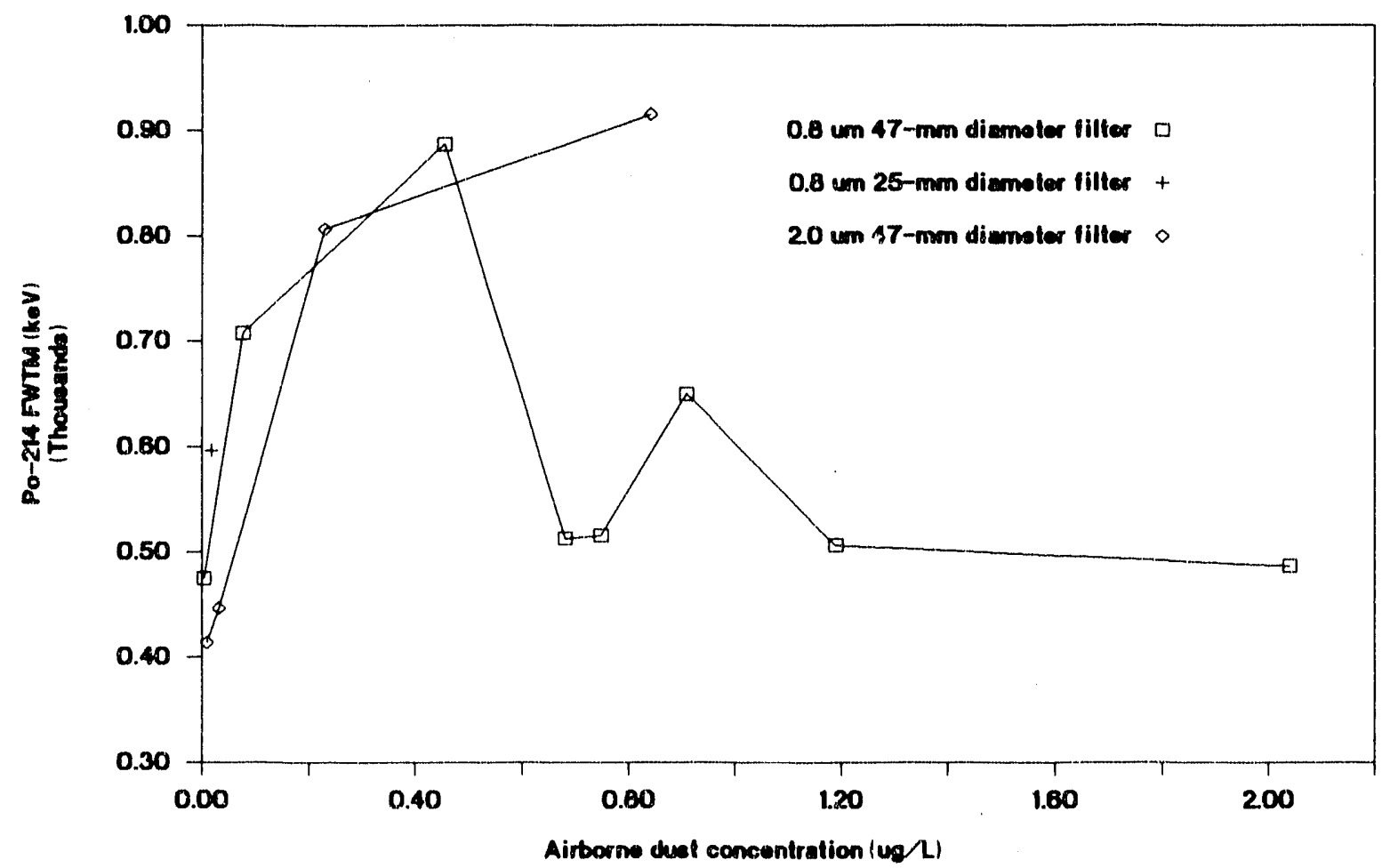

Figure 16. FWTM of ${ }^{214} \mathrm{Po}$ alpha peak versus average airborne dust loading for samplings performed using the: Merlin Gerin Edgar alpha CAM equipped with three different sample filters. 


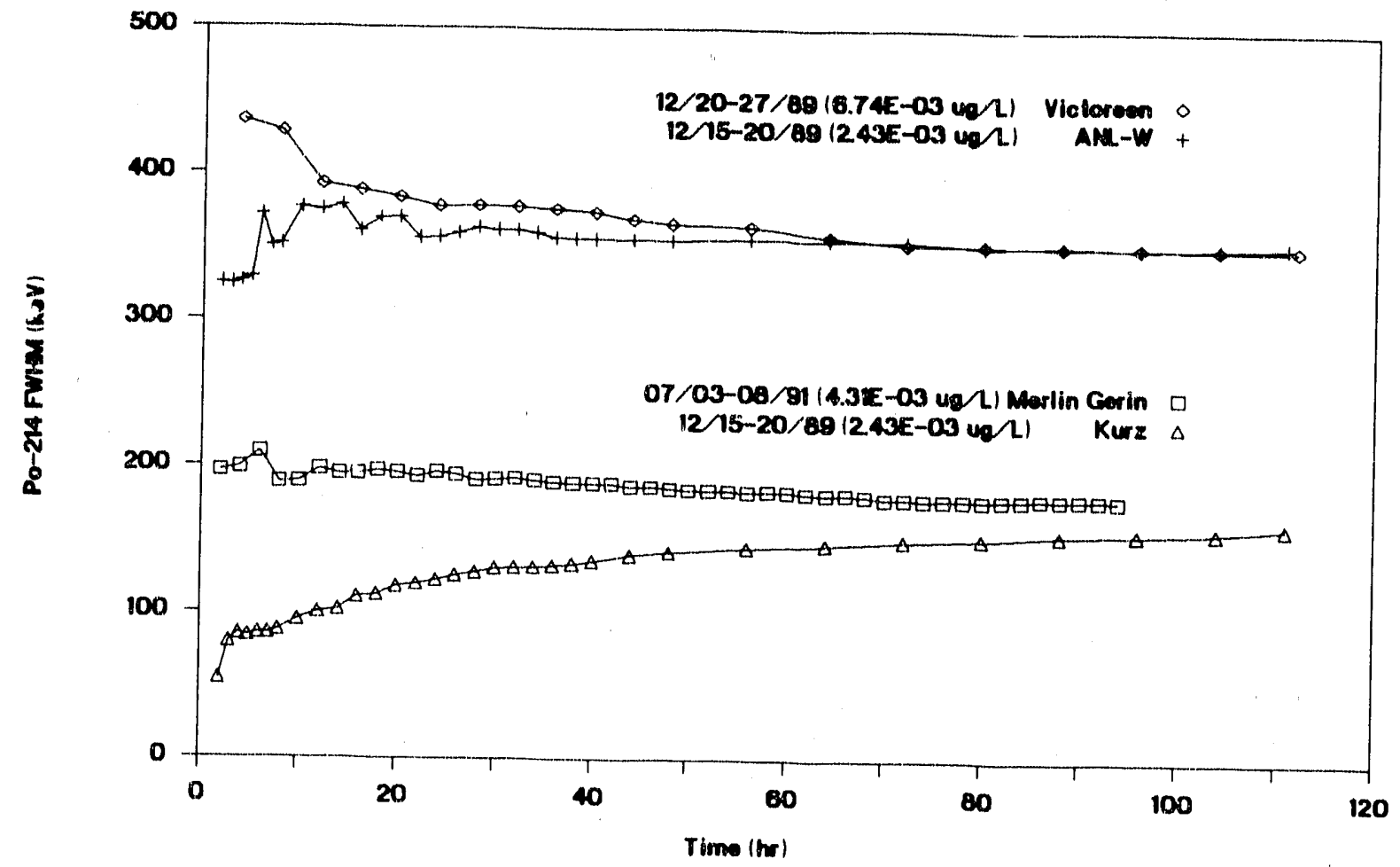

Figure 17. FWHM of ${ }^{214} \mathrm{Po}$ alpha peak versus sampling time for samplings of ambient air performed using ANL-W, Kurz. model 8311, Merlin Gerin Edgar, and Victoreen model 758 alpha CAMs.

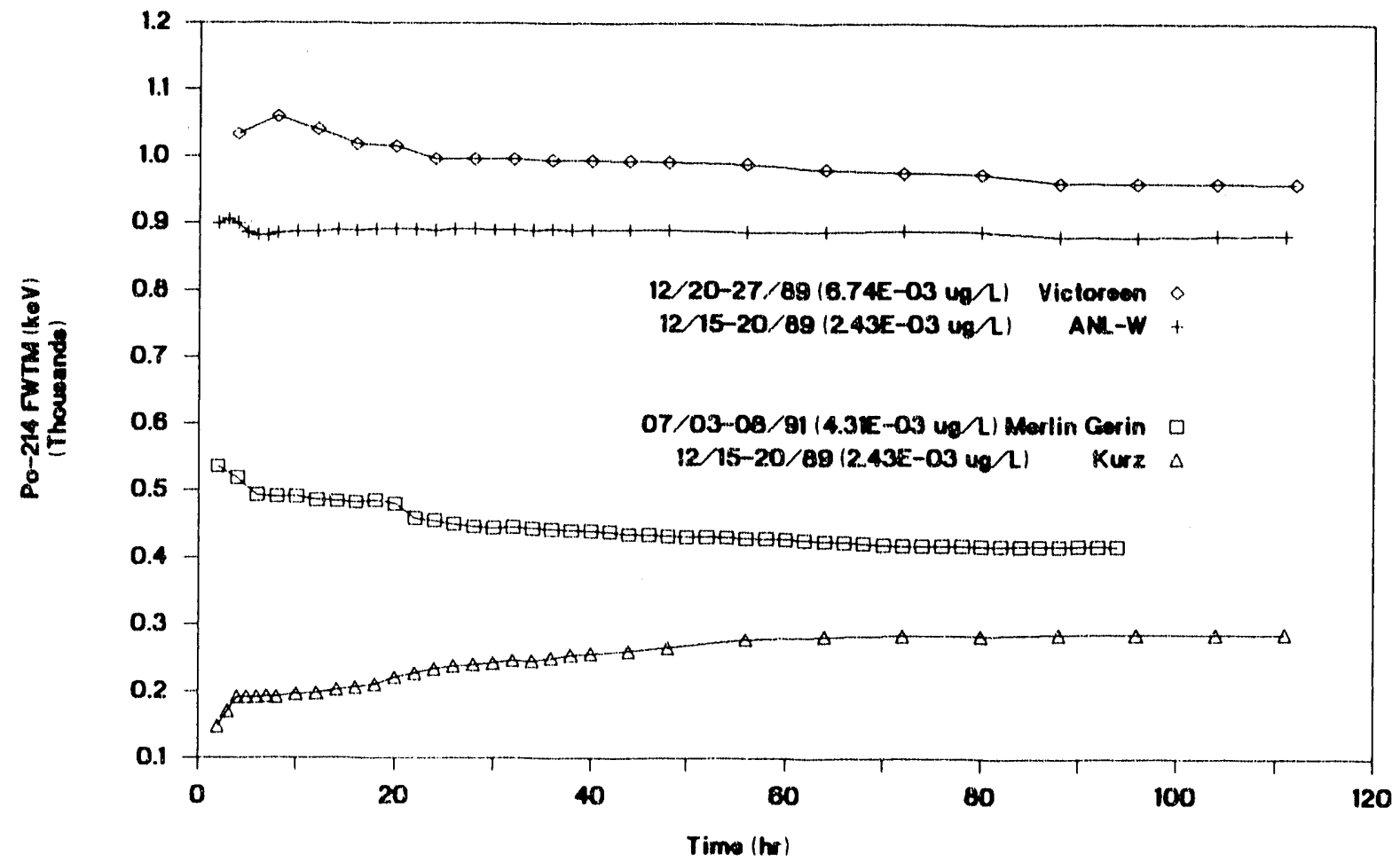

Figure 18. FWTM of ${ }^{214} \mathrm{Po}$ alpha peak versus sampling time for samplings of ambient air performed using the ANL-W, Kurz model 8.311, Merlin Gerin Edgar, and Victoreen model 758 alpha CAMs. 


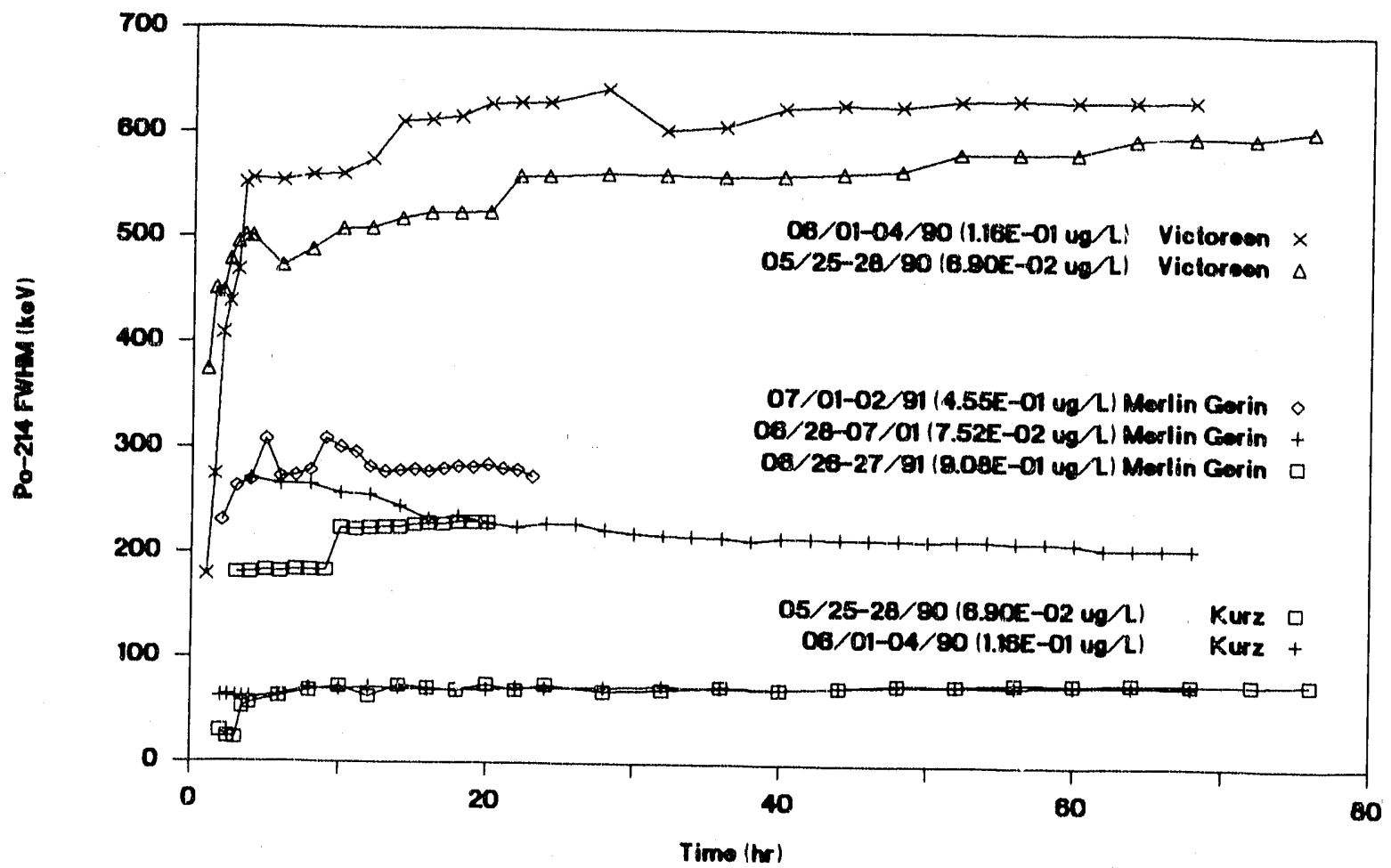

Figure 19. FWHM of ${ }^{214} \mathrm{Po}$ alpha peak versus sampling time for samplings of acrosolized blank dust performed using the ANL-W, Kurz model 8311, Merlin Gerin Edgar, and Victoreen model 758 alpha CAMs.

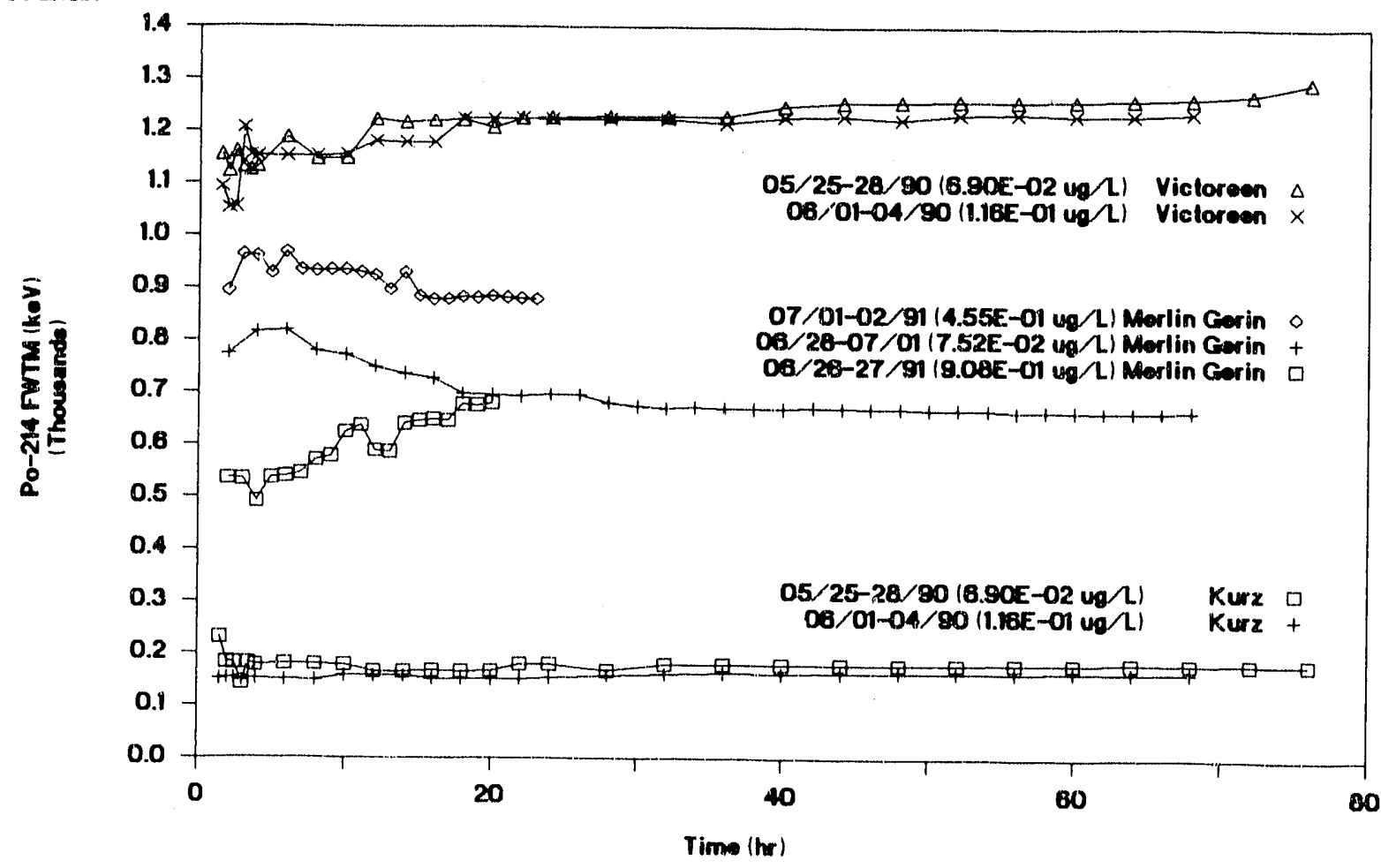

Figure 20. FWTM of ${ }^{214} \mathrm{Po}$ alpha peak versus sampling time for samplings of acrosolized blank dust performed using the ANL-W, Kurz model 8311, Merlin Gerin Edgar, and Victoreen model 758 alpha CAMs. 
remaining three CAMs, its width remained about the same or became somewhat narrower over comparable sampling times. For the sampling of ambient air performed using the Kurz CAM, the FWHM and FWTM of the $7.69 \mathrm{MCV}$ alpha peak were, respectively, about 80 and $190 \mathrm{keV}$ after 3 hours of sampling, but increased to about 140 and $270 \mathrm{keV}$, respectively, after 48 hours. The fact that the Kurz CAM does not employ a sample collection filter accounts for its excellent initial resolution, but this design is also reponsible for the broadening of Kurz alpha peaks with continued sampling. In the absence of a mechanism to slowly turn the impactor plate during sampling, particulates are concentrated on the face of the Kurz alpha detector at locations directly beneath the holes in the plate impactor. The widths of Kurz alpha peaks broaden with time for the simple reason that they must always traverse the layer of aerosols deposited beneath them in order to strike the detector. As the thickness of this layer grows, alpha particles lose proportionately larger fractions of their initial energies in traversing it.

The benelit of the eollimator installed in the Merlin Gerin CAM is evident in Figures 17 through 20. The FWHM and FWTM of the ${ }^{214}$ Po peak for samplings performed using the Merlin Gerin CAM were only about one-hall corresponding values for the ANL-W and Victoreen CAMs. In the case of the Merlin Gerin CAM, the FWHM and FWTM of the ${ }^{214}$ Po peak during the sampling of ambient air decreased from maxima of 209 and $536 \mathrm{kcV}$, respectively, after a few hours of sampling to minima of 179 and $419 \mathrm{kcV}$, respectively, after 94 hours. The resolutions of the ANL-W and Victoreen CAMs were very similar. In the case of the latter two CAMs, during samplings of ambient air the FWHM and FWTM of the $7.69 \mathrm{MeV}$ peak ranged between about 350 and $400 \mathrm{keV}$ and between about 900 and $1,000 \mathrm{keV}$, respectively.

As shown in Table 1, the detector installed in the ANL.W CAM had a diameter of $31.9 \mathrm{~mm}$ while the diameter of the detector installed in the Victoreen CAM was $46.5 \mathrm{~mm}$. Given the circumstanee that smaller diameter detectors normally have better resolution than larger diameler detectors, the similarity of the resolutions of the ANL-W and Victoreen CAMs may be due to minor differenes in their designs. In the case of the Victoreen CAM, the sample collection filter was held in place by means of a steel ring having an inside dianceler of $41.3 \mathrm{~mm}$, meaning that the effective diameter of the lifter was smaller than the diameter of the alpha detector. In the case of the ANL-W CAM, the filler holder ring had an inside diameter of about $42 \mathrm{~mm}$, so the effective diameter of the sample collection lilter was larger than the diameter of the alpha detector. The detector and filter were separaled by $3.2 \mathrm{~mm}$ in the case of the ANL-W CAM but were separated by only $1.8 \mathrm{~mm}$ in the casce of the Victoreen CAM. So the average pathlength between the filter and detector was similar for both the ANL-W and Victoreen CAMs.

As shown in Figures 19 and 20, higher dust concentrations generally resulted in poorer resolution. In the calse of the Victoreen CAM, the FWHM of the $7.69 \mathrm{MeV}$ peak increalied from an average välue of about $360 \mathrm{keV}$ when the dust concentration was about $0.0(0) \mu \mathrm{g} / \mathrm{L}$. to average values of about $58(7$ and $640 \mathrm{keV}$ during samplings when dust concentrations averaged 0.07 and $0.1 \mu \mathrm{g} / \mathrm{L}$, respectively. Average IFWTM values for the Victoreen CAM increased only modestly during the latter two samplings. The results indicate that, as was the case with the Merlin Gerin CAM, the resolution of the Kur\% CAM improved and was more stable when dust concentrations were elevated. However, the explanation given lor the apparent improvement in the resolution of the Merlin Gerin CAM when dust concentrations were above $0.5 \mu \mathrm{g} / \mathrm{L}$ cannot apply to the Kurz CAM due to the late that aeressols collected on the face of the Kurz detector are deposited on the surface of the acrosol layer facing away from the detector rather than loward it. Perhaps when dust 
concentrations are sufficiently high, entrained particulates bombarding the surface of the Kurz detector more effectively displace aerosols already on the surface.

\section{Coefficients Used in Analysis Algorithms}

The coefficients $k_{1}, k_{2}$, and $k_{3}$ used, respectively, in the two-, three-, and four-window analysis algorithms to subtract background counts from the ${ }^{239} \mathrm{Pu} \mathrm{ROI}$ were calculated at 30 -minute intervals for each sampling of ambient air and aerosolized blank dust performed using the Merlin Gerin CAM. The average values and standard deviations of the three coefficients during each sampling are given in Table 7. Standard deviations given in Table 7 were calculated at the one-sigma (67\%) confidence level. Similar results for the ANL-W, Kurz, RADeCO, and Victoreen CAMs can be found in Reference 3.

The average values of the coefficients $k_{1}, k_{2}$, and $k_{3}$ during samplings performed when the Merlin Gerin CAM was equipped with a $0.8 \mu \mathrm{m}, 47-\mathrm{mm}$ diameter or a $2.0 \mu \mathrm{m}, 47-\mathrm{mm}$ diameter filter are plotted as a function of average airborne dust concentration in Figures 21, 22, and 23, respectively. These figures show that in all cases the coefficients increased with increasing dust concentration and that at any given dust concentration. the coefficients were normally higher when the $2.0 \mu \mathrm{m}$ filter was used. The coefficients increased with increasing dust concentration due to the fact that ${ }^{218} \mathrm{Po},{ }^{212} \mathrm{~Pb}$, and ${ }^{212} \mathrm{Bi}$ already collected on the filter were more quickly covered by dust when the concentrations of airborne dust were elevated. The higher coefficients for the $2.0 \mu \mathrm{m}$ filter, indicate that, as might be expected, alpha particles emitted from the more porous filter had a higher probability of interacting with the filter medium. The results plotted in Figures 21 and 22 indicate that when the $0.8 \mu \mathrm{m}$ filter was used, $k_{1}$ and $k_{2}$ both increased asymptotically to maximum values of about 0.3 and 0.7 , respectively. Although the trend is less clearly defined, the results for the $0.8 \mu \mathrm{m}$ filter plotted in Figure 23 indicate that $\mathrm{k}_{3}$ also approached a constant value (about 0.14 ) when dust concentrations were above $0.4 \mu \mathrm{g} / \mathrm{L}$. The leveling off of the coefficients at high dust concentrations correlates well with the general behavior of the resolutions of the $6.00 \mathrm{MeV}{ }^{218} \mathrm{Po} /{ }^{212} \mathrm{Bi}$ and $7.69 \mathrm{MeV}{ }^{214}$ Po alpha peaks.

According to Equation (10), when background count rates are not negligible, the LLD is proportional to the standard deviation of the coefficient used for background subtraction. Standard deviations of the coefficients given in Table 7 for samplings performed using the $0.8 \mu \mathrm{m}, 47-\mathrm{mm}$ diameter filter are plotted, expressed in pereent, as a function of average airborne dust concentration in Figure 24. Similar results for the samplings performed using the $2.0 \mu \mathrm{m}, 47-\mathrm{mm}$ diameter filter are plotted in Figure 25. The results plotted in Figure 24 show that, excluding what might be a couple of anomalous results, the dispersion of each coeflicient for samplings performed using the $0.8 \mu \mathrm{m}$ filter was not significantly affected by dust concentration. Ignoring the two anomalously high results, one for $k_{1}( \pm 100 \%)$ and one for $k_{3}( \pm 78 \%)$, standard deviations of $k_{1}$ and $k_{2}$ both averaged about $\pm 34 \%$, while that of $k_{3}$ averaged about $\pm 50 \%$. On the other hand, as shown in Figure 25, when the $2.0 \mu \mathrm{m}$ filter was used, the $k_{1}$ and $k_{3}$ coefficients exhibited much more scatter at higher dust concentrations than at lower dust concentrations. The results for the $2.0 \mu \mathrm{m}$ filter indicate that the standard deviation of $k_{3}$, which ranged between $\pm 32 \%$ and $\pm 58 \%$ below $0.03 \mu \mathrm{g} / \mathrm{L}$, jumped to about $\pm 95 \%$ when dust concentrations reached $0.1 \mu \mathrm{g} / \mathrm{L}$. (As was previously described, $\mathrm{k}_{3}$ is calculated assuming that the ratios of the high and low energy sides of the 6.00 and $7.69 \mathrm{MeV}$ alpha peaks remain proportional. If, when dust concentrations become elevated, the centroids of the two peaks shift in different directions or by different amounts, the proportionality constant, $\mathrm{k}_{3}$, can change 
Table 7. Average values of coefficients $k_{1}, k_{2}$, and $k_{3}$ for the Merlin Gerin alpha CAM for samplings of ambient air and aerosolized blank dust.

\begin{tabular}{|c|c|c|c|c|}
\hline $\begin{array}{l}\text { Sampling dates } \\
(\mathrm{m} / \mathrm{d} / \mathrm{y})\end{array}$ & $\begin{array}{c}\text { Average dust } \\
\text { concentration } \\
(\mu \mathrm{g} / \mathrm{L})\end{array}$ & $\begin{array}{l}\text { Two-window } \\
\text { algorillom } \\
k_{1}\end{array}$ & $\frac{\begin{array}{c}\text { Three-window } \\
\text { algorithm }\end{array}}{k_{2}}$ & $\begin{array}{l}\text { Four-window } \\
\text { algorithm } \\
k_{3}\end{array}$ \\
\hline \multicolumn{5}{|l|}{$0.8 \mu \mathrm{m}$ filter } \\
\hline $07 / 03-08 / 91$ & $4.31 \pm 0.481 \mathrm{0} .03$ & $4.42 \pm 1.40 \mathrm{E}:-02$ & $3.51 \pm 1.40 \mathrm{~F}: 01$ & $9.70 \pm 7: 10 \mathrm{E}-0.3$ \\
\hline $07 / 02-03 / 4) 1$ & $8.47 \pm 0.95[E-0.3$ & $6.27 \pm 1.91 \mathrm{I}:-02$ & $4.18 \pm 1.471:-01$ & $2.73 \pm 1.11 \mathrm{E}-02$ \\
\hline $06 / 24-26 / 91$ & $1.23 \pm 0.1+\mathrm{E}-02$ & $5.82 \pm 1.538:-112$ & $3.51 \pm 1.05 \mathrm{~F}-01$ & $2.32 \pm 0.83$ E.02 \\
\hline $06 / 14-18,91^{4}$ & $1.74 \pm 0.191:-02$ & $1.48 \pm 0.381:-01$ & $6.25 \pm 1.781:-01$ & $2.11 \pm 0.63 \mathrm{E}-0 \mathrm{I}$ \\
\hline $06 / 18-21 / 91$ & $2.39 \pm 0.27 \mathrm{E}-02$ & $8.67 \pm 3.35 \mathrm{E}:-02$ & $4.34 \pm 1.8 .3 \mathrm{E}:-01$ & $1.21 \pm 0.64 \mathrm{E}-01$ \\
\hline $06 / 28-07 / 01 / 91$ & $7.52 \pm 0.8+1.0 .02$ & $1.4 .3 \pm 0.36 \mathrm{~J}:-01$ & $5.67 \pm 1.64 \mathrm{E}-01$ & $8.21 \pm 3.50 \mathrm{E}-02$ \\
\hline $07 / 08 \times 09,01$ & $2.11 \pm 0.241:-01$ & $2.18 \pm 2.18 \mathrm{E}-01$ & $6.54 \pm 2.29[\therefore-01$ & $4.71 \pm 2.67 \mathrm{E}-02$ \\
\hline $07 / 01-02 \% 1$ & $4.55 \pm 0.51 \mathrm{I}:-01$ & $3.11 \pm 0.9+\mathrm{E}:-01$ & $7.86 \pm 2.21 \mathrm{E}-(0)$ & $1.46 \pm 0.64 \mathrm{E}-01$ \\
\hline $06,26-27 / 91$ & $9.08 \pm 1.021:-01$ & $3.38 \pm 1.78 \mathrm{E}-01$ & $6.84 \pm 2.17 \mathrm{E}-01$ & $1.32 \pm 0.70 \mathrm{E}-01$ \\
\hline \multicolumn{5}{|l|}{$2.0 \mu \mathrm{m}$ filter } \\
\hline $06 / 07-10 / 91$ & $8.19 \pm(1.92[\vdots-0.3$ & $6 . \% 0 \pm 3.94 \square-(12$ & $5.50 \pm 2.43 \mathrm{E}-01$ & $1.11 \pm 0.64 \mathrm{E}: 01$ \\
\hline $06 /(0)+06,91$ & $9.58 \pm 1.07[8-0.3$ & $8.69 \pm 2.75 \mathrm{E}-02$ & $5.51 \pm 2.61 \mathrm{~F} .01$ & $1.15 \pm 0.57 \mathrm{E}-01$ \\
\hline$(66 / 11 \ldots 1+19) 1$ & $3.25 \pm 0.361 .02$ & $2.10 \pm 0.591:-01$ & $6.36 \pm 1.80 \mathrm{E}:-01$ & $2.53 \pm 0.80[-01$ \\
\hline $07 / 17-18 / 91$ & $\therefore .02 \pm 0.561:-12$ & $2.18 \pm 0.71 \mathrm{E} .01$ & $5.41 \pm 2.35 \mathrm{E}-(01$ & $1.20 \pm 0.88 \mathrm{E}-01$ \\
\hline $07 / 10-11 / 01$ & $1.12 \pm 0.11 \mathrm{~L}:-01$ & $3.08 \pm 1.10 \mathrm{E}=01$ & $7.38 \pm 3.13 \mathrm{~F}:-01$ & $1.80 \pm 1.72 \mathrm{E}-01$ \\
\hline $07 / 15-16 / 41$ & $2.29 \pm 0.2015-011$ & $314 \pm 1.39 \mathrm{E}:-01$ & $7.04 \pm 2.05 \mathrm{E}: 01$ & $9.40 \pm 8.851 \mathrm{~B} 02$ \\
\hline $07 /(09-10,91$ & $8 .+1 \pm 0.9+1: .01$ & $0 .(12 \pm 3.12 \mathrm{E}:-01$ & $9.26 \pm 3.04[5-01$ & $1.06 \pm 0.87 \mathrm{E}-01$ \\
\hline
\end{tabular}

dramatically as the peak centroids move. The abrupt increase in the standard deviation of $k_{3}$ above $0.03 \mu \mathrm{g} / \mathrm{L}$ might be the result of the movement of the peak centroids during sampling.) The standard deviation of $k_{1}$ did nol exhibit the sarne abrupt increase as the standard deviation of $k_{3}$, but rather it increased asymptotically with increasing dust concentration from a value of about $\pm 28 \%$ at 0.03 $\mu \mathrm{g} / \mathrm{L}-10 \pm 528$ at $0.6 \mu \mathrm{g}$. In the case of the $2.0 \mu \mathrm{m}$ filter, the dispersion of $\mathrm{k}_{2}$ was least affected by dust concentration. The standard deviation of the latter coefficient was $\pm 47 \%$ at $0.01 \mu \mathrm{g} / \mathrm{L}$ but only $\pm 2 y \%$ at $0.2 \mu \mathrm{g} / \mathrm{L}$. 


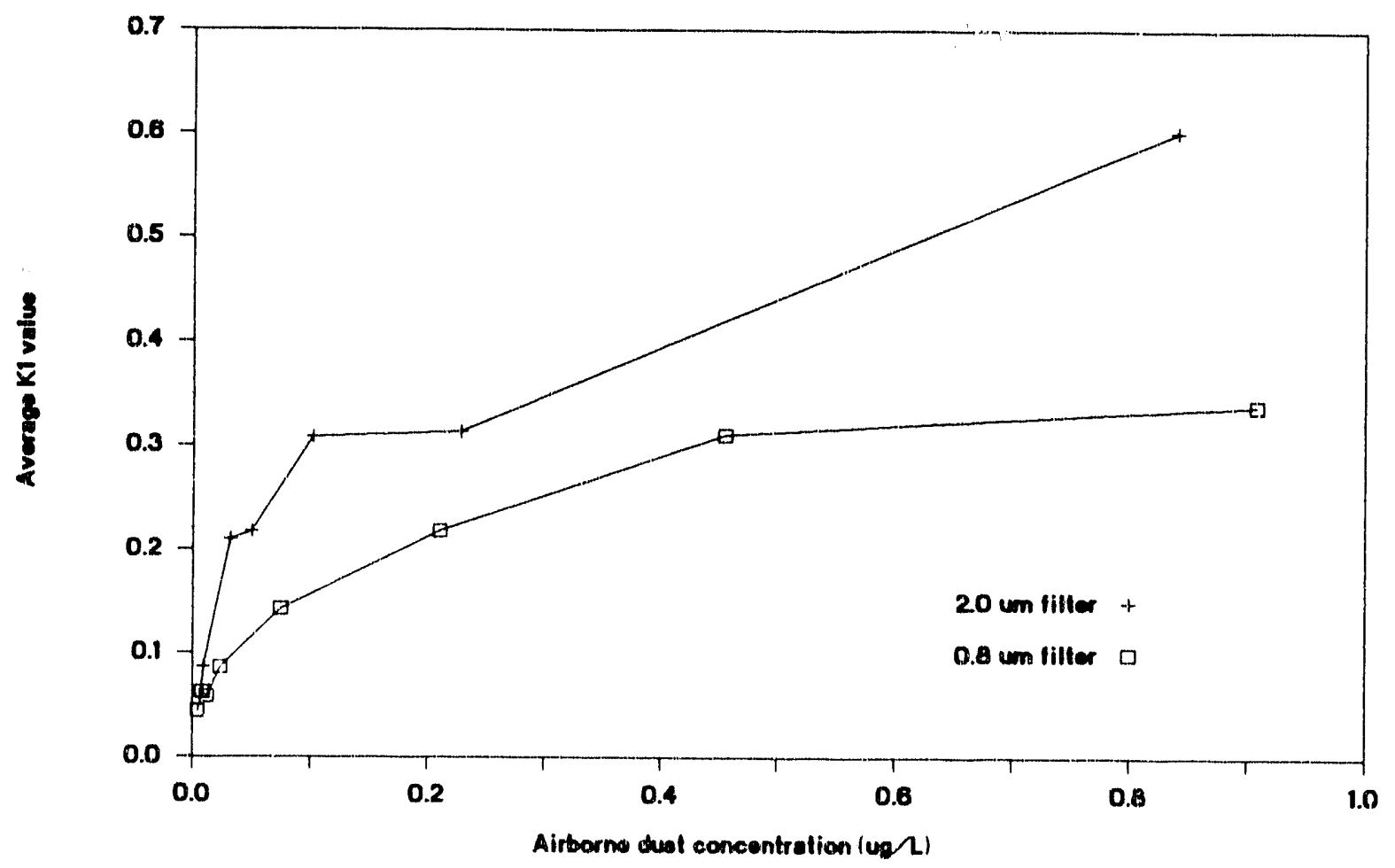

Figure 21. Average value of ecefficient $k_{1}$ for the Merlin Gerin C.AM versus average airborne dust concentration.

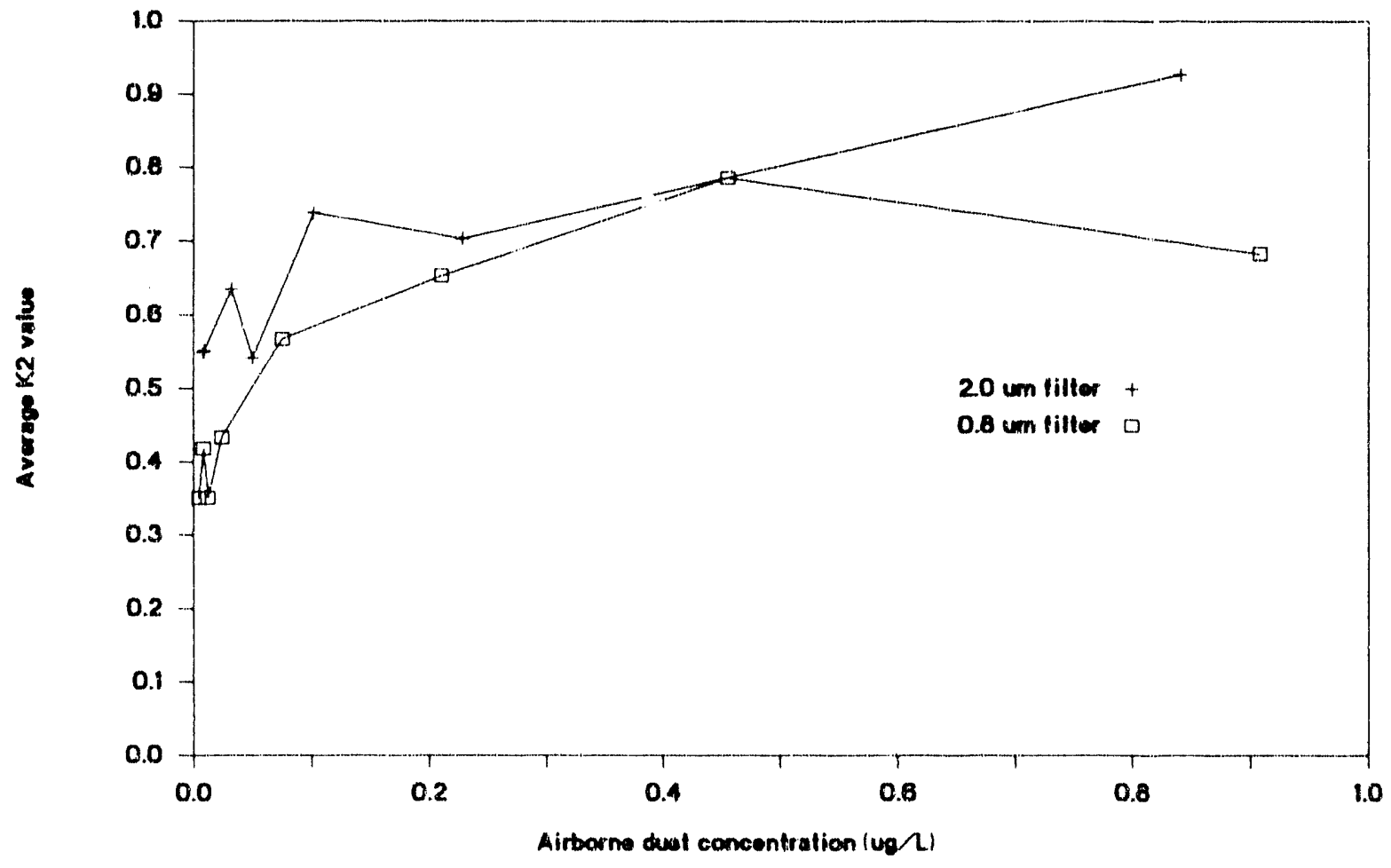

Figure 22. Average value of coefficient $k_{2}$ for the Merlin Gerin CAM versus average airborne dust concentration. 


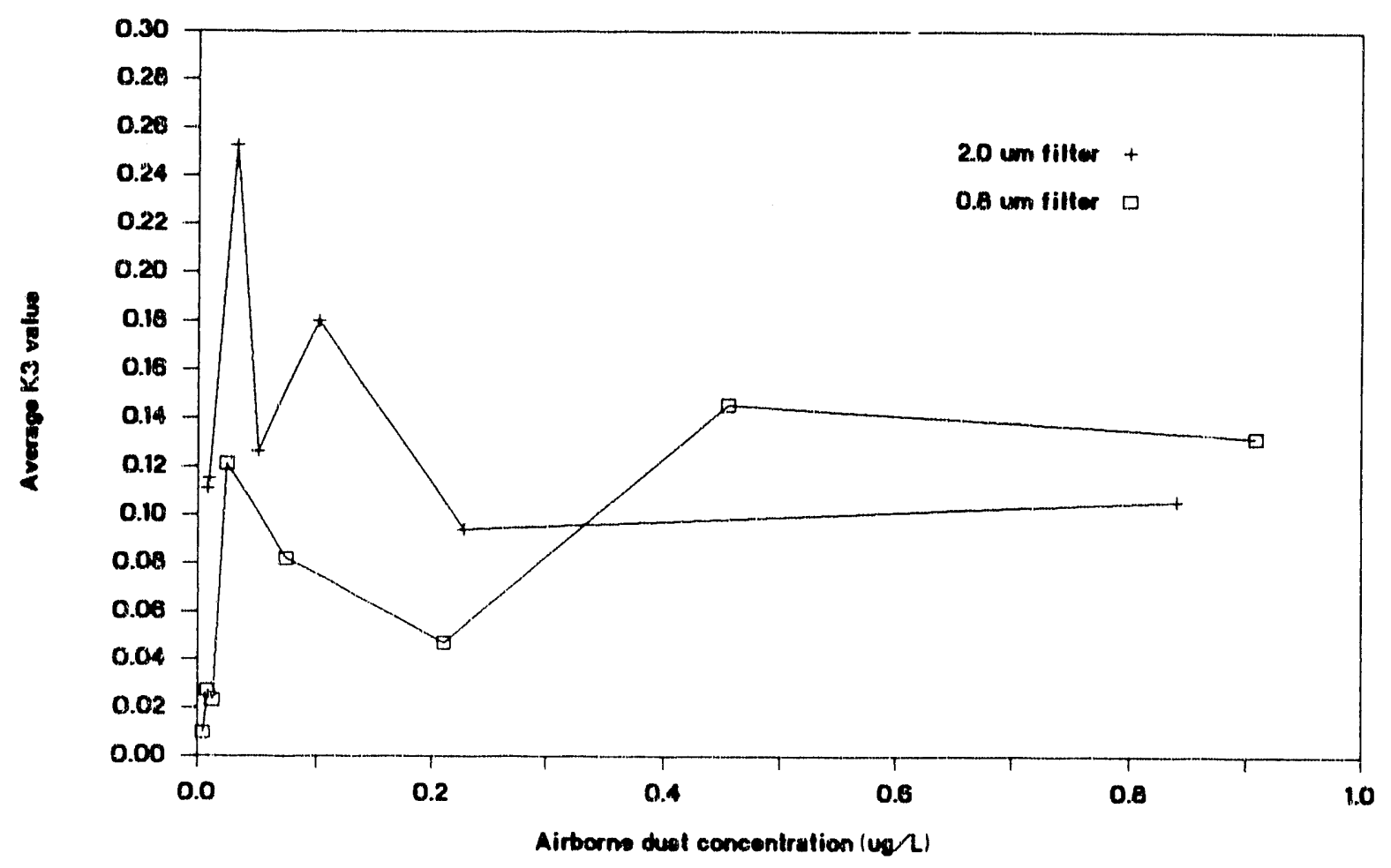

Figure 23. Average value of coefficient $\mathrm{k}_{3}$ for the Merlin Gerin CAM versus average airborne dust concentration.

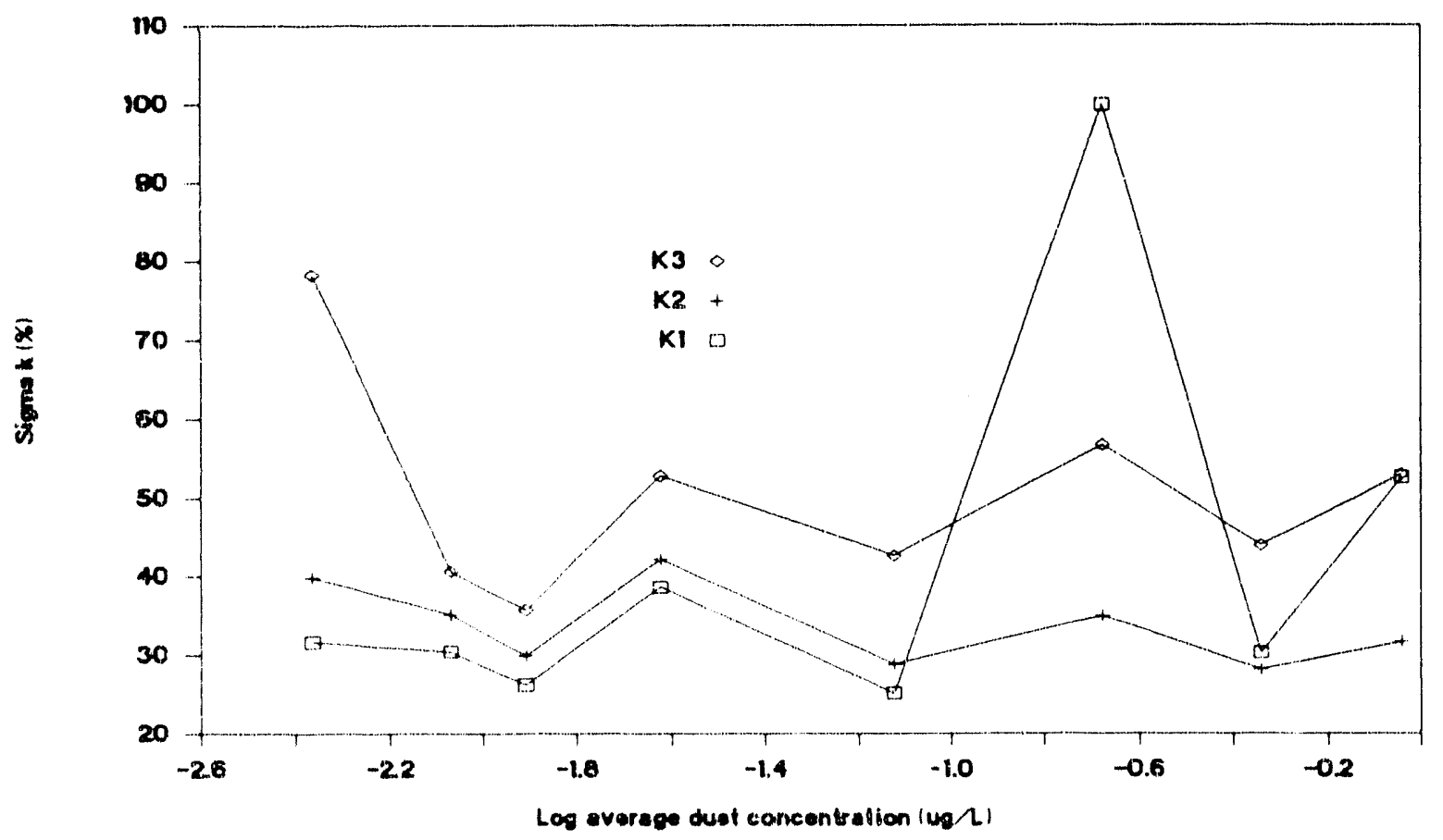

Figure 24. Standard deviations of coefficients $k_{1}, k_{2}$, and $k_{3}$ versus average airborne dust concentration for samplings performed using the Merlin Gerin CAM equipped with a $(1) .8 \mu \mathrm{m}, 47-\mathrm{mm}$ diameter filter. 


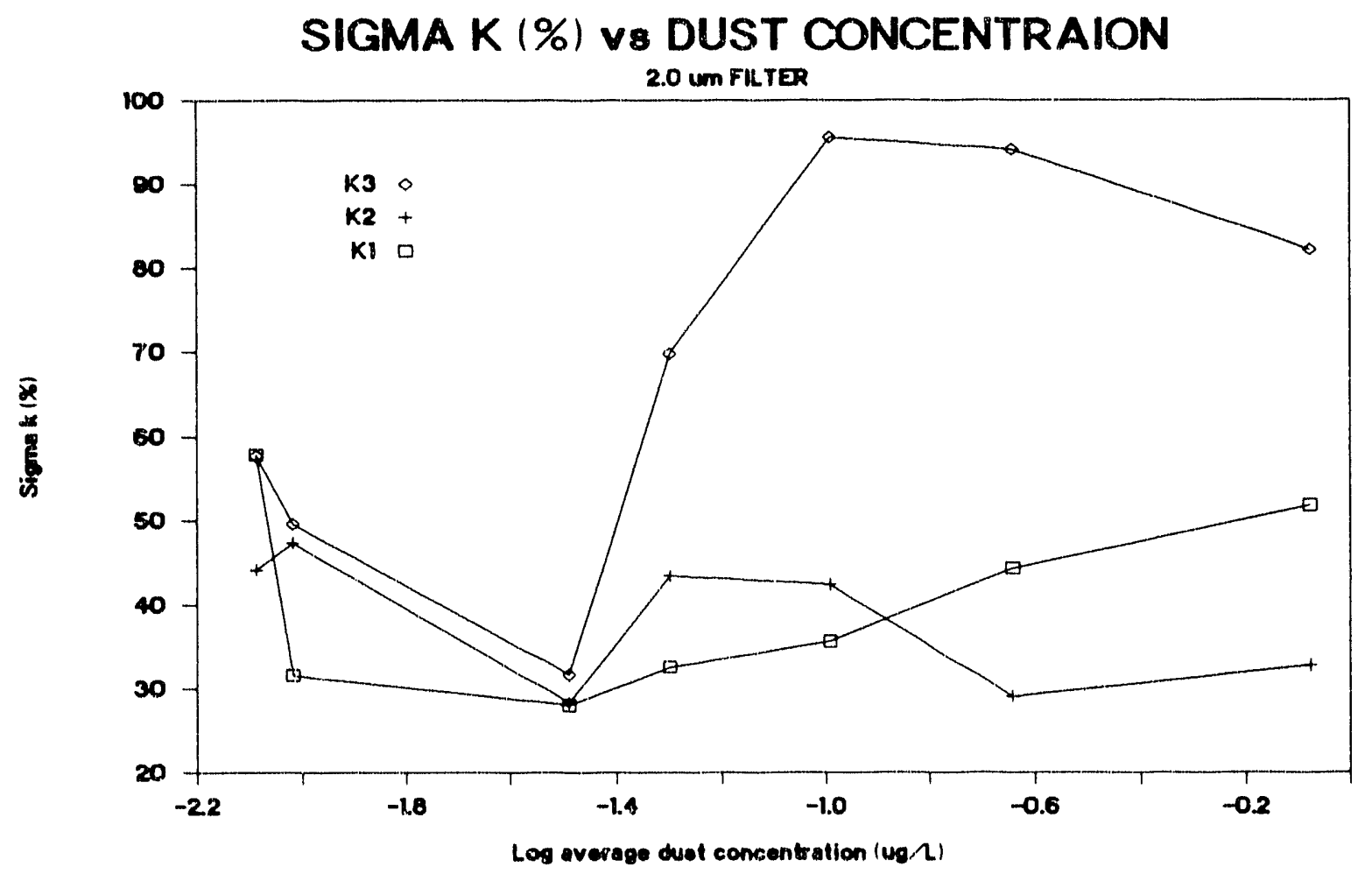

Figure 25. Standard deviations of coefficients $k_{1}, k_{2}$, and $k_{3}$ versus average airborne dust concentration for samplings performed using the Merlin Gerin CAM equipped with a $2.0 \mu \mathrm{m}, 47-\mathrm{mm}$ diameter filter.

The results plotted in Figures 24 and 25 indicate that the two- and three-window spectrum analysis algorithms will generally provide better sensitivity for airborne ${ }^{239} \mathrm{Pu}$ than the four-window algorithm for the Merlin Gerin CAM when equipped with either the 0.8 or $2.0 \mu \mathrm{m}$ pore-size filter. They also indicate that the $0.8 \mu \mathrm{m}$ filter will provide better sensitivity than the $2.0 \mu \mathrm{m}$ filter, especially at higher dust concentrations.

Because cumulative spectra were stored at 60-minute intervals during the initial samplings of ambient air performed using the ANL-W, Kurz, RADeCO, and Victoreen CAMs, while spectra collected during subsequent samplings of acrosolized blank dust were stored at 30-minute intervals, in order to provide a common basis for comparing spectral results, the coefficients $k_{1}, k_{2}$, and $k_{3}$ for selected samplings of aerosolized blank dust were also calculated using every other spectrum. The average values and standard deviations of the coefficients determined using a 60-minute counting interval are given in Table 8. Standard deviations given in Table 8 are expressed in pereent.

The results for the Merlin Gerin CAM show that using a 60-minute counting interval yielded the same average values for the coefficients determined using a 30 -minute counting interval but reduced the standard deviations of the coefficients by between $13 \%$ and $56 \%$. The standard deviations of $k_{2}$ showed the most improvement.

The values of the coefficients for the Kurz and Merlin Gerin CAMs were consistently lower than values of corresponding coefficients determined for the remaining three CAMs. This simply 
Table 8. Average values of eofficients $k_{1}, k_{2}$, and $k_{3}$ for the ANL-W, Kurı, Merlin Gerin, RADeCO, and Victoreen CAMs for selected samplings of ambient air and acrosolized blank dust $(\Delta T=6() \mathrm{min})$.

\begin{tabular}{|c|c|c|c|c|c|}
\hline & Sampling & Average dust & $\begin{array}{l}\text { liwo-window } \\
\text { algorithm }\end{array}$ & $\begin{array}{l}\text { Ihree-window } \\
\text { algorilhm }\end{array}$ & $\begin{array}{l}\text { Iour-window } \\
\text { algorithm }\end{array}$ \\
\hline$C \triangle M$ & $(\mathrm{~m} / \mathrm{d} / \mathrm{y})$ & $(\mu \mathrm{g} / 1)$ & $(\%)$ & $(\%)$ & $(\%)$ \\
\hline \multicolumn{6}{|c|}{ Ambicnt Air } \\
\hline ANI -W & $12 / 15-20,80$ & $2.4 .3 \pm(0.49) 1:-0.3$ & $2.821:-01 \pm 9.6$ & $4.801:-(1) \pm 7.5$ & $1.981:-01 \pm 9.1$ \\
\hline ANI.W & $12 / 20-27 / 80$ & $6.74 \pm 0.4010 .40 .3$ & $3.031 \vdots-01 \pm 7.6$ & $4.801:-01 \pm 0.2$ & $2.101:-01 \pm 8.1$ \\
\hline Kurz. & $12 / 15-20 / 89$ & $2.4 .3 \pm 0.491:-0.3$ & $3.68 \mathrm{E}:-() 2 \pm 22.0$ & $3.531 \div-(01 \pm 14.7$ & $8.421: .(12 \pm 18.1$ \\
\hline MCierin & $07 /(03-1) 8 / 9) 1$ & $4.31 \pm 0.481:-0.3$ & 4.40 I:-(1)2 \pm 26.8 & $3.44 \mid \therefore-(0) \pm 20.7$ & 9.50 1:-(1).3 \pm 0.8 .4 \\
\hline RADe(C) & $06 / 12-14 / 90$ & $7.56 \pm 3.781 i-0.3$ & $3.571 \vdots-01 \pm 9.2$ & $0.77 \mid:-01 \pm 4.9$ & $1.71 \mid 1.01 \pm 12.9$ \\
\hline Victoreen & $12 / 20-27 / 89)$ & $0.74 \pm 0.401:-0.3$ & $3.6(0) 1:-0) ! \pm 0.7$ & $(1081:-01 \pm 3.9$ & $2.741-(1) \pm 4.7$ \\
\hline \multicolumn{6}{|c|}{ Blank Dust } \\
\hline Kurs & $(60 / 19-2(1) 90)$ & $2.4 x \pm 0.10[--0)\}$ & $3 .(4) \mid:-(12 \pm 22.6$ & $4.371 . .01 \pm 22.9$ & $1.32 \mid \vdots-(1) \pm 29.6$ \\
\hline Mejern! & $017 /(1) 1-(12 / 0)$ & $4.55 \pm 0.511:-01$ & $3.11 \mid i-01 \pm 26.1$ & $7.77 \mid \therefore-(01 \pm \mid 8.01$ & $1.441:-(1) 1 \pm 38.9$ \\
\hline $\mathrm{RADe}\left({ }^{\circ}\right)$ & $(06 / 10-20 / \%)$ & $2.4 x \pm 0.1011 . .01$ & $5.941:-(01 \pm 9.3$ & $8.241 . .011 \pm 4.0$ & $2.4 .51:-(11 \pm 27.4$ \\
\hline Victoreen & $(0,19-20,00)$ & $2.4 x \pm 0.10[i-01$ & $8.421 \vdots-01 \pm 9.1$ & $8.781 . .01 \pm 4.0$ & $3.9410 .01 \pm 24.4$ \\
\hline
\end{tabular}

reflects the fict that the resolutions of the Kure and Merlin Gerin CAMs were much betler than the resolutions of the other three CAMs. However, the standard deviations of the coefficients determined for the Kure and Merlin Gerin CAM were also typically much higher than the standard deviations of eorresponding coeflicients determined for the other CAMs. As shown in Table 8 , in the case of the samplings of ambient air, all three coefficients determined for the ANL-W, RADCCO, and Victoreen CAMs were remarkably stable during the samplings. Their standard deviations ranged berween $\pm 4 \%$ and $\pm 1.3 \%$ and were normally below $\pm 10 \%$. Similar results lor the Kurz and Merlin Gerin CAMs lior samplings of ambient air ranged between $\pm 15 \%$ and $\pm 68 \%$. In all casces, all threc coefficients increased when airborne dust concentrations were artificially elevated, but generally the relative standard deviations remained unchanged.

Because the three coefficients used for subtracting batkground from the ${ }^{239} \mathrm{Pu}$ ROI change as a function of sampling time and are also affecled hy changes in airborne dust concentration, it would be useful to be able to predict their current values during sampling based on a measurement of some characteristic of the background peaks. Since the magnitude of each coefficient reflects the degree of scattering of higher energy alpha particles to lower energy, the values of the coeflicients should be correlated to the widths of the background alpha peaks. To explore this possibility, the values of the three coelficients during three samplings performed using the Merlin Gerin CAM were pletted as a function of the FWHM and FWTM of the $7.69 \mathrm{MeV}{ }^{214} \mathrm{P}_{0}$ alpha peak. Values of the coefficient $k_{1}$ are plotted versus FWHM and FWTM in Figures 26 and 27. respectively. Values of $k_{2}$ 


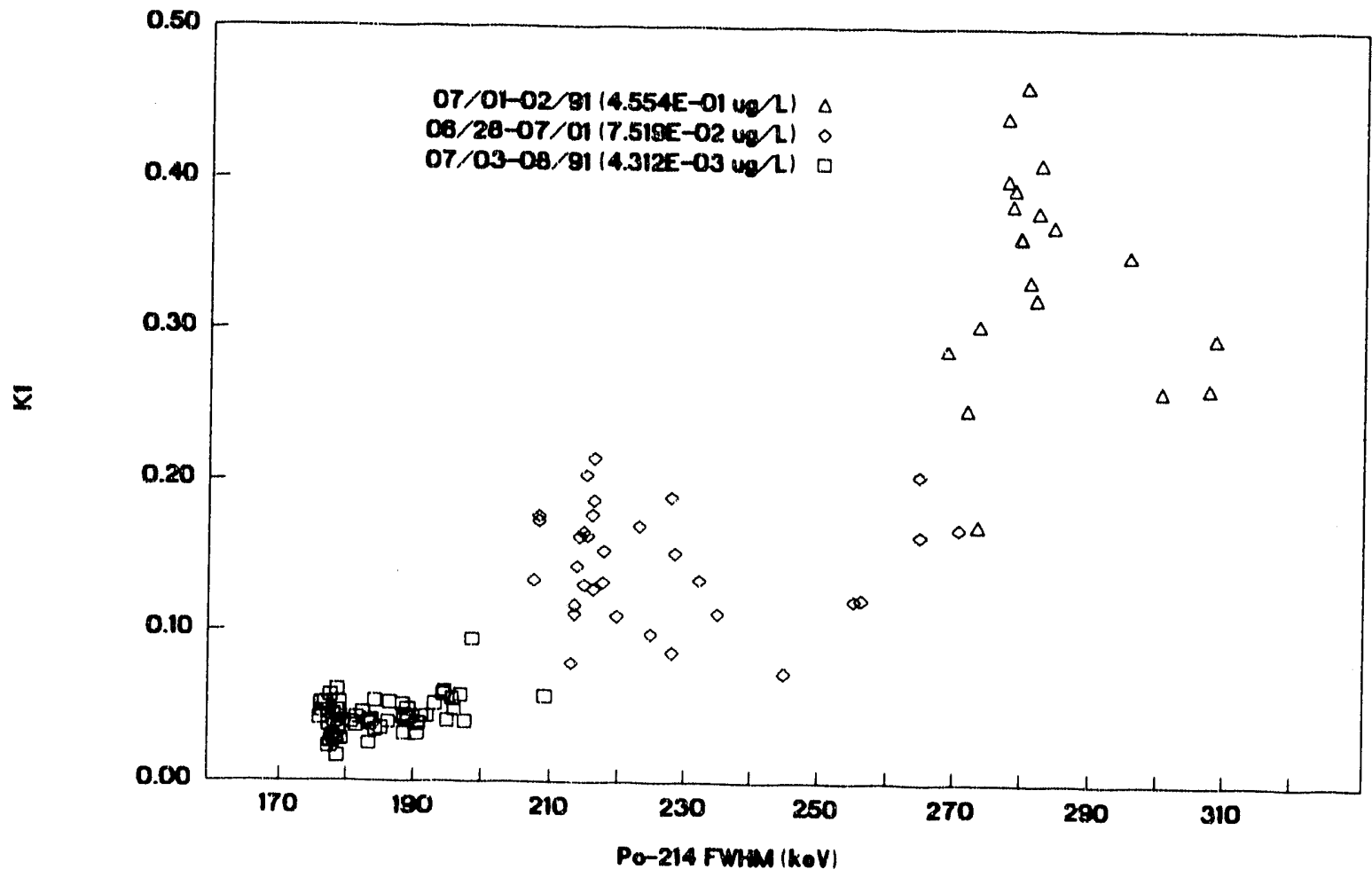

Figure 26. $\mathrm{k}_{1}$ values versus the FWHM of the ${ }^{214} \mathrm{Po}$ alpha peak for three samplings performed using the Merlin Gerin CAM.

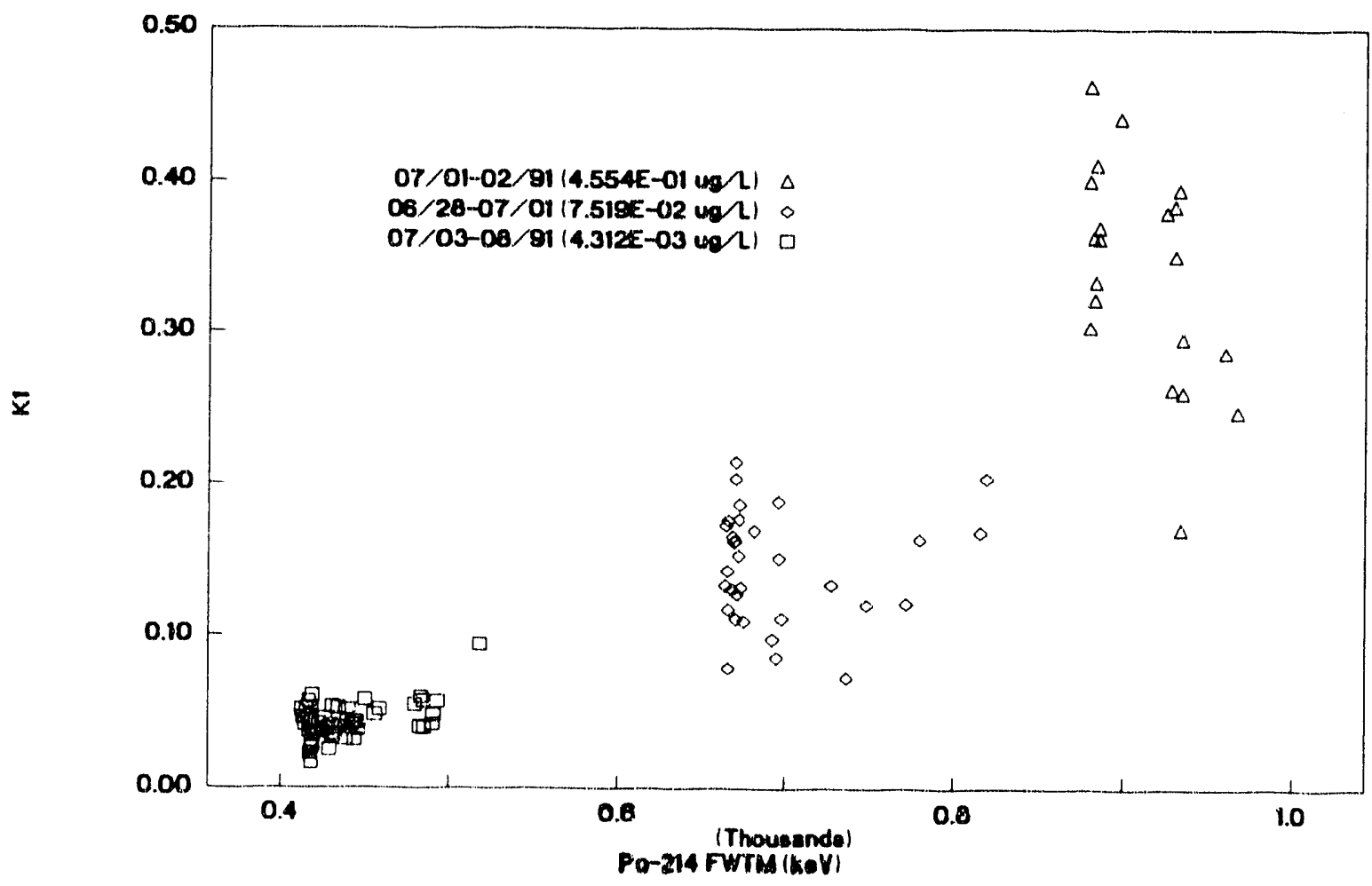

Figure 27. $\mathrm{k}_{1}$ values versus the FWTM of the ${ }^{214} \mathrm{Po}$ ) alpha peak for three samplings performed using the Merlin Gerin CAM. 
and $\mathrm{k}_{3}$ are plotted against the FWHM and FWTM of the $7.69 \mathrm{MeV}$ alpha peak in Figures 28 and 29 and Figures 30) and 31, respectively.

Although the data plotted in Figures 26 through 31 exhibit a substantial amount of scatter, they do indicate that the average value of each coefficient increases as the $7.69 \mathrm{MeV}$ peak broadens. These results suggest that if the FWHM and FWTM of the $7.69 \mathrm{McV}$ alpha peak were frequently measured and the values stored during sampling, their average values during some predefined preceeding time interval could be used to estimate the current values of the coefficients. Results presented in Table 8 show that the coefficients determined for the Merlin Gerin CAM exhibited much more seatter than the coefficients determined for the ANL-W, RADeCO, and Victoreen CAMs. Plots like those shown in Figures 26 through 31 should be constructed using similar data for the latter three CAMs to determine if this approach to estimating the values of the coefficients has real merit.

\section{Lower Limit of Detection}

The cumulative spectra collected during each sampling were analyzed using the two-, three-, and four-window analysis algorithms previously described to determine, among other things, the LLD concentration for airborne ${ }^{239} \mathrm{Pu}$. The LLD concentration during any given counting interval was calculated at the $95 \%$ confidence level using Equation (5) and the experimentally determined values for counting efficiency and activity collection efficiency presented previously. Because the activity collection efficiency of the Merlin Gerin CAM was not measured during this study, for the purpose of calculation, the activity collection efficiency of the Merlin Gerin CAM was assumed to be $100 \%$. Given the fact that the activity collection efficiencies of the RADeCO and Victoreen CAMs when equipped with filters similar to those used with the Merlin Gerin CAM were both $97 \%$ or better, the assumption of $100 \%$ activity collection efficiency for the Merlin Gerin CAM is reasonable.

In the case of the Merlin Gerin CAM, LLDs were normally calculated using a 30)-minute counting interval. Only the spectra collected during one sampling of ambient air and one sampling of acrosolized blank dust were also analyzed using a 60-minute counting interval. When the shorter counting interval was used. LLDs were calculated using the coefficients listed in Table 7 and spectral data for consecutive spectra, and when the longer counting interval was used, LLDs were calcualted using the eoeficients listed in Table 8 and spectral data for every other spectrum. Spectrum analysis results for the Merlin Gerin CAM for samplings of ambient air, acrosolized blank dust, and acrosolized spiked dust, that were calculated based on a 30 -minute counting interval, are presented in Tables $\mathrm{C}-1$ through $\mathrm{C}-22$ in Appendix C. Similar results for the two samplings of ambient air and acrosolized blank dust that were calculated using a 60 -minute counting interval are presented in Tables C-2.3 and C-24, respectively, in Appendix C.

LLDs for the ANL-W, Kurz. RADeCO, and Victoreen CAMs were previously reported in Referenee 3. However, the LLDs given in Reference 3 were calculated using the standard deviation of the mean of each coefficient $k_{1}, k_{2}$, and $k_{3}$, rather than the standard deviation. For any given set of data, the standard deviation of the mean is calculated by dividing the standard deviation of the data by the square root of the number of data points in the set. Because the number of values calculated for each coefficient for cach sampling was normally quite large, estimating the uncertainty in each coefficient using the standard deviation of the mean was probably unrealistic. Therefore, LLDs for the ANL-W, Kurz. RADeCO, and Victoreen CAMs were recalculated using the coefficients and 


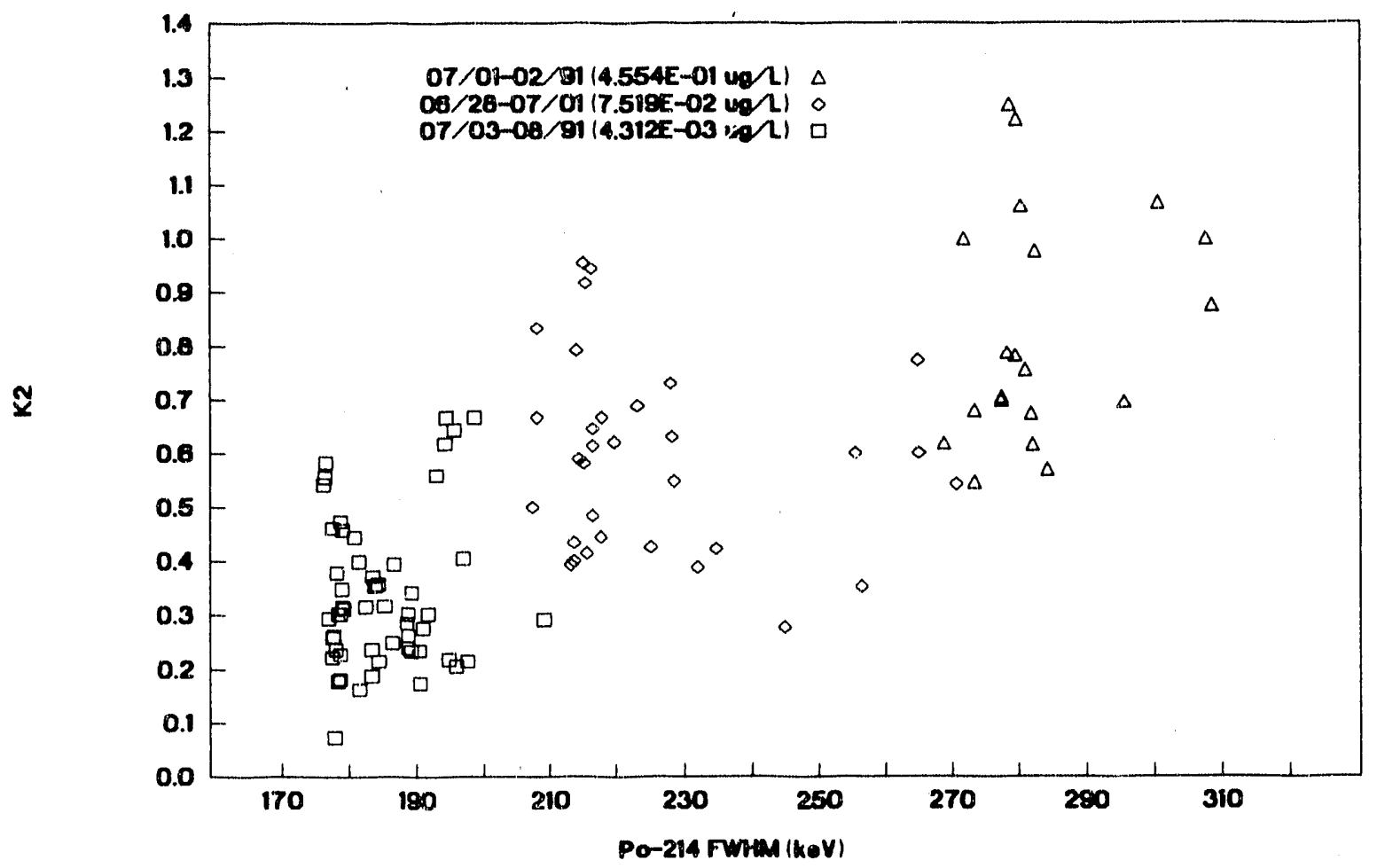

Figure 28. $k_{2}$ values versus the FWHM of the ${ }^{214} \mathrm{Po}$ alpha peak for three samplings performed using the Merlin Gerin CAM.

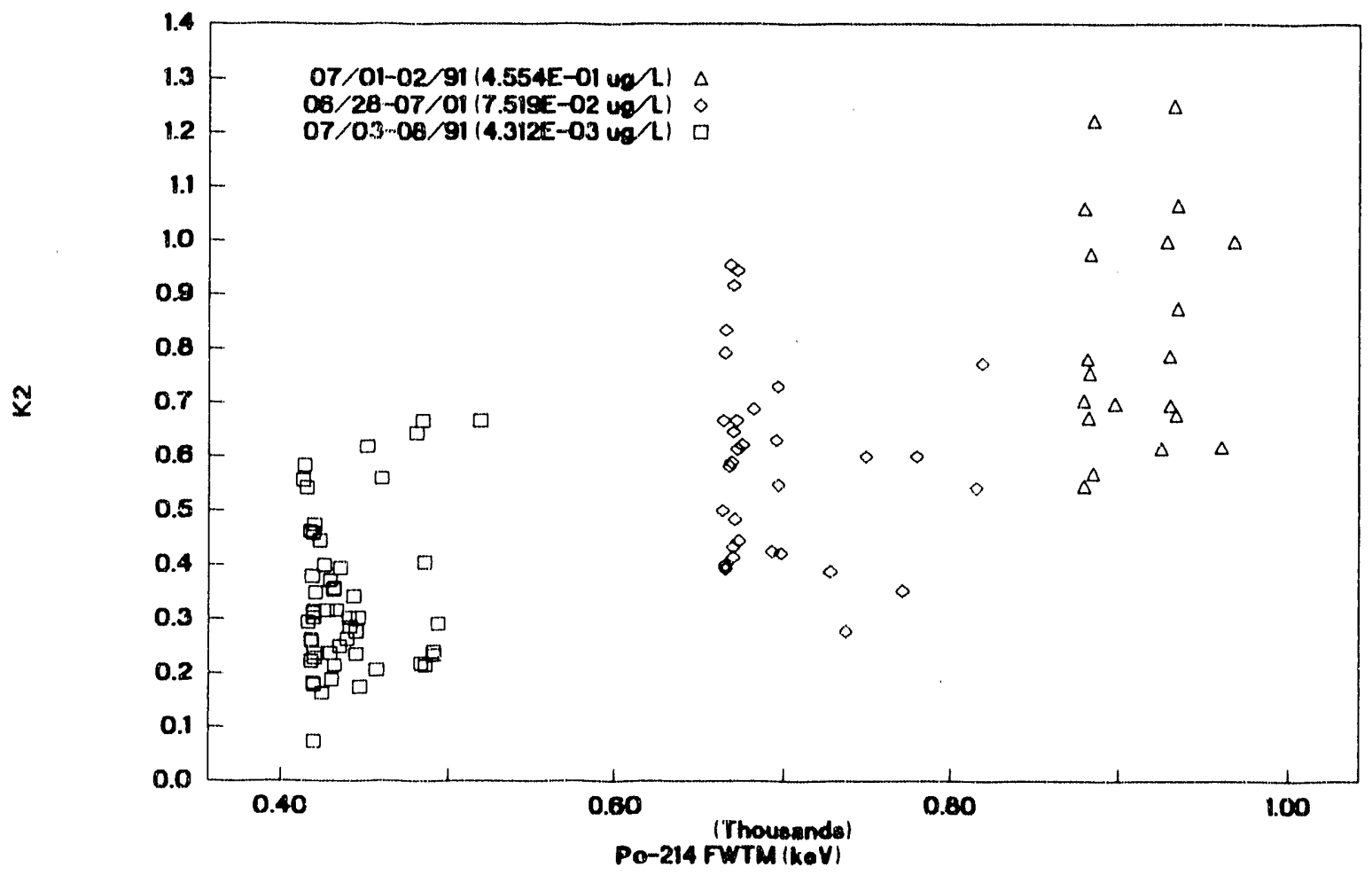

Figure 29. $k_{2}$ values versus the FWTM of the ${ }^{214}$ Po alpha peak for three samplings performed using the Merlin Gerin CAM. 


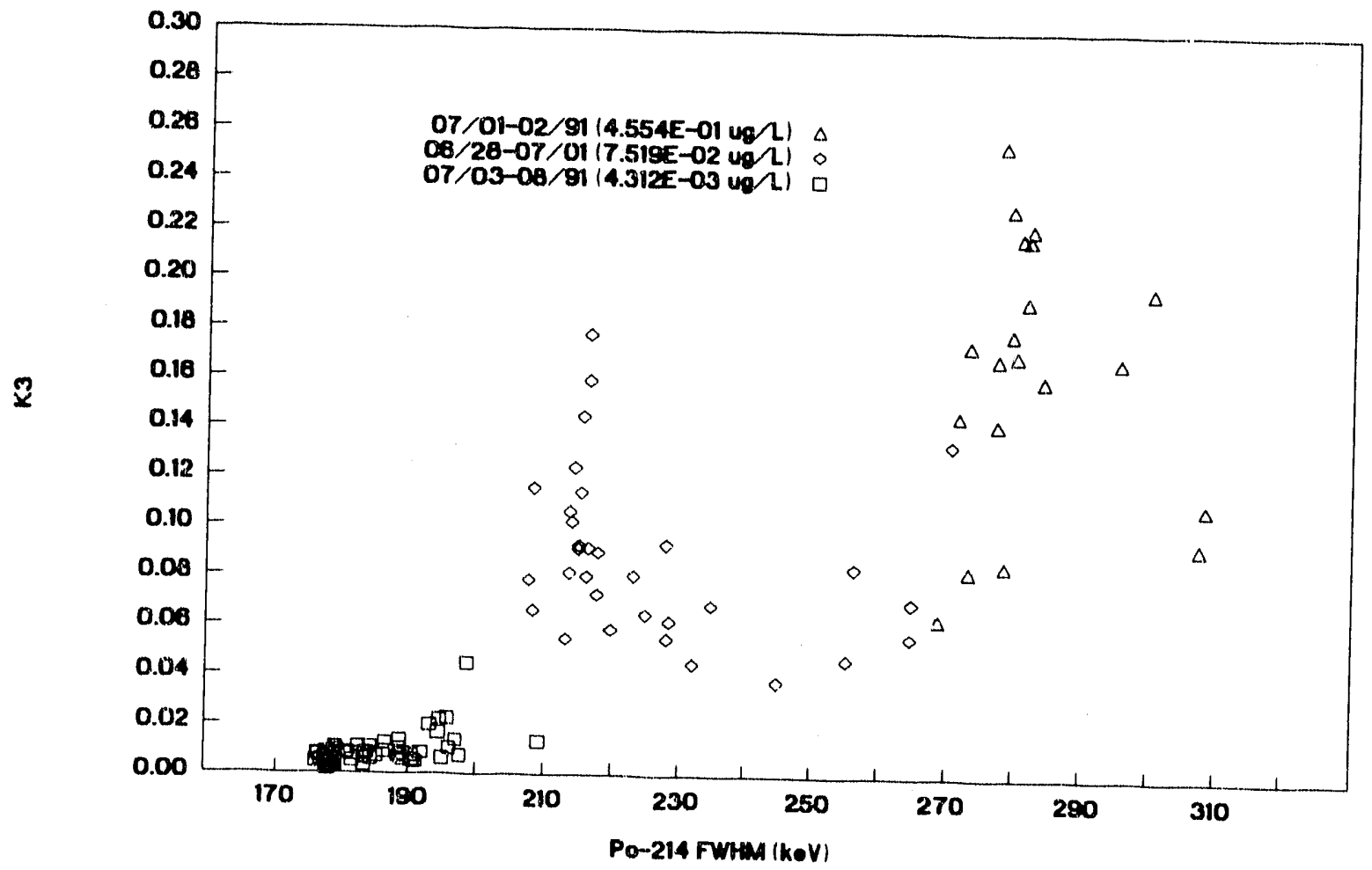

Figure 30. $k_{3}$ values versus the FWHM of the ${ }^{214} \mathrm{Po}$ alpha peak for three samplings performed using the Merlin Gerin CAM.

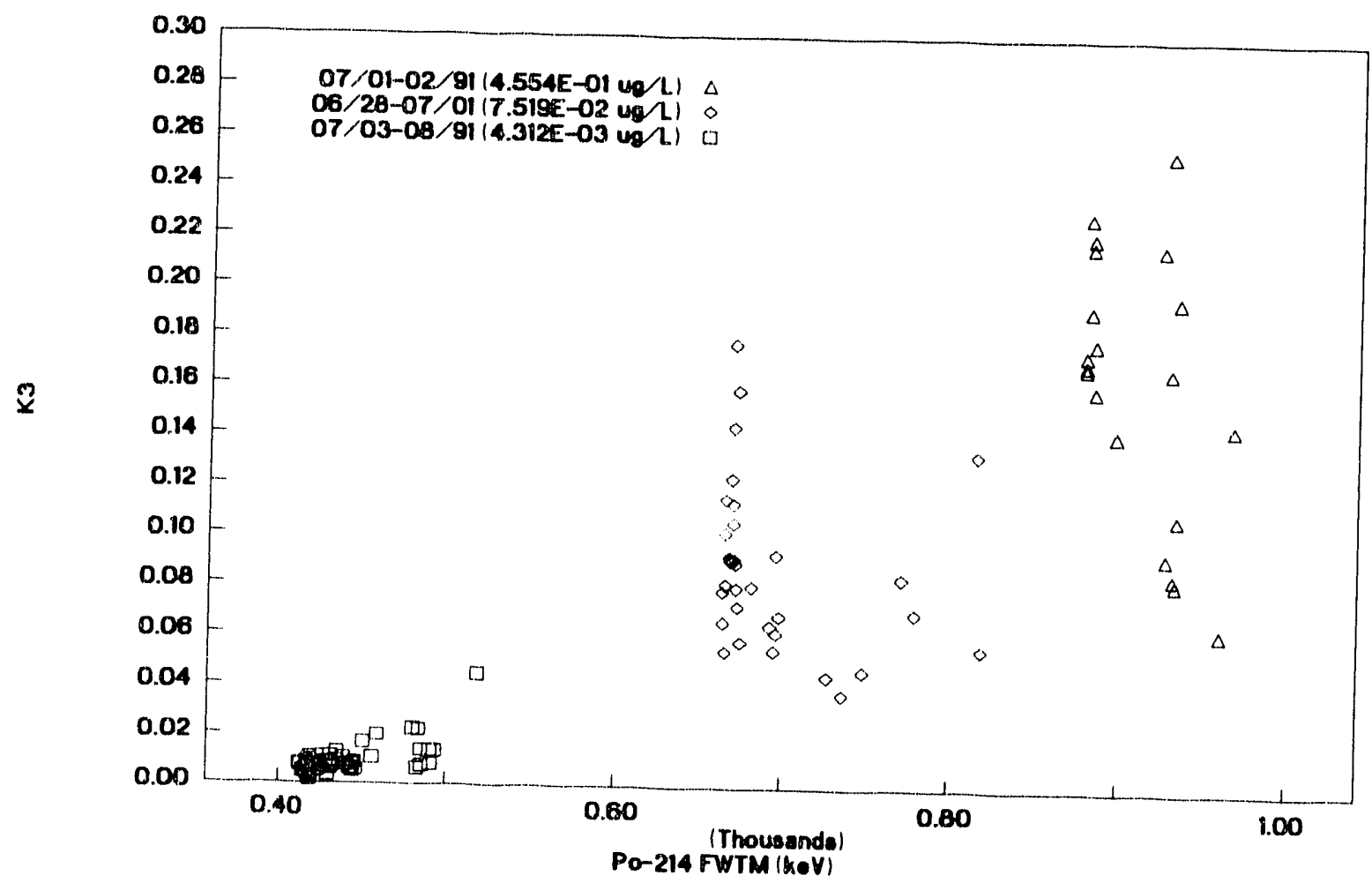

Figure 31. $k_{3}$ values versus the FWTM of the ${ }^{214} \mathrm{Po}$ alpha peak for three samplings performed using the Merlin Gerin CAM. 
standard deviations given in Table 8. In the case of these four CAMs, LLDs were recalculated using only a 6()-minute counting interval. Spectrum analysis results for samplings of ambient air and acrosolized blank dust performed using the four previously mentioned CAMs are presented in Tables C-25 through C-32 in Appendix C.

The average ${ }^{239} \mathrm{Pu}$ LLD concentrations during the first 24 hours of each sampling performed using the Merlin Gerin CAM are presented in Table 9 expressed as $\mathrm{pCi} / \mathrm{L}$. For cach sampling, LLDs are given for each of the three spectrum analysis algorithms. The average airborne dust concentration during each sampling is also listed in Table 9.

Table 9. Average ${ }^{239} \mathrm{Pu}$ LL,D concentration during samplings of ambient air and acrosloized blank dust performed using the Merlin Gerin CAM.

\begin{tabular}{|c|c|c|c|c|}
\hline $\begin{array}{l}\text { Sampling dates } \\
(\mathrm{m} / \mathrm{d} / \mathrm{y})\end{array}$ & $\begin{array}{c}\text { Average dust } \\
\text { concentration } \\
(\mu \mathrm{g} / 1)\end{array}$ & $\begin{array}{l}\text { Two-window } \\
\text { algorithm } \\
(\mathrm{pCi} / \mathrm{L})\end{array}$ & $\begin{array}{c}\text { Threc-window } \\
\text { algorithm } \\
(\mathrm{pCi} / \mathrm{L})\end{array}$ & $\begin{array}{c}\text { Four-window } \\
\text { algorithm } \\
(\mathrm{pCi} / \mathrm{L})\end{array}$ \\
\hline \multicolumn{5}{|l|}{$0.8 \mu \mathrm{m}$ filter } \\
\hline $07 / 0.3-08 / 91$ & $4.31 \pm 0.48 \mathrm{E}-03$ & $2.86 \pm 1.02 \mathrm{E}-02$ & $3.16 \pm 1.09 \mathrm{E}-02$ & $3.75 \pm 1.66 \mathrm{E}-02$ \\
\hline $07 /(02-() 3 / 91$ & $8.47 \pm 0.95 \mathrm{E}-(03$ & $2.70 \pm 0.63 \mathrm{E}-02$ & $2.68 \pm 0.69 \mathrm{E}-(1)$ & $2.73 \pm 0.91 \mathrm{E}-(02$ \\
\hline $06 / 24-26 / 91$ & $1.23 \pm 0.14 \mathrm{E}-02$ & $2.79 \pm 0.65 \mathrm{E}-02$ & $2.72 \pm 0.76 \mathrm{E}-02$ & $2.97 \pm 0.89 \mathrm{E}-02$ \\
\hline $06 / 14-18 / 91^{a}$ & $1.74 \pm 0.19 \mathrm{E}-02$ & $1.29 \pm 0.38 \mathrm{E}-() 2$ & $3.95 \pm 1.71 \mathrm{E}-02$ & $4.57 \pm 2.22 \mathrm{E}-02$ \\
\hline (1) $6 / 18-21 / 91$ & $2.39 \pm 0.27 \mathrm{E}-02$ & $4.15 \pm 1.91 \mathrm{E}-(02$ & $3.24 \pm 1.24 \mathrm{E}-(02$ & $4.74 \pm 2.08 \mathrm{E}-(02$ \\
\hline $06 / 28-07 / 01 / 91$ & $7.52 \pm 0.84 \mathrm{E}-(02$ & $4.55 \pm 1.26 \mathrm{E}-02$ & $4.50 \pm 1.14 \mathrm{E}-(02$ & $6.58 \pm 2.21 \mathrm{E}-02$ \\
\hline $07 / 08-09 / 91$ & $2.11 \pm 0.24 \mathrm{E}-01$ & $1.74 \pm 0.27 \mathrm{E}-(01$ & $5.59 \pm 1.30 \mathrm{E}-(12$ & $8.58 \pm 3.98$ E- 02 \\
\hline$(07 / 01-(12 / 91$ & $4.55 \pm 0.51 \mathrm{E} .01$ & $9.38 \pm 1.64$ E-(02 & $7.50 \pm 2.00 \mathrm{E}-02$ & $1.07 \pm 0.37 \mathrm{E}-01$ \\
\hline $06 / 26-27 / 91$ & $9.08 \pm 1.02 \mathrm{E}-01$ & $1.82 \pm 0.54 \mathrm{E}-01$ & $7.74 \pm 1.50 \mathrm{E}-() 2$ & $1.09 \pm 0.41 \mathrm{E}-(01$ \\
\hline \multicolumn{5}{|l|}{$2.0 \mu \mathrm{m}$ filter } \\
\hline $06 / 07-10 / 91$ & $8.19 \pm 0.92 \mathrm{E}-(03$ & $3.41 \pm 2.23 \mathrm{E}-02$ & $2.08 \pm 1.04 \mathrm{E}-(02$ & $2.08 \pm 1.22 \mathrm{E}-02$ \\
\hline $06 / 04-06 / 91$ & $9.58 \pm 1.07$ E- 0.3 & $1.53 \pm 0.29 \mathrm{E}-02$ & $1.93 \pm 0.54 \mathrm{E}_{-}(12$ & $2.41 \pm 1.03 \mathrm{E}-(02$ \\
\hline $06 / 11-14 / 91$ & $3.25 \pm 0.36 \mathrm{E}-(02$ & $6.42 \pm 2.24 \mathrm{E}-(02$ & $5.07 \pm 1.66 \mathrm{E}-(02$ & $5.31 \pm 1.66 \mathrm{E}-(1) 2$ \\
\hline $07 / 17-18 / 91$ & $5.02 \pm 0.56 \mathrm{E}-(02$ & $2.25 \pm 0.84 \mathrm{E}-(02$ & $2.02 \pm 0.87 \mathrm{E}-(12$ & $3.71 \pm 3.66 \mathrm{E}-(02$ \\
\hline$(07 / 10-11 / 91$ & $1.02 \pm 0.11 \mathrm{E}-01$ & $3.19 \pm 1.42 \mathrm{E}-(02$ & $2.9(0) \pm 1.23 \mathrm{E}-(1) 2$ & $6.14 \pm 3.94 \mathrm{E}-(12$ \\
\hline $07 / 15-16 / 91$ & $2.29 \pm 0.26 \mathrm{E}-(01$ & $1.11 \pm 0.29 \mathrm{E}-01$ & $5.87 \pm 2.17 \mathrm{E}-(02$ & $2.53 \pm 0.99 \mathrm{E}-01$ \\
\hline $07 / 09-10 / 91$ & $8.41 \pm 0.94 \mathrm{E}-(01$ & $1.27 \pm 0.32 \mathrm{E}-01$ & $6.10 \pm 1.20 \mathrm{E}-() 2$ & $1.49 \pm 0.88$ E-01 \\
\hline
\end{tabular}


Each LLD given in Table 9 represents the concentration of ${ }^{239} \mathrm{Pu}$ that the Merlin Gerin CAM can detect $95 \%$ of the time after sampling for 30) minutes. The sensitivity requirement defined in DOE Order $548(0.11$ is that alpha CAMs used at DOE facilities should be able to detect $0.002 \mathrm{pCi} / \mathrm{L}$ of ${ }^{239} \mathrm{Pu}$ in 8 hours. This translates into $0.032 \mathrm{pCi} / \mathrm{L}$ for a sampling time of 30 minutes. The results presented in Table 9 show that the Merlin Gerin CAM generally met this sensitivity requirement when dust concentrations were below $0.1 \mu \mathrm{g} / \mathrm{L}$.

Average LL.D conentrations given in Table 9 for the 0.8 and $2.0 \mu \mathrm{m}$ filters are plotied as a function of average airborne dust eoneentration in Figures 32 and 33, respectively. Although the data are not all well behaved, the behavior of the collective data resembles that of the eocfficients used for background subtraction (sec Figures 21 through 23). Like the coefficients, the LLDs for both filters appear to asymptotically approach maximum values. This follows Equation (10), which dictates that when background eounts are not negligible, the LLD is proportional to the product of the coeflicient, its relative standard deviation, and the change in background counts in the ${ }^{239} \mathrm{Pu}$ ROI during the counting interval. When the rate at which acrosols are deposited on the filter becomes sulficiently high, a quasi-steady-state condition is reached due to the fact that the range of an alpha particle in solid matter is so extremely short (between 20 and $30 \mu \mathrm{m}$ ). When the deposition rate is very high, only those alpha particles emitted from atoms that decay within a relatively brief time following their collection have a chance of making it out of the acrosol layer and striking the alpha detector. Because the precursors of ${ }^{214} \mathrm{Po},{ }^{212} \mathrm{Bi}$, and ${ }^{212} \mathrm{Po}$ are relatively long lived, when airborne dust concentrations are elevated, a significant number of the alpha particles emitted from these isotopes never escape the acrescl layer. Thus, the fraction of background alpha particles that are scattered into the ${ }^{2.39} \mathrm{Pu}$ ROI does not increase indefinitely with increasing dust concentration, but rather it approaches a maximum value that is governed by the half-lives of the background isotopes and the ranges of the alpha particles they emit.

Figures 32 and 33 show that the two-, three-, and four-window spectrum analysis algorithms provided essentially the same sensitivity when airborne dust concentrations were below about $0.05 \mu \mathrm{g} / \mathrm{L}$. However, when dust concentrations were above $0.05 \mu \mathrm{g} / \mathrm{L}$, the three-window algerithm consistently yielded the lowest LLDs for both the 0.8 and $2.0 \mu \mathrm{m}$ filters. For samplings performed using the $2.0 \mu \mathrm{m}$ lilter, the data show that the four-window algorithm eonsistently provided the poorest sensitivity when dust eoneentrations were elevated. Results for samplings done using the $0.8 \mu \mathrm{m}$ filter indicate that the four-window algorithm was significantly better than the two-window algorithm in two out of four samplings performed when dust coneentrations were above $0.05 \mu \mathrm{g} / \mathrm{L}$.

Average LLDs for the ANL-W, Kurz, Merlin Gerin, RADeCO, and Victoreen CAMs calculated using a one-hour counting interval are summarized in Table 10. The LLDs are expressed as $\mathrm{pCi} / \mathrm{L}$ and are average values during the first 24 hours of each sampling of ambient air and air synthetically !aden with blank dust. In cach case, the uncertainty is the one-sigma standard deviation of the average value during the first 24 hours of sampling. The ANL-W and Kurz CAMs and the ANL-W and Victoreen CAMs were operated simultaneously in the same environment during two of the samplings of ambient air and the Kurz, RADeCO, and Victoreen CAMs sampled the same air during one sampling of acrosolized blank dust.

According to the common interpretation, the DOE sensitivity requirement that alpha CAMs should be capable of measuring one DAC (0.0()2 pCi/L) of ${ }^{239} \mathrm{Pu}$ when integrated over 8 hours (8 DAC-hours) equates to being capable of detecting $0.016 \mathrm{pCi} / \mathrm{L}$ in one hour. The results presented 


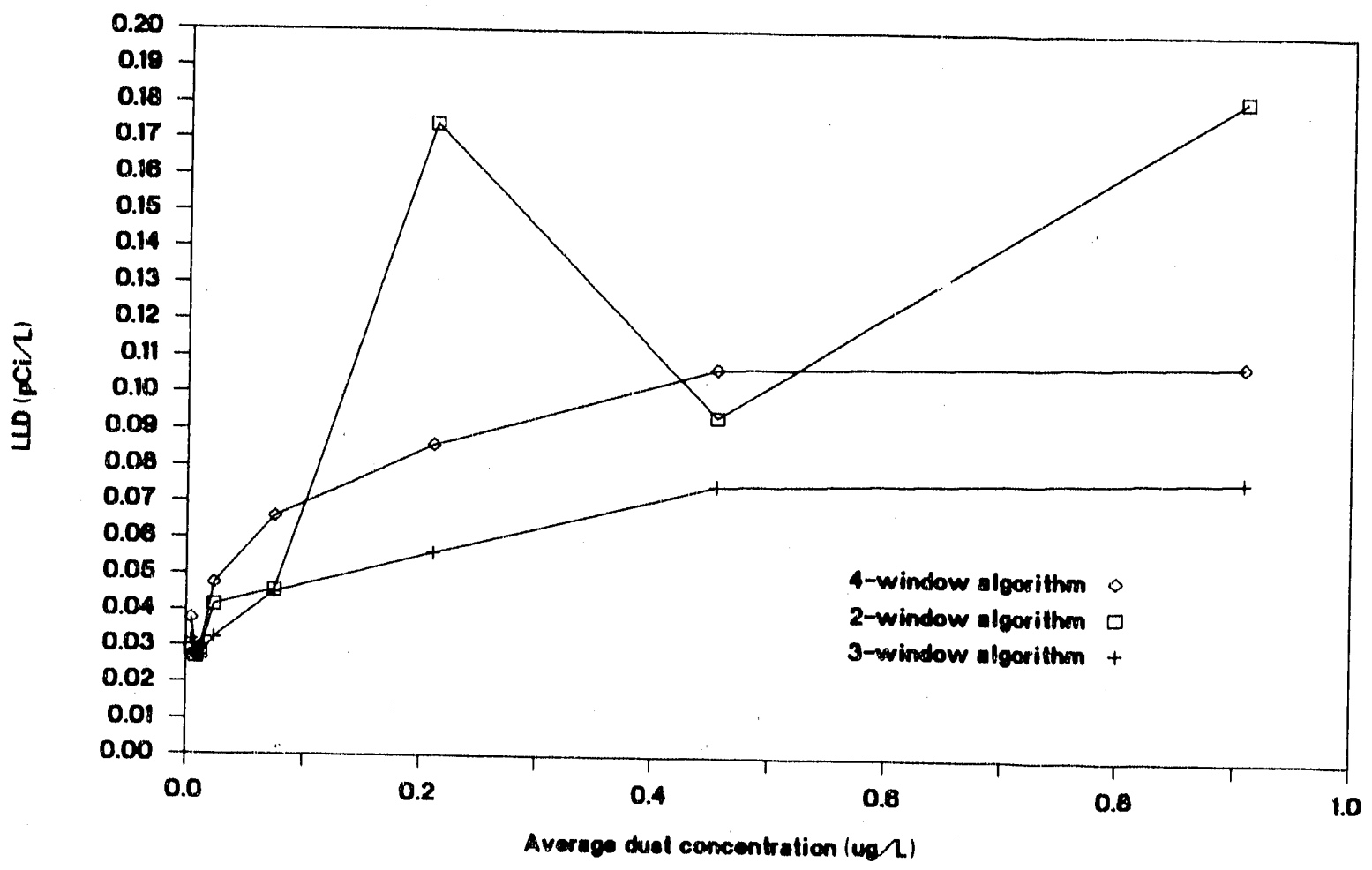

Figure 32. Average ${ }^{239} \mathrm{Pu}$ LLD concentration versus average airborne dust concentration for samplings performed using the Merlin Gerin alpha CAM equipped with a $0.8 \mu \mathrm{m}, 47-\mathrm{mm}$ diamter filter (0-24 hr).

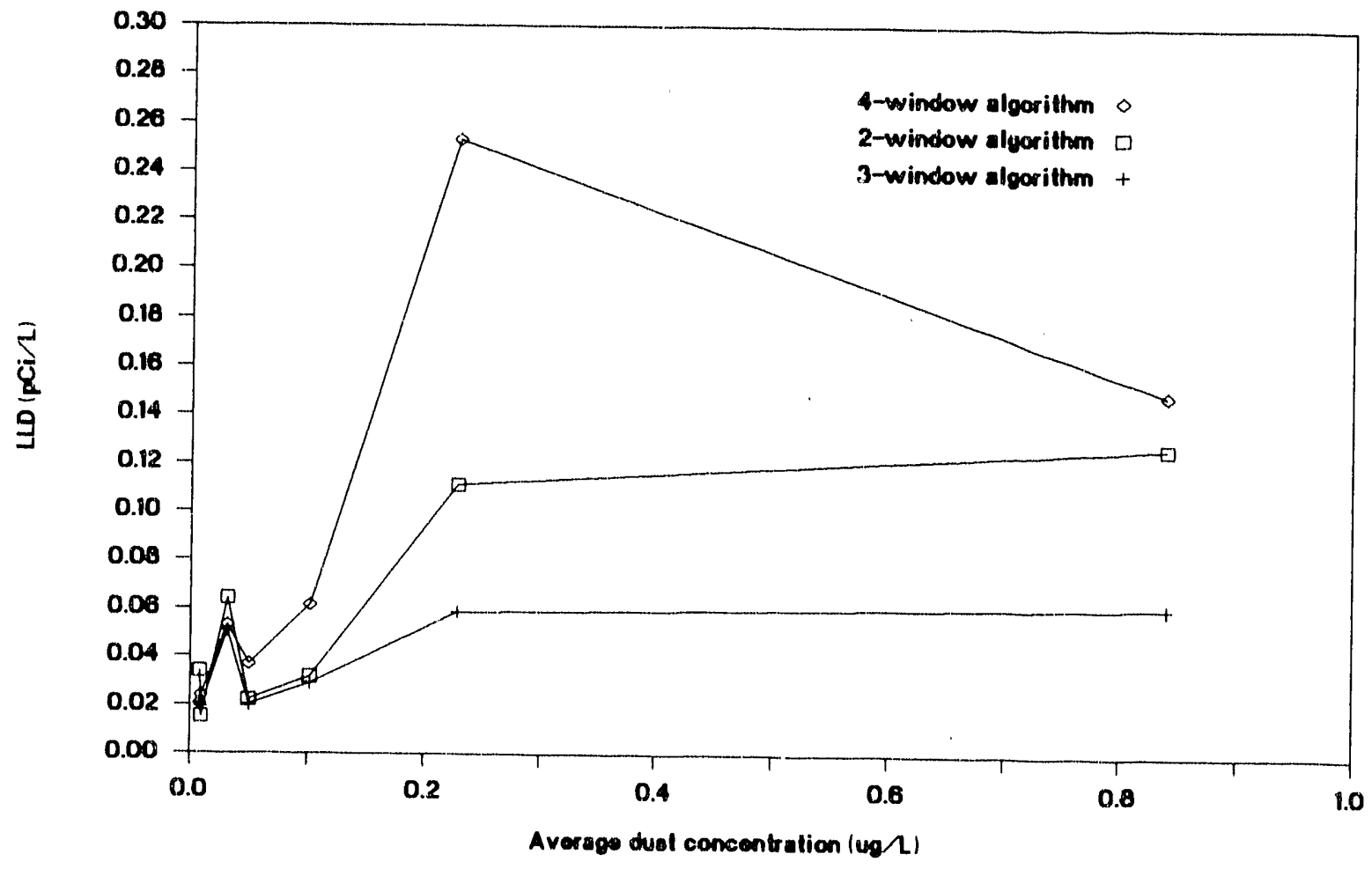

Figure 33. Average ${ }^{239} \mathrm{Pu}$ LLD concentration versus average airborne dust concentration for samplings performed using the Merlin Gerin alpha CAM equipped with a $2.0 \mu \mathrm{m}, 47-\mathrm{mm}$ diamter filter $(0-24 \mathrm{hr})$. 
Table 10. Comparison of ${ }^{239} \mathrm{Pu}$ LLD concentrations.

\begin{tabular}{|c|c|c|c|c|c|}
\hline & & Average dust & $\begin{array}{l}\text { Two-window } \\
\text { algorithm }\end{array}$ & $\begin{array}{l}\text { Threc-window } \\
\text { algorithm }\end{array}$ & $\begin{array}{l}\text { lour-window } \\
\text { algorithm }\end{array}$ \\
\hline C:AM & $\begin{array}{c}\text { Sampling } \\
\text { dalcs (m/d/y) }\end{array}$ & $\begin{array}{c}\text { concentration } \\
(\mu \mathrm{g} / \mathrm{l})\end{array}$ & $(p(\mathrm{i} / \mathrm{I})$. & $(p(i / 1)$ & $(p(\mathrm{i} / \mathrm{I})$ \\
\hline \multicolumn{6}{|c|}{ Ambient Air } \\
\hline$\Lambda N I-W$ & $12 / 1.5-20 / 89$ & $2.4 .3 \pm 0.49 \mathrm{li}-0.3$ & $5.40 \pm 0.90 \mathrm{~J} i-(14$ & $3.90 \pm 0.601 i_{-}(04$ & $4.00 \pm 0.70 \quad i_{n}(04$ \\
\hline Kur & $12 / 1.5-20 / 80$ & $2.4 .3 \pm 0.49 \quad 1:-0.3$ & $2.69 \pm 0.58 \quad 1 ;-0.3$ & $3 . .34 \pm \cdot 0.7811-0.3$ & $3.57 \pm 0.81 \quad i .-0.3$ \\
\hline MCicrin & $(07 /(0.3-08 / 9)$ & $4.31 \pm 0.481 \div-(1) 3$ & $1.21 \pm 0.421 ;-02$ & $1.1 .5 \pm 0.351 .-02$ & $1.6 .3 \pm 0.071:-0) 2$ \\
\hline$A N I . W$ & $12 / 20-27 / 80$ & $0.74 \pm 0.406:-0.3$ & $5.40 \pm 1.00) 1:-04$ & $3.90 \pm 0.7015-(04$ & $4.4(1 \pm 0.7() \mathrm{I}:-04$ \\
\hline Victoreen & $12 / 20-27 / 80$ & $0.74 \pm 0.40 \mathrm{~B}:-0.3$ & $2.21 \pm 0.451 i-(02$ & $1.20 \pm 0.2(1)-.02$ & $1.31+0.201:-(1) 2$ \\
\hline RADC(C) & $(0) / 12-14 / 90$ & $7.56 \pm .3 .781:-0.3$ & $1.69 \pm 0.441:-(12$ & $7.49 \pm 1.961:-0.3$ & $2.1 .3 \pm(1.61 \quad 1:-02$ \\
\hline \multicolumn{6}{|c|}{ Blank Dust } \\
\hline Kur\% & $00 / 19-20 / 90$ & $2.48 \pm 0.10 \mid \vdots-01$ & $1.18 \pm 0.201:-(1) .3$ & $2.61 \pm 0.471:-(1.3$ & $2.90 \pm 0.8 .5 \quad \vdots .-(0.3$ \\
\hline RADCC $(O)$ & $(06 / 19-20-90$ & $2.48 \pm 0.10[i-(0]$ & $2.92 \pm 0.391 ;-02$ & $1.07 \pm 0.171 \ldots-02$ & $6.99 \pm 1.231:-(12$ \\
\hline Victoreen & $(06-19-2(1) / 90)$ & $2.48 \pm 0.101 \vdots-(01$ & $3.90 \pm 0.53 \mathrm{~V}:-(12$ & $1.39 \pm 0.221 .-(12$ & $7.79 \pm 1.1 .3 \mathrm{l}:-0 ?$ \\
\hline MCicrin & $07 /(0)-(12 / 9) 1$ & $4.5 .5 \pm 0.511 i-(01$ & $3.99 \pm 0.64 \mathrm{l} i-(02$ & $2.45 \pm 0.56[5-(02$ & $4.70 \pm 1.111 \vdots .(1) 2$ \\
\hline
\end{tabular}

in Table 10 show that when dust concentrations were below $0.008 \mu \mathrm{g} / \mathrm{L}$, all live CAMs inct the DOE sensitivity requirement when the three window spectrum analysis algorithm was used. They also show that the Kurz, RADeCO, and Victoreen CAMs also met the sensitivity requirement when the airborne dust concentration was $0.25 \mu \mathrm{g} / \mathrm{L}$.

LLD concentrations during samplings of ambient air that were determined using the (wo)-, three-, and four-window analysis algorithms are plotted as a function of sampling time in Figures 34 , 35, and 36, respectively. For the samplings of ambient air, the ANL-W CAM exhibited by lar the best sensitivity. When airborne dust concentrations were about $0.0(12$ and $0 .(0) 7 \mu \mathrm{g} / \mathrm{L}$, LLDs for the ANL-W CAM were essentially identical for both samplings for all three analysis algorithms, the six LLDs having an average value of $0.00045 \mathrm{pCi} / \mathrm{L}$. 'The Kurz CAM exhibited the second best sensitivity for samplings performed when the dust concentration was below $0.008 \mu \mathrm{g} / \mathrm{L}$. The average values of the LLDs for the Kurz CAM determined using the three algorithms were all about $0.003 \mathrm{pCi} / \mathrm{L}$. The best average LLDs for the Merlin Gerin, RADeCO, and Victoreen CAMs were all about (0.01 pCi/L, about a factor of twenty higher than the average LLD for the ANL-W CAM. While the LLDS of the ANL-W and Kure CAMs were unaffected by the choice of analysis algerithm, the LLDs for the RADeCO and Victoreen CAMs showed some dependence on which algorithm was used for an?lysis. In the case of the latter two CAMs, the three-window algorithm yiclded average LLD. that were between factors of 2 and 3 lower than the highest LLDs for these two CAMs.

When airborne dust concentrations were artificially elevaled to values above $0.2 \mu \mathrm{g} / \mathrm{L}$, the Kure CAM exhibited a sensitivity much better than those of the RADeCO, Victoreen, or Merlin Gerin 


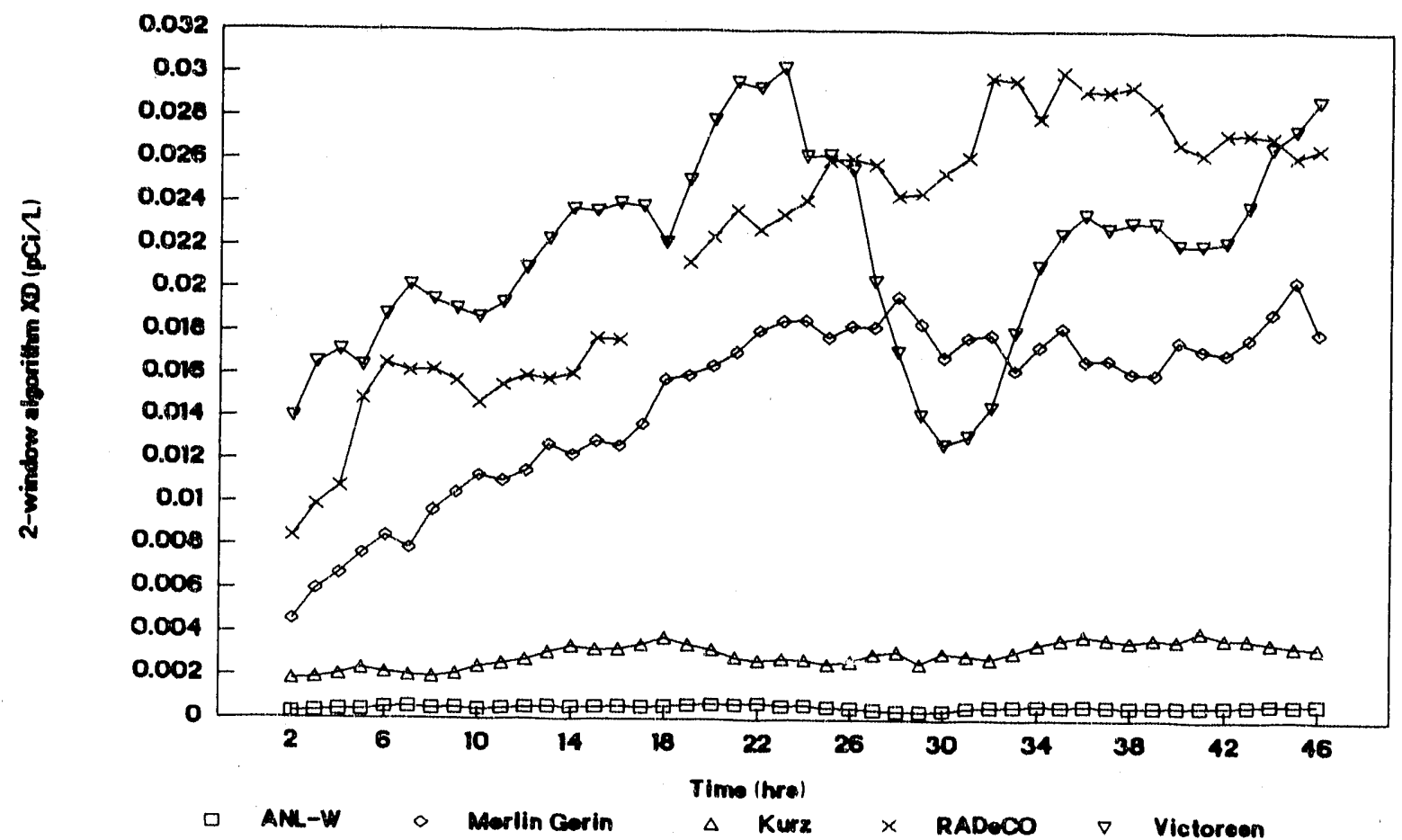

Figure 34. ${ }^{239} \mathrm{Pu}$ LLD concentration versus sampling time for the two-window algorithm for samplings of ambient air performed using the ANL-W, Kurz model 8311, Merlin Gerin Edgar, RADeCO model 452, and Victoreen model 758 alpha CAMs.

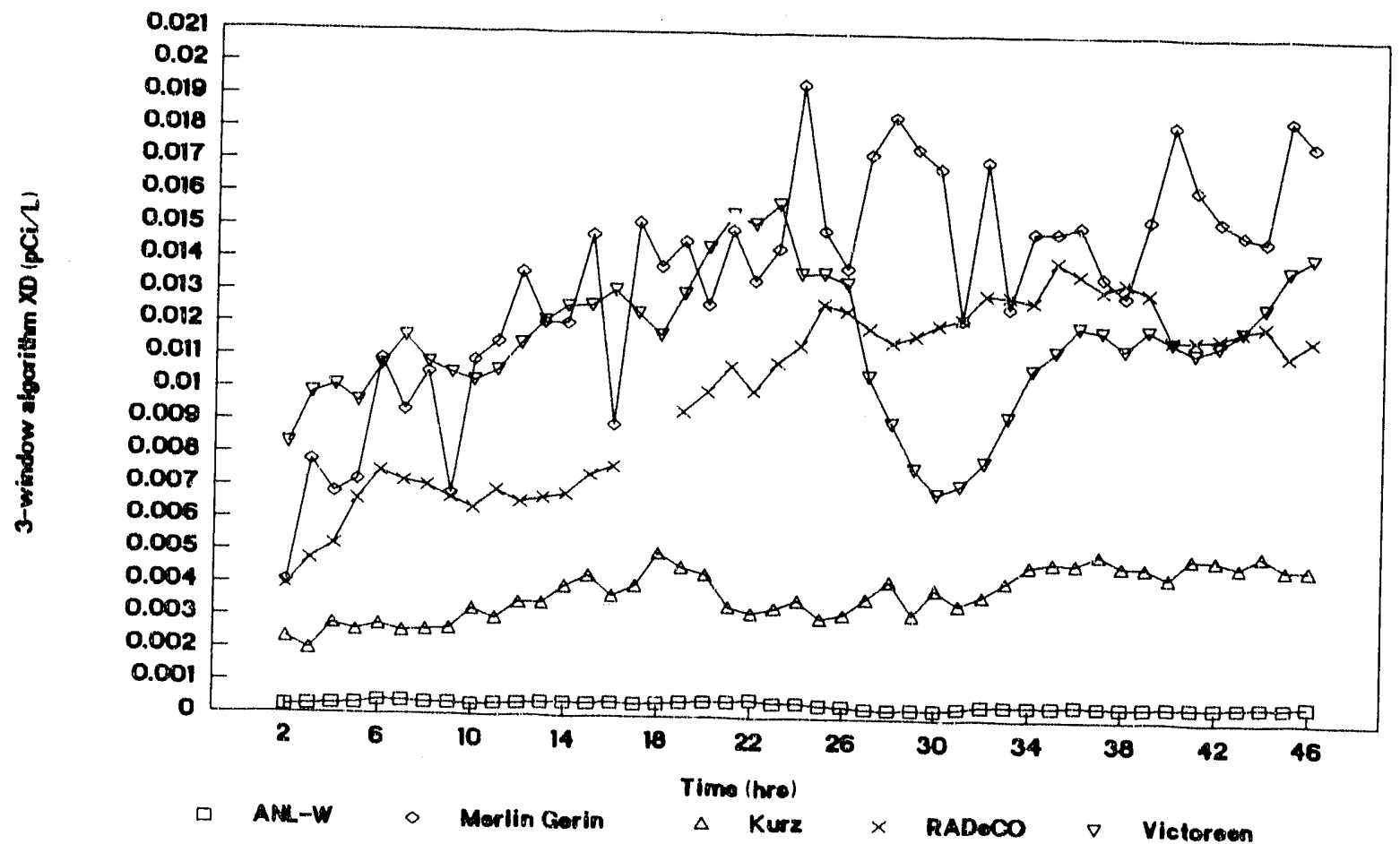

Figure 35. ${ }^{239} \mathrm{Pu}$ LLD concentration versus sampling time for the three-window algorithm for samplings of ambient air performed using the ANL-W, Kurz model 8311, Merlin Gerin Edgar, RADeCO model 452, and Victoreen model 758 alpha CAMs. 


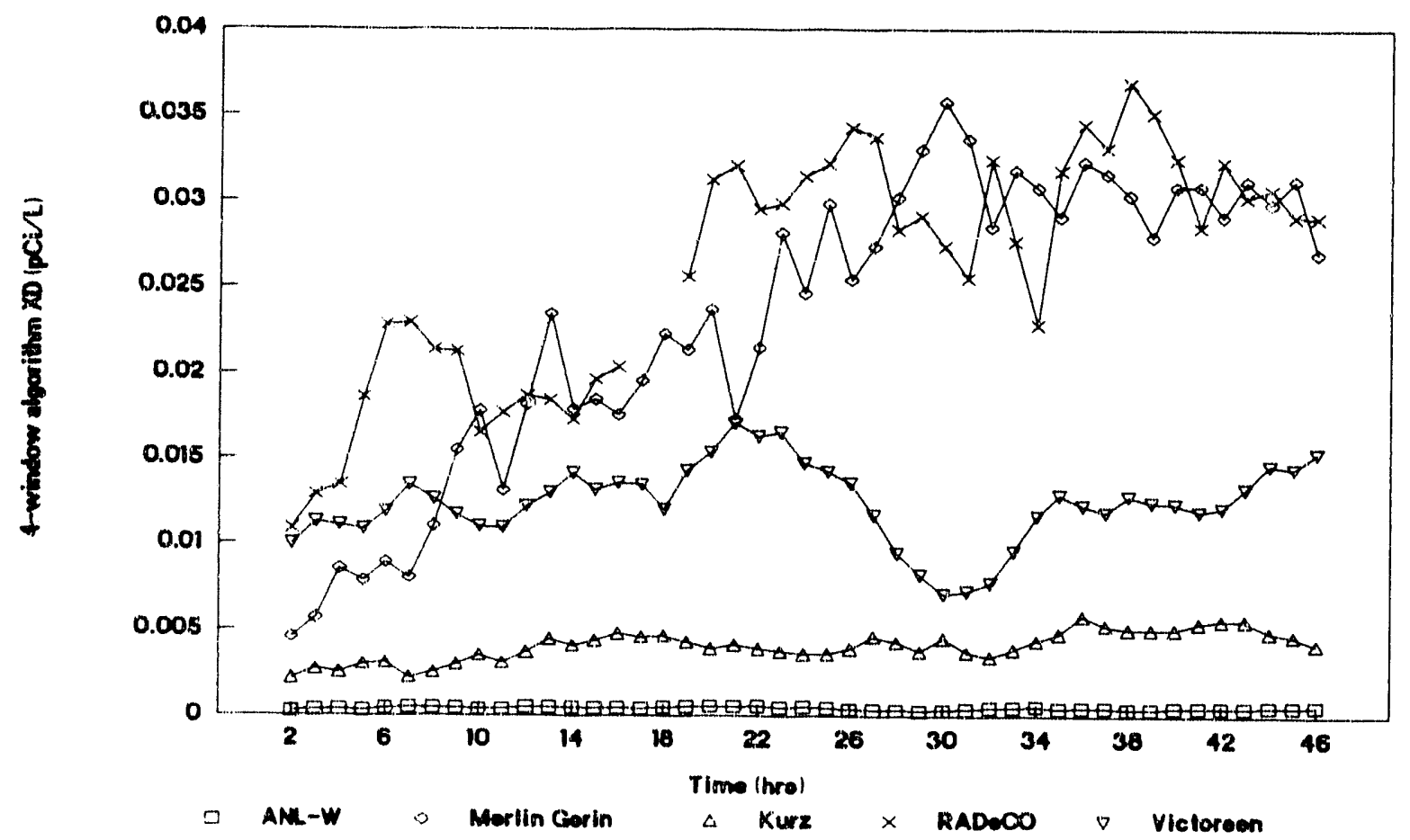

Figure 36. ${ }^{239} \mathrm{Pu}$ LL.D concentration versus sampling time for the four-window algorithm for saniplings of ambient air pertormed using the ANL-W. Kurz model 8311, Merlin Gerin Edgar. RADeCO model 452, and Victoreen model 758 alpha CAMs.

CAMs. The best average L.LD for the Kurz CAM was $0 .(0) 1 \mathrm{pCi} / \mathrm{L}$ for the $(w 0$-window analysis algorithm, which was about a factor of 10 better than the best average LLDs for the RADeCO, Victoreen, and Merlin Gerin CAMs. For the samplings of aerosolized blank dust, the three-window analysis algorithm provided the hest sensitivity for the RADeCO, Victoreen, and Merlin Gerin CAMs. The best LLDs for the latter three CAMs were $0.01,0.01$, and $0.02 \mathrm{pCi} / \mathrm{L}$, respectively.

The results show that the two CAMs equipped with inertial impactors (i.e., the ANL-W and Kurz CAMs) had L.LDs that were a factor of 10 or more below the LLDs calculated for the remaining three CAMs. LLDs for the Merlin Gerin and RADeCO CAMs, which were both equipped with collimators. were generally only slightly belter than LLDs determined for the Victoreen (AM. which was not equipped with an impactor or a collimator. In an effort to better understind why the CAMs exhibited such a wide range of sensitivities for airborne ${ }^{239} \mathrm{Pu}$, using the equality given in Equation (11), the cequation used to calculate LLDs, Equation (5), was rewritten as:

$$
\left(X_{\mathrm{J}}\right)_{\mathrm{n}}=\begin{gathered}
4.05 .3 \mathrm{O}_{\mathrm{k}} \cdot\left(\mathrm{N}_{13}\right)_{\mathrm{n}} \\
2.22 \epsilon \mathrm{Y} \frac{\mathrm{Hj} \Delta \mathrm{T} \| \mathrm{j} \Delta \mathrm{T}\}}{2}
\end{gathered}
$$

and $\left(N_{13}\right)_{n}$ and $\left(o_{\text {hed }}\right)_{n}$ were ploted as a function of sampling time for the samplings indicated in Table 10. Results for the two-window analysis algorithm for samplings of ambient air are presented in Figures 37 and 38 , where $\left(N_{13}\right)_{n}$ is plotted in Figure 37 and $\left(o_{\text {hgd }}\right)_{n}$ is pletted in Figure 38 . 


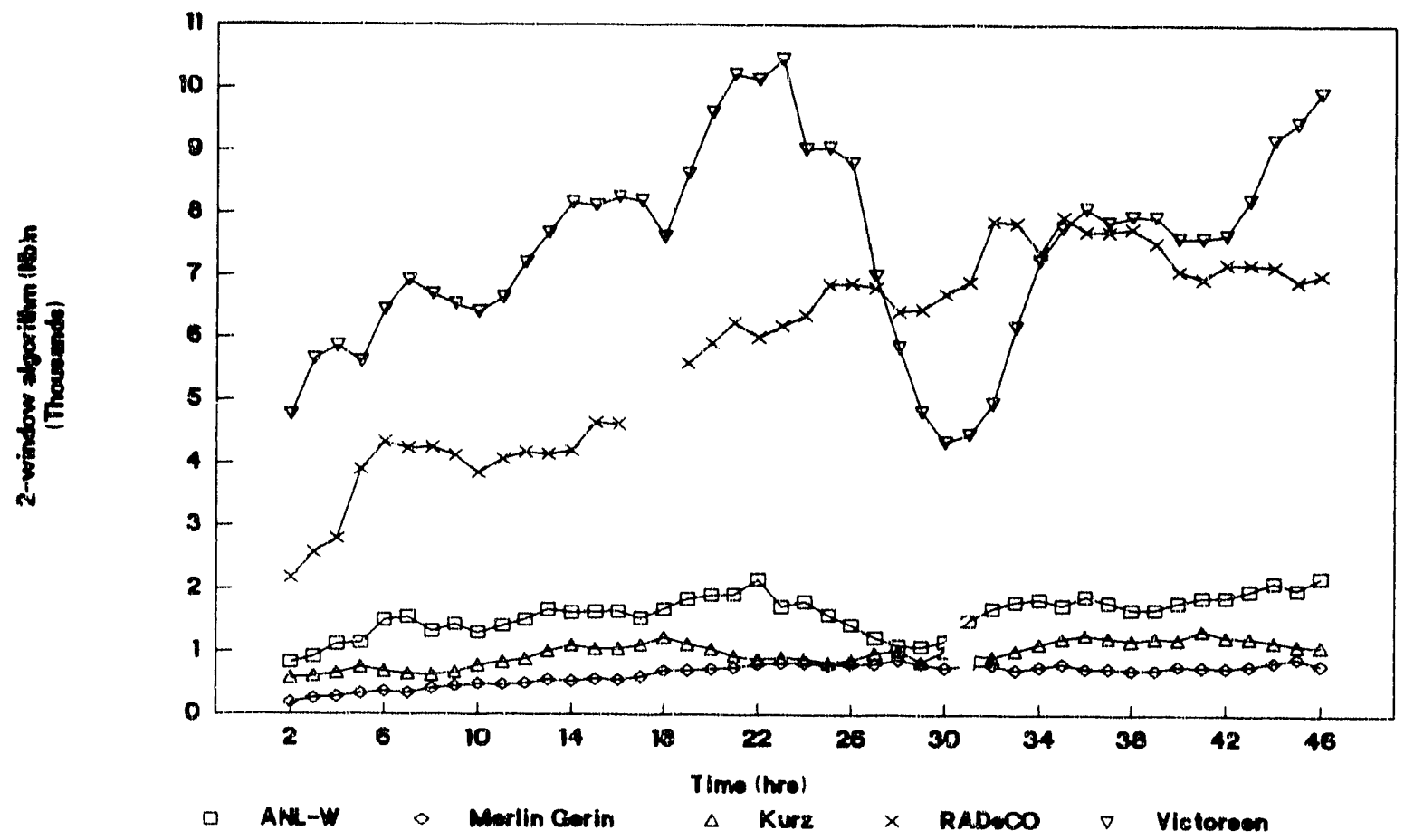

Figure 37 . Two-window algorithm $\left(\mathrm{N}_{\mathrm{B}}\right)_{\mathrm{n}}$ during samplings of ambient air performed using the ANLW, Kurz, Merlin Gerin, RADeCO, and Victoreen CAMs.

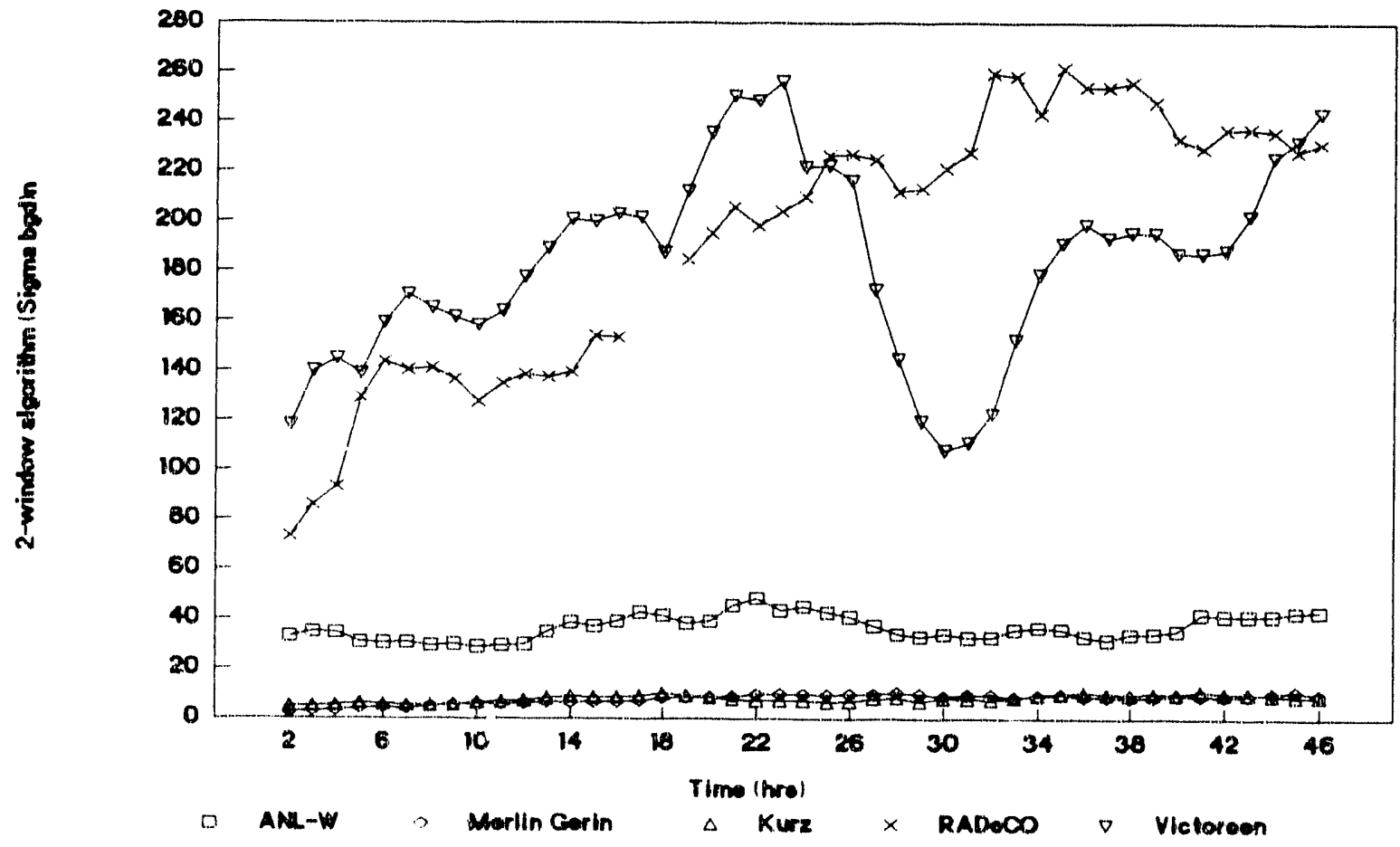

Figure 38. Two-window algorithm $\left(\sigma_{\text {hgd }}\right)_{n}$ during samplings of ambient air performed using the ANL-W, Kurz, Merlin Gerin, RADeCO, and Victoreen CAMs. 
As an aid to understanding the effect of the various operating parameters on the LLDs of the CAMs. the values of the counting efficiency $(\epsilon)$, activity collection efficiency ( $Y$ ), and flow rate (F) during the samplings of ambient air are listed in Table 11. Also given in Table 11 are the values of the product of the number of disintegrations per minute per $\mathrm{pCi}(2.22)$ and the previously mentioned parameters, which all reside in the denominator of Equation (12).

Figure 37 shows that during the first 24 hours of sampling the background count rate in the ${ }^{233)} \mathrm{Pu}$ ROI was much higher for the Vieloreen and RADCCO CAMs than for the ANL-W, KurL, and Merlin Gerin CAMs. During the tirst 24 hours, the background court rate in the ${ }^{23{ }^{4}} \mathrm{Pu}$ ROI averaged about $125 \mathrm{cpm}$ lor the Vietoreen CAM and about $70 \mathrm{cpm}$ for the RADeCO CAM. Similar values for the other three CAMs ranged between about $25 \mathrm{cpm}$ in the case of the ANL-W CAM to about $8 \mathrm{cpm}$ in the case of the Merlin Gerin CAM. The very low count rate for the Merlin Gerin CAM may be attributed, in part, to the collimator, but it also ecrtainly reflects the lact that the sampling llow rate through the Merlin Gerin CAM was only about $19 \mathrm{~L} / \mathrm{min}$. The low background count rate for the ANL-W CAM is remarkable given the fact that it sampled at $239 \mathrm{~L} / \mathrm{min}$. As was previously discussed. the two-stage virtual impactor on the ANL-W CAM removed better than 95\% of the radon daughlers entrained in the sample airstream.

Background count rates in the ${ }^{239} \mathrm{Pu}$ ROI were high enough (o) allow using the approximation given by Equation ( 11$)$. Therefore, the $\left(\sigma_{\text {hgd }}\right)_{n}$ results plotted in Figure 38 are, in each case, simply the product of the standard deviation of $k_{1}$ given in Table 8 (absolute values, not relative values) and the $\left(N_{13}\right)_{n}$ values plotled in Figure 37. The $\left(\sigma_{\text {bgd }}\right)_{n}$ values plotted in Figure 38 show that, everything clse being equal, the Kure and Merlin Gerin CAMs should have had the best sensitivities for airborne ${ }^{2314} \mathrm{Pu}$. The reasons these two CAMs did not have the best sensitivities is evident in Table 11. In the case of the Kure CAM, its poor activity collection efficiency undermined its performance. The activity collection efficiency of the Kurz CAM was about a factor sf six lower than the collection elficiencies of the other four CAMs. In the case of the Merlin Gerin CAM, the main factor that adversely affected its sensitivity was its poor counting efficiency. As shown in Table 11 , the absolute counting efficiency of the Merlin Gerin CAM for ${ }^{239}$ Pu was only about one-tenth that of the ANL-W, Kurz., and RADCCO CAMs.

Table 11. Operating parameters during samplings of ambient air.

\begin{tabular}{|c|c|c|c|c|c|c|}
\hline & Sampling & Average dust & $\begin{array}{l}\text { Counling } \\
\text { cfficiency }\end{array}$ & $\begin{array}{l}\text { Collecuon } \\
\text { cfficiency }\end{array}$ & $\begin{array}{l}\text { llow } \\
\text { ratc }\end{array}$ & $\begin{array}{c}\text { Produc: } \\
2.22 \bullet \varepsilon \bullet Y \bullet 1\end{array}$ \\
\hline$C A M$ & $\begin{array}{l}\text { dilles } \\
\text { (mody) }\end{array}$ & $\begin{array}{c}\text { concentration } \\
(\mu \mathrm{g} / 1)\end{array}$ & $\epsilon(c / d)$ & $Y$ & (I./min) & $(\mathrm{c} / \mathrm{p}(\mathrm{i}) \cdot(\mathrm{l} / \mathrm{min})$ \\
\hline$A N I \cdot W$ & $12,15 \ldots 20,80$ & $2.43 \pm 0.441:-0.3$ & 01.33 .5 & 0.97 & 239.5 & 172.8 \\
\hline Kurz. & $12 / 15-20 / 80$ & $2.4 .3 \pm(0.49) 1-(1.3$ & 0.30 .8 & 0.18 & 47.9 & 7.0 \\
\hline MCierin & $07 /(1.3-018 / 9)$ & $4.31 \pm(5.481:-0.3$ & 0.03 .3 & 1.00 & 18.7 & 1.4 \\
\hline $\mathrm{RADe}(\mathrm{O})$ & $(6 / / 12-14 / 4)$ & $7.56 \pm 3.7831: 0.03$ & 0.185 & 0.97 & 56.6 & 22.5 \\
\hline Victoreen & $1220-27(86)$ & $0.74 \pm 0.40$ & 0.273 & 0.97 & 37.1 & 21.8 \\
\hline
\end{tabular}


As was previously discussed, the resolutions of the ANL-W and Victoreen CAMs were comparable and much worse than the resolutions of the Merlin Gerin and Kurz CAMs. (See Figures 17 through 20). The reason the ANL-W CAM had the best sensitivity for airborne ${ }^{239}$ Pu can be attributed to its relatively good counting efficiency, very high sampling flow rate $(240 \mathrm{~L} / \mathrm{min})$, and the fact that the two-stage inertial impactor discarded better than $95 \%$ of the radon daughters present in the sample airstream.

\section{Quantitative Measurements}

This section presents the results of quantitative measurements of airborne ${ }^{239} \mathrm{Pu}$ made using the Merlin Gerin Edgar alpha CAM. Similar results for the Kurz, RADeCO, and Victoreen CAMs were reported in Reference 3. As was previously discussed, the Merlin Gerin CAM sampled the atmosphere inside a glove box equipped with a simple air-driven aerosolizer that was loaded with soil that had been spiked with ${ }^{239} \mathrm{Pu}$ and sieved to $100 \mathrm{mesh}(<150 \mu \mathrm{m})$. Based on analyses of several samples removed from the soil, the average concentration of ${ }^{239} \mathrm{Pu}$ in the sieved soil was $1.8 \mathrm{nCi} / \mathrm{g}$.

For the five samplings of airborne ${ }^{2.39} \mathrm{Pu}$ performed, sampling durations ranged from 12 to 39 hours; however, the aerosolizer was normally operated only during the last 6 to 9 hours of each sampling (see Table 4). In one case, the July 30-August 1, 1991, sampling, the CAM sampled ambient air for about 13 hours and the aerosolizer was then operated for about 9 hours, but when the aerosolizer was turned off, rather than discontinuing sampling, sampling was allowed to proceed for about another 17 hours.

The average concentrations of airborne dust and ${ }^{239} \mathrm{Pu}$ during the five samplings of airborne ${ }^{239} \mathrm{Pu}$ are summarized in Table 12. Also given in Table 12 are the volume of air sampled during the time the aerosolizer was operating and the concentration of ${ }^{239} \mathrm{Pu}$ in the dust collected on the sample filter. Following each sampling, the ${ }^{239} \mathrm{Pu}$ activity on the sample filter was segregated using radiochemical separation techniques and quantified using high-resolution alpha spectrometry. The average concentration of airborne ${ }^{239} \mathrm{Pu}$ during each sampling was calculated dividing the total quantity of ${ }^{239} \mathrm{Pu}$ on the samplefilter by the volume of air sampled during the time the acrosolizer was operating. In the case of the July 30-August 1, 1991, sampling, an average airborne concentration was also calculated using the volume of air sampled from the time the acrosolizer began operating until the sampling was terminated the following day.

The resulis presented in Table 12 indicate average concentrations of airborne ${ }^{239} \mathrm{Pu}$ ranged from about $0.0013 \mathrm{pCi} / \mathrm{L}(0.7 \mathrm{DAC})$ to $0.012 \mathrm{pCi} / \mathrm{L}$ (5.9 DAC). Concentrations of ${ }^{2.39} \mathrm{Pu}$ in the dust collected on the sample filters were fairly constant, ranging from 5.6 to $7.0 \mathrm{nCi} / \mathrm{g}$, about a factor of three higher than the average concentration of ${ }^{239} \mathrm{Pu}$ in the bulk samples of soil that were aerosolized. As shown in Table 12, in one case, the July 29-30, 1991, sampling, the average concentration of airborne dust was about a factor of two higher than the highest average concentration during the samplings of aerosolized blank dust.

Average concentrations of airborne ${ }^{239}$ Pu determined analyzing alpha spectra using the two-, three-, and lour-window analysis algorithms are presented in Table 13 for each of the five samplings of acrosolized spiked dust performed using the Merlin Gerin CAM. In each case, concentrations of ${ }^{239} \mathrm{Pu}$ were calculated using a counting interval of 30 minutes. With one exception, the results for each sampling are the average concentrations measured during the time the acrosolizer was operating. 
Because in the case of the July 30-August 1, 1991, sampling the Merlin Gerin CAM was allowed to continue sampling after the acrosolizer was turned off, for this sampling, average ${ }^{239} \mathrm{Pu}$ concentrations were also determined for the period between the time the aerosolizer began operating and the time sampling was terminated. For the purpose of comparison, the average airborne ${ }^{2.39} \mathrm{Pu}$ concentrations determined via radiechemical analyses of the sample filters are also listed in Table 13.

The results presented in Table 13 show that when airborne dust concentrations were below $1 \mu \mathrm{g} / \mathrm{L}$, average concentrations of airborne ${ }^{239} \mathrm{Pu}$ measured using the Merlin Gerin CAM were usually in good agreement with the independently determined eoneentrations. When airborne dust concentrations were below $1 \mu \mathrm{g} / \mathrm{L}$, the ratio of measured to known average concentrations ranged from $0.8 \pm 0.4$ to $1.7 \pm 0.7$ in the case of the two-window algorithm, from $0.4 \pm 0.1$ to $1.0 \pm 0.5$ in the case of the three-window algorithm, and from $0.6 \pm 0.4$ to $1.3 \pm 0.8$ in the case of the four-window algorithm. For the two samplings having average airborne dust concentrations above $1 \mu \mathrm{g} / \mathrm{L}$, airborne ${ }^{239} \mathrm{Pu}$ concentrations measured using the Merlin Gerin CAM were consistently low. 'n the case of the latter two samplings, ratios of measured to known concentrations ranged from 0.10) \pm 0.02 for the three-window algorithm to $0.4 \pm 0.1$ for the $(w 0$-window algorithm.

The concentrations of airborne ${ }^{239} \mathrm{Pu}$ during the July $25-26$ and July 30-August 1, 1991 , samplings that were calculated using the two-, three-, and four-window analysis algorithms are plotted as a function of sampling time in Figures 39 and 40, for the two respective samplings. These plots exhibit two features that were common to the results for all live samplings: (a) ${ }^{239} \mathrm{Pu}$ concentrations

Table 12. Average concentrations of airborne dust and ${ }^{239} \mathrm{Pu}$ based on weighings and radiochemical analyses of the sample filters.

\begin{tabular}{|c|c|c|c|c|}
\hline \multirow{2}{*}{$\begin{array}{c}\text { Sampling } \\
\text { datus } \\
(\mathrm{m} / \mathrm{d} / \mathrm{y})\end{array}$} & \multirow{2}{*}{$\begin{array}{l}\text { Sample } \\
\text { volume } \\
\text { (I.) }\end{array}$} & \multicolumn{2}{|c|}{ Average airhorne concentration } & \multirow{2}{*}{$\begin{array}{l}\text { Concentration of } \\
239 \mathrm{pu} \text { in } \\
\text { collected dust } \\
\text { (n(.i/g) }\end{array}$} \\
\hline & & $\begin{array}{l}\text { Dust } \\
(\mu \mathrm{g} / \mathrm{I})\end{array}$ & $\begin{array}{c}23{ }^{2} \mathrm{Pu} \\
(\mathrm{p}(\mathrm{i} / \mathrm{L} .)\end{array}$ & \\
\hline $07 / 24 / 91$ & $9.161:+0.3$ & $2.28 \pm 0.25|-(0)|$ & $1.59 \pm 0.201:-0.3$ & $6.99 \pm 0.6 .315+00$ \\
\hline$(07 / 30-(1) 8 /(1) / / 9) 1^{h}$ & $9.971 \vdots+0.3$ & $6.80 \pm 0.76[i-0) 1$ & $3.81 \pm 0.4 .3 \quad 1.0 .3$ & $5.60 \pm 0.4111+00$ \\
\hline $07 / 30-(5) /\left(01 / 91^{\circ}\right.$ & $2.911 \vdots+04$ & $2.33 \pm 0.26[i-(1) 1$ & $1.31 \pm 0.151 . .03$ & $5.60 \pm 0.411:+00$ \\
\hline$(07 / 24-25 / 91$ & $8.601 i+0.3$ & $7.48 \pm 0.84+1-01$ & $4.62 \pm 0.521:-0.3$ & $6.17 \pm 0.44 \mathrm{~J}:+00$ \\
\hline $07 / 25-2(1 / 9) 1$ & $6.9 .31:+0.3$ & $1.19 \pm 0.131 \mathrm{1}+00$ & $8.22 \pm 0.93$ & $6.90 \pm 0.501 i+00$ \\
\hline$(17 / 29-30 / 91$ & $9.05 \mathrm{~L}+0.3$ & $2.04 \pm 0.231 i+00$ & $1.18 \pm 0.14 \mathrm{I}:-02$ & $5.79 \pm 0.43 \mathrm{~L}+00$ \\
\hline
\end{tabular}

a. Iixcept as noted below for the $07 / 3(1-08 / 01 / 9 \mathrm{i}$ sampling, the sample volume is only the volume of air sampled during the time the acrosolizer was operating.

b. Average airborne dust and ${ }^{239} \mathrm{Pu}$ concentrations during the 8.77 hours the aerosolizer was operating.

c. Average airborne dust and ${ }^{239} \mathrm{Pu}$ concentrations from the lime the aerosolizer was uncovered until sampling was lerminated (25.60 hours). 
Table 13. Comparison of average airborne ${ }^{239} \mathrm{Pu}$ concentrations (pCi/L).

\begin{tabular}{|c|c|c|c|c|}
\hline \multirow{2}{*}{$\begin{array}{l}\text { Sampling } \\
\text { dates } \\
(\mathrm{m} / \mathrm{d} / \mathrm{y})\end{array}$} & \multirow{2}{*}{$\begin{array}{l}\text { Radiochemical } \\
\text { analysis } \\
\text { of filter }\end{array}$} & \multicolumn{3}{|c|}{ Analysis of $(\mathrm{AM}$ spectra $(\Delta \mathrm{T}=30 \mathrm{~min}$.) } \\
\hline & & $\begin{array}{l}\text { 'lwo-window } \\
\text { algorithm }\end{array}$ & $\begin{array}{l}\text { Threc-window } \\
\text { algorithm }\end{array}$ & $\begin{array}{l}\text { Four-window } \\
\text { algorithm }\end{array}$ \\
\hline $07 / 24 / 91^{\mathrm{a}}$ & $1.59 \pm 0.20 \mathrm{E}-0.03$ & $1.68 \pm 0.53 \mathrm{~F}-0.3$ & $1.54 \pm 0.561:-0.3$ & $2.10 \pm 0.711:-0.3$ \\
\hline $07 / 30-08 /(01 / 4)]^{b, c}$ & $3.81 \pm 0.43 \mathrm{E}-0.3$ & $3.25 \pm 0.65 \mathrm{~F} .0 .3$ & $1.50 \pm 0.34 \mathrm{E}-(0.3$ & $2.47 \pm 0.491:-0.3$ \\
\hline $07 / 30-08 / 01 / 91^{\mathrm{b}, \mathrm{d}}$ & $1.31 \pm 0.156-0.03$ & $2.19 \pm 0.96 \mathrm{E}-0.3$ & $1.10 \pm 0.40 \mathrm{I}:-0.3$ & $1.6 .5 \pm 0.741:-0.3$ \\
\hline $07 / 24-2.5 / 91^{\mathrm{h}}$ & $4.62 \pm 0.52 \quad 1:-0.3$ & $3.76 \pm 0.69 \mathrm{E}-0.3$ & $2.09 \pm 0.51 \quad 1:-0.3$ & $2.91 \pm 0.531:-0.3$ \\
\hline $07 / 25-26 / 9)^{2}$ & $8.22 \pm 0.93[i-0.3$ & $3.72 \pm 0.401:-0.3$ & $1.76 \pm 0.29 \mathrm{E}:-0.3$ & $2.70 \pm 0.3 .31:-0.3$ \\
\hline $07 / 29-30 / 4) 1^{\mathrm{e}}$ & $1.18 \pm 0.141:-02$ & $4.70 \pm 1.061:-03$ & $1.17 \pm 0.45 \mathrm{E}:-(0.3$ & $2.65 \pm 0.81 \mathrm{E}-0.3$ \\
\hline
\end{tabular}

a. Used average values of $k_{1}, k_{2}$, and $k_{3}$ determined for $7 / 8-9 / 91$ sampling of blank dust.

b. Used average values of $k_{1}, k_{2}$, and $k_{3}$ determined for $7 / 1-2 / 91$ sampling of blank dust.

c. Average concentration from 14.5 to 23 hours (period acrosolizer was operating).

d. Average concentration from 14.5 16) 38 hours.

c. Used average values of $k_{1}, k_{2}$, and $k_{3}$ deternined for 6/26-27/91 sampling of blank dust.

calculated using all three algorithms were usually negative prior to acrosolizer operation and (b) among the three algorithms used to analyze spectra, the two-window algorithm consistently yielded the highest and the three-window algorithm the lowest ${ }^{239} \mathrm{Pu}$ concentrations.

The initial negative concentrations shown in Figures 39 and 40 are due to the fact that the alpha spectra collected during any given sampling were analyzed using constant values for the coefficients $\mathrm{k}_{1}, \mathrm{k}_{2}$, and $\mathrm{k}_{3}$. As indicated in Table 13 , coefficients used to analyze spectra collected during the July 25-26, 1991, sampling of acrosolized spiked dust were those determined for the June 26-27, 1991, sampling of acrosolized blank dust. Similarly, coefficients used to analyze spectra collected during the July 30-August 1, 1991, sampling of acrosolized spiked dust were those delermined for the July 1-2, 1991, sampling of aerosolized blank dust. In each case, the sampling of acrosolized blank dust from which the set of coefficients was selected was based on the similarity of the airborne dust concentration during the sampling to that during the sampling of acrosolized spiked dust when the aerosolizer was operating. As was previously discussed, during samplings of aerosolized spiked dust the Merlin Gerin CAM sampled relatively dust-free ambient air for a number of hours prior to acrosolizer operation. During this time, the coefficients used for analysis were simply too large and, consequently, calculated ${ }^{239} \mathrm{Pu}$ concentrations were negative.

In general, ${ }^{239} \mathrm{Pu}$ concentrations determined analyzing spectra using the two-window algorithm were in better agreement with the concentrations determined via radiochemical analysis of sample filters than the concentrations determined using the three- and four-window algorithms. 


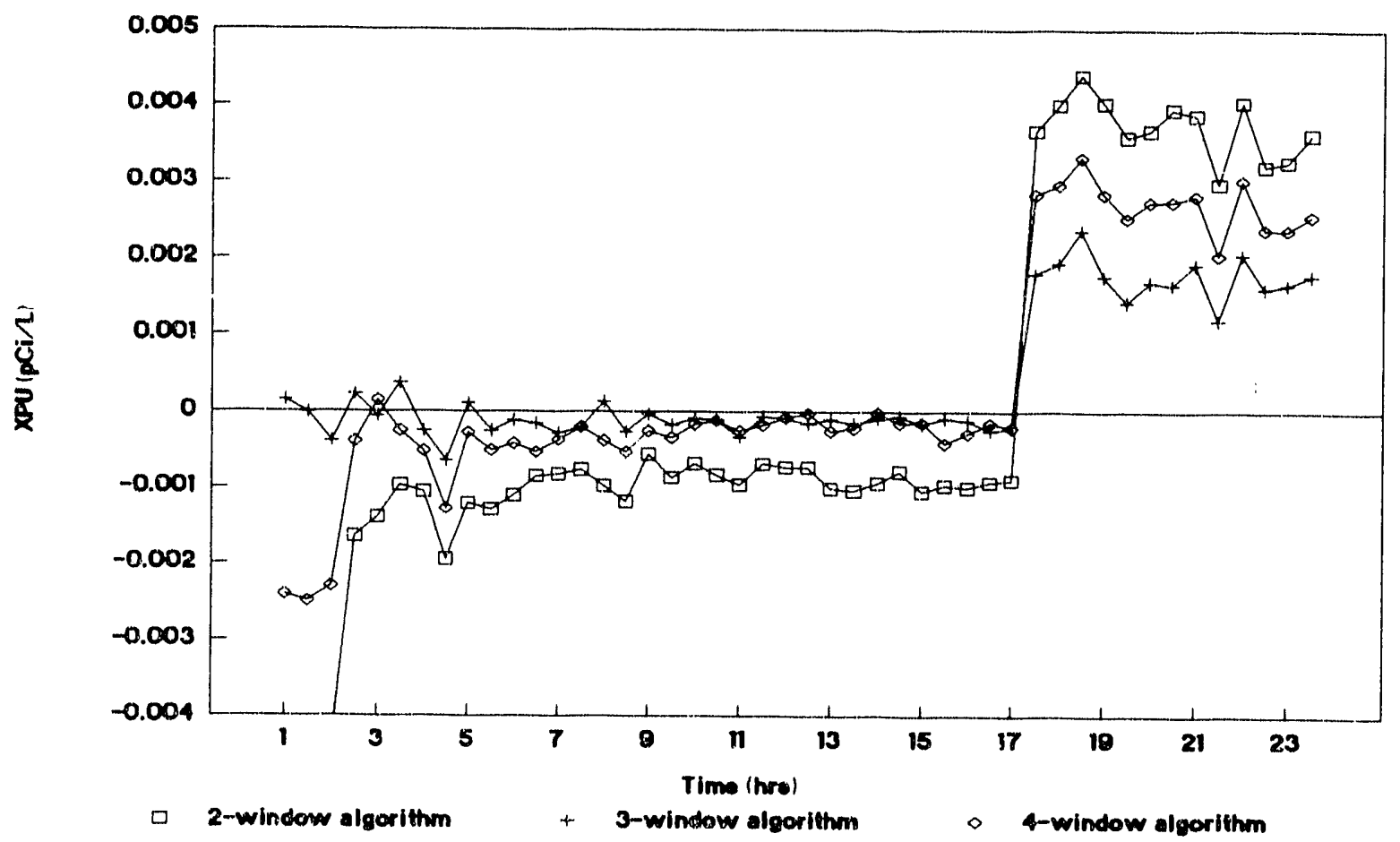

Figure 39. ${ }^{239} \mathrm{Pu}$ concentration versus sampling time for a sampling of acrosolized spiked dust performed July 25-26, 1991, using the Merlin Gerin Edgar alpha CAM.

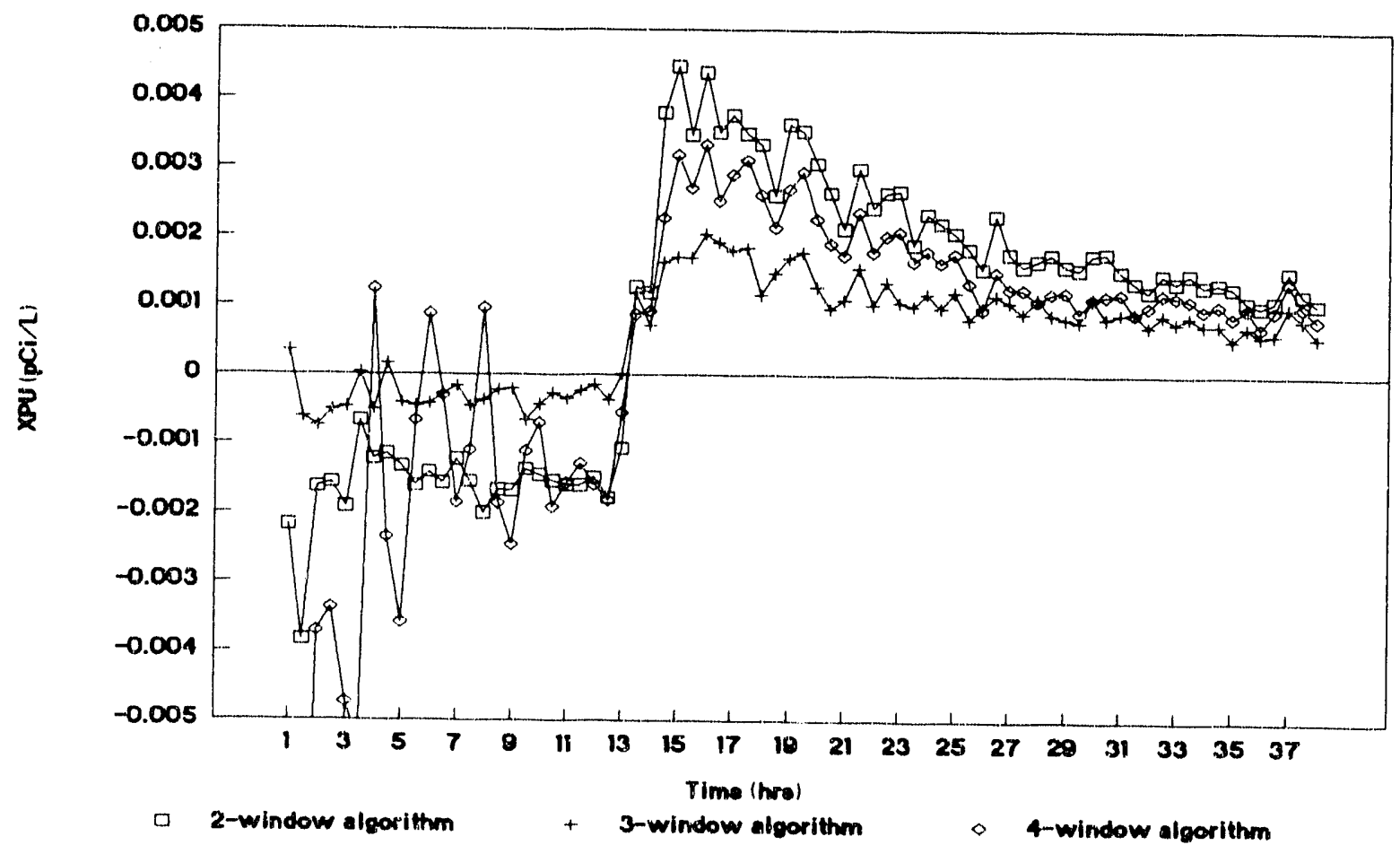

Figure 40. ${ }^{239} \mathrm{Pu}$ concentration versus sampling time for a sampling of acrosolized spiked dust performed July 3()-August 1. 1991, using the Merlin Gerin Edgar alpha CAM. 


\section{CONCLUSIONS AND RECOMMENDATIONS}

\section{Conclusions}

The ANL-W, Kurz model 8311, Merlin Gerin Edgar, RADeCO model 452, and Victoreen model 758 alpha CAMs each had LLDs for ${ }^{239} \mathrm{Pu}$ that met or exceeded the sensitivity requirement of 8 DAC-hours specified in DOE Order 5480.11. When airborne dust concentrations were less than $0.008 \mu \mathrm{g} / \mathrm{L}$ and one-hour long counting intervals were used, the ANL-W and Kurz CAMs exhibited by far the best sensitivities for airborne ${ }^{239} \mathrm{Pu}$. The average LLDs for these two CAMs were $0.0(0) 45$ and $0.003 \mathrm{pCi} / \mathrm{L}$, respectively. The best average LLDs for the Merlin Gerin, RADeCO, and Victoreen CAMs were all about $0.01 \mathrm{pCi} / \mathrm{L}$, about a factor of twenty higher than the average LLD for the ANL-W CAM. While the LLDs of the ANL-W and Kurz CAMs were unaffected by the choice of analysis algorithm, the LLDs for the RADeCO and Victoreen CAMs showed some dependence on which algorithm was used for analysis. In the case of the latter two CAMs, the three-window algorithm yiclded the lowest LLDs.

When airborne dust concentrations were above $0.2 \mu \mathrm{g} / \mathrm{L}$, the Kurz CAM was much niore sensitive than the RADeCO, Victoreen, or Merlin Gerin CAMs. The best average LLD for the Kurz CAM was $0.001 \mathrm{pCi} / \mathrm{L}$ for the two-window analysis algorithm, which was about a factor of 10 better than the best average LLDs for the RADeCO, Victoreen, and Merlin Gerin CAMs. For the samplings of acrosolized blank dust, the three-window analysis algorithm provided the best sensitivity for the RADeCO, Victoreen, and Merlin Gerin CAMs.

The two-stage virtual impactor installed in the ANL-W CAM and the inertial plate impactor installed in the Kurz CAM removed the majority of the radon and thoron daughters entrained in their sample airstreams. The removal of these indigenous alpha emitters significantly reduced background count rates in the ${ }^{239} \mathrm{Pu} \mathrm{ROI}$. This is reflected in the remarkably low ${ }^{2{ }^{29}} \mathrm{Pu}$ LLDs measured for the ANL-W and Kurz CAMs. However, in the case of the Kur $\angle$ CAM which collects particulates directly on the face of a solid-state silicon detector, this benefit must be weighed against the possible detriment of discarding some fraction of the particulates in the air being sampled. Results of this study indicate that, on average, only about $18 \%$ of the airborne ${ }^{239} \mathrm{Pu}$ activity that entered the Kur CAM remained fixed to the surface of the silicon detector following the completion of sampling. A study (see footnote a) recently completed at ITRI showed that the Kurz CAM retained only about $5 \%$ of the $10 \mu \mathrm{m}$ particles entrained in the sample airstream. The poor particle retention efficiency of the KurL CAM and the possibility that the retention efficiency might be dependent on such things as sampling duration and airborne dust concentration make it a poor candidate for quantitative measurements during buried waste retrieval operations at the RWMC.

The resolutions of the ANL-W and Victoreen CAMs were comparable and much worse than the resolutions of the Merlin Gerin and Kurz CAMs. The reason the ANL-W CAM had the best sensitivity for airborne ${ }^{239} \mathrm{Pu}$ can be atributed to its relatively good counting efficiency, very high sampling llow rate $(240 \mathrm{~L} / \mathrm{min})$, and the fact that the two-stage inertial impactor discarded better than $95 \%$ of the radon daughters present in the sample airstream.

The background coefficients determined for the Merlin Gerin CAM increased with increasing dust concentration and at any given dust concentration, the coeflicients were normally higher when 
the $2.0 \mu \mathrm{m}$ filter was used. The higher coefficients for the $2.0 \mu \mathrm{m}$ filter indicate that, as might be expected, alpha particles emitted from the more porous filter had a higher probability of interacting with the filter medium. When the $0.8 \mu \mathrm{m}$ filter was used, $\mathrm{k}_{1}$ and $\mathrm{k}_{2}$ both increased asymptotically to maximum values of about 0.3 and 0.7 , respectively. Although the trend was less clearly defined, $k_{3}$ also approached a constant value (about 0.14 ) when dust concentrations were above $0.4 \mu \mathrm{g} / \mathrm{L}$. The dispersion of each coefficient for samplings performed using the $0.8 \mu \mathrm{m}$ filter was not significantly affected by dust concentration. On the other hand, when the $2.0 \mu \mathrm{m}$ filter was used, the dispersion if the $\mathrm{k}_{1}$ and $\mathrm{k}_{3}$ coefficients was much larger at higher dust concentrations than at lower dust concentrations. Based on these considerations, the $0.8 \mu \mathrm{m}$ filter should generally provide better sensitivity than the $2.0 \mu \mathrm{m}$ filter, especially at higher dust concentrations.

When airborne dust concentrations were below $1 \mu \mathrm{g} / \mathrm{L}$, average concentrations of airborne ${ }^{239} \mathrm{Pu}$ measured using the Merlin Gerin CAM were usually in good agreement with the concentrations independently determined using radiochemical analysis methods. In general, for samplings performed using the Merlin Gerin CAM, ${ }^{239} \mathrm{Pu}$ concentrations determined analyzing spectra using the two-window algorithm were in better agreement with the concentrations determined via radiochemical analysis of sample filters than the coneentrations determined using the three- and four-window algorithms.

\section{Recommendations}

Because the three coefficients used for subtracting background from the ${ }^{239} \mathrm{Pu}$ ROI all changed as a function of sampling time and were also affected by changes in airborne dust concentration, if a ROI-based spectrum analysis approach is adopted, it will be necessary to estimate the current value of the background coefficient when sampling air during waste retrieval operations. Since the magnitude of the coefficient reflects the degree of scattering of higher energy background alpha particles to lower energy, the value of the coefficient should be correlated to basic parameters of the background alpha peaks such as width and skewness.

The coefficients calculated at 30-minute intervals during several samplings performed using the Merlin Gerin CAM were modestly correlated to the values of the FWHM and FWTM of the $7.69 \mathrm{MeV}{ }^{214} \mathrm{Po}$ alpha peak during the same samplings. This suggests that if the FWHM and FWTM of the $7.69 \mathrm{MeV}$ alpha peak were frequently measured and the values stored during sampling, their average values during some predefined preeding time interval could be used to estimate the current value of the coefficient. Another, perhaps equally promising option, would be to monitor the skewness or asymmetry of the background alpha peaks. Because the background coefficients determined for the ANL-W, RADeCO, and Victoreen CAMs exhibited much less seatter than the coefficients determined for the Merlin Gerin CAM, spectral data for the latter three CAMs should be examined to determine if this approach to estimating the value of the background coefficient during sampling has real merit.

The evaluations perlormed in this study indicate that the ANL-W CAM will be suitable for monitoring air quality during waste retrieval operations at the RWMC. Several CAM sample collection heads should be fabricated as soon as practical using the ANL-W design that utilizes a two-stage virtual impactor. A solid-state silicon alpha detector and preamplifier will have to be purchased for each CAM unit that is fabricated. 
In addition to the items previously mentioned, two additional solid-state silicon alpha detectors and associated preamplifiers should be purchased to allow testing an alternative alpha CAM design. The design concept is to utilize two alpha detectors that sequentially assay the same sample collection filter. One detector will assay the sample collection filter in the usual manner while particulates are being deposited on it. The second detector will assay the same filter after a decay time of about 10 minutes following its removal from the sample airstream. The basic idea is to allow the majority of the 3.1-minute ${ }^{218} \mathrm{Po}$ on the sample collection filter to decay before it is assayed by the second alpha detector. A 10 minute decay time will reduce the ${ }^{218}$ Po activity on the filter by $90 \%$, resulting in a substantial reduction in the number of $6.00 \mathrm{MeV}$ alpha particles that are scattered into the ${ }^{239} \mathrm{Pu}$ ROI. Consequently, the second detector will have much better sensitivity for airborne TRU than the detector that assays the sample filter positioned in the sample airstream.

One can envision a CAM unit that employs three sample collection filters-one positioned in the sample airstream bencath one alpha detector, a second inside a decay chamber isolated from .he sample airstream, and a third positioned beneath a second alpha detector. If the three filters were spaced 120 degrees apart on a circular filter holder assembly, the assembly could be rotated 120 degrees every 10 minutes so that the fiiter assayed by the second detector would be returned to the sample airstream the same time the filter in the decay chamber was moved beneath the second detector. In this manner, monitoring would remain continuous, but the shorter-lived background isotopes that reduce detection sensitivity would be allowed to decay during monitoring. 


\section{REFERENCES}

1. DOE Order 548().11, "Radiation Protection for Occupational Workers," U.S. Department of Encrgy, Washington D.C., 1988.

2. C. V. McIsaac and C. R. Amaro, Real-time Transuranic Monitoring with a Victoreen Model 758 Alpha Continuous Air Monitor, EGG-WM-8774, September 1989.

3. C. V. McIsaac, C. W. Sill, R. J. Gchrke, P. G. Shaw, P. D. Randolph, C. R. Amaro, R. J. Pawclko, D. N. Thompson, and G. G. Loomis, Rapid Monitoring for Transuranic Contaminants During Buried Waste Retrieval, EGG-WTD-9412, March 1991.

4. C. V. McIsaac, P. D. Randolph, C. R. Amaro, D. N. Thompson, and R. J. Pawelko, "Sensitivities of Alpha Continuous Air Monitors for Detection of Airborne ${ }^{239} \mathrm{Pu}$," Waste Processing, Transportation, Storage and Disposal, Technical Programs and Public: Education, Vol.II, Proceedings of the Symposium on Waste Management at Tucson, Arizona, February 24-28, 1991, p. 695.

5. P. G. Shaw, C. V. McIsaac, C. W. Sill, G. G. Loomis, M. R. Winberg, A. L. Frecman, and D. N. Thompson, Test Plan for Contamination Control Related Experiments, EGG-WM-9059, March 1990.

6. M. R. Winberg, Test Plan for FY-91 Alpha CAM Evaluation, EGG-WTD-9571, March 1991.

7. T. J. Yulc, "An On-Line Monitor for Alpha-Emitting Aerosols," IEEE Transactions on Nuclear Science, NS-23, N(). 1, 1978.

8. G. K. Rusch, W. P. McDowell, and W. G. Knapp, "The ZPR-9 Airborne Plutonium Monitoring System," IEEE Transactions on Nuclear Science, NS-2.3, No. 1, 1976.

9. J. M. Larson and D. L. Hall, "ZPPR Plutonium Monitor," ZPR-I Memo No. 389, February 1976.

10. Model 8311 Alpha Detector User's Guide, 360113, Rev XA2, Preliminary, Kurz Instruments Incorporated, Monterey, California, 1989.

11. C. W. Sill, "Precipitation of Actinides as Fluorides or Hydroxides for High-Resolution Alpha Spectrometry," Nucl and Chem Waste Management, Vol.7, 1987, p. 201.

12. L. A. Curric, Lower Limit of Detection: Definition and Elaboration of a Proposed Position for Radiological Effluent and Environmental Measurements, NUREG/CR-4007, September 1984. 


\section{Appendix A}

Description of Alpha Spectrum Analysis Methods 
A-2 


\section{APPENDIX A}

\section{DESCRIPTION OF ALPHA SPECTRUM ANALYSIS METHODS}

Three different spectrum analysis algorithms were used to analyze each alpha spectrum that was collected. These algorithms determine net counts in the ${ }^{239} \mathrm{Pu}$ peak by subtracting from the total counts in the peak some fraction of the counts in adjacent background regions of the spectrum. The three algorithms used employed one region of interest (ROI) that encompassed the energy region of the ${ }^{239} \mathrm{Pu}$ peak and either one, two, or three background ROIs. Hence, they are commonly referred to as the two-, three-, and four-window algorithms. In all three cases, the $n$ unts in the ${ }^{239} \mathrm{Pu}$ peak are expressed as a simple linear equation involving a single coefficient whose value must be experimentally determined. The value of the coefficient determines what fraction of the counts in the background ROI(s) must be subtracted from the counts in the ${ }^{239} \mathrm{Pu}$ ROI in order to yield zero net counts in the absence of ${ }^{239} \mathrm{Pu}$. The three equations for net counts in the ${ }^{239} \mathrm{Pu}$ ROI are:

Two-window algorithm:

$C_{P u}=C_{1}-k_{1} C_{2}$

Three-window algorithm:

$C_{P u}=C_{4}-k_{2}\left(C_{3}+C_{5}\right)$

Four-window algorithm:

$c_{P u}=c_{6}-\frac{k_{3}\left\{C_{7} C_{8}\right\}}{c_{9}}$

where,

$C_{1}, C_{4}$, and $C_{6}$ are the total number of counts in the ${ }^{239} \mathrm{Pu} R O \mathrm{I}$, and $c_{2}, c_{3}, c_{5}, c_{7}, c_{8}$, and $C_{9}$ are the total number of counts in the corresponding background ROIs.

The energy ranges of the ROIs that were used for the three different algorithms are given in Table A-1. Also presented in Table A-1 are the energy ranges of the ROIs used to integrate counts in the three major background alpha peaks. ROIs 10, 11 , and 12 were used to integrate counts in the ${ }^{218} \mathrm{Po} /{ }^{212} \mathrm{Bi}$ ( $\left.\mathrm{RaA} / \mathrm{ThC}\right),{ }^{214} \mathrm{Po}\left(\mathrm{RaC}^{\prime}\right)$, and ${ }^{212} \mathrm{Po}\left(\mathrm{ThC}^{\prime}\right.$ ) alpha peaks, which have energies of $6002.55 / 6061.80,7686.90$, and $8784.37 \mathrm{keV}$, respectively. 1 Gross count rates in these latter ROIs were monitored to determine how effective the ANL-W and Kurz impactors were in reducing the quantities of radon and thoron daughters collected.

The initial step in the analysis of each alpha spectrum was the determination of the gross number of counts in each of the 12 ROIs defined in Table A-1. This was accomplished using a computer program that was written and compiled in $C$ and run on a VAX 3200 . 
TABLE A-1. Energy ranges of the ROIs used to analyze alpha spectra (MeV)

\begin{tabular}{|c|c|c|c|c|c|}
\hline$\underline{\mathrm{ROI}}$ & ANL-W & Kurz & $\begin{array}{l}\text { Merlin } \\
\text { Gerin }\end{array}$ & RADeCO & Victoreen \\
\hline $\begin{array}{r}1 \\
2 \\
3 \\
4 \\
5 \\
6 \\
7 \\
8 \\
9 \\
10 \\
11 \\
12\end{array}$ & $\begin{array}{l}3.01-5.29 \\
5.29-6.12 \\
2.97-4.13 \\
4.13-5.29 \\
5.29-5.74 \\
4.10-5.18 \\
5.91-6.12 \\
6.32-7.54 \\
7.54-7.81 \\
3.25=6.12 \\
6.12-7.81 \\
7.82-9.34\end{array}$ & $\begin{array}{l}5.00-5.25 \\
5.26-6.14 \\
2.93-4.09 \\
4.09-5.25 \\
5.26-5.70 \\
4.11-5.21 \\
6.02-6.14 \\
6.34-7.69 \\
7.70-7.82 \\
3.28-6.14 \\
6.15-7.82 \\
7.82-9.34\end{array}$ & $\begin{array}{l}3.03-5.19 \\
5.21-6.23 \\
3.01-4.14 \\
4.15-5.19 \\
5.20-5.64 \\
4.14-5.19 \\
6.06-6.23 \\
6.44-7.74 \\
7.78-7.89 \\
3.29-6.23 \\
6.24-7.89 \\
7.90-8.96\end{array}$ & $\begin{array}{l}2.99-5.27 \\
5.29-6.22 \\
2.97-4.11 \\
4.13-5.27 \\
5.29-5.73 \\
4.11-5.21 \\
6.04-6.22 \\
6.41-7.71 \\
7.73-7.89 \\
3.25-6.22 \\
6.24-7.89 \\
7.91-9.34\end{array}$ & $\begin{array}{l}3.00-5.29 \\
5.29-6.15 \\
2.97-4.13 \\
4.13-5.29 \\
5.29-5.74 \\
4.11-5.17 \\
5.95-6.15 \\
6.35-7.54 \\
7.54-7.80 \\
3.25-6.15 \\
6.16-7.80 \\
7.81-9.34\end{array}$ \\
\hline
\end{tabular}

The coefficients $k_{1}, k_{2}$, and $k_{3}$ in Equations A-1 through A-3 were calculated using spectral data collected during samplings of ambient air and air synthetically ladin with blank dust. In the absence of ${ }^{239} \mathrm{Pu}$, each of the three equations should yield zero net ${ }^{239} \mathrm{Pu}$ counts. Using Equation A-1 as ari exampie, for spectra $n-1$ and $n$, one obtains the following equalities.

$$
\begin{aligned}
& 0=\left(C_{1}\right)_{n-1}-k_{1}\left(C_{2}\right)_{n-1} \\
& 0=\left(C_{1}\right)_{n}-k_{1}\left(C_{2}\right)_{n}
\end{aligned}
$$

If we assume that $k_{1}$ is a constant for two consecutive spectra, we can solve for $k_{1}$ as:

$$
k_{1}=\frac{\left(C_{1}\right)_{n}-\left(C_{1}\right)_{n-1}}{\left(C_{2}\right)_{n}-\left(C_{2}\right)_{n-1}}
$$

Similarly, using Equations $A-2$ and A-3 for two consc sutive spectra, we obtain the following equations for $k_{2}$ and $k_{3}$ :

$$
\begin{aligned}
& k_{2}=\frac{\left(C_{4}\right)_{n}-\left(C_{4}\right)_{n-1}}{\left(C_{3}+C_{5}\right)_{n}-\left(C_{3}+C_{5}\right)_{n-1}} \\
& k_{3}=\frac{\left(C_{6}\right)_{n}-\left(C_{6}\right)_{n-1}}{\frac{\left\{\left(C_{7}\right)_{n}-\left(C_{7} i_{n-1}\right\}\left\{\left(C_{8}\right)_{\left.n-\left(C_{8}\right)_{n-1}\right\}}\right.\right.}{\left\{\left(C_{9}\right)_{n}-\left(C_{9}\right)_{n-1}\right\}}}
\end{aligned}
$$


Using Equations $A-6, A-7$, and $A-8$, the coefficients $k_{1}, k_{2}$, and $k_{3}$ were calculated for each spectrum collected during samplings of ambient air and air laden with blank dust. All three coefficients were calculated for each spectrum collected using each of the four CAMs tested. Mean values and standard deviations of the coefficients for samplings of ambient air and aerosolized blank dust are presented in the main text.

The number of background and net counts in the ${ }^{239} \mathrm{Pu}$ ROI and their statistical uncertainties were then calculated using the following formula.

Two-window algorithm:

$$
\begin{aligned}
& \left(C_{P_{u}}\right)_{n}=\left(C_{1}\right)_{n}-k_{1}\left(C_{2}\right)_{n} \\
& \left(C_{\text {bgd }}\right)_{n}=k_{1}\left(C_{2}\right)_{n} \\
& \left(N_{B}\right)_{n}=\left(C_{2}\right)_{n}-\left(C_{2}\right)_{n-1} \\
& \left(N_{\text {bgd }}\right)_{n}=k_{1}\left\{\left(C_{2}\right)_{n}-\left(C_{2}\right)_{n-1}\right\} \\
& \left(N_{P u}\right)_{n}=\left(C_{P_{u}}\right)_{n}-\left(C_{P_{u}}\right)_{n-1} \\
& \left(\sigma_{\text {bgd }}\right)_{n}=\left\{k_{1}{ }^{2}\left(N_{B}\right)_{n}+\left(N_{B}\right)_{n}{ }^{2}\left(\sigma_{k_{1}}\right)^{2}\right\}^{1 / 2} \\
& \left(\sigma_{N_{P_{u}}}\right)_{n}=\left\{\left[\left(C_{1}\right)_{n}-\left(C_{1}\right)_{n-1}\right]+\left(\sigma_{b g d}\right)^{2}\right\}^{1 / 2}
\end{aligned}
$$

Three-window algorithm:

$$
\begin{aligned}
& \left(C_{P u}\right)_{n}=\left(C_{4}\right)_{n}-k_{2}\left(C_{3}+C_{5}\right)_{n} \\
& \left(C_{\text {bgd }}\right)_{n}=k_{2}\left(C_{3}+C_{5}\right)_{n} \\
& \left(N_{B}\right)_{n}=\left(C_{3}+C_{5}\right)_{n}-\left(C_{2}+C_{5}\right)_{n-1} \\
& \left(N_{b g d}\right)_{n}=k_{2}\left\{\left(C_{3}+C_{5}\right)_{n}-\left(C_{3}+C_{5}\right)_{n-1}\right\} \\
& \left(N_{P u}\right)_{n}=\left(C_{P u}\right)_{n}-\left(C_{P u}\right)_{n-1} \\
& \left(\sigma_{b g d}\right)_{n}=\left\{k_{2}^{2}\left(N_{B}\right)_{n}+\left(N_{B}\right)_{n}^{2}\left(\sigma_{k_{2}}\right)^{2}\right\}^{1 / 2} \\
& \left(\sigma_{N_{P u}}\right)_{n}=\left(\left[\left(C_{4}\right)_{n}-\left(C_{4}\right)_{n-1}\right]+\left(\sigma_{b g d}\right)^{2}\right\}^{1 / 2}
\end{aligned}
$$

Four-window algorithm:

$$
\left(C_{p_{u}}\right)_{n}=\left(C_{6}\right)_{n}-\frac{k_{3}\left(C_{7} C_{8}\right)_{n}}{\left(C_{9}\right)_{n}}
$$




$$
\left(C_{\text {bgd }}\right)_{n}=\frac{k_{3}\left(C_{7} C_{8}\right)_{n}}{\left(C_{9}\right)_{n}}
$$

$$
\left(N_{B}\right)_{n}=\frac{\left(C_{7} C_{8}\right)_{n}}{\left(C_{9}\right)_{n}}-\frac{\left(C_{7} C_{8}\right)_{n-1}}{\left(C_{9}\right)_{n-1}}
$$

$\left(N_{b g d}\right)_{n}=k_{3}\left(N_{B}\right)_{n}$

$\left(N_{p_{u}}\right)_{n}=\left(C_{p_{u}}\right)_{n}-\left(C_{p_{u}}\right)_{n-1}$

$\left(\sigma_{\text {bgd }}\right)_{n}=\left\{k_{3}{ }^{2}\left(N_{B}\right)_{n}+\left(N_{B}\right)_{n}^{2}\left(\sigma_{k_{3}}\right)^{2}\right\}^{1 / 2}$

$\left(\sigma_{N_{P_{u}}}\right)_{n}=\left\{\left[\left(C_{6}\right)_{n}-\left(C_{6}\right)_{n-1}\right]+\left(\sigma_{b g d}\right)^{2}\right\}^{1 / 2}$

where,

$\left(C_{P u}\right)_{n}$ is the net count in the ${ }^{239} \mathrm{Pu}$ ROI at the end of counting interval $n$,

$\left(C_{\text {bgd }}\right)_{n}$ is the calculated background counts in the ${ }^{239} \mathrm{Pu}$ RoI at the end of counting interval $n$,

$\left(N_{B}\right)_{n}$ is the change in gross counts in the background ROI(s)

during counting interval $n$,

$\left(N_{b g d}\right)_{n}$ is the change in the calculated background counts in the ${ }^{239} \mathrm{Pu}$ ROI during counting interval $\mathrm{n}$,

$\left(\mathrm{N}_{\mathrm{Pu}}\right)_{n}$ is the change in the net counts in the ${ }^{239} \mathrm{Pu}$ ROI

during counting interval $n$,

$\left(\sigma_{b g d}\right)_{n}$ is the statistical uncertainty in $\left(\mathrm{N}_{\mathrm{bgd}}\right)_{n}$, and

$\left(\sigma_{\mathrm{NP}_{\mathrm{Pu}}}\right)_{\mathrm{n}}$ is the statistical uncertainty in $\left(\mathrm{N}_{\mathrm{Pu}}\right)_{\mathrm{n}}$.

Concentrations of airborne ${ }^{239} \mathrm{Pu}$ during samplings were calculated for each counting interval using the following approach. The number of net counts in the ${ }^{239} \mathrm{Pu}$ ROI at time $t$ is a function of the total activity deposited on the filter and the counting efficiency of the alpha detector.

$C_{P u}(t)=2.22 \epsilon \int_{0}^{t} A(t) d t$ 
where,

$C_{P_{u}}(t)$ is the number of background-corrected counts in the ${ }^{239} \mathrm{Pu}$ ROI at time $t$,

2.22 is the number of disintegrations per minute (dpm) per $\mathrm{pCi}$,

$\epsilon$ is the absolute counting efficiency of the alpha detector [counts per minute (cpm) per dpm], and

$A(t)$ is the ${ }^{239} \mathrm{Pu}$ activity deposited on the filter at time $t(p C i)$.

Because, in our case, the activity deposited on the filter at time $t$ is the product of the activity collection efficiency of the sample filter, the concentration of ${ }^{239} \mathrm{Pu}$ in the air being sampled, sampling flow rate, and cumulative sampling time, Equation A-30 may be rewritten as

$C_{p u}(t)=2.22 \in \int_{0}^{t} Y X_{p u} F t d t$

where,

$Y$ is the ${ }^{239} \mathrm{Pu}$ collection efficiency of the detector or sample collection filter,

$X_{P u}$ is the concentration of ${ }^{239} \mathrm{Pu}$ in the air being sampled $(\mathrm{pC} \mathrm{i} / \mathrm{L})$,

$F$ is the flow rate at which air is sampled (L/minute), and

$t$ is the cumulative sample time (minutes).

If we assume that $Y, X_{P_{u}}$, and $F$ are constants, the integration of Equation A-31 yields the following formula for net ${ }^{239} \mathrm{Pu}$ counts as a function of sampling time.

$C_{P u}(t)=2.22 \in Y \quad X_{P u} F t^{2}$

2

Equation A-32 shows that ${ }^{239} \mathrm{Pu}$ net counts increase as the square of sampling time. The change in net ${ }^{239} \mathrm{Pu}$ counts between cumulative sampling (counting) times $t_{1}$ and $t_{2}$ is then:

$C_{P u}\left(t_{2}\right)-C_{P_{u}}\left(t_{1}\right)=2.22 \epsilon Y X_{P u} F\left[\left(t_{2}\right)^{2}-\left(t_{1}\right)^{2}\right]$ 
Solving Equation $A-33$ for $X_{P_{u}}$ yields:

$$
X_{P u}=\frac{C_{P u}\left(t_{2}\right)-C_{P u}\left(t_{1}\right)}{2.22 \epsilon Y \frac{F\left[\left(t_{2}\right)^{2}-\left(t_{1}\right)^{2}\right]}{2}}
$$

or,

$$
X_{P u}=\frac{C_{P u}\left(t_{2}\right)-C_{P u}\left(t_{1}\right)}{2.22 \epsilon Y F\left[\left(t_{2}-t_{1}\right)\left(t_{2}+t_{1}\right)\right]}
$$

Because spectra were stored at regular intervals during sampling, we can express sampling times $t_{1}$ and $t_{2}$ as multiples of the counting interval that was used during sampling. For $t_{2}$ equal to $n \Delta T$ and $t_{1}$ equal to $(n-j) \Delta T$, where $n$ and $j$ are integers and $\Delta T$ is the length of the counting interval, the concentration of airborne ${ }^{239} \mathrm{Pu}$ for the $\mathrm{n}^{\text {th }}$ counting interval may be expressed as:

$$
\left(X_{P u}\right)_{n}=\frac{\left(C_{P u}\right)_{n}-\left(C_{P u}\right)_{n-j}}{2.22 \epsilon Y[F(n-j / 2) \Delta T][j \Delta T]}
$$

The term $[F(n-j / 2) \Delta T]$ corresponds to the cumulative sample volume at the time midway between the times the $(n-j)^{\text {th }}$ and $n^{\text {th }}$ spectra were stored. The $(n-j / 2)$ factor reflects the fact that ${ }^{239} \mathrm{pu}$ counts recorded for a given counting interval are due to both the total ${ }^{239} \mathrm{Pu}$ activity accumulated on the filter prior to the start of the counting interval and the ${ }^{239} \mathrm{Pu}$ activity deposited during the counting interval. Net

${ }^{239} \mathrm{Pu}$ counts contributed by the ${ }^{239} \mathrm{Pu}$ activity deposited during the counting interval are equal to the number of counts that would have been contributed if one-half the added activity had been present at the

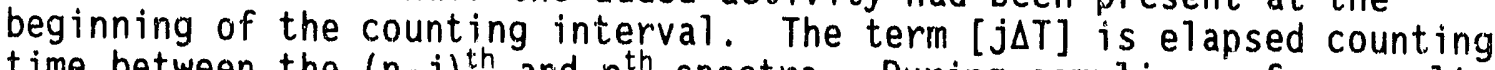
time between the $(n-j)^{\text {th }}$ and $n^{\text {th }}$ spectra. During samplings of aerosolized dust performed during this study, cumulative spectra were stored every 30 minutes; so for those samplings $\Delta T$ in Equation $A-36$ was set equal to 30 minutes. Airborne concentrations of ${ }^{239} \mathrm{Pu}$ were normally calculated using $j$ equal to 1 , meaning differences in net ${ }^{239} \mathrm{Pu}$ counts in successive one-half hour counting intervals were usually used to estimate airborne ${ }^{239} \mathrm{Pu}$ concentrations. However, spectra collected during several samplings of ambient air and aerosolized dust were also analyzed using $j$ equal to 2 in order to assess the effect of increasing the counting interval to 1 hour. Because all spectra collected using the ANL-W CAM were stored at one-hour intervals, $\Delta T$ in Equation $A-36$ was set equal to 60 minutes when the ANL-W spectra were analyzed. Although the ANL-W CAM was not used to sample aerosolized dust spiked with ${ }^{239} \mathrm{Pu}$, concentrations of airborne ${ }^{239} \mathrm{Pu}$ were also calculated for samplings 
of ambient air performed using the ANL-W CAM.

The minimum detectable change in net ${ }^{239} \mathrm{Pu}$ counts during each counting interval was calculated using the methods described by Currie.? The equation he suggests is:

$\left(N_{D}\right)_{n}=f\left\{2 \Delta+[Z(1-\alpha)+Z(1-\beta)] \sqrt{2}\left(\sigma_{\text {bgd }}\right)_{n}\right\}$

where,

$f$ is a correction to the LLD counts that takes into account systematic calibration errors,

$\Delta$ is a correction to the LLD counts that takes into account baseline errors,

$Z(1-\alpha)$ is the number of background standard deviations to be used to determine a critical level,

$Z_{(1-\beta)}$ is the number of background standard deviations above the critical level used to determine LLD ${ }^{239} \mathrm{Pu}$ counts, and

$\left(\sigma_{b g d}\right)_{n}$ is the standard deviation in the difference between the ${ }^{239} \mathrm{Pu}$ ROI background counts in the $n^{\text {th }}$ and $(n-j)^{\text {th }}$ spectra.

Formula for $\left(\sigma_{b g d}\right)_{n}$ for the two-, three-, and four-window analys is algorithms are given as Equations A-14, A-21, and A-28, respectively. Values of $\left(N_{0}\right)_{n}$ were calculated at the $95 \%$ confidence level.

$Z(1-\alpha)$ has a value of 1.645 for $95 \%$ confidence of no false positives, and

$Z(1-\beta)$ has a value of $\$ .645$ for $95 \%$ confidence of no false negatives. Because systematic calibration errors were estimated to be negligible compared to other sources of uncertainty, $f$ was set equal to 1.0 when values of $\left(N_{0}\right)_{n}$ were calculated. Also, because baseline errors were small compared to uncertainties in the changes in the background counts in the ${ }^{239} \mathrm{Pu}$ ROI, the term $\Delta$ in Equation A-37 was set equal to zero when LLD counts were calculated. With these stipulations, inserting the appropriate values into Equation A-37 yields the following simplified equation.

$\left(N_{D}\right)_{n}=4.653\left(\sigma_{b g d}\right)_{n}$

It should be noted that the constant 2.71 normally added to the right-hand side of Equation A-38 is absent from the equation. The constant was always much smaller than the product $4.653\left(\sigma_{\text {bgd }}\right)_{n}$, so L.D counts were calculated omitting the constant.

LLD counts calculated using Equation A-38 were converted to LLD concentrations using the following approach. If we assume that the concentration of airborne ${ }^{239} \mathrm{Pu}$, the activity collection efficiency, and sampling flow rate remain constant during sampling, then the amount of activity collected at any time $t$ is given by 


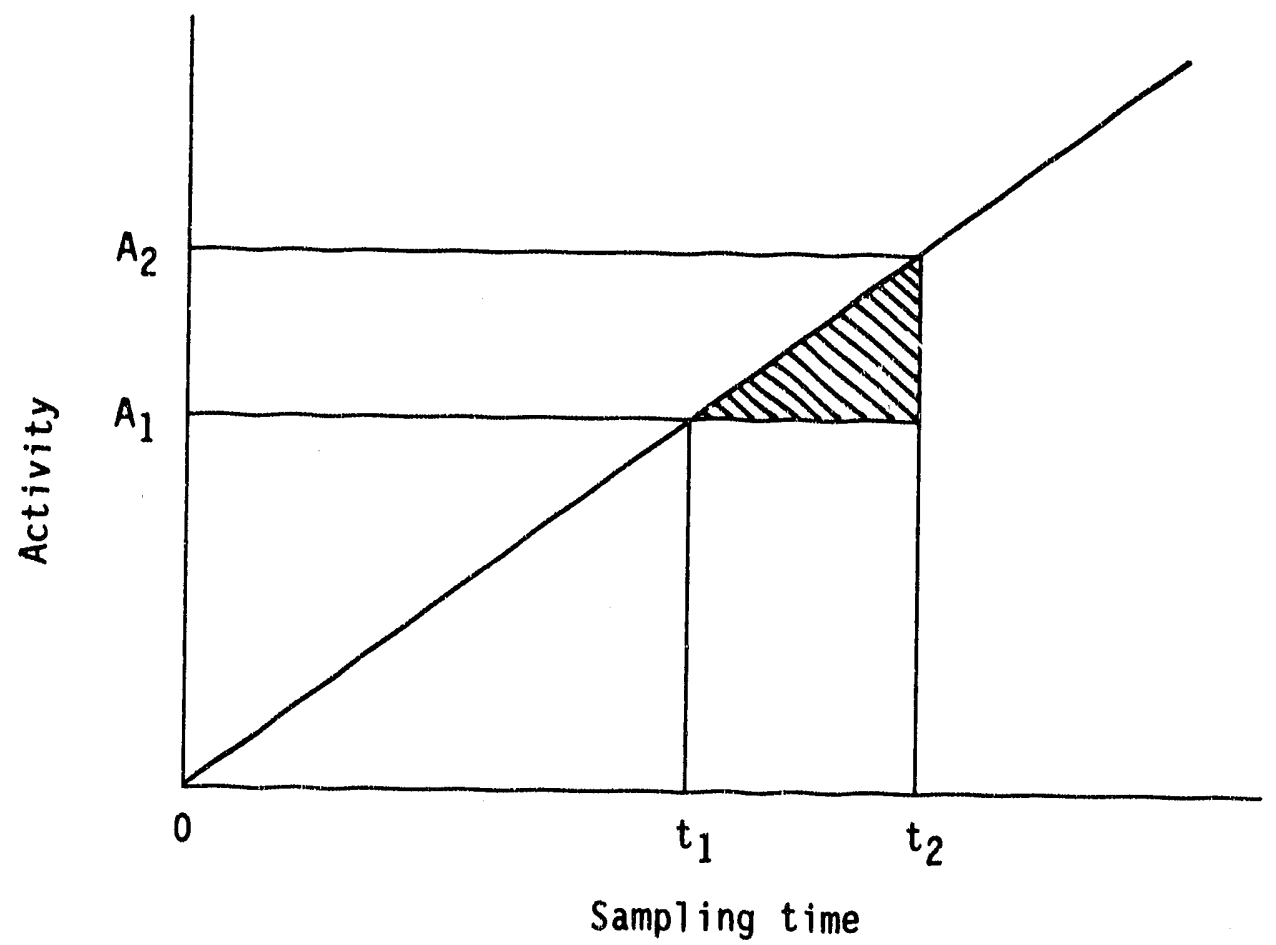

Figure A-1. Change in collected activity during a sampling interval.

$A(t)=Y X_{P u} F t$

The amount of activity collected during a given counting interval may be easily calculated with the aide of Figure $A-1$, which is a plot of collected activity versus cumulative sampling time. The amount of activity collected between times $t_{1}$ and $t_{2}$ is equal to the area of the hatched triangle shown in Figure $A-1$. The amount of activity collected during the sampling interval, $\triangle A$, is

$\Delta A=1 / 2\left(t_{2}-t_{1}\right)\left(Y X_{P u} F t_{2}-Y X_{P u} F t_{1}\right)$

or

$\Delta A=1 / 2 Y X_{P u} F\left(t_{2}-t_{1}\right)^{2}$

For $t_{2}=n \Delta T$ and $t_{1}=(n-j) \Delta T$, Equation $(A-41)$ may be rewritten as

$\Delta A=1 / 2 \quad Y X_{P u} F j^{2} \Delta T^{2}$

The change in net ${ }^{239} \mathrm{Pu}$ counts between cumulative sampling (colinting) times $t_{1}$ and $t_{2}$ is then:

$C_{P u}\left(t_{2}\right)-C_{P u}\left(t_{1}\right)=\frac{2.22 \epsilon Y X_{P u} F j^{2} \Delta T^{2}}{2}$ 
Solving for $\left(X_{p u}\right)_{n}$, the concentration of airborne ${ }^{239} \mathrm{Pu}$ during the counting interval is then given by

$$
\left(X_{p_{u}}\right)_{n}=\frac{\left(C_{P u}\right)_{n}-\left(C_{P u}\right)_{n-j}}{2.22 \epsilon Y \frac{[F j \Delta T][j \Delta T]}{2}}
$$

LLD counts calculated using Equation A-38 were substituted into Equation A-44 to convert them to LLD concentrations, expressed as $\mathrm{pCi} / \mathrm{L}$.

$$
\left(X_{d}\right)_{n}=\frac{\left(N_{D}\right)_{n}}{2.22 \epsilon Y \frac{[F j \Delta T][j \Delta T]}{2}}
$$

In the case of the Merl in Gerin CAM, Equation A-45 was normally evaluated using $j$ equal to one, meaning the LLDs were usually estimated based on successive one-half hour counting intervals. However, for selected samplings of ambient air and aerosolized blank dust performed using the Merlin Gerin CAM, spectra were also analyzed using $j$ equal to 2 to determine if using a one-hour long counting interval significantly improved the LLD for ${ }^{239} \mathrm{Pu}$.

For selected samplings of ambient air and aerosolized blank dust performed during FY-1990 using the ANL-W, Kurz, RADeCO, and Victoreen CAMs spectra were reanalyzed using successive one-hour long counting intervals. These data provide a basis for comparing the LLDs of the five CAMs that were tested.

\section{REFERENCES FOR APPENDIX A}

1. E. Browne and R. B. Firestone, Table of Radioactive Isotopes, John Wiley \& Sons, New York, USA (1986).

2. L. A. Currie, "Lower Limit of Detection: Definition and Elaboration of a Proposed Position for Radiological Effluent and Environmental Measurements," NUREG/CR-4007 (September 1984). 


$$
\text { A-12 }
$$


Appendix B

Resolution: Additional Data and Plots 


\section{APPENDIX B}

\section{RESOLUTION: ADDITIONAL DATA AND PLOTS}

Average FWHM and FWTM of the $6.00 \mathrm{Mev}{ }^{218} \mathrm{Po} /{ }^{212} \mathrm{Bi}$ and $7.69 \mathrm{MeV}$

${ }^{214} \mathrm{Po}$ alpha peaks for selected samplings performed using the $A N L-W$, Kurz, and Victoreen CAMs are presented in Tables $\mathrm{B}-1, \mathrm{~B}-2$, and $\mathrm{B}-3$, respectively.

Average FWHM and FWTM of the $6.00 \mathrm{Mev}{ }^{218} \mathrm{Po} /{ }^{212} \mathrm{Bi}$ alpha peak for selected samplings of ambient air performed using the ANL-W, Kurz, Merl in Gerin, and Victoreen alpha CAMs are plotted as a function of sampling time in Figures $B-1$ and $B-2$, respectively.

Average FWHM and FWTM of the $6.00 \mathrm{Mev}{ }^{218} \mathrm{Po} /{ }^{212} \mathrm{Bi}$ alpha peak for selected samplings of aerosolized blank dust performed using the Kurz, Merlin Gerin, and Victoreen alpha CAMs are plotted as a function of sampling time in Figures $B-3$ and $B-4$, respectively. 
TABLE B-1. Average FWHM and FWTM of the ${ }^{218} \mathrm{Po} /{ }^{212} \mathrm{Bi}$ and ${ }^{214} \mathrm{Po}$ alpha peaks for selected samplings performed using the ANL-W alpha CAM $(0.8 \mu \mathrm{m})$

\begin{tabular}{|c|c|c|c|c|c|c|}
\hline \multirow[b]{2}{*}{$\begin{array}{l}\text { Sampling } \\
\text { Date }(\mathrm{s}) \\
(\mathrm{m} / \mathrm{d} / \mathrm{y})\end{array}$} & \multirow[b]{2}{*}{$\begin{array}{c}\text { Average Dust } \\
\text { Concentration } \\
\qquad\left(\mu_{\mathrm{g}} / \mathrm{L}\right)\end{array}$} & \multicolumn{2}{|c|}{${ }^{218_{\mathrm{PO}}}{ }^{212} \mathrm{Bi}$} & \multicolumn{3}{|c|}{${ }^{214} \mathrm{Po}_{\mathrm{O}}$} \\
\hline & & $\frac{\text { FWHM }}{(k e V)}$ & $\frac{\text { FWTM }}{(\mathrm{keV})}$ & $\frac{\text { FWHM }}{(\mathrm{keV})}$ & \multicolumn{2}{|c|}{$\frac{\text { FWTM }}{(\mathrm{keV})}$} \\
\hline \multicolumn{7}{|l|}{ 4-12 HR: } \\
\hline $12 / 15-20 / 89$ & $2.43 \pm 0.49 E-03$ & $214 \pm 50$ & $728 \pm 45$ & $354 \pm 21$ & $887 \pm$ & 6 \\
\hline $12 / 20-27 / 89$ & $6.74 \pm 0.40 E-03$ & $256 \pm 22$ & $667 \pm 35$ & $346 \pm 9$ & $941 \pm$ & 10 \\
\hline $12 / 12-14 / 89$ & $8.85 \pm 0.53 E-03$ & $200 \pm 40$ & $640 \pm 19$ & $352 \pm 14$ & $883 \pm$ & 17 \\
\hline \multicolumn{7}{|l|}{ 14-30 HR: } \\
\hline $12 / 15-20 / 69$ & $2.43 \pm 0.49 E-03$ & $300 \pm 28$ & $785 \pm 13$ & $364 \pm 7$ & $891 \pm$ & 1 \\
\hline $12 / 20-27 / 89$ & $6.74 \pm 0.40 E-03$ & $307 \pm 3$ & $742 \pm 20$ & $355 \pm 2$ & $927 \pm$ & 4 \\
\hline $12 / 12-14 / 89$ & $8.85 \pm 0.53 E-03$ & $281 \pm 16$ & $678 \pm 34$ & $354 \pm 7$ & $897 \pm$ & 1 \\
\hline \multicolumn{7}{|l|}{ 32-48 HR: } \\
\hline $12 / 15-20 / 89$ & $2.43 \pm 0.49 E-03$ & $330 \pm 19$ & $784 \pm 8$ & $357 \pm 3$ & $890 \pm$ & 1 \\
\hline $12 / 20-27 / 89$ & $6.74 \pm 0.40 E-03$ & $339 \pm 13$ & $732 \pm 21$ & $353 \pm 1$ & $920 \pm$ & 2 \\
\hline $12 / 12-14 / 89$ & $8.85 \pm 0.53 E-03$ & $306 \pm 3$ & $723 \pm 11$ & $349 \pm 1$ & $900 \pm$ & 2 \\
\hline
\end{tabular}

TABLE B-2. Average FWHM and FWTM of the ${ }^{218} \mathrm{Po} /{ }^{212} \mathrm{Bi}$ and ${ }^{214} \mathrm{Po}$ aipha peaks for selected samplings performed using the Kurz alpha CAM

\begin{tabular}{|c|c|c|c|c|c|c|}
\hline \multirow{3}{*}{$\begin{array}{l}\text { Sampling } \\
\text { Date }(\mathrm{s}) \\
(\mathrm{m} / \mathrm{d} / \mathrm{y})\end{array}$} & \multirow{3}{*}{$\begin{array}{l}\text { Average Dust } \\
\text { Concentration } \\
\qquad\left(\mu_{g} / \mathrm{L}\right)\end{array}$} & \multicolumn{2}{|c|}{${ }^{218} \mathrm{PO}_{\mathrm{O}}{ }^{212} \mathrm{Bi}$} & \multicolumn{3}{|c|}{$214 \mathrm{Po}_{0}$} \\
\hline & & \multirow{2}{*}{$\frac{\text { FWHM }}{(\mathrm{keV})}$} & \multirow{2}{*}{$\frac{\text { FWTM }}{(\mathrm{keV})}$} & \multirow{2}{*}{$\frac{\text { FWHM }}{(\mathrm{keV})}$} & \multirow{2}{*}{\multicolumn{2}{|c|}{$\frac{\text { FWTM }}{(\mathrm{keV})}$}} \\
\hline & & & & & & \\
\hline \multicolumn{7}{|l|}{ 4-12 HR: } \\
\hline $12 / 15-20 / 89$ & $2.43 \pm 0.49 E-03$ & $74 \pm 15$ & $173 \pm 16$ & $89 \pm 6$ & $193 \pm$ & 3 \\
\hline $12 / 27-01 / 02 / 90$ & $8.60 \pm 0.50 E-03$ & $75 \pm 9$ & $178 \pm 9$ & $91 \pm 10$ & $191 \pm$ & 9 \\
\hline $05 / 25-28 / 90$ & $6.90 \pm 0.40 E-02$ & $64 \pm 1$ & $127 \pm 1$ & $65 \pm 6$ & $176 \pm$ & 6 \\
\hline $07 / 02-02 / 90$ & $1.10 \pm 0.07$ E-01 & $69 \pm 4$ & $193 \pm 2$ & $78 \pm 1$ & $224 \pm$ & 2 \\
\hline $06 / 01-04 / 90$ & $1.16 \pm 0.06 \mathrm{E}-01$ & $68 \pm 2$ & $160 \pm 10$ & $67 \pm 5$ & $153 \pm$ & 5 \\
\hline $06 / 27-27 / 90$ & $5.48 \pm 0.28$ E-01 & $78 \pm 3$ & $205 \pm 17$ & $115 \pm 2$ & $375 \pm$ & 36 \\
\hline \multicolumn{7}{|l|}{ 14-24 HR: } \\
\hline $12 / 15-20 / 89$ & $2.43 \pm 0.49 E-03$ & $106 \pm 7$ & $226 \pm 15$ & $118 \pm 9$ & $225 \pm$ & 15 \\
\hline $12 / 27-01 / 02 / 90$ & $8.60 \pm 0.50 E-03$ & $113 \pm 12$ & $228 \pm 18$ & $120 \pm 7$ & $237 \pm$ & 10 \\
\hline $05 / 25-28 / 90$ & $6.90 \pm 0.40 E-02$ & $66 \pm 1$ & $137 \pm 10$ & $72 \pm 2$ & $171 \pm$ & 7 \\
\hline $06 / 01-04 / 90$ & $1.16 \pm 0.06 \mathrm{E}-01$ & $67 \pm 1$ & $184 \pm 8$ & $70 \pm 1$ & $153 \pm$ & 2 \\
\hline \multicolumn{7}{|l|}{ 26-48 HR: } \\
\hline $12 / 15-20 / 89$ & $2.43 \pm 0.49 E-03$ & $131 \pm 9$ & $268 \pm 19$ & $135 \pm 4$ & $254 \pm$ & 8 \\
\hline $12 / 27-01 / 02 / 90$ & $8.60 \pm 0.50 E-03$ & $133 \pm 6$ & $261 \pm 12$ & $138 \pm 7$ & $261 \pm$ & 6 \\
\hline $05 / 25-28 / 90$ & $6.90 \pm 0.40 E-02$ & $68 \pm 1$ & $158 \pm 5$ & $72 \pm 3$ & $178 \pm$ & 5 \\
\hline $06 / 01-04 / 90$ & $1.16 \pm 0.06 E-01$ & $69 \pm 1$ & $181 \pm 4$ & $73 \pm 1$ & $162 \pm$ & 2 \\
\hline
\end{tabular}


TABLE B-3. Average FWHM and FWTM of the ${ }^{218} \mathrm{Po} /{ }^{212} \mathrm{Bi}$ and ${ }^{214} \mathrm{Po}$ alpha peaks for selected samplings performed using the Victoreen alpha CAM $(0.8 \mu \mathrm{m})$

\begin{tabular}{|c|c|c|c|c|c|}
\hline \multirow{3}{*}{$\begin{array}{l}\text { Sampling } \\
\text { Date }(\mathrm{s}) \\
(\mathrm{m} / \mathrm{d} / \mathrm{y})\end{array}$} & \multirow{3}{*}{$\begin{array}{l}\text { Average Dust } \\
\text { Concentration } \\
\qquad\left(\mu_{g} / L\right)\end{array}$} & \multicolumn{2}{|c|}{$218_{\mathrm{Po} /} 212_{\mathrm{Bi}}$} & \multicolumn{2}{|c|}{${ }^{214}$ Po } \\
\hline & & FWHM & FWTM & FWHM & FWTM \\
\hline & & (keV) & $(\mathrm{keV})$ & $(\mathrm{keV})$ & (keV) \\
\hline \multicolumn{6}{|l|}{ 4-12 HR: } \\
\hline $12 / 20-27 / 89$ & $6.74 \pm 0.40 \quad E-03$ & $278 \pm 5$ & $741 \pm 72$ & $419 \pm 24$ & $1044 \pm 14$ \\
\hline $12 / 12-14 / 89$ & $8.85 \pm 0.59 E-03$ & $261 \pm 37$ & $687 \pm 23$ & $395 \pm 3$ & $1013 \pm 12$ \\
\hline $05 / 25-28 / 90$ & $6.90 \pm 0.40 E-02$ & $224 \pm 15$ & $780 \pm 12$ & $495 \pm 15$ & $1167 \pm 37$ \\
\hline $07 / 02-02 / 90$ & $1.10 \pm 0.07 E-01$ & $118 \pm 60$ & $575 \pm 45$ & $509 \pm 13$ & $1189 \pm 1$ \\
\hline $06 / 01-04 / 90$ & $1.16 \pm 0.06 \quad E-01$ & $221 \pm 61$ & $663 \pm 18$ & $561 \pm 8$ & $1158 \pm 13$ \\
\hline $06 / 27-27 / 90$ & $5.48 \pm 0.28 E-01$ & $199 \pm 68$ & $609 \pm 18$ & $588 \pm 19$ & $1244 \pm 6$ \\
\hline \multicolumn{6}{|l|}{ 14-24 HR: } \\
\hline $12 / 20-27 / 89$ & $6.74 \pm 0.40 E-03$ & $316 \pm 29$ & $789 \pm$ & $383 \pm 5$ & $1010 \pm 12$ \\
\hline $12 / 12-14 / 89$ & $8.85 \pm 0.59 E-03$ & $317 \pm 3$ & $702 \pm 3$ & $372 \pm 2$ & $973 \pm 7$ \\
\hline $05 / 25-28 / 90$ & $6.90 \pm 0.40 E-02$ & $376 \pm 17$ & $863 \pm 37$ & $534 \pm 19$ & $1219 \pm 7$ \\
\hline $06 / 01-04 / 90$ & $1.16 \pm 0.06 E-01$ & $282 \pm 7$ & $705 \pm 43$ & $621 \pm 9$ & $1209 \pm 24$ \\
\hline \multicolumn{6}{|l|}{ 26-48 HR: } \\
\hline $12 / 20-27 / 89$ & $6.74 \pm 0.40 \quad E-03$ & $335 \pm 1$ & $790 \pm$ & $373 \pm 5$ & $995 \pm 2$ \\
\hline $12 / 12-14 / 89$ & $8.85 \pm 0.59 E-03$ & $318 \pm 3$ & $727 \pm$ & $355 \pm 9$ & $957 \pm 13$ \\
\hline $05 / 25-28 / 90$ & $6.90 \pm 0.40 E-02$ & $413 \pm 13$ & $906 \pm$ & $563 \pm 3$ & $1241 \pm 14$ \\
\hline $06 / 01-04 / 90$ & $1.16 \pm 0.06$ E-01 & $338 \pm 31$ & $804 \pm 10$ & $623 \pm 15$ & $1224 \pm 5$ \\
\hline
\end{tabular}




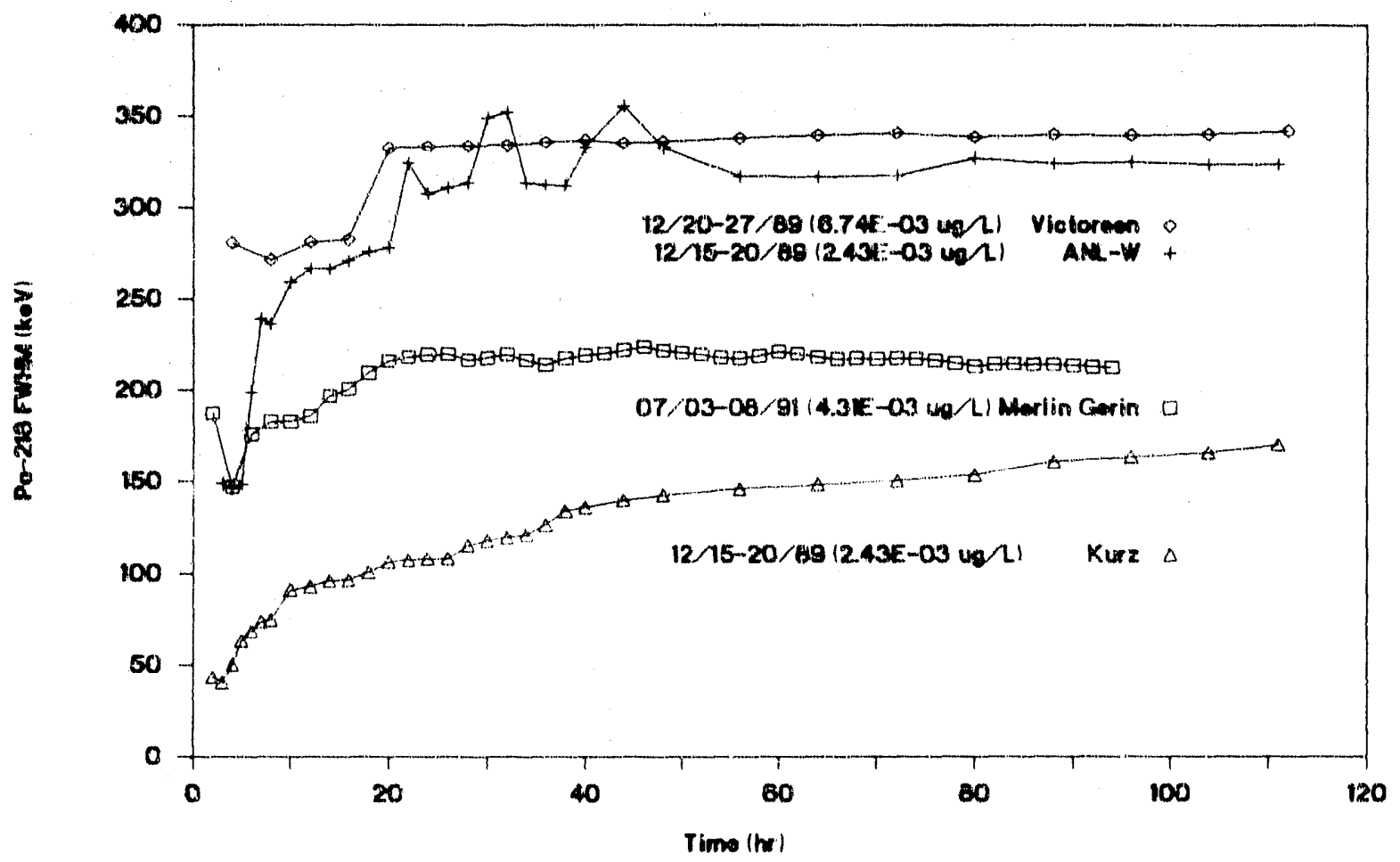

FIGURE B-1. FWHM of the ${ }^{218} \mathrm{Po}_{\mathrm{O}} /{ }^{212} \mathrm{Bi}$ alpha peak versus sampling time for samplings of ambient air performed using the ANL-W, Kurz, Merlin Gerin, and Victoreen aipha CAMs.

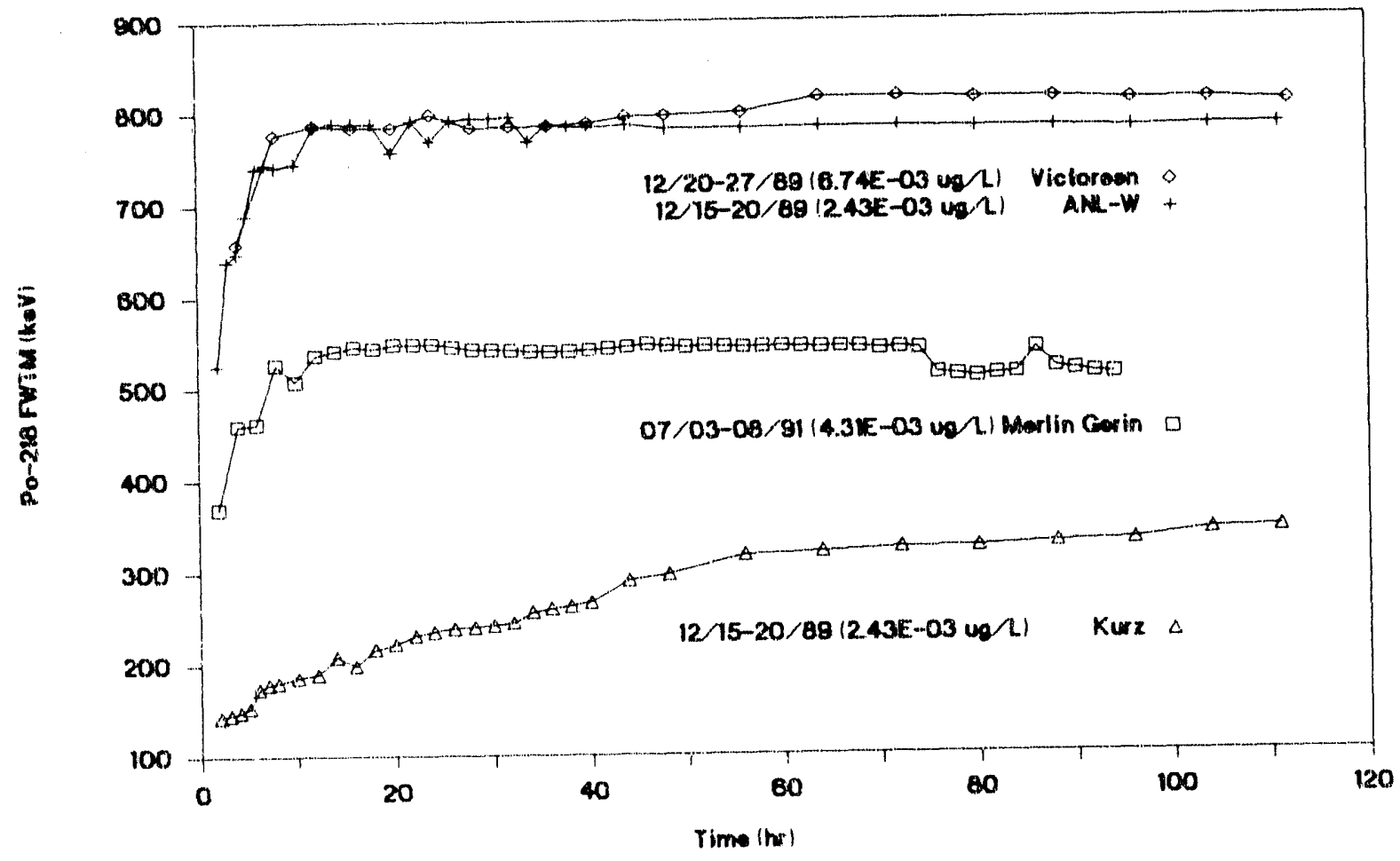

FIGURE B-2. FWTM of the ${ }^{218} \mathrm{Po}_{\mathrm{o}} / 212 \mathrm{Bi}$ alpha peak versus sampling time for samplings of ambient air performed using the ANL-W, Kurz, Merl in Gerin, and Victoreen alpha CAMs. 


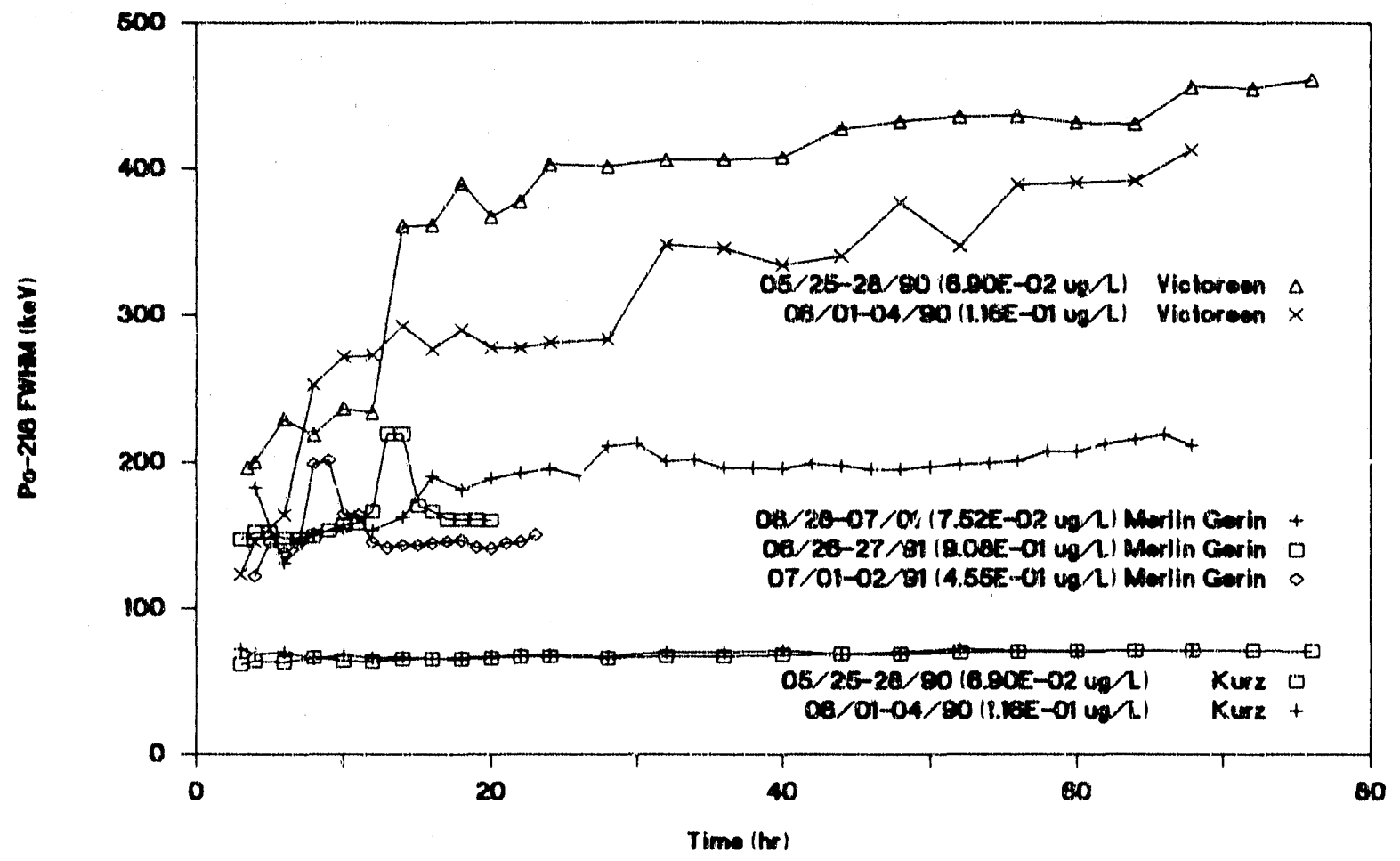

FIGURE B-3. FWHM of the ${ }^{218} \mathrm{Po} /{ }^{212} \mathrm{Bi}$ alpha peak versus sampling time for samplings of aerosolized blank dust performed using the Kurz, Merlin Gerin, and Victoreen alpha CAMs.

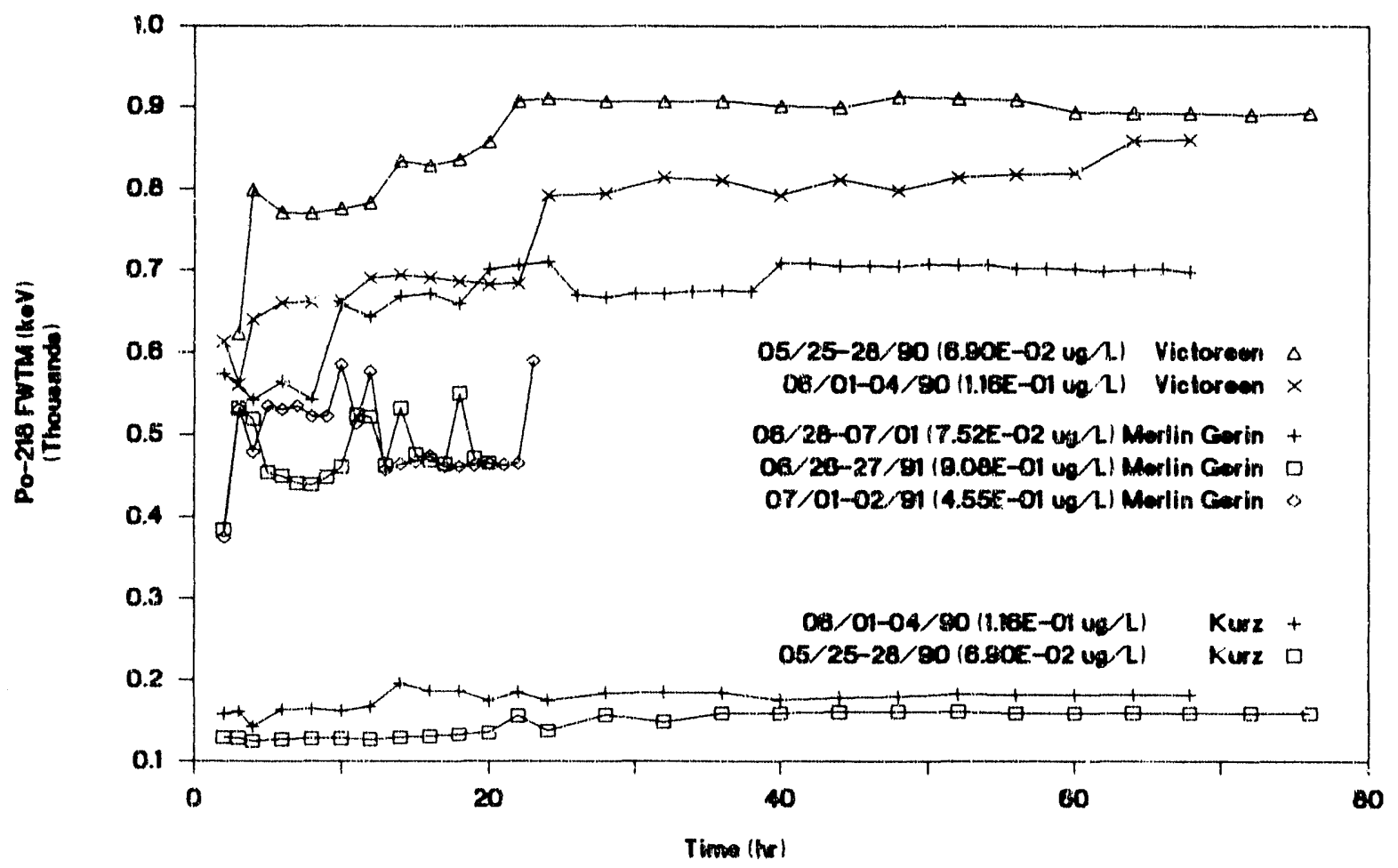

FIGURE B-4. FWTM of the ${ }^{218} \mathrm{Po}_{0} /{ }^{212} \mathrm{Bi}$ aipha peak versus sampling time for samplings of aerosolized blank dust performed using the Kurz, Merlin Gerin, and Victoreen alpha CAMs. 
B-8 
Appendix C

Spectrum Analysis Results

C-1 


\section{Appendix C}

\section{Spectrum Analysis Results}

Tables C-1 through C-24 (on microfiche) present listings of calculated spectral analysis results for samplings of ambient air and of acrosolized clean and spiked dust performed using the Merlin Gerin Edgar alpha CAM. Results presented in Tables C-1 through C-22 were calculated using successive spectra collected at 30-minute intervals. Results presented in Tables C-23 and C. 24 were calculated using successive spectra collected at 60-minute intervals.

Spectral analysis results for the ANL-W, Kurz, RADeCO, and Victoreen CAMs are presented in Tables C.-25 through C-32 (on microfiche). Results presented in Tables C-25 through C-32 were calculated using data for successive spectra collected at 60-minute intervals. Data in Tables C-1 through C-32 are presented in the format shown on page C-4. 
$1 \quad \mathrm{n}$

Spectrum number. (Data in row that shows spectrum number were calculated using the two-window algorithm.)

1

1

2

3

4

5

6

7

8

9

10

11

12

13

For K2: Data in this row were calculated using the three-window algorithm.

For K3: Data in this row were calculated using the four-window algorithm.

Time

Cumulative sampling time (minutes).

Flow

Cumulative sample volume (L).

Cpu

Net counts in ${ }^{239} \mathrm{Pu}$ ROI calculated using Equation A-9, A-16 or A-23.

Cbkg

Background counts in ${ }^{239} \mathrm{Pu}$ ROI calculated using Equation A-10, A-17, or A-24.

$\mathrm{Nb}(\mathrm{n}) \quad$ Change in counts in background $\mathrm{ROI}(\mathrm{s})$ calculated using Equation A-11, A-18, or A-25.

Nbkg Change in background counts in ${ }^{239} \mathrm{Pu}$ ROI calculated using Equation A-12, A-19, or A-26.

Npu Change in net counts in ${ }^{239}$ Pu ROI calculated using Equation A-13, A-20, or A-27.

〜 bkg Standard deviation of background counts in ${ }^{239} \mathrm{Pu}$ ROI calculated using Equation A-14, A-21, or A-28.

Standard deviation of net counts in ${ }^{239} \mathrm{Pu}$ ROI calculated using Equation A-15, A-22, or A-29.

Concentration of airborne ${ }^{239} \mathrm{Pu}$ calculated using Equation A-36 (pCi/L).

Minimum detectable change in net ${ }^{239} \mathrm{Pu}$ counts calculated using Equation A-38 (counts).

Minimum detectable concentration of airborne ${ }^{239} \mathrm{Pu}$ calculated using Equation A-45 (pCi/L). 

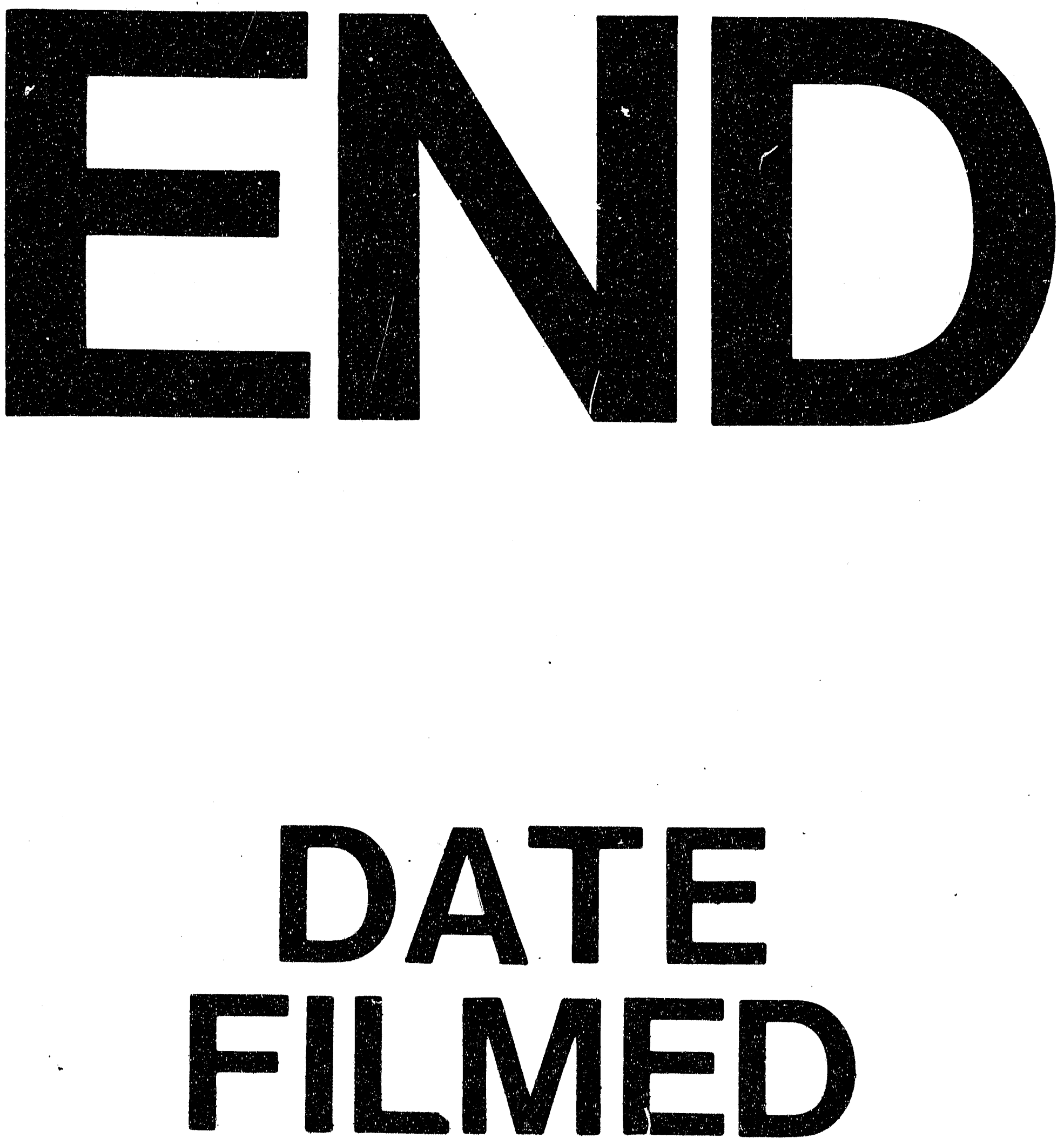

1

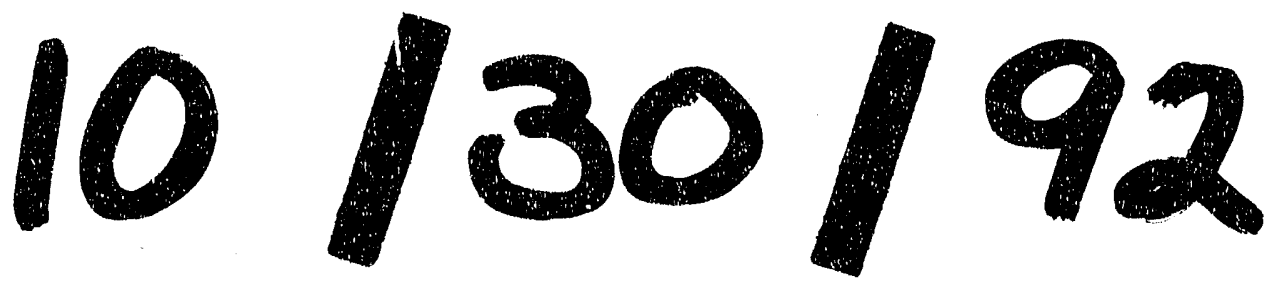


